\title{
Understanding scuba divers' response to coral bleaching: An application of Protection Motivation Theory
}

by

Stephanie D. Verkoeyen

\author{
A thesis \\ presented to the University of Waterloo \\ in fulfillment of the \\ thesis requirement for the degree of \\ Doctor of Philosophy \\ in \\ Geography
}

Waterloo, Ontario, Canada, 2018

(C) Stephanie D. Verkoeyen 2018 


\section{Author's Declaration}

I hereby declare that I am the sole author of this thesis. This is a true copy of the thesis, including any required final revisions, as accepted by examiners.

I understand that my thesis may be made electronically available to the public. 


\begin{abstract}
Numerous studies have shown that healthy coral reefs are important to the dive experience. Thus, the expected increase in frequency and magnitude of coral bleaching events has the potential to alter global flows of dive tourists. There is disagreement about how coral bleaching might affect tourists' dive-related behaviour, nor is it clear why one form of substitution might be preferred over another. While previous research has sought to explain tourists' or recreationists' behaviour by considering an individual's commitment to an activity and/or place, there is a growing number of studies that suggest taking people's estimation of their options and ability to react to a threat into account provides a clearer picture of the decision to respond to a threat. Application of such a cognitive framework may also provide new insight to the question of how place attachment and activity involvement transmit their effect on behavioural intentions. This study applied Protection Motivation Theory (PMT) to help understand the motivational factors associated with intended adaptation to a coral bleaching event.

An online survey was sent out to Australian and Canadian dive club members to assess PMT constructs in relation to six behavioural intentions and attachment variables. Multiple regression analysis and mediation analysis was used respectively to analyse the effects of threat and coping appraisal variables on behavioural intentions and consider their mediating influences for attachment variables. This study provided the first empirical evidence of scuba diver adaptation in response to marginal reef conditions, indicating that the majority of respondents would significantly alter their behaviour in some way. PMT was able to explain between $12.8 \%$ and $47.7 \%$ of the variance in behavioural intentions, with response efficacy and self-efficacy consistently emerging as
\end{abstract}


the strongest significant predictors, highlighting the importance of including some measure of subjective adaptive capacity. Consideration of multiple behavioural intentions demonstrates the variability of model performance and highlights the need to consider the context of adaptation behaviour when interpreting results.

Canadian divers perceived dive reduction to be more effective and had a greater perceived ability to alter their dive rate than Australian divers, whereas Australian divers were significantly more likely to change the location of diving within a destination or within a region, suggesting there may be differences in the perception of available local or regional alternatives. Perceived severity is a significant negative predictor of cognitive behavioural intentions for Australian divers, possibly because Australian divers showing a significantly greater emotional attachment to place.

This study did not support the notion of PMT as a useful extension of place activity and activity involvement effects in terms of additional explained variance, but did offer some insights into competing and indirect effects when considering attachmentbehaviour models beyond that of place attachment-spatial adaptation/activity involvement-activity adaptation. Overall, greater attachment typically predicts less ability to perform an adaptation and less perceived effectiveness of an adaptation, suggesting adaptation may be perceived to be of less utility to activity or place-attached individuals.

Implications for future research and the dive tourism industry are discussed. As the majority of respondents indicated an intention to significantly alter their behaviour in some way, the economic ramifications of coral bleaching are likely to be significant. Further, tourists' tendency towards spatial adaptation is an important consideration as a contributor to greenhouse gas emissions. Ultimately, PMT presents a useful framework 
for policy makers, destination marketers, and investment developers to consider the elasticity of dive tourism demand in the mid-to-long term, which can inform decisions about capital investments and supply-side adaptations. Several methodological limitations are discussed and recommendations for further research are suggested, including further qualitative research to provide contextual information for the different response variables, and consideration of adaptations in supply-side factors. 


\section{Acknowledgments}

I'd like to thank my advisor, Dr. Sanjay Nepal, for his continued guidance throughout this process. Sanjay, thank you for helping me navigate the ins and outs of completing a $\mathrm{PhD}$, and offering support when needed. Thanks to Professors Dan Scott, Bryan Smale, and Luke Potwarka for being part of my committee. Your feedback and suggestions helped make this thesis a stronger study.

Special thanks to the staff at the Centre for Teaching Excellence and the WatCV crew for providing an outlet to maintain momentum and work collaboratively. And to my family, most notably my husband, for your unwavering belief in me.

I would like to acknowledge the financial support provided by the Ontario Graduate Scholarship and the University of Waterloo, without which it would not have been possible to continue on in the program. 


\section{Table of Contents}

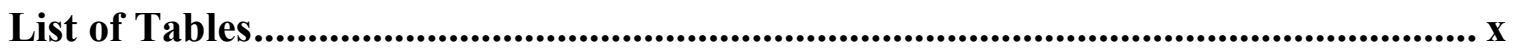

List of Figures ................................................................................................................. xi

Acronyms ........................................................................................................................ xii

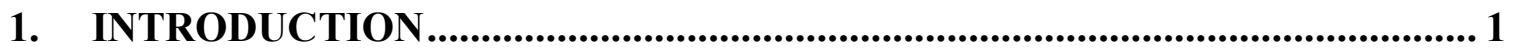

1.1 Divers' response to coral bleaching ..........................................................................

1.2 Tourists' behavioural adaptation to climate change ..................................................10

1.3 Role of cognition ..........................................................................................................11

1.4 Overview of Protection Motivation Theory ...............................................................14

1.5 Study purpose and hypotheses.................................................................15

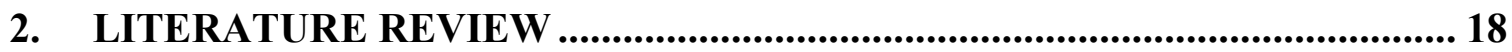

2.1 Outline ......................................................................................................... 18

2.2 Identifying a suitable theoretical framework ………………………………………... 18

2.2.1 Theory of Reasoned Action/Planned Behaviour ...................................................... 18

2.2.2 Transactional Theory of Stress and Coping ……………………………….......2

2.2.3 Protection Motivation Theory ……………………………………………....26

2.3 Applying Protection Motivation Theory to climate change adaptation..................30

2.4 Applying Protection Motivation Theory to tourism and climate change ..............34

2.5 Extension to Protection Motivation Theory ……………………………………….......38

2.5.1 Personality variables as sources of information ..................................................... 38

2.5.1.1 Place attachment and activity involvement .................................................................. 41

2.5.1.2 Influence of place attachment and activity involvement on behavioural intentions........... 44

2.5.1.3 Coping appraisal as a mediator of activity involvement and place attachment..................49

2.5.1.4 Risk appraisal as a mediator of activity involvement and place attachment ...............52

2.6 Limitations of Protection Motivation Theory................................................................58

2.7 Summary …...........................................................................................59

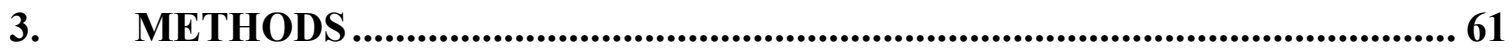

3.1 Research design ..............................................................................................61

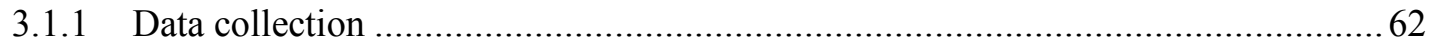

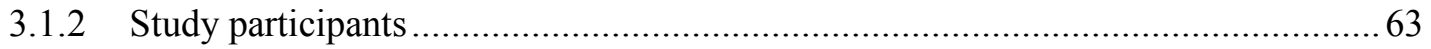

3.2 Measures.......................................................................................................68

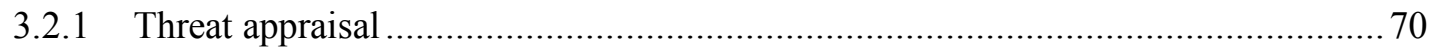

3.2.1.1 Perceived severity ........................................................................................ 70

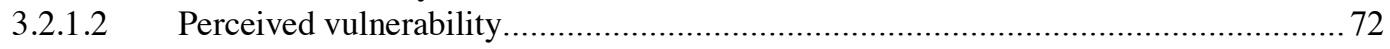

3.2.2 Coping appraisal ....................................................................................... 73

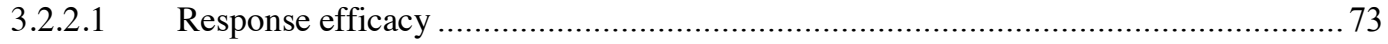

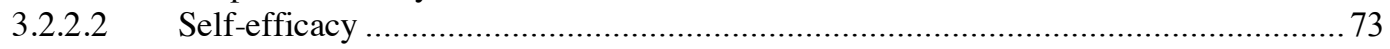

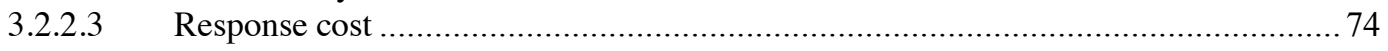

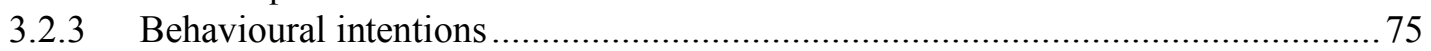

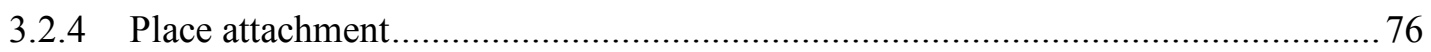

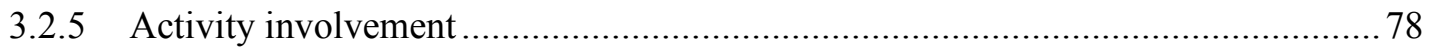

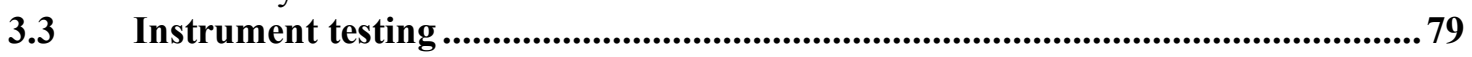

3.4 Data analysis.......................................................................................................... 81

3.4.1 Multiple linear regression................................................................................. 83

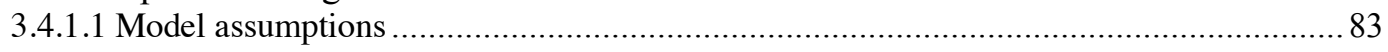

3.4.1.2 Comparing regression coefficients between two samples .............................................. 90 
4. REGRESSION OF PROTECTION MOTIVATION THEORY VARIABLES 97

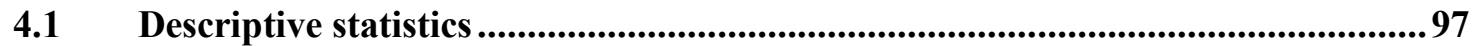

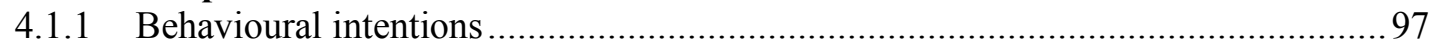

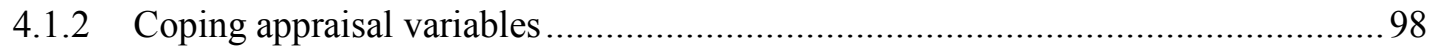

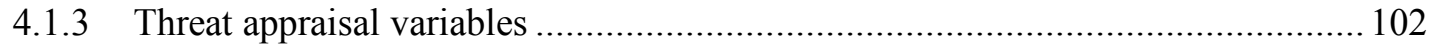

4.2 Bivariate correlations of independent and dependent variables.......................... 103

4.3 Predicting behavioural intentions using Protection Motivation Theory............. 103

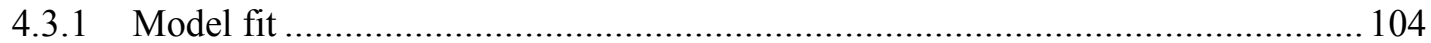

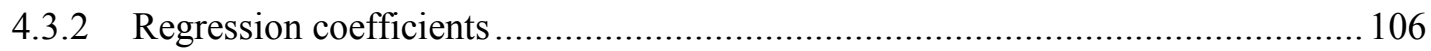

4.4 Differences in prediction of behavioural intentions by geographic proximity ... 108

\section{MEDIATION OF ACTIVITY INVOLVEMENT AND PLACE}

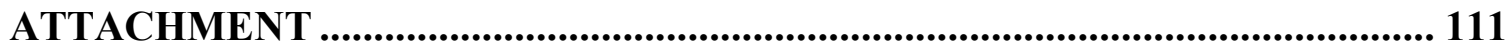

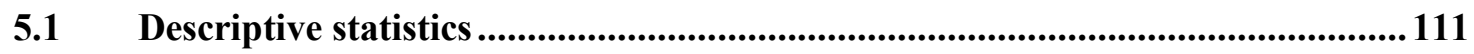

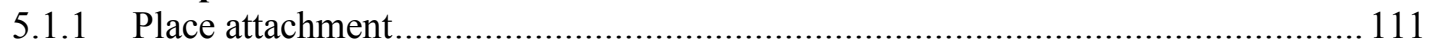

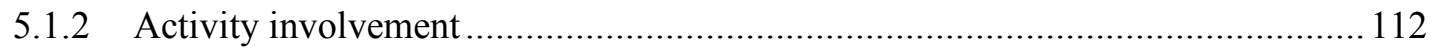

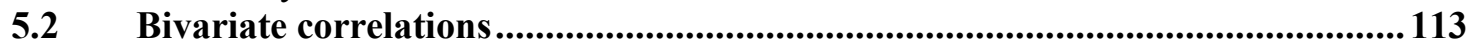

5.3 Direct and indirect effects of activity involvement and place attachment .......... 113

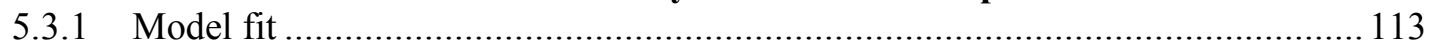

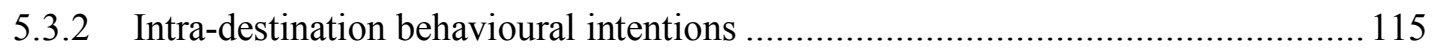

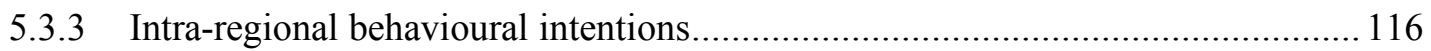

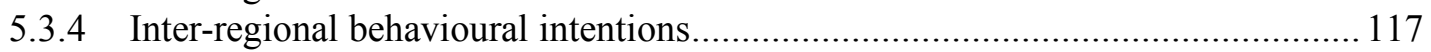

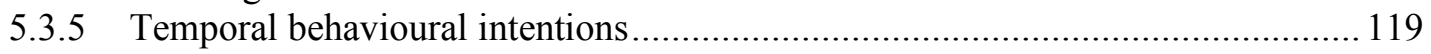

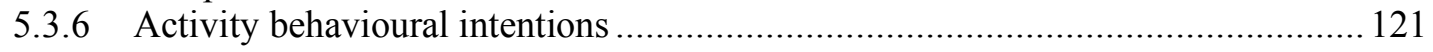

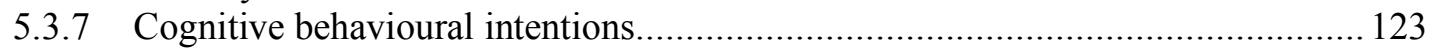

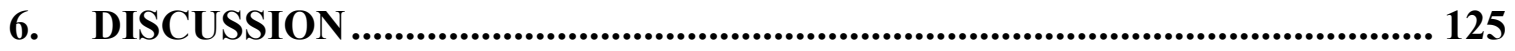

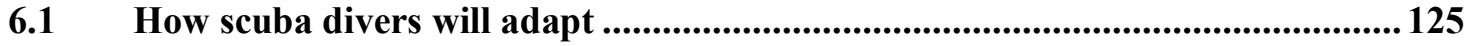

6.2 Why scuba divers will/will not adapt ........................................................................ 129

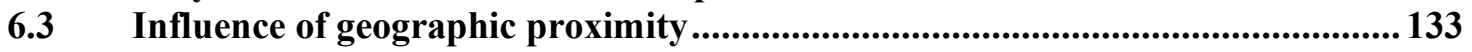

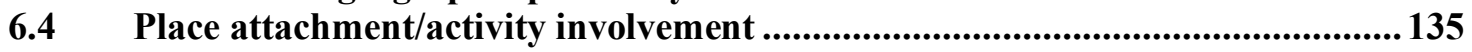

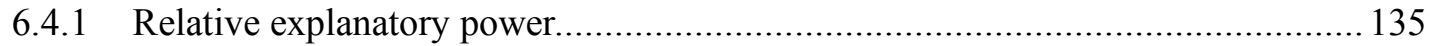

6.4.2 Direct and indirect effects of attachment variables ............................................. 136

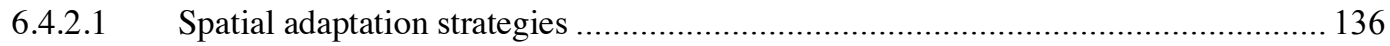

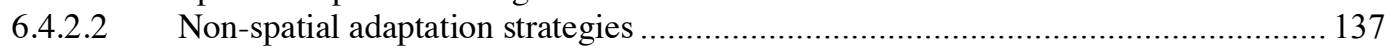

7. SUMMARY AND CONCLUSION................................................................ 141

7.1 Practical implications and recommendations............................................... 143

7.2 Theoretical implications and recommendations.............................................. 145

7.3 Methodological implications and recommendations .......................................... 148

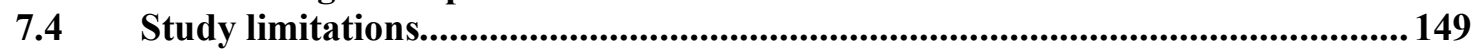

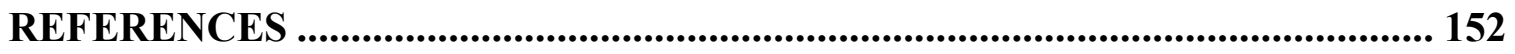

APPENDIX A: Recruitment Email................................................................ 168

APPENDIX B: Information Letter and Consent Form ..................................... 169

APPENDIX C: Online Questionnaire................................................................... 171

APPENDIX D: Feedback Letter to Participants ................................................. 178

APPENDIX E: Socio-demographic Regression Results ..................................... 179 
APPENDIX F: Correlation Tables......................................................................... 183 


\section{List of Tables}

Table 1: Summary of key Protection Motivation Theory variables......................................30

Table 2: Applications of Protection Motivation Theory in climate change research .........32

Table 3: Applications of Protection Motivation Theory in tourism and climate change research

Table 4: Summary of studies examining the relationship between place attachment and/or activity involvement and behavioural intentions

Table 5: Summary of studies examining the relationship between place attachment and/or activity involvement and coping appraisal variables ..................................................51

Table 6: Summary of studies examining the relationship between place attachment and/or activity involvement and risk appraisal variables .......................................................55

Table 7: Participating and non-participating Canadian and Australian dive clubs ............65

Table 8: Sample demographic and diver characteristics ..................................................67

Table 9: Place attachment measures (adapted from Moskwa, 2012) .................................77

Table 10: Activity involvement measures (adapted from Kyle et al., 2007).......................79

Table 11: Survey changes in response to received feedback..............................................80

Table 12: Descriptive statistics of behavioural intentions ....................................................98

Table 13: Descriptive statistics of coping appraisal variables...........................................100

Table 14: Descriptive statistics of threat appraisal variables .............................................102

Table 15: Regression models for PMT variables predicting behavioural intentions ........105

Table 16: Regression coefficients for threat and coping appraisal variables predicting

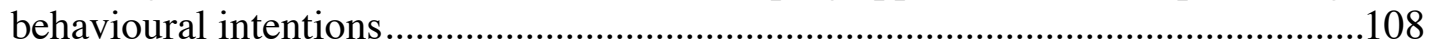

Table 18: Differences in behavioural intentions by geographic proximity ......................109

Table 19: Descriptive statistics of place attachment variables ............................................111

Table 20: Descriptive statistics of activity involvement variables....................................112

Table 21: Direct and total effect models for attachment variables predicting behavioural intentions ....................................................................................................114 


\section{List of Figures}

Figure 1: Global distribution of coral reefs (National Oceanic and Atmospheric

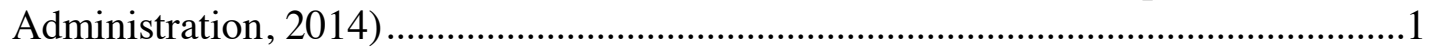

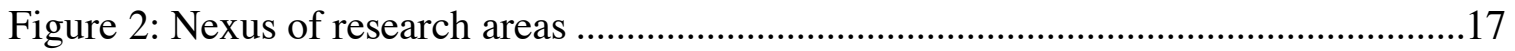

Figure 3: Protection Motivation Theory (Rogers, 1983) .................................................29

Figure 4: Conceptual diagram of a simple mediation model ............................................40

Figure 5: Conceptual diagram of mediation model for activity involvement and place attachment.

Figure 6: Image depicting coral landscape that is "mostly white" (Climate Commission, 2013)

Figure 7: Conceptual diagram of prediction of behavioural intentions ............................82

Figure 8: Histograms and normal probability plots for regressions on BIS1 and BIA......86

Figure 9: Scatterplots for regressions on BIS2 and BIC ...............................................87

Figure 10: Partial regression plots for regressions on SES1/RCS1 and BIS1 ...................88

Figure 11: (A) Illustration of a direct effect of X on Y. (B) Illustration of an indirect

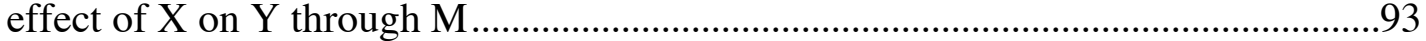

Figure 12: Visualization of the likelihood of divers' different behavioural intentions ......97

Figure 13: Visualization of the range in explained variance of the different adaptation

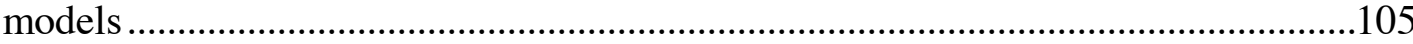

Figure 14. Visualization of the relative contribution and direction of the relationship of

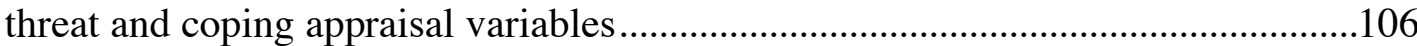

Figure 15: Relationship between activity involvement and intra-destination behavioural intentions (BIS1) via threat and coping appraisal variables

Figure 16: Relationship between place attachment and intra-destination behavioural intentions (BIS1) via threat and coping appraisal variables ....................................116

Figure 17: Relationship between activity involvement and intra-regional behavioural intentions (BIS2) via threat and coping appraisal variables...

Figure 18: Relationship between place attachment and intra-regional behavioural intentions (BIS2) via threat and coping appraisal variables

Figure 19: Relationship between activity involvement and inter-regional behavioural intentions (BIS3) via threat and coping appraisal variables....

Figure 20: Relationship between place attachment and inter-regional behavioural intentions (BIS3) via threat and coping appraisal variables

Figure 21: Relationship between activity involvement and temporal behavioural intentions (BIT) via threat and coping appraisal variables

Figure 22: Relationship between place attachment and temporal behavioural intentions

(BIT) via threat and coping appraisal variables

Figure 23: Relationship between activity involvement and activity behavioural intentions

(BIA) via threat and coping appraisal variables.

Figure 24: Relationship between place attachment and activity behavioural intentions

(BIA) via threat and coping appraisal variables.

Figure 25: Relationship between activity involvement and cognitive behavioural intentions (BIC) via threat and coping appraisal variables

Figure 26: Relationship between place attachment and cognitive behavioural intentions

(BIC) via threat and coping appraisal variables 


\title{
Acronyms
}

\author{
AI Activity Involvement \\ BI Behavioural Intentions \\ GBR Great Barrier Reef \\ IPCC Intergovernmental Panel on Climate Change \\ PA Place Attachment \\ PMT Protection Motivation Theory \\ PS Perceived Severity \\ PV Perceived Vulnerability \\ RC Response Costs \\ RE Response Efficacy \\ SE Self-efficacy \\ SEM Structural Equation Modelling \\ TPB Theory of Planned Behaviour \\ TRA Theory of Reasoned Action
}




\section{INTRODUCTION}

Scuba diving has been a popular marine leisure pursuit since the 1960s. Along with dive equipment improvements and increased mobility, the continued addition of new diving sites has brought scuba diving in easy reach of mass tourism markets, leading to the birth of the dive tourism industry. As of 2012, it was estimated that there are at least 30 million certified scuba divers worldwide (Lew, 2013), many of whom live in the developed countries of the northern hemisphere. In contrast, warm water coral reefs are the most popular diving destinations, boasting high biological diversity and warm, clear waters. Most coral is found in a band between 30 degrees north and south latitude in the tropics and subtropics (Figure 1). Over $40 \%$ of the coral reef area of the world is in the South Pacific, of which Australia accounts for roughly 17\%; an additional third is in Southeast Asia, while the Caribbean accounts for about 10\% (Burke, Reytar, Spalding, \& Perry, 2011).

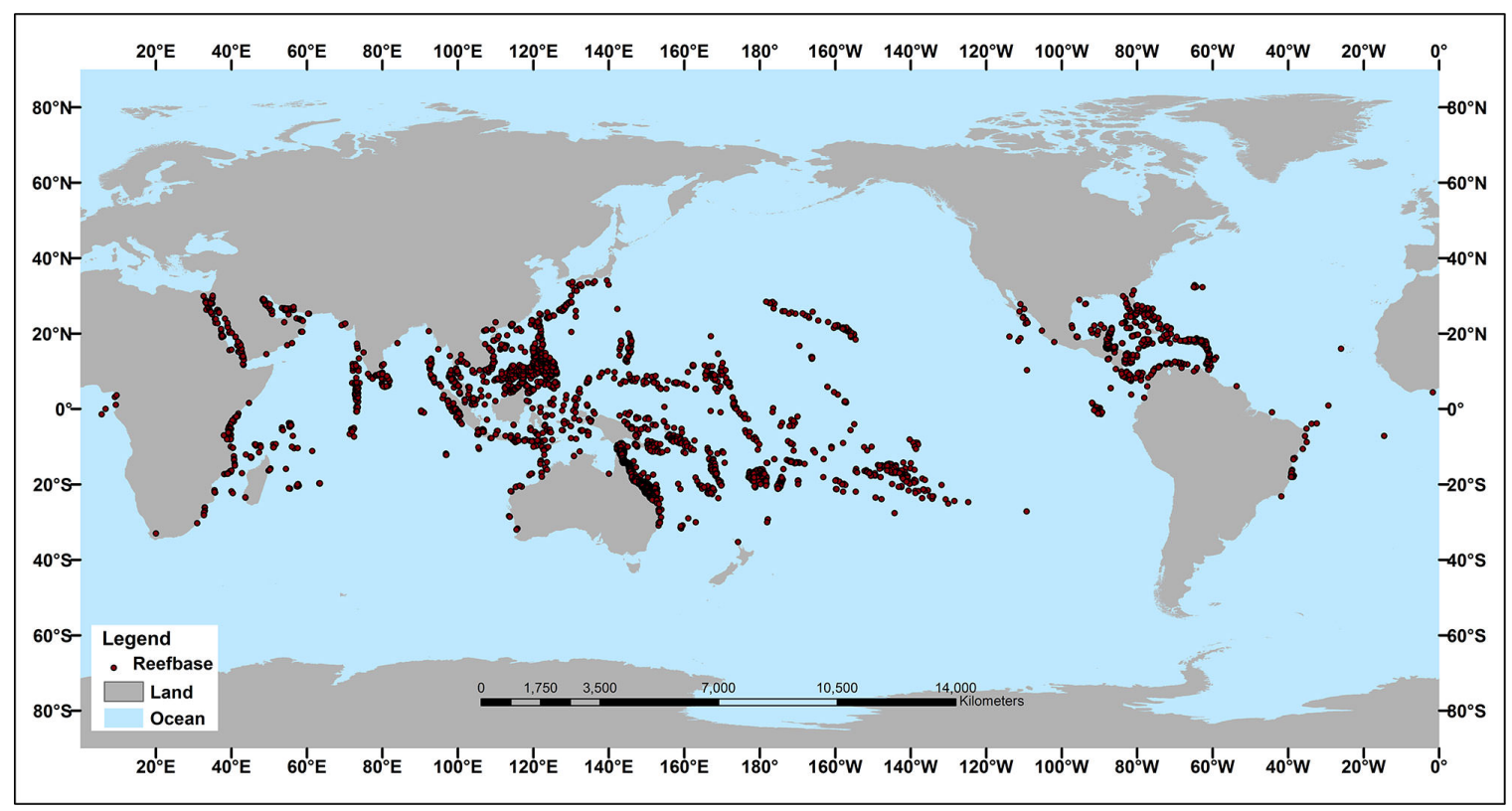

Figure 1: Global distribution of coral reefs (National Oceanic and Atmospheric Administration, 2014) 
Studies investigating diver motivations consistently cite the opportunity to look at corals and other underwater marine life as the main reason for diving (Ditton, Osburn, Baker, \& Thailing, 2002; Garrod, 2008; Meyer, Thapa, \& Pennington-Gray, 2002; Shani, Polak, \& Shashar, 2012; Thailing \& Ditton, 2003; Todd, Graefe, \& Mann, 2002; Uyarra et al., 2005). Similarly, the condition of the underwater environment is among the main contributors to diver satisfaction (Davis \& Tisdell, 1996; Dearden, Bennett, \& Rollins, 2006; Fitzsimmons, 2007; Graham, Idechong, \& Sherwood, 2000; Loomis, Anderson, Hawkins, \& Paterson, 2008; MacCarthy, O'Neill, \& Williams, 2006; Musa, 2002; Musa, Kadir, \& Lee, 2006; Paterson, Young, Loomis, \& Obenour, 2012; Tabata, 1992). Pointing to the dive industry's strong dependency on this single dimension, Musa et al. (2006) reported that underwater nature, which included both marine life and coral reefs, was the only factor to significantly influence overall diver satisfaction. In another study, coral appeared to exert a greater influence than fish on divers' overall trip enjoyment in Fiji (Fitzsimmons, 2007), paralleling previous work on snorkelers visiting the Great Barrier Reef (GBR) (Shafer \& Inglis, 2000).

A handful of studies have also examined reasons for an unsatisfactory dive experience. Comparing evaluations of resource conditions in the Florida Keys, Anderson and Loomis (2012) and Young and Loomis (2009) found that severely bleached reefs and algal covered reefs were generally considered unacceptable. Meanwhile, tourists to the Maldives frequently cited dead coral as the most disappointing aspect of their holiday (48\%) (Westmacott, Cesar, \& Pet-Soede, 2000). Graham et al. (2000) compare diver satisfaction in Palau before (1997) and after (2000) the 1998 mass coral bleaching event, finding a decrease of 1.2 points (on a 5-point scale) in mean scores for corals/reef. 
Collectively, the findings from these studies suggest that healthy coral reefs are important to the dive experience. But these marine ecosystems are also considered to be one of the most vulnerable to climate change (Hoegh-Guldberg et al., 2007). At present, more than half of the world's reefs are considered to be at medium or high risk of degradation (Burke et al., 2011). Estimates suggest that effectively $19 \%$ of the original area of the world's coral reefs have been lost. The beginning of the $21^{\text {st }}$ century could see $15 \%$ of reefs seriously threatened with loss, while this number jumps to $20 \%$ midcentury, though neither of these figures consider the threat posed by global climate change, having been made under a 'business as usual' scenario (Wilkinson, 2008). Declines in coral reefs will have a dramatic effect on the estimated 500 million people that depend on reefs for provisioning (e.g. food, livelihoods, construction material, medicine), regulation (e.g. shoreline protection, water quality), support (e.g. primary production, nutrient cycling) and cultural (e.g. religion, tourism) services, 30 million of whom are virtually totally dependent on coral reefs for their livelihoods or for the land on which they live (Wilkinson, 2008). Unsurprisingly, it is the small, low-lying coastal and island nations within the developing regions of the tropics that are likely to be especially hard hit (Wong et al., 2014).

Globally, ocean warming appears to be the primary climate-related driver affecting reef health (Burke et al., 2011; Selig, Casey, \& Bruno, 2010; Wong et al., 2014), though increases in atmospheric $\mathrm{CO}_{2}$ will also impact coral reefs in coming decades, slowing coral growth and weakening their skeletons (Cao \& Caldeira, 2008; Silverman, Lazar, Cao, Caldeira, \& Erez, 2009), which has been shown to increase the likelihood of temperature-induced coral bleaching (Anthony, Kline, Diaz-Pulido, Dove, 
\& Hoegh-Guldberg, 2008). It is worth noting that some of the physical changes projected to occur in the coming century have occurred in the past (Pandolfi and Greenstein 2007). Coral communities rebounded from decimation by climatic events, recovering over periods of 4 to 100 my (Newell 1971). However, today's reefs face the added challenges of frequent anthropogenic disturbance, which has an impact on resilience to perturbations (Hughes et al. 2003; Pandolfi et al. 2006), and an unprecedented change in the rates and magnitude of CO2 concentration (Pandolfi, 2011).

Increasing sea surface temperatures are the primary trigger for coral bleaching (Brown, 1997; Fitt, McFarland, Warner, \& Chilcoat, 2000; Hoegh-Guldberg, 1999; Hoegh-Guldberg et al., 2007). When water is too warm, corals expel the algae (zooxanthellae) living in their tissues, resulting in the characteristic white colouring of bleached coral. Natural variation in water temperatures, in combination with other local stressors, has always caused bleaching episodes. However, abnormally high ocean temperatures in recent years has led to bleaching events that are more frequent, intense, and widespread (Coral Reef Watch, 2018). Between 1980 and 1997, approximately 370 observations of coral bleaching were reported globally, while more than 3,700 were reported between 1998 and 2010 (Burke et al., 2011).

The 1998 mass coral bleaching event is considered the worst of the twentieth century (Hoegh-Guldberg, 1999). Elevated water temperatures were recorded across much of the tropics, linked to an unusually strong El Niño and La Niña sequence. The bleaching affected entire reef ecosystems across the world, killing about $16 \%$ of global corals. Worst hit areas, like the central and western Indian Ocean, experienced coral loss from 50 to $90 \%$ (Goreau, McClanahan, Hayes, \& Strong, 2000). Other temperature- 
driven mass bleaching events have occurred since 1998, causing even greater damage in some regions. Extensive bleaching occurred on the Great Barrier Reef in 2002, while parts of the Caribbean saw its worst bleaching to date in 2005 (Eakin et al., 2009; Wilkinson, 2008). In 2016, the northern portion of the GBR experienced "the worst mass bleaching event in its history," according to a statement from the Australian Research Council. Documented by the National Coral Bleaching Taskforce in aerial surveys, observations of more than 500 coral reefs showed that the majority were undergoing extensive and severe bleaching. The coral bleaching shifted southward in 2017 as the reef system experienced its second year of consecutive mass bleaching. In total, $1500 \mathrm{~km}$ of its $2250 \mathrm{~km}$ total length experienced severe bleaching at some point in 2016-2017 (Mooney, 2017).

Since the 1990s, there have seen significant increases in sea surface temperature, with more than $70 \%$ of the world's coastlines warming at an average rate of $0.18 \pm$ $0.16^{\circ} \mathrm{C}$ per decade (Wong et al., 2014). Given this warming trend, it is expected that coral bleaching and mortality will continue to increase in frequency and magnitude, with estimates that $99 \%$ of all reef locations will experience at least one severe bleaching event by the last decade of the twenty-first century (under the A1B emission scenario) (Wong et al., 2014). Corals recovering from a bleaching event are likely to be vulnerable to disease for several months (Miller et al., 2009), while severe bleaching has also been associated with decreased reproductive capacity (Hoey et al., 2016), all of which suggest a bleak future for coral reefs (Hoegh-Guldberg, Poloczanska, Skirving, \& Dove, 2017; Van Hooidonk et al., 2016).

There are currently more than 100 countries benefitting from the recreational 
value provided by coral reefs (Burke et al., 2011), suggesting that there will be serious economic repercussions with the decline in coral reef health. The Great Barrier Reef Marine Park, for example, attracts almost 2 million visits each year, generating 5.4 billion AUD annually (Deloitte Access Economics, 2013). While bleaching is expected to occur globally, regional variations in weather patterns, sea levels, and reef structure/conditions may result in some areas being harder hit than others (Eakin, Lough, Heron, \& Liu, 2018). Thus, some of the world's top dive destinations may be disproportionately impacted by coral bleaching in the future, which has the potential to alter global flows of dive tourists. Generally, it has been suggested that increasing temperatures in midlatitude countries combined with increased storms in tropical areas could result in diminished tourist flows from mid-latitude countries to tropical coastal regions, i.e. 'poleward' movement, with large developing countries and small island nations most affected (Amelung et al., 2007; Perch-Nielson et al., 2010).

Geographic variations in the thermal stress facing reefs under projected climate scenarios was first demonstrated by Donner et al. (2005). Using monthly SST data from the UK Hadley Centre's HadCM3 model, the authors determined that the frequency of bleaching events will likely increase fastest around islands of Micronesia, Melanesia, Indonesia, and the northern Caribbean, as well as the Malaysian archipelago. Currently, Asia-Pacific is internationally recognized as a premier dive destination, which includes Papau New Guinea, Fiji, the Solomon Islands, the Philippines, Maldives, Vanuatu, and Thailand, benefitting as they do from the Western European and Australian dive markets, as well as the growing domestic southeastern Asian market. Meanwhile, the Great Barrier Reef, South Pacific, Red Sea, Caribbean Sea, and Indian Ocean are also viewed as major 
global dive destinations, though each serves more limited markets because of accessibility constraints (e.g. South Pacific and the Great Barrier Reef are geographically remote from Europe and North America, while the Red Sea and Indian Ocean are similarly remote from North America) (Lew, 2013). If bleaching projections are on target, some of the world's top dive destinations will be disproportionately impacted by climate change in the future, potentially altering global flows of dive tourists. There is also the possibility of new markets emerging, e.g. Africa and the Middle East are expected to see significant increases in domestic and international divers as development continues and hostilities settle (Lew, 2013), as well some corals may experience a poleward range expansion caused by warming (Wong et al., 2014).

Since tourism and recreation implicitly involve activities undertaken by choice during leisure time, it follows that individuals have a great deal of flexibility in choosing the time, space and type of activities they wish engage in (Gössling, Scott, Hall, Ceron, \& Dubois, 2012), and thus have considerable capacity to adapt to risks or opportunities presented by environmental changes (Scott, Gössling, \& Hall, 2012). Therefore, it is important for tourism and recreation researchers to develop a better understanding of adaptation behaviour in response to adverse recreation conditions.

\subsection{Divers' response to coral bleaching}

There is disagreement among researchers and tourism stakeholders about how coral bleaching is and might affect tourists' dive-related behaviour. Some argue that such climate-induced environmental change has given rise to a new tourism phenomenon, sometimes referred to as 'disappearing destinations', 'last chance tourism', or 'climate disaster tourism', in which a destination or attraction is sought out before it is degraded or 
'lost' to climate change (Lemelin, Dawson, \& Stewart, 2013; Lemelin, Dawson, Stewart, Maher, \& Lueck, 2010). However, most destinations and tour operators appear to strongly resist attempts to associate with climate change or last chance tourism marketing, considering it to be a short sighted view, and there has been little research to support such a trend (Scott, Gossling, \& Hall, 2012). For example, when asked if divers were coming to see bleached reefs, $83 \%$ of Caribbean dive operators strongly disagreed or disagreed with this statement (Sealey-Baker, 2011).

Many dive operators simply do not believe that climate change will have any effect on their operations (Gossling, Lindén, Helmersson, Liljenberg, \& Quarm, 2008; Marshall, Marshall, Abdulla, Rouphael, \& Ali, 2011; Sealey-Baker, 2011). Gossling et al. (2008), for example, found that most dive operators did not think global environmental change had had any consequences on dive tourism, going so far as to state: "as long as the water is clear, people will continue to dive" (p. 83). When directly asked, $40 \%$ of divers in Zanzibar and 33\% in Mafia responded they would be willing to dive on a bleached reef (Andersson, 2007), suggesting there may still be a market for degraded reefs. Many divers speak of an innate level of enjoyment that comes with just being in the water scuba diving (Davis \& Tisdell, 1996; Fitzsimmons, 2007; Hillmer-Pegram, 2011; Maccarthy et al., 2006). Other divers embark on "pilgrimages" to visit various popular dive sites around the world, and thus are less concerned about poor conditions (Belk, Wallendorf, \& Holbrook, 1991).

A third possibility is that divers will alter their behaviour in some way, so as to avoid or minimize their exposure to changes to the marine environment. After the 1998 mass bleaching event, Cesar (2000) reported that the percentage of dive tourists visiting 
El Nido in the Philippines decreased, with resorts that used to cater to the exclusive highend of the dive market faring most poorly. Diver numbers are estimated to have dropped from almost total resort capacity in the mid-1980s to roughly $10 \%$ of resort guests, though, given the time elapsed there may be more than reef degradation at work. A similar study off the coast of East Africa found that over $80 \%$ of those who were aware of the bleaching (28\% of total divers surveyed in Zanzibar; $45 \%$ in Mombasa) indicated that knowledge that an area was bleached would affect their decision to visit and/or dive in that area (Westmacott et al., 2000).

There is a need for empirical investigation into how scuba divers will respond to coral bleaching. To date, research into tourists' behavioural adaptation and climate change has largely focused on ski and winter tourism, emphasizing the relationship between warming temperatures and declining snow cover (Scott et al., 2012). This body of research provides a useful point of comparison for exploring potential differences in marine and terrestrial-based adaptation behaviour.

A further comparison can be made by considering a fundamental difference in the type of dive visitor to a bleached reef: one who has travelled overseas to reach the destination (i.e., tourist) and one who lives in the same local or regional area of coral bleaching (i.e., domestic tourist or recreationist). These divers differ in terms of their resource proximity and climate change exposure. This distinction is of significance from a practical standpoint. Despite the northern hemisphere accounting for a significant number of certified scuba divers, a report released by the World Tourism Organization revealed that only one in three divers will regularly take a diving holiday overseas (World Tourism Organization, 2001), suggesting local/regional divers may account for a 
significant segment of the market.

Previous research suggests that resource proximity is strongly correlated to aspects of visitation behaviour. This has been explained by both the proximity hypothesis (Van Dijk \& Van der Wulp, 2010) and distance decay (Gregory et al., 2009; Wu \& Cai, 2006), the idea being that those more proximate engage in shorter, more frequent visits, while use declines with increasing distance. Proximity has also been found to influence the types of activities people undertake when they visit (Giles-Corti et al., 2005; Rossi et al., 2015). Meanwhile, Brody, Zahran, Vedlitz, \& Grover (2008) found that risks posed by climate change are more likely to register when the threat or sense of vulnerability is most overt, as in the case of sea level rise and adjacency to a coastline. What remains unclear is whether or not these differences translate to differences in adaptation behaviour.

\subsection{Tourists' behavioural adaptation to climate change}

The concept of recreation substitution has been applied to understand changes in demand. Introduced by Hendee and Burdge (1974), substitutability was originally defined as interchangeability among activities in satisfying participants' motives, needs and preferences" (p. 157). Initially, it was contended that the substitute activity be perceived as similar as possible to the original, emphasizing the replacement of one activity with another. However, this was not supported by research. Rather, subsequent studies suggest that substitutes in the same activity are considered to be more similar to the original experience than different activity substitutes (Baumgartner \& Heberlein, 1979; Manfredo \& Anderson, 1987; Shelby, Vaske, \& Heberlein, 1989). On this basis, Brunson and Shelby (1993) proposed a broader definition to acknowledge that a chosen substitute may 
have little apparent connection to the "motives, needs or preferences" of the original experience, where recreation substitution became defined as: "the interchangeability of recreation experiences such that acceptably equivalent outcomes can be achieved by varying one or more of the following: the timing of the experience, the means of gaining access, the setting, and the activity" (p. 69).

The results from studies applying recreation substitution to understand how skiers may adapt their future behaviour in response to marginal snow conditions, suggest that the majority of skiers would significantly alter their behaviour in some way. König (1998), for example, found that $75 \%$ of Australian skiers would alter their ski behaviour if the region experienced "very little natural snow in the next five years". A decade later, Pickering, Castley, and Burtt (2010) used the same survey instrument, finding an increase in the proportion of skiers who would alter their behaviour (90\%). Meanwhile, in Switzerland, $70 \%$ of respondents indicated they would alter their behaviour were the next five winters to be snow deficient (Behringer, Buerki, \& Fuhrer, 2000). The concern has been raised that use of phrases like "very little snow" or "snow deficient" leave room for interpretation (Scott et al., 2012), prompting some studies to adopt an analogue approach (e.g., Dawson, Scott, \& McBoyle, 2009; Steiger, 2011), provide detailed scenario descriptions (e.g., Vivian, 2011), or focus on current behavioural responses (e.g., Rutty et al., 2015). In each of these studies, skiers were proportionately more likely to engage in spatial substitution (38-68\%) compared to temporal (11-36\%) or activity substitution (0$25 \%)$. What is not clear, and represents a gap in knowledge, is an explanation of why substitution occurs, if at all.

\subsection{Role of cognition}


In the broader climate change literature, adaptive capacity has historically emphasized the role of objective assets or determinants, such as political support, financial capital, and human resources, in what Mortreux and Barnett (2017) refer to as the first generation of adaptive capacity research. Objective capacity highlights what could be done, given access to available resources. But the objective ability or capacity of a human actor only partly determines if an adaptive response is taken. A significant limitation of these first generation assessments of adaptive capacity is the inherent assumption that capacity translates into action (Mortreux \& Barnett, 2017).

In an attempt to examine the extent to which capacity explains adaptation, Grothmann and Patt (2005) shifted focus to an understanding of adaptation contingent upon individual perceptions, heralding the second generation of adaptive capacity research that emphasized mobilizing capacities. Indeed, there are a growing number of studies in multiple sectors examining the link between cognitive factors and adaptation, which suggest that by taking people's estimation of their options and ability to react to a threat into account, along with the effectiveness and costs of these options, one can gain a much clearer picture of the decision to respond to a threat (Grothmann \& Patt, 2005; Marshall \& Marshall, 2007; Marshall, Tobin, Marshall, Gooch, \& Hobday, 2013; Viscusi \& Chesson, 1999; Weber, 1997).

An individual's perception of their options or ability can in turn be influenced by a number of different factors, including geographic proximity. For example, within discussions about the role of weather and climate, anecdotal evidence suggests that recreationists are able to adjust their plans in response to weather conditions on short notice, while tourists are typically less flexible (Amelung, Nicholls, \& Viner, 2007). 
More recently, results from Rutty and Scott (2016) provide evidence that different forms of holidays can have varying degrees of resilience to climatic conditions, finding that domestic tourists or recreationists are more flexible and can afford to accept a narrower range of climatic conditions, making decisions on short notice, such as whether or not to go to the beach based on the weather forecast. If there are differences in adaptation behaviour between tourist and recreationist divers, considering the compositional and structural differences in perception may provide some insight as to why these differences exist.

Previous research has sought to explain tourists' or recreationists' behaviour by considering an individual's commitment to an activity (e.g., Hyun \& Ditton, 2006; Oh, Sutton, \& Sorice, 2013; Sutton \& Oh, 2015) and/or place (e.g., Graefe \& Dawson, 2013; Han \& Noh, 2015; Wang, 2010; Wynveen, Kyle, Hammitt, \& Absher, 2007). Commitment to activity and place provide insight into the underlying motivations for recreationists' engagement in specific leisure pursuits and visitation to specific recreation settings, which is useful when considering the likelihood of altering the nature or location of recreation participation.

Dawson, Havitz, \& Scott (2011) were the first to use place loyalty and activity involvement to explain skiers' adaptation behaviour. Using cluster analysis, the authors found that highly involved skiers were more likely to change their skiing behaviour as a result of poor snow conditions than were less involved individuals. To explain this seemingly counter-intuitive result, the authors draw upon the principles of Social Judgment Theory (Sherif, Sherif, \& Nebergall, 1965), suggesting that the specialized knowledge of highly involved individuals means they are more likely to perceive factors 
such as marginal snow conditions as a constraint or conflict than less involved individuals. However, there is limited empirical investigation to support this claim using a comprehensive framework linking activity involvement or place attachment with intentions to change one's behaviour. Application of an existing cognitive framework may provide new insight to the question of how place activity and activity involvement transmit their effect on behavioural intentions.

\subsection{Overview of Protection Motivation Theory}

Protection Motivation Theory (Rogers, 1983) outlines the cognitive responses resulting from fear appeals. Threat appraisal focuses on the source of a threat and factors that increase or decrease the probability of a maladaptive response (e.g., denial, wishful thinking). Perceptions of the severity of, and one's vulnerability to the threat inhibit maladaptive responses. In relation to diving for example, divers may consider the environmental impact of coral bleaching and their likelihood of encountering a bleached reef environment.

Coping appraisal focuses on the coping responses available to deal with a threat and factors that increase or decrease the probability of an adaptive response (e.g., following behavioural advice). The belief that behaviour will be effective in reducing the threat (i.e., response efficacy) and the belief that one is capable of performing the behaviour (i.e., self-efficacy) both increase the probability of an adaptive response. For example, divers may consider the extent to which changing dive location would reduce their chances of an unsatisfying dive experience and whether they are capable of doing so. Conversely, there may be a number of response costs that impede the performance of an adaptive behaviour (e.g., availability of resources). For example, divers may believe 
that changing dive location may require additional finances.

Protection motivation (i.e., intention to perform a recommended behaviour) results from these two appraisal processes. It is a positive function of perceptions of severity, vulnerability, response efficacy, and self-efficacy, and a negative function of perceived response costs of the adaptive behaviour. Protection motivation is typically equated with behavioural intentions, operating as a mediating variable between the threat and coping appraisal processes and protective behaviour.

\subsection{Study purpose and hypotheses}

This study ties together existing research on climate/environmental change, tourism behaviour, and PMT in an effort to understand tourists' behavioural intention to coral bleaching (Figure 2). The overall purpose of this research is to understand divers' responses to a hypothetical coral bleaching event. Associated with this goal are several specific research objectives, which are described below.

The first objective of this research is to evaluate how divers intend to respond to coral bleaching in the future. There is disagreement among researchers and tourism stakeholders about how coral bleaching might affect tourists' dive-related behaviour. There is a need for empirical investigation into how scuba divers will respond to coral bleaching, considering differences in response of divers compared to skiers, and dive tourists compared to dive recreationists. From previous investigations into recreation substitution it is clear that some tourists and recreationists prefer to engage in spatial substitution in response to changes in resource condition; others favour a change in activity or participation intensity, while a proportion of visitors show no outward change in behaviour. 
The second objective of this research is to examine the extent to which Protection Motivation Theory (PMT) predicts climate-induced behavioural change. There is a need to understand the cognitive processes that determine whether or not one adapts their behaviour in response to a given threat. A cognitive approach focuses on how individuals think, with the belief that such thought processes affect the way in which people behave, thus offering insight into how tourists' perceptions influence their behaviour. To achieve this, the present study employed to help understand the motivational factors associated with intended adaptation to a coral bleaching event. It was expected that the constructs that comprise PMT (i.e., perceived vulnerability, perceived severity, response efficacy, self-efficacy, response costs) would combine to explain significant proportions of the variance in behavioural intentions. Specifically, it was expected that:

- as perceived vulnerability increases, intention to adapt increases

- as perceived severity increases, intention to adapt increases

- as perceived effectiveness of a behavioural intention increases, intention to adapt increases

- as perceived ability to carry out adaptation increases, intention to adapt increases

- as perceived cost increases, intention to adapt decreases

This research will consider whether these relationships hold true for different adaptation behaviours previously identified in recreation substitution studies (i.e., spatial adaptation, temporal adaptation, activity adaptation), as well as a form of cognitive adaptation.

The third objective of this research is to examine the role of geographic proximity to coral reefs within specific behavioural intentions. Based on previous research comparing tourists' and recreationists, it is expected that divers who are more proximate to coral reefs will be have greater flexibility in how they respond to coral bleaching, as 
expressed through differences in self-efficacy, and that they will accept a narrower range of conditions, as expressed through differences in threat appraisal.

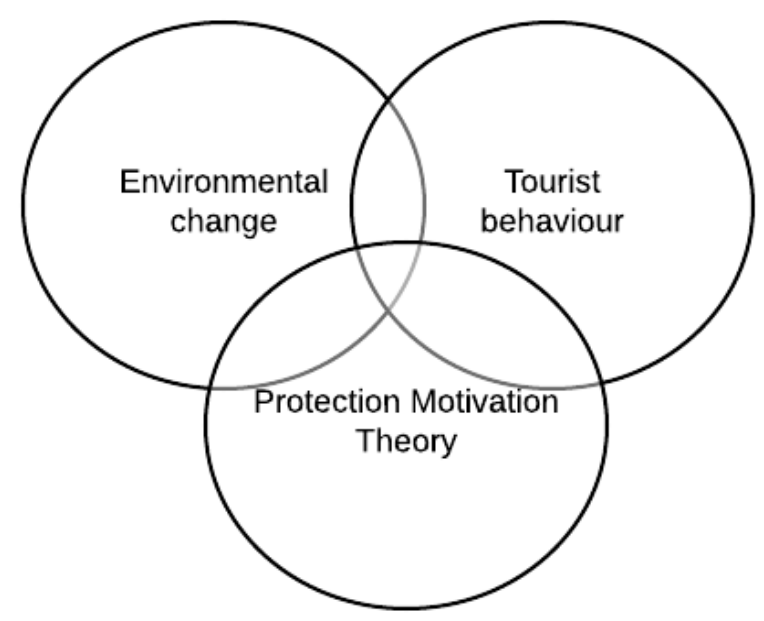

Figure 2: Nexus of research areas

The fourth objective of this research is to examine the extent to which a mediated model of activity involvement/place attachment and behavioural intentions predicts climate-induced behavioural change. This investigation hypothesizes that PMT will be a useful framework to assess how place activity and activity involvement transmit their effect on behavioural intentions by accounting for both the direct and indirect effect of these variables through the risk and coping appraisal processes. Theoretical and empirical justification for this type of mediation analysis is provided in the next chapter. 


\section{LITERATURE REVIEW}

\subsection{Outline}

The following chapter is divided into two main sections. The first section describes the selection of Protection Motivation Theory (PMT) as the theoretical framework for this study through a comparison to two commonly applied behavioural models in tourism and recreation studies: the Theory of Planned Behaviour and the Transactional Theory of Stress and Coping. The second section details an extension of PMT, considering activity involvement and place attachment as sources of information that initiate the framework's cognitive mediating processes. To provide insight as to how activity involvement and place attachment influence behavioural intentions, the relationships between place attachment/activity involvement and behavioural intentions, threat appraisal variables, and coping appraisal variables are explored.

\subsection{Identifying a suitable theoretical framework}

\subsubsection{Theory of Reasoned Action/Planned Behaviour}

The Theory of Reasoned Action (TRA) and its extension, the Theory of Planned Behaviour (TPB), are some of the most widely cited behaviour theories in social psychology. Developed out of attitude research into Expectancy Value Models, the models suggest that an individual's decision to engage in a particular behaviour arises from a belief that performing the behaviour will lead to a specific outcome, where intention to perform a certain behaviour precedes the actual behaviour (Ajzen \& Fishbein, 1969). Attitudes and subjective norms determine intention, where an attitude is an opinion about whether behaviour is positive or negative, while a subjective norm refers to perceived social pressure to perform or not perform the behaviour. Behavioural 
intentions are higher, that is to say a person is more motivated to perform a particular behaviour, if the behaviour is evaluated as positive, and is perceived to be something a person's important others would approve of.

The Theory of Planned Behaviour extends this model to account for situations in which an individual's control over the behaviour is incomplete (Ajzen, 1985, 1991). Incorporating a measure for perceived behavioural control accounts for factors that exist outside of an individual, a concept which closely aligns with Bandura's concept of selfefficacy (Ajzen, 1991; Conner \& Armitage, 1998). The more resources and opportunities perceived to be available to an individual, and the fewer anticipated obstacles or impediments, the greater one's perceived control over the behaviour. Much like the relationships between behavioural intentions and attitudes and subjective norms, higher levels of perceived behavioural control are typically associated with more favourable intentions to perform behaviours. Hagger, Chatzisarantis, and Biddle's (2002) metaanalysis of 72 health studies employing the TPB demonstrated that perceived behavioural control was one of the most consistent and reliable predictors of physical activity-related intentions and behaviours. Similarly, Yuzhanin and Fisher's (2016) meta-analysis of 15 tourism studies that use TPB to predict intentions to choose a tourist destination found that the majority of the reviewed studies concluded that perceived behavioural control was the most influential factor in predicting intentions of travelling to a particular destination.

According to the TPB, intentions are the most direct predictors of behaviour (Ajzen, 1991, 2005). There is considerable empirical evidence to support the notion that specific behaviours can be reasonably accurately predicted from intentions. Meta- 
analyses of studies spanning a range of behaviours have reported mean intentionbehaviour correlations of 0.63 (Van den Putte, 1991), 0.47 (Armitage \& Conner, 2001), 0.53 (Sheppard, Hartwick, \& Warshaw, 1988), and 0.45 (Randall \& Wolff, 1994), while a meta-analysis of these and other meta-analyses found an overall correlation between intention and behaviour of 0.53 (Sheeran, 2002).

Despite its success in predicting human behaviour, the TPB is not without its limitations. Most notably, the TPB tends to ignore situational factors (Sutton, 1998). In other words, the model does not address the notion that intentions can change because the context changes. For example, an intention to scuba dive at a particular location might change in the event of coral bleaching. That is to say, when examining scuba divers' adaptation behaviour, this is the difference between predicting travel intentions to dive at a particular destination and predicting intentions to travel elsewhere because of changes in dive conditions. In the case of the latter it is important to understand why a person might want or need to find different dive conditions - what is the change in context, i.e., the risk or threat that necessitates this change in behaviour?

Risk perceptions can become overriding factors when introduced into travel decisions, changing the context of conventional models of decision-making. There is general agreement that tourists tend to avoid destinations with greater perceived risks (Batra, 2008; Chen \& Noriega, 2004; Floyd, Gibson, Pennington-Gray, \& Thapa, 2004; Kingsbury \& Brunn, 2004; Law, 2006; Sönmez \& Graefe, 1998a, 1998b), though some tourists seek out risky activities and destinations (Dickson \& Dolnicar, 2004; Fuchs, 2013; Khoo-Lattimore \& Mura, 2011). Following the 9/11 terrorist attacks, most tourism risk studies focus on risks posed by terrorism, political instability, and crime. As a result, 
some authors suggest that there is a blurred distinction between safety, security, and risk (Yang \& Nair, 2014).

Earlier risk studies acknowledged a much broader subset of risks to a person while undertaking tourist activities (e.g., Jacoby \& Kaplan, 1972; Roehl \& Fesenmaier, 1992; Solomon, 1999; Sönmez \& Graefe, 1998b). For example, Roehl \& Fesenmaier (1992) identified seven dimensions of risk, these being physical (possibility of physical danger, injury or sickness), financial (possibility that trip will not provide value for money), time (possibility that trip will be a waste of time), equipment (possibility of mechanical, equipment or organizational problems), social (possibility that trip will influence others' opinions of self), psychological (possibility that trip will not reflect selfimage), and satisfaction (possibility that trip will not provide personal satisfaction).

Tourist satisfaction is widely acknowledged as a factor that influences future behavioural intention (Fornell, Johnson, Anderson, Cha, \& Bryant, 1996; Hellier, Geursen, Carr, \& Rickard, 2003; Oliver, 1980; Um, Chon, \& Ro, 2006). Yet, the extent to which satisfaction is considered as an influence on future intentions is often limited to revisit intentions and communications (e.g., recommend or speak highly of destination to friends/family). There is little consideration given to changes at a destination that could pose a risk to one's personal satisfaction with a trip. This idea is core to past tourism and climate change adaptation studies (i.e., how might change in snow conditions influence ski tourists' behaviour), but potential behavioural changes have not been framed in terms of risk. The advantage of doing so is that it brings the reason for behavioural adaptation to the fore. This requires that the decision-making model used to explain or predict behaviour must explicitly consider risk perceptions. 
To achieve this, what has previously been depicted as recreation substitution in climate change adaptation studies may be more appropriately framed as displacement. In most studies, skiers have been asked how they would alter their ski behaviour if: the region experienced "very little natural snow in the next five years" (König, 1998; Pickering et al., 2010); the next five winters were snow deficient (Behringer et al., 2000); or the next three of five winters had very little snowfall, like in the winter of 2001-02 (Dawson et al., 2011; Dawson, Scott, \& Havitz, 2013). Framed this way, the application of recreation substitution is problematic. By definition, substitution means that a decision has already been made but the intended activity is no longer possible (Iso-Ahola, 1986). Decisions made in the planning stage of participation are not addressed. Thus, it is challenging to use recreation substitution to predict how behaviour might change in some hypothetical future. That is to say, there is no guarantee that declining snow cover, or a similar type of impact, will necessarily prevent recreation. In contrast, Rutty et al. (2015) asked skiers how they would react in the present if their in-situ resort were closed, making it a suitable application of recreation substitution.

Displacement is used to describe the behaviour of users who become consciously dissatisfied with some type of change at a site and alter their behaviour in response (Becker, 1981; Schreyer \& Knopf, 1984). Similar to recreation substitution, this behaviour can take the form of altering the timing of use (temporal displacement), the spatial location of use (spatial displacement), or the activities in which one engages (activity displacement). The advantage of this reconceptualization is that, because displacement refers to a perceived adverse change at a recreation site that causes one to change their behaviour, it is necessary to consider if a change at a tourist or recreation 
site is perceived as adverse, and thus whether it poses a risk to satisfaction.

\subsubsection{Transactional Theory of Stress and Coping}

The above review of TRA/TPB suggests that an appropriate theoretical framework to understand scuba divers' behavioural intentions should include both measures of perceived behavioural control and risk perception. One model that fits these criteria is the Transactional Theory of Stress and Coping (Lazarus \& Folkman, 1984), which has been used to model the process by which an individual becomes stressed and copes with that stress. When faced with a stressor, the potential threat is evaluated in a process known as primary appraisal (akin to threat or risk appraisal), followed by a secondary appraisal in which the controllability of the stressor and a person's coping resources are evaluated.

Schneider and Hammitt (1995) suggested that Lazarus and Folkman's (1984) model could be used for understanding how recreationists cope with conflicts. Previous research suggests that goal interference on the part of recreationists is at the heart of recreational conflict (Jacob \& Schreyer, 1980). Thus, coping with this interference can be understood as a response to the stress created by the situation. The short-term outcome of the stress-coping process is measured as level of detraction, which represents a general measure of how the situation affects the overall recreation experience. The resulting recreation conflict appraisal and response model has been applied in several studies to examine how outdoor recreationists deal with negative setting elements during their recreation experience (Bedoya, 2013; Hall \& Cole, 2007; Miller \& McCool, 2003; Schuster, Hammitt, \& Moore, 2006; Schuster, Hammitt, Moore, \& Hammitt, 2003; Tseng, 2009; Wang \& Chang, 2010). 
Stress-coping studies emphasize how the degree of stress influences choice of coping behaviour. Kuentzel and Heberlein (1992) were the first to suggest that there is a hierarchy of coping strategies that parallels different levels of perceived impact. They proposed that with increasing impact, a visitor first adopts a cognitive coping strategy, then a within-site behavioural coping strategy, before finally leaving altogether. Using a cognitive coping strategy, individuals re-evaluate a situation in a more positive light. The two most commonly applied cognitive coping strategies in recreation research are product shift and rationalization. Product shift involves a "change in the definition of the experience and standards for the importance of characteristics of that experience" (Shelby, Vaske, \& Heberlein, 1989, p. 276), while rationalization involves a reevaluation of an undesirable situation in a more favourable light to alleviate stress and inconsistencies (Manning, 1986). In both cases, the ultimate result is that is that satisfaction remains high, without an obligation to remove oneself from the situation. The study results, however, did not support this assertion. Schneider and Hammitt (1995) similarly failed to find a clear relationship between intensity of conflict and coping response. In contrast, Miller and McCool (2003) observed that recreationists with a high level of stress were more like to adopt "extreme" coping behaviours, such as absolute displacement, while low levels of stress coincided with more subtle cognitive coping strategies.

Rather than simply evaluate the degree of stress or negativity of an event, a more useful measure would assess what is threatened. For example, Miller and McCool (2003) measure stress by asking respondents' "level of concern that detracting elements caused". In contrast, asking respondents "what level of concern you expect for the following 
dimensions of your life without any adaptation" provides a greater understanding of the type of impact the stressor or threat has by shifting the focus to what it is the detracting element is a threat to. Furthermore, within the broader climate change adaptation literature, assessment of adaptation often takes place within the assessment of vulnerability, since the two are now seen as inextricably linked (Luers, Lobell, Sklar, Addams, \& Matson, 2003; O’Brien, Eriksen, Schjolden, \& Nygaard, 2004). From a practical standpoint, knowing if a stressor is perceived as likely can have a significant influence on whether it is perceived as a threat, which could affect selection of coping strategies, and thus may account for inconsistent results.

Studies applying the stress-coping framework often fail to consider coping appraisal, reducing the framework's utility for understanding climate change adaptation. As demonstrated above, inclusion of some measure of perceived behavioural control significantly increases the prediction of behavioural intentions. When considered, coping appraisal items are operationalized in terms of the perceived controllability of a situation (e.g., Schuster et al., 2003). The logic being, if a situation is perceived as controllable, a person is more likely to deal directly with the stressor (i.e. behavioural coping), whereas the focus in an uncontrollable situation is on managing one's own responses (i.e. cognitive coping). However, controllability alone does not directly speak to the utility of coping strategies at responding to a particular stress experience, which is useful when interest is in which coping strategy or strategies a person will choose. Schuster et al. (2006) suggested that future stress-coping research should consider the efficacy of coping mechanisms, but this suggestion has not, as of yet, been applied. 


\subsubsection{Protection Motivation Theory}

From the review of these two models, an appropriate theoretical framework applied to understand scuba divers' behavioural intentions should include measures of: risk perception (both perceived severity and perceived vulnerability), perceived behavioural control, and efficacy of coping mechanisms. One model that fits these criteria is the Protection Motivation Theory (PMT) (Rogers, 1975, 1983). Like the stresscoping framework, PMT has common origins in the work of Lazarus (1966). Based upon simple, control-system concepts, both models propose the same appraisal processes, but differ in how these appraisal processes are operationalized, which may address some of the deficiencies of stress-coping studies raised in the previous section.

PMT was originally developed as a framework for understanding the persuasive impact of fear appeals, focusing on the conditions under which fear appeals influence behaviour (Rogers, 1975). Central to this work was the question of whether fear appeals could directly affect behaviour, or whether this influence was more indirect. Specifically, Rogers sought to identify the key variables in fear appeals and their cognitive meditational processes. Originally, three main stimulus variables were proposed as part

of a fear appeal: i) threat noxiousness or severity; ii) probability of threat occurrence if no protective behaviour is adopted; and iii) efficacy of coping response for reducing or eliminating the threat. Each stimulus variable in turn initiates a corresponding cognitive meditational process. Thus, the magnitude of noxiousness of a threat initiates perceptions of severity; the probability of threat occurrence initiates perception of vulnerability; and the availability of effective coping responses initiates perceptions of response efficacy. In other words, the impact of the stimulus variables is mediated by perceived severity, 
perceived vulnerability, and perceived response efficacy. These three cognitive processes mediate the effects of the components of fear appeals upon attitudes by arousing what Rogers' terms “protection motivation".

Rogers' (1975) conceptualization of protection motivation was that of an intervening variable that "arouses, sustains, and directs activity" (p. 98). That is to say, the intent to adopt a recommendation is mediated by the amount of protection motivation aroused. In this way, protection motivation is synonymous with the intention to perform protective health behaviour.

The theory was later extended to provide a more general account of the impact of persuasive communications (Rogers, 1983). The revised version of PMT includes a broader range of factors, in addition to persuasive communications, that initiate cognitive processes. PMT was also expanded to incorporate additional cognitive mediating processes, including perceptions of the rewards of maladaptive responses, self-efficacy, and response costs. With the incorporation of self-efficacy theory, the theory was presented as a possible general model of attitude change.

According to self-efficacy theory, psychological change arises when expectancies of personal mastery or efficacy are altered (Bandura, 1977, 1982). Expectancy concerning mastery or effective coping is viewed as two independent expectancies: outcome expectancy (the belief that a behaviour will/will not result in a given outcome), and self-efficacy expectancy (the belief that one is/is not capable of performing a behaviour). Using this terminology, both probability of occurrence and coping response efficacy can be viewed as outcome expectancies: the former that persistence in current behaviour will lead to an undesirable event, and the latter that an alternative behaviour 
will avert the undesired consequences (Rogers \& Maddux, 1983). Thus, the basic components of protection motivation may be considered applicable to attitude-change beyond fear appeals.

The inclusion of self-efficacy also significantly improved the model's predictive ability, it being the most powerful predictor of behavioural intentions (Rogers \& Maddux, 1983). This finding has been confirmed in subsequent meta-analyses of applications of PMT to health-related intentions and behaviour (e.g., breast self-examination, smoking cessation, adopting a healthy diet), where self-efficacy consistently exhibits the strongest correlation with protection motivation (Floyd, Prentice-Dunn, \& Rogers, 2000; Milne, Sheeran, \& Orbell, 2000). While similar meta-analyses do not exist for applications of PMT outside the health field, study findings outlined in section 2.3 follow this pattern. Following Leventhal's (1970) parallel response model, perceptions of severity, vulnerability, rewards of maladaptive responses, self-efficacy, response efficacy, and response costs were organized into two independent cognitive mediating processes, focusing on threat appraisal and coping appraisal (Figure 3). The threat appraisal process focuses on the source of a threat and factors that affect the probability of a maladaptive response, such as denial. The extent to which a potential threat poses harm (perceived severity) and the likelihood of experiencing a given threat (perceived vulnerability) inhibit maladaptive responses. 


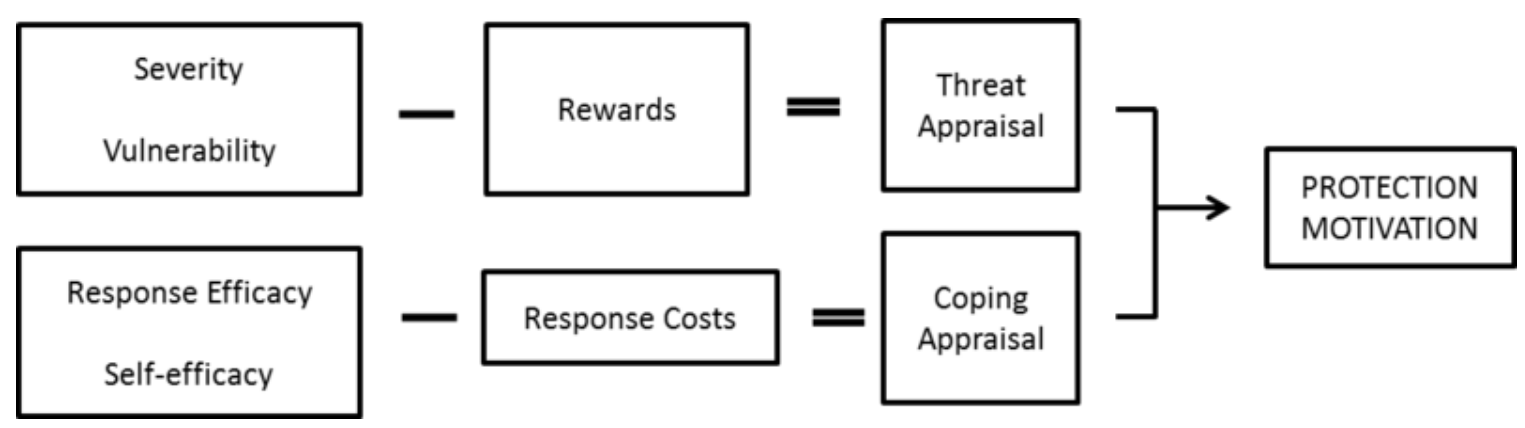

Figure 3: Protection Motivation Theory (Rogers, 1983)

While perceptions of severity and vulnerability inhibit maladaptive responses, intrinsic (e.g., pleasure) or extrinsic (e.g., social approval) rewards may increase the likelihood of maladaptive responses. However, this component is rarely assessed because any reward associated with not performing protective behaviour can be rephrased as a response cost of engaging in protective behaviour (Abraham, Sheeran, Abrams, \& Spears, 1994). For example, the reward of possible reduced cost associated with visiting environmentally degraded settings could be rephrased as a response cost associated with travelling elsewhere.

Coping appraisal, meanwhile, focuses on coping responses to deal with the threat and factors that affect the probability of a protective or adaptive response. Both the belief that the adaptive response is able to prevent or minimize a given threat (perceived response efficacy) and the belief that one is able to perform this response (perceived selfefficacy) increase the probability of adaptive behaviour. For example, a scuba diver may consider the extent to which diving somewhere outside a region that is experiencing bleaching may produce a satisfactory experience and whether they are able to travel elsewhere. While perceived response efficacy and self-efficacy increase the probability of an adaptive response, perceived response costs or barriers may inhibit an adaptive 
response. For example, there may be an increased financial cost to divers travelling further abroad.

Protection motivation results from these two appraisal processes: a positive function of perceptions of severity, vulnerability, response efficacy, and self-efficacy, and a negative function of perceptions of the rewards associated with maladaptive responses and the response costs of the adaptive behaviour. For protection motivation to be elicited, perceptions of severity and vulnerability should outweigh the rewards associated with maladaptive responses, and perceptions of response efficacy and self-efficacy should outweigh the response costs of the adaptive behaviour. Table 1 summarizes the key variables of PMT.

\section{Table 1: Summary of key Protection Motivation Theory variables}

\begin{tabular}{lll}
\hline Threat appraisal & Threat severity & $\begin{array}{l}\text { Perceived extent to which a potential threat } \\
\text { poses harm }\end{array}$ \\
& $\begin{array}{l}\text { Threat } \\
\text { vulnerability } \\
\text { Response } \\
\text { Cfficacy } \\
\text { Self-efficacy }\end{array}$ & $\begin{array}{l}\text { Perceived likelihood of experiencing a given } \\
\text { threat } \\
\text { Belief that the adaptive response is able to } \\
\text { prevent or minimize a given threat } \\
\text { Belief that one is able to perform the adaptive } \\
\text { response } \\
\text { Costs associated with adaptation }\end{array}$ \\
& Response costs & $\begin{array}{l}\text { Intention to engage in a protective (i.e., } \\
\text { adaptive) response }\end{array}$ \\
\hline Protection motivation & &
\end{tabular}

\subsection{Applying Protection Motivation Theory to climate change adaptation}

Grothmann and Patt (2005) were the first to apply PMT to a climate change adaptation context, developing the Model Private Proactive Adaptation to Climate Change. The model distinguishes between adaptive responses (i.e., responses that avoid damage) and maladaptive responses (i.e., avoidant reactions, such as denial of the threat). 
However, an avoidant reaction can also be seen as an adaptive coping strategy to protect a person's psychological well-being if he/she does not have the means of avoiding damage, sometimes referred to as a cognitive coping strategy. In their model, protection motivation and coping appraisal are relabelled as behavioural intention and perceived adaptive capacity respectively, becoming one of the first studies to acknowledge the importance of individual's subjective adaptive capacity in determining behavioural intentions. The model also acknowledges several external influences, including the social discourse about climate change, cognitive biases/heuristics, risk experience appraisal, adaptation incentives, and the reliance on public adaptation, noting that private adaptation to climate change, unlike health protective behaviours for which PMT was developed, can also be achieved by others' adaptive actions.

The authors apply the model to two different case studies to examine its explanatory power: the first examining flood preparedness in Cologne, Germany; the second explaining adaptations in farm management strategies in Zimbabwe. In the first case study, socio-cognitive factors proved to be better predictors of household-level adaptation than socio-economic variables, explaining between $26 \%$ and $45 \%$ of the variance in all four behavioural intentions. In contrast, the socio-economic model yielded significant explanations of the variance in behavioural intentions in only three of four cases, accounting for between $3 \%$ and $35 \%$ of the variance. Results from the second case study provide conceptual support for the model, suggesting that people's failure to adapt can be explained by cognitive factors. Specifically, they suggest that farmers were not changing their behaviour in response to information about climate change not because of a lack of means, but because of a lack of behavioural intention. This lack of intention 
results from a difference between farmers' perception of the risks and objectively assessed risks (i.e., low threat perception), and an unwillingness to believe that their actions can actually protect them from harm (i.e., low response efficacy).

Grothmann and Patt's findings align with that of a growing number of empirical studies examining the link between cognitive factors and adaptation, which suggest that taking people's estimation of their options and ability to react to a threat into account, along with the effectiveness and costs of these options, provides a much clearer picture of the decision to respond to the threat (Marshall \& Marshall, 2007; Marshall et al., 2013; Viscusi \& Chesson, 1999; Weber, 1997). In subsequent applications of PMT to predict agricultural adaptation behaviour (Dang, Li, Nuberg, \& Bruwer, 2014; Truelove, Carrico, \& Thabrew, 2015; van Duinen, Filatova, Geurts, \& van der Veen, 2015), adaptation to water stress (Kuruppu \& Liverman, 2011; Tapsuwan \& Rongrongmuang, 2015), and flooding associated with sea-level rise (Koerth, Vafeidis, Hinkel, \& Sterr, 2013), between $23 \%$ and $49 \%$ of variation in climate change behavioural intentions is explained using the framework. Self-efficacy and response efficacy are most frequently identified as being the strongest predictors of adaption intention (Dang et al., 2014; Kuruppu \& Liverman, 2011; Truelove et al., 2015) further highlighting the importance of incorporating a measure of subjective adaptive capacity when determining individuals' behavioural intentions (Table 2).

Table 2: Applications of Protection Motivation Theory in climate change research

\begin{tabular}{lll}
\hline Study & Context & Main findings/conclusions \\
\hline $\begin{array}{l}\text { Dang et al. } \\
(2014)\end{array}$ & $\begin{array}{l}\text { How farmers appraise their } \\
\text { private adaptive measures } \\
\text { and influential factors }(\mathrm{n}=\end{array}$ & $\begin{array}{l}\text { Statistically significant explanatory } \\
\text { variables explained 29 to 34.3\% of the } \\
\text { 598) }\end{array}$ \\
& $\begin{array}{l}\text { variation of farmers' adaptation } \\
\text { assessments }\end{array}$ \\
& Adaptive measures with high perceived
\end{tabular}


Grothmann and

Patt (2005)

Koerth et al.

(2013)

Kuruppu \&

Liverman

(2011)

Tapsuwan et al (2015)

Truelove et al. (2015)

van Duinen et al. (2015)
Examine two case studies to explore the validity of MPPACC to explaining climate change adaptation $(\mathrm{n}=157)$

Examine motivation of coastal dwellers to adapt proactively to rising sealevels and associated flood events $(n=257)$

Evaluate how perceptions of both climate change impacts on water resources and capacity to adapt to these impacts shape the uptake of anticipatory adaptation actions $(\mathrm{n}=132)$

Understand motivating factors/barriers likely to drive/ hinder people's intentions to install and use decentralized water systems (DWS) $(\mathrm{n}=295)$

Psychological mechanisms that facilitate or constrain agricultural adaptation behaviour $(\mathrm{n}=192)$

Explore the influence of risk appraisal and coping self-efficacy and perceived adaptation efficacy were mostly used

Case study 1: socio-cognitive factors proved to be better predictors of householdlevel adaptation than socio-economic variables, explaining between $26 \%$ and $45 \%$ of the variance in all four behavioural intentions

Case study 2: farmers were not changing their behaviour in response to information about climate change not because of a lack of means, but because of a lack of behavioural intention. This lack of intention results from a difference between farmers' perception of the risks and objectively assessed risks (i.e. low threat perception), and an unwillingness to believe that their actions can actually protect them from harm (i.e. low response efficacy)

PMT explains $19.1 \%$ of the variance of the implemented adaptation measures

Flood risk appraisal had the greatest effect on household-level adaptation and was the only predictor with a significant value

Although respondents believed in the effectiveness of the adaptation actions, they identified adaptation costs as the main barrier to implementation

Beliefs of self-efficacy play a key role in behavioural intention formation

Variances explained in adaptive and maladaptive coping scores by key PMT variables were significant and were 19\% and $16 \%$, respectively

Response efficacy was the most influential factor in predicting adaptive coping

Note: authors do not include measure of self-efficacy, which may contribute to low explained variance

PMT was significant in predicting intentions of 3 of 4 adaptive behaviours

Efficacy beliefs were consistently the strongest predictors of intention

PMT explains $10 \%$ of the total variance in implemented field-level measures, $43 \%$ of 
appraisal factors on

farmers' adaptation motivation and the adoption of three types of behavioural intentions $(\mathrm{n}=$ 142) the total variance in the implementation of farm-level measures, and $30 \%$ of the total variance in joint measures (i.e., adoption of field and farm-level measures)

Various components of the threat and coping appraisal processes influence adoption decisions differently across three scales of drought adaptation measures

\subsection{Applying Protection Motivation Theory to tourism and climate change}

There are only three known applications of PMT within the field of tourism and climate change (Table 3). Tapsuwan and Rongrongmuang (2015) identify how well stakeholders in the dive tourism industry of Thailand can adapt to climate change threats. However, the small sample (9 semi-structured in-depth interviews) is limited to supplyside stakeholders, and there is no mention of coping appraisal items in the results or discussion, which limits the utility of this application. Nevertheless, the authors suggest that an analysis of the demand side of the tourism industry would be a worthwhile pursuit for insights on how climate change will affect tourists' behaviour and preferences.

Horng, Hu, Teng, and Lin (2014) apply PMT to evaluate tourists' Energy Saving and Carbon Reduction behaviours, emphasizing tourism as a threat to the environment (i.e., mitigating behaviour), rather than climate change as a threat to tourism (i.e., adaptation behaviour). Conceptually, climate change adaptation measures have more in common with health-related behaviours than do climate change mitigating behaviours (Hunter \& Röös, 2016). Unlike mitigating behaviours, which deal with actions to reduce greenhouse gas emissions to avoid further increased climate change, and thus must consider the latent conflict between collective benefits and individual costs, both adaptation and health behaviours seek to reduce direct personal risk.

The study by Wang et al. (2018) is the only known application of PMT to 
individual tourists' adaptation behaviour. However, there are several significant conceptual and methodological issues that affect the validity and reliability of the study's results. Conceptually, the authors seek to integrate PMT with Bryant et al.'s (2000) individual's (farmer's) climate change adaptation process model to allow "simultaneous consideration of the potential transformations induced by climate change in light of the qualities of tourism systems and possible cognitive mediating factors that these changes may generate from tourists" (Wang et al., 2018, p. 5). In practise, this involves separately assessing tourists' climate change perception, shift in destination attractiveness (as a result of climate change), and threat appraisal as it relates to relates to effect of climate change on destination attractiveness (e.g., I feel that the effects of climate change will severely alter the destination attractiveness of Kenting). A more direct way to capture shifts in destination attractiveness, understood here as the perceived ability of a destination to satisfy one's holiday needs, is to frame threat appraisal in terms of satisfaction risk, as discussed in section 2.2.1.

In the cause of coping appraisal, the authors evaluate the effects of green tourism behaviours on destination attractiveness. This is problematic because the coping behaviours specified do not match the behavioural intentions evaluated. For example, the survey asks respondents whether "green tourism behaviours will reduce the changes in the destination attractiveness of Kenting" (Wang et al., 2018, p. 16), as a measure of response efficacy. However, behavioural intentions focus on specific behavioural (e.g., I left Kenting sooner than planned), physical (e.g., find shaded areas in Kenting to engage in tourism activities), and psychological (e.g., media reports have made me think of the impacts of changes to the attractiveness of Kenting) adaptations. Furthermore, the 
construct of self-efficacy focuses on belief of effectiveness rather than ability to perform (e.g., my green tourism behaviours in Kenting will reduce the changes in the destination attractiveness), resulting in a redundancy with response efficacy. Nor do the authors evaluate response costs.

Perhaps most concerning is the preconditions set to determine the included survey responses. The authors limit the sample to participants who: (i) perceive climate change; (ii) believe they would not travel to Kenting if its destination attractiveness were altered by climate change; and (iii) would adjust their tourism behaviours in response to these hypothetical shifts in destination attractiveness, thus removing 223 of the 556 questionnaires submitted. The rationale offered is that other respondents were excluded because adaptation is not possible in these participants. Yet, this very removal has eliminated the possibility of evaluating the merit of this assumption, effectively biasing the sample to comply with the proposed framework. For example, the fourth hypothesis proposes that "a threat appraisal has a significant positive relation with a coping appraisal" (Wang et al., 2018, p. 9). Yet, those participants for who this relationship may not have held true are not a part of the study sample. It is perhaps unsurprising that the authors find support for all six of their hypotheses and a high explanatory power $\left(\mathrm{R}^{2}=\right.$ $0.58)$.

In light of this critique, the goal of applying PMT to the study of tourists' adaptation behaviour is to develop a better understanding of what motivates a person to perform a given behaviour when encountering adverse recreation conditions. Specifically, coral bleaching has been identified as a potential threat to diver satisfaction. Previous applications of PMT in tourism research suggest that the nature of the perceived 
threat can have implications for the utility of the model. For example, Horng et al. (2014)

found that threat appraisal was not as effective a predictor as expected. The authors

suggest that this may be because tourists do not generally believe that tourism poses a

serious threat to the environment, contrasting the immediacy and urgency of a health risk, for which the framework was originally designed, with that of the risks posed by climate change. Similarly, Tapsuwan et al. (2015) suggest that the limited evidence of active climate change mitigation and adaptation is partly a result of respondents' perceiving climate change as a long term, global problem beyond their control. Moreover, this could have implications for the predictive ability of coping appraisal, such that "a minimum level of threat or concern must exist before people start contemplating the benefits of possible actions and ruminate their competence to actually perform them" ((Schwarzer, 1992, p. 235).

\section{Table 3: Applications of Protection Motivation Theory in tourism and climate change research}

\begin{tabular}{|c|c|c|}
\hline Study & Context & Main findings/conclusions \\
\hline \multirow[t]{2}{*}{$\begin{array}{l}\text { Horng et al. } \\
\text { (2014) }\end{array}$} & \multirow{2}{*}{$\begin{array}{l}\text { Explore tourists' energy } \\
\text { saving and carbon } \\
\text { reduction (ESCR) } \\
\text { behaviour and its influent } \\
\text { factors }(\mathrm{n}=512)\end{array}$} & $\begin{array}{l}\text { PMT explains } 43.7 \% \text { of the variation in } \\
\text { tourism ESCR behaviours }\end{array}$ \\
\hline & & $\begin{array}{l}\text { Strongest predicators of tourist ESCR } \\
\text { behaviours are behavioural intentions and } \\
\text { self-efficacy; threat appraisal is not as } \\
\text { effective a predictor as expected }\end{array}$ \\
\hline \multirow[t]{2}{*}{$\begin{array}{l}\text { Tapsuwan \& } \\
\text { Rongrongmuan } \\
\text { g (2015) }\end{array}$} & \multirow{2}{*}{$\begin{array}{l}\text { Identify how well } \\
\text { stakeholders in the dive } \\
\text { tourism industry of } \\
\text { Thailand can adapt to } \\
\text { climate change threats }(n= \\
\text { 9) }\end{array}$} & $\begin{array}{l}\text { Respondents' demonstrated distorted } \\
\text { perceptions with regards to the temporal } \\
\text { and spatial scales of climate change }\end{array}$ \\
\hline & & $\begin{array}{l}\text { Respondents believed that climate change } \\
\text { was happening, but that it was a long term } \\
\text { and global problem beyond their control }\end{array}$ \\
\hline \multirow[t]{2}{*}{$\begin{array}{l}\text { Wang et al. } \\
(2018)\end{array}$} & \multirow{2}{*}{$\begin{array}{l}\text { Evaluate effects of climate } \\
\text { change perception, } \\
\text { hypothetical shifts in } \\
\text { destination attractiveness, } \\
\text { and threat and coping } \\
\text { appraisals on tourists' }\end{array}$} & $\begin{array}{l}\text { PMT explained } 58 \% \text { of the variation in } \\
\text { tourists' behavioural intentions, with each } \\
\text { construct significantly contributing in the } \\
\text { expected direction }\end{array}$ \\
\hline & & $\begin{array}{l}\text { Significant issues in the study's approach } \\
\text { call into question the validity of these }\end{array}$ \\
\hline
\end{tabular}


behavioural intentions in results.

coastal destinations

\subsection{Extension to Protection Motivation Theory}

\subsubsection{Personality variables as sources of information}

Originally, persuasive communications were the only considered initiator of threat and coping appraisal processes. These "fear appeals" describe the unfavourable consequences that might result from failure to adopt the message's recommendations. Rogers (1983) later expanded on the number of stimulus variables, or sources of information, that can initiate these cognitive mediating processes. In particular, verbal persuasion (e.g., conversations with others) and observational learning (e.g., directly witnessing use of protective responses) were identified as important environmental sources of information, while personality variables (e.g., an individual's commitments and beliefs) and prior experiences (e.g., prior experience with protective measures) were identified as important intrapersonal sources of information. Collectively, these provide the individual with a general knowledge of potential threats and potential protective responses. The individual must then assess this information to determine whether or not to engage in a given protective measure in response to a given threat.

What Rogers refers to as "personality variables", are more commonly referred to as background factors in other models (e.g., TRA/TPB). Examples of these personality variables or background factors commonly applied to explain tourists' or recreationists' behaviour include considering an individual's commitment to an activity (e.g., Hyun \& Ditton, 2006; Oh, Sutton, \& Sorice, 2013; Sutton \& Oh, 2015) and/or place (e.g., Graefe \& Dawson, 2013; Han \& Noh, 2015; Wang, 2010; Wynveen, Kyle, Hammitt, \& Absher, 2007). Within tourism and climate change adaptation research, Dawson et al. (2011) used 
place loyalty and activity involvement to explain skiers' adaptation behaviour.

Commitment to activity and place provide insight into the underlying motivations for recreationists' engagement in specific leisure pursuits and visitation to specific recreation settings, which is useful when considering the likelihood of persons altering the nature or location of their recreation participation. However, few comprehensive frameworks linking activity involvement or place attachment with intentions to change one's behaviour have been fully developed or tested, resulting in limited understanding of how adaptation decisions can be explained by these constructs. Applying a PMT framework may provide new insight to the question of how place activity and activity involvement transmit their effect on behavioural intentions.

Within a PMT framework, adopting place attachment and activity involvement as sources of information frames risk and coping appraisal variables as mediators. A mediator variable explains the relationship between an independent and dependent variable. The simplest mediation model is any causal system in which at least one causal antecedent $(\mathrm{X})$ is proposed as influencing an outcome $(\mathrm{Y})$ through an intervening variable (M) (Figure 4). In this model, $\mathrm{X}$ may influence $\mathrm{Y}$ via two distinct pathways: the direct effect, in which X effects Y without passing through M (pathway c'), and the indirect effect, in which the effect first passes from $\mathrm{X}$ to $\mathrm{M}$ (pathway a) and then from $\mathrm{M}$ to $\mathrm{Y}$ (pathway b). This indirect effect represents how $\mathrm{X}$ influences $\mathrm{Y}$ through a causal sequence. That is to say, it is assumed that $\mathrm{X}$ causes $\mathrm{M}$, which in turn causes $\mathrm{Y}$; M cannot carry X's effect on Y if M is not causally located between X and Y. In this way, employing mediation analysis may explain how place activity and activity involvement affect behavioural intentions. 


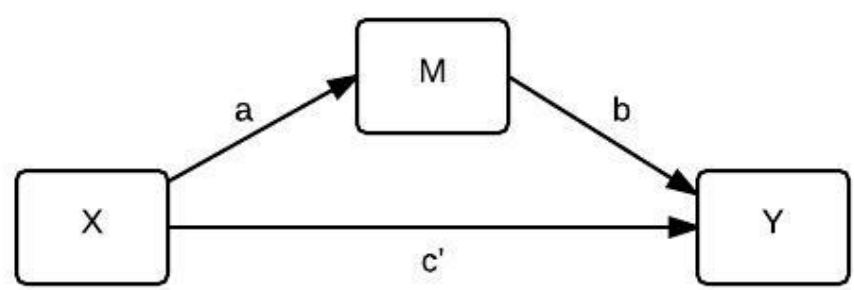

\section{Figure 4: Conceptual diagram of a simple mediation model}

In the previous sections, it was established that threat appraisal and coping appraisal are likely to influence behavioural intentions. The goal of the following sections is to explore the relationships between place attachment and activity involvement and (i) behavioural intentions; (ii) threat appraisal variables; and (iii) coping appraisal variables. Doing so will provide insight into how activity involvement and place attachment influence behavioural intentions both directly and indirectly (Figure 5).

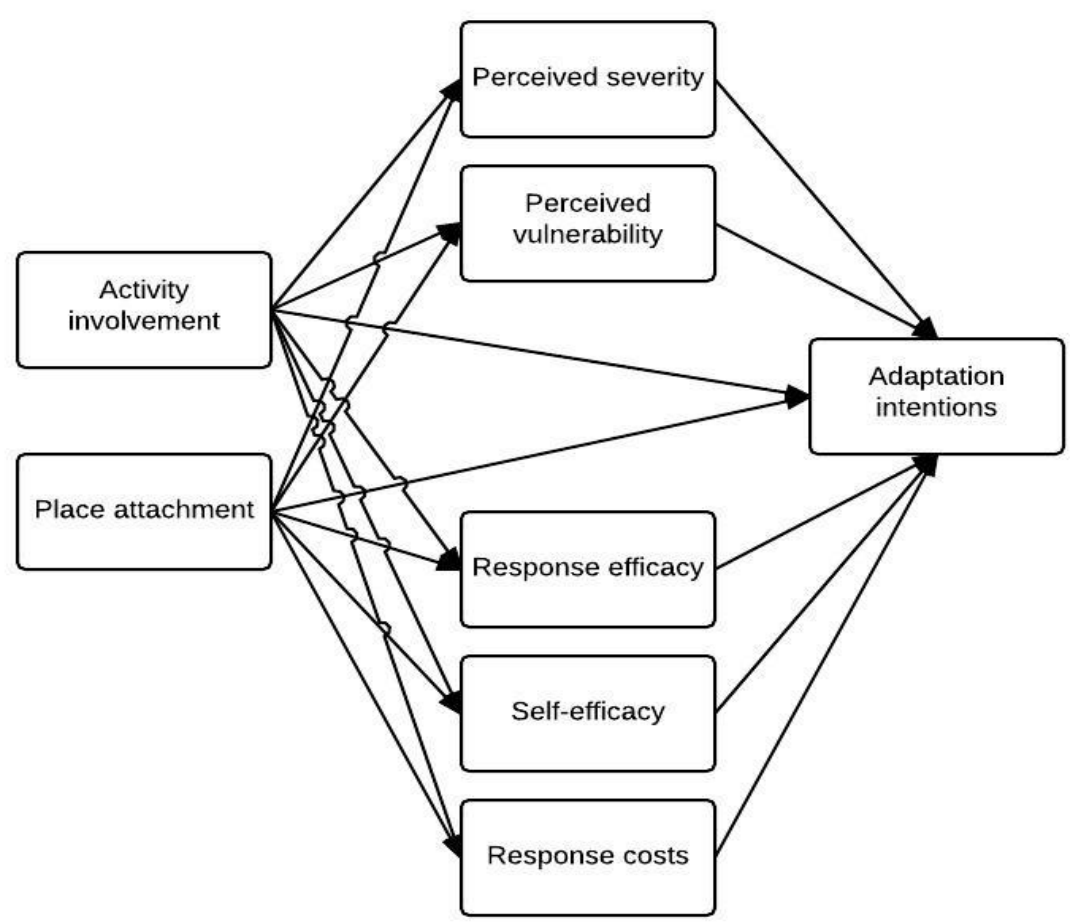

Figure 5: Conceptual diagram of mediation model for activity involvement and place attachment 


\subsubsection{Place attachment and activity involvement}

Both place attachment and activity involvement are comprised of a constellation of attitudes with affective, cognitive, and behavioural components. The concept of place attachment is used to describe a users' bond to a particular space. Several analogous concepts exist within the leisure literature, including sense of place (Tuan, 1974), place dependence (Stokols \& Shumaker, 1981), place identity (Proshansky, 1978), rootedness(Tuan, 1980), and place bonding (Hammitt, Backlund, \& Bixler, 2004). Williams and Roggenbuck (1989) combined place identity and place dependence as a general measure of place attachment, which has been primarily used in recreational contexts where respondents' interaction with the setting is sporadic (e.g., Bricker \& Kerstetter, 2000; Kyle, Graefe, Manning, \& Bacon, 2004; Moore \& Graefe, 1994). Place dependence is a function of how well a space facilitates an individual's preferred activity relative to alternative places and the availability of social and physical resources. For example, a person may exhibit high place dependence if they require use of specific resources because of the place's unique ability to facilitate desired experiences. Place identity, on the other hand, relates to the symbolic and emotional attachments a person forms with a place. For example, a person may form a strong attachment with a setting because it offers them the opportunity to express and affirm their identity. Williams and Vaske (2003) confirmed the validity and generalizability of this two-dimensional conceptualization for place attachment across several settings.

Activity involvement is most often conceptualized in terms of personal relevance. Involvement reflects the degree to which a person devotes his or herself to an activity or associated product (Peter \& Olson, 1987; Zaichkowsky, 1985). While the dimensions that 
encompass involvement have been rigorously debated, there is general consensus that it is best conceptualized as a multidimensional construct (Havitz \& Dimanche, 1997, 1999; Kyle \& Chick, 2002; Laurent \& Kapferer, 1985; McIntyre, 1989; McIntyre \& Pigram, 1992). Wellman, Roggenbuck, and Smith (1982) were the first to include a 'centrality to lifestyle' measure, in an effort to capture the importance of an activity to one's life. Subsequently, McIntyre (1989) added Wellman's centrality to lifestyle component to Laurent and Kapferer's (1985) enduring involvement scale, which consisted of product importance and derived enjoyment (which were combined into 'attraction'), as well as self-expression. Over a decade of empirical testing support the use of centrality, attraction and self-expression as measures of involvement (Gahwiler \& Havitz, 1998; Iwasaki \& Havitz, 2004; Kyle et al., 2004), yet some authors believed other components should be added to the construct to elaborate on affective attachment (Havitz \& Dimanche, 1999; Kyle \& Chick, 2002). To this end, Kyle, Absher, Norman, Hammitt, and Jodice (2007) developed the Modified Involvement Scale. Adapted from McIntyre's $(1989,1992)$ scale, the authors created a social bonding dimension separate from centrality, as well as distinguished the symbolic and expressive elements of enduring involvement through identity affirmation and identity expression measures (adapted from self-expression). Use of the scale has been supported in a number of subsequent applications (e.g., Chang \& Gibson, 2011; Dawson et al., 2011; Jun \& Kyle, 2011)

The notion of activity devotion and attachment is at the root of recreation specialization (Bryan, 1977). According to specialization theory, specialization is an indicator of intensity of involvement. A key proposition of the theory is that individuals advance towards more specialized status the longer they participate in an activity. 
Relying almost exclusively on survey research and standardized scales, most studies have treated recreational specialization as a characteristic condition of individuals' involvement at some point in time (Scott \& Shafer, 2001), and thus have actually measured leisure involvement and commitment rather than specialization, given that recreation specialization is fundamentally a framework of change. For this reason studies applying the concept of recreation specialization will also be considered within this review.

Eder and Arnberger (2012) suggest that the inclusion of activity involvement in combination with place attachment may improve understanding of visitors' perceptions of social and ecological conditions. Doing so recognizes that attachment and commitment to a place is not the same as commitment and attachment to an activity. In the case of scuba diving for example, for some scuba divers, "[d]iving for its own sake has little interest - it is the place that offers uniqueness and discovery opportunities" (Moskwa, 2012, p. 41), while for others "scuba diving is also just a feeling of being underwater, the feeling of weightlessness, it is an experience in itself" (Hillmer-Pegram, 2011, p. 49).

Incorporating both place attachment and activity involvement is also important when considering different types of coping behaviour, as each has different, perhaps competing, effects. Previous investigations are often limited to considering the influence of activity involvement on activity substitution, and the influence of place attachment on site substitution. Yet, a reluctance to engage in one type of coping strategy, may well result in a strong preference for another. For example, the place-attached walkers and cyclists who opted to remain within the park despite perceived conflict, preferred instead 
to change the timing of their activity (i.e. temporal displacement) (Wang \& Chang, 2010).

\subsubsection{Influence of place attachment and activity involvement on behavioural intentions}

Studies examining the relationship between place attachment and behavioural intentions find that, in general, place attachment is negatively related to willingness to alter the location of recreation (Oh et al., 2013; Wang, 2010; Williams, Patterson, Roggenbuck, \& Watson, 1992) and activity involvement is negatively related to willingness to alter the type of activity (Hyun \& Ditton, 2006; Needham \& Vaske, 2013; Oh et al., 2013; Sutton \& Ditton, 2005; Tseng, 2009) (Table 4). However, this relationship did not always hold true for all dimensions of place attachment or activity involvement (Graefe \& Dawson, 2013; Han et al., 2015; Wynveen et al., 2007). For example, Graefe and Dawson (2013) found that only the rootedness dimension of place bonding had a significant influence on choosing an activity other than camping or a camping setting outside the Adirondack Park, while enduring involvement in the activity of camping was not a significant predictor of substitution variables. In another instance, elements of specialization were positively related to site substitution via intervening pathways (Oh et al., 2013). For example, the overall path from specialization to substitution through activity-specific experience preferences was positive, suggesting that specialization may not always lead to decreased substitution when the focus is on goaloriented, activity-specific behaviour.

Significant direct relationships between activity involvement or place attachment and behavioural intentions have also offered limited explanatory power (Oh et al., 2013; Sutton \& Oh, 2015; Wynveen et al., 2007). Several studies using multiple regression 
analysis suggest that there may be a weak direct relationship between activity involvement/place attachment and behavioural intentions. For example, though specialization was indirectly related to site substitution via place dependence and identity, activity-specific and activity-general experience preferences, and consumptive orientation, variance explained in site substitutability never exceeded $8 \%$ (Oh et al., 2013). Similarly, a hypothesized model that linked commitment and substitutability explained only $5 \%$ of the variance in activity substitutability (Sutton and Oh, 2015). Meanwhile, though place-bonding elements were significant predictors of campers' willingness-to-substitute resources, variance explained never exceeded 18\% (Wynveen et al., 2007).

In each case, the authors postulate that this could be an indication that important intervening variables have been omitted. In particular, "[o]ther important factors such as constraints or displacement (e.g., crowding) may be main drivers of substitutability and subsequent substitution decisions" (Oh et al., 2013, p. 269). Similarly, Sutton and Oh (2015) note the limitation that "the model includes no measure of the availability or use of constraint negotiation strategies" (p. 350). Schneider and Stanis (2007) suggest that coping models have many parallels to the leisure constraint model, and can offer a deeper understanding of constraint negotiation by detailing the appraisal process.

Table 4: Summary of studies examining the relationship between place attachment and/or activity involvement and behavioural intentions

\begin{tabular}{|c|c|c|c|}
\hline & Study & Context & Main findings/conclusions \\
\hline \multirow[t]{2}{*}{$\begin{array}{l}\text { Place } \\
\text { attach- } \\
\text { ment }\end{array}$} & \multirow[t]{2}{*}{$\begin{array}{l}\text { Graefe \& } \\
\text { Dawson } \\
(2013)\end{array}$} & \multirow{2}{*}{$\begin{array}{l}\text { Explored psychological } \\
\text { factors, including } \\
\text { experience use history, } \\
\text { enduring involvement, } \\
\text { place bonding, that } \\
\text { contributed to visitors' } \\
\text { substitution preferences }\end{array}$} & $\begin{array}{l}\text { Higher levels of rootedness was associated } \\
\text { with choosing an activity other than camping } \\
\text { or a camping setting outside the Adirondack } \\
\text { Park as the most preferred substitution option }\end{array}$ \\
\hline & & & $\begin{array}{l}\text { None of the other place bonding dimensions } \\
\text { (identity, belongingness, dependence, and }\end{array}$ \\
\hline
\end{tabular}


and their willingness to

make a resource

substitution for

roadside camping in the

Adirondack Park $(\mathrm{n}=$

216)

Han et al. Explored what factors

(2015)

are important to explain coastal tourists' site substitution decisions, and whether there were any difference in site substitution decisions by geographical scale $(n=314)$

Oh et al. Examined a model in (2013)

Wang \& Chang

(2010)

et al. (1992) which site substitution decision is a function of experience preferences, consumptive orientation, and place attachment, surveying Texas freshwater anglers $(\mathrm{n}=351)$ Explored how place attachment influenced recreation conflict and coping behaviors based on the Transactional Stress/Coping Model, examining the interference between bikers and walkers in Bali Zon-An Park in Taipei County

The utility of an emotional/symbolic attachment to place was examined through an analysis of the relationships between use history, perceived substitutability, sociodemographic and trip characteristics, and sensitivity to wilderness impacts and level of attachment in four wilderness areas in the south-eastern United

familiarity) had a significant influence

\author{
(n)
}

\begin{tabular}{|c|c|c|}
\hline (2010) & $\begin{array}{l}\text { recreation conflict and } \\
\text { coping behaviors based } \\
\text { on the Transactional } \\
\text { Stress/Coping Model, } \\
\text { examining the } \\
\text { interference between } \\
\text { bikers and walkers in } \\
\text { Bali Zon-An Park in } \\
\text { Taipei County }\end{array}$ & $\begin{array}{l}\text { experienced perceived conflicts; relatively } \\
\text { high place attachment users preferred walking } \\
\text { at a different time of day; the highest place } \\
\text { attachment users reported some conflicts, but } \\
\text { did not tend to leave the park in response }\end{array}$ \\
\hline $\begin{array}{l}\text { Williams } \\
\text { et al. } \\
\text { (1992) }\end{array}$ & $\begin{array}{l}\text { The utility of an } \\
\text { emotional/symbolic } \\
\text { attachment to place was } \\
\text { examined through an } \\
\text { analysis of the } \\
\text { relationships between } \\
\text { use history, perceived } \\
\text { substitutability, socio- } \\
\text { demographic and trip } \\
\text { characteristics, and } \\
\text { sensitivity to wilderness } \\
\text { impacts and level of } \\
\text { attachment in four } \\
\text { wilderness areas in the } \\
\text { south-eastern United }\end{array}$ & $\begin{array}{l}\text { Willingness to substitute was associated with } \\
\text { lower place attachment scores in four } \\
\text { wilderness areas; link between substitutability } \\
\text { and wilderness attachment depended on study } \\
\text { area }\end{array}$ \\
\hline
\end{tabular}




\begin{tabular}{|c|c|c|c|}
\hline & \multirow{3}{*}{$\begin{array}{l}\text { Wynveen } \\
\text { et al. } \\
(2007)\end{array}$} & \multirow{3}{*}{$\begin{array}{l}\text { States }(\mathrm{n}=892) \\
\text { Hypothesized that EUH } \\
\text { and place bonding } \\
\text { would be significantly } \\
\text { related to campers' } \\
\text { willingness to substitute } \\
\text { their camping location } \\
\text { for another local } \\
\text { campground, } \\
\text { examining the effect of } \\
\text { "setting type" on the } \\
\text { hypothesized } \\
\text { relationships in three } \\
\text { southern Appalachian } \\
\text { campgrounds }(\mathrm{n}=424)\end{array}$} & \\
\hline & & & $\begin{array}{l}\text { Negative relationship between the familiarity } \\
\text { dimension of place bonding and campers' } \\
\text { willingness to make a resource substitution; } \\
\text { dependence and affect dimensions were not } \\
\text { related to substitution. Variance explained } \\
\text { never exceeded } 18 \%\end{array}$ \\
\hline & & & $\begin{array}{l}\text { Note: setting type influenced the relationships, } \\
\text { e.g., in wilderness areas, the rootedness } \\
\text { dimension was positively related to } \\
\text { willingness to substitute }\end{array}$ \\
\hline \multirow[t]{5}{*}{$\begin{array}{l}\text { Activity } \\
\text { involve- } \\
\text { ment }\end{array}$} & \multirow[t]{2}{*}{$\begin{array}{l}\text { Choi et al. } \\
\text { (1994) }\end{array}$} & \multirow{2}{*}{$\begin{array}{l}\text { Examined } \\
\text { substitutability in terms } \\
\text { of differences in } \\
\text { activity choice, social } \\
\text { group, and } \\
\text { specialization level of } \\
\text { Texas anglers }(n=502)\end{array}$} & $\begin{array}{l}\text { No link between specialization level and } \\
\text { activity substitutability for saltwater anglers } \\
\text { when specialization was measured in terms of } \\
\text { avidity over the previous } 12 \text { months }\end{array}$ \\
\hline & & & $\begin{array}{l}\text { Note: this single-item indicator may not be a } \\
\text { good measure of specialization or commitment }\end{array}$ \\
\hline & $\begin{array}{l}\text { Ditton \& } \\
\text { Sutton } \\
(2004)\end{array}$ & $\begin{array}{l}\text { Examined the extent to } \\
\text { which anglers were } \\
\text { willing to make } \\
\text { substitution decisions } \\
\text { when constrained, and } \\
\text { identify explanatory } \\
\text { variables for } \\
\text { substitution decisions }\end{array}$ & $\begin{array}{l}\text { As importance of fishing relative to other } \\
\text { activities increased, anglers' ability to } \\
\text { substitute other activities for fishing decreased }\end{array}$ \\
\hline & $\begin{array}{l}\text { Graefe \& } \\
\text { Dawson } \\
(2013)\end{array}$ & $\begin{array}{l}\text { Explored psychological } \\
\text { factors, including } \\
\text { experience use history, } \\
\text { enduring involvement, } \\
\text { place bonding, that } \\
\text { contribute to visitors' } \\
\text { substitution preferences } \\
\text { and their willingness to } \\
\text { make a resource } \\
\text { substitution for } \\
\text { roadside camping in the } \\
\text { Adirondack Park ( } \mathrm{n}= \\
216 \text { ) }\end{array}$ & $\begin{array}{l}\text { Enduring involvement in the activity of } \\
\text { camping was not a significant predictor of } \\
\text { substitution variables }\end{array}$ \\
\hline & $\begin{array}{l}\text { Hyun \& } \\
\text { Ditton } \\
(2006)\end{array}$ & $\begin{array}{l}\text { Explored the } \\
\text { relationship between } \\
\text { independent variables } \\
\text { such as demographic } \\
\text { characteristics, } \\
\text { constraints, and }\end{array}$ & $\begin{array}{l}\text { Anglers' willingness to substitute fishing in } \\
\text { other locations was negatively associated with } \\
\text { specialization variables }\end{array}$ \\
\hline
\end{tabular}


specialization variables

as predictors and

willingness to substitute

one fishing location

for another $(n=1005)$

Needham

Examined the

\& Vaske

(2013)

relationship between

hunter specialization

and activity

substitutability of deer

and elk hunters in the

United States $(\mathrm{n}=$

9567)

Oh et al. Examined a model in

(2013)

Sutton \& Tested whether

Oh (2015) willingness to substitute

other activities for

fishing is indirectly

related to level of

fishing commitment

through experience

preferences,

consumptive

orientation, and

perceived constraints

on fishing activity using

recreational fishers

from Queensland $(\mathrm{n}=$ 1197)
Tseng

(2009)
Direct inverse relationship between specialization and activity substitutability that tends to generalize across multiple states and species hunted

Recreation specialization may indirectly play an important role in recreational anglers' substitution decisions through the influence of constructs such as place attachment and consumptive orientation

Overall, total effects of specialization on site substitution were negative, indicating that an angler's overall perception of substitutable sites decreases as specialization increases; However, in some of the intervening pathways, elements of specialization were positively related to site substitution, e.g., through activity-specific experience preferences

Specialization explained $8 \%$ of the variance in site substitutability

Strong direct relationship between level of commitment and ability to undertake an activity substitution - highly committed fishers were significantly less likely to report that there are other activities that would provide them with the same level of satisfaction and enjoyment that they receive from fishing

Hypothesized model that linked commitment and substitutability only through intervening variables explained only $5 \%$ of the variance in activity substitutability

Participants with a high level of activity commitment expressed less willingness to apply extreme actions (e.g., changing locations or activities) in response to crowding related situations or interpersonal conflicts; 
more likely to apply cognitive adjustment strategies to maintain their participation in boating

\subsubsection{Coping appraisal as a mediator of activity involvement and place attachment}

Early research focused on the relationship between activity involvement/place attachment and one's perception of constraints. In general, this appears to be a positive relationship (Table 5). Respondents with higher levels of commitment to activity or place consistently exhibit higher levels of perceived constraints (Hendricks, Chavez, \& Bricker, 2008; Jun \& Kyle, 2011; Sutton \& Oh, 2015). This has been explained based on the assumption that higher levels of commitment equate to higher levels of participation or more specific resource requirements, which suggests that there are likely to be more factors that prevent the desired level or type of participation from being achieved.

This in turn has implications for one's intentions to adapt their behaviour. Sutton and Oh (2015) demonstrate that perceived fishing constraints mediates the relationship between activity commitment and substitutability, where commitment had a positive effect on perceived constraints, which, in turn, negatively affected the likelihood of substituting other activities for fishing. Examining the relationship between activity commitment and boaters' coping behaviours, Tseng (2009) found that including leisure constraints accounted for $63.5 \%$ of the variance in behavioural coping, and $17.3 \%$ of variance in cognitive coping.

Fewer studies have focused on the relationship between place attachment or activity involvement and one's ability to overcome these perceived constraints (Alexandris, Kouthouris, Funk, \& Tziouma, 2013; Havitz, Kaczynski, \& Mannell, 2013; Jun \& Kyle, 2011). Jackson, Crawford, and Godbey (1993) advocated that leisure 
constraints not be viewed as insurmountable obstacles, but rather factors that have to be negotiated. This negotiated process is grounded in self-efficacy theory. Several authors have spoken to the potential utility of the self-efficacy construct to leisure constraint negotiation (Hubbard \& Mannell, 2001; Loucks-Atkinson \& Mannell, 2007; White, 2008). For example, Loucks-Atkinson and Mannell (2007) examined the role of selfefficacy in the constraints' negotiation process for individuals with fibromyalgia, defining negotiation-efficacy as "people's confidence in their ability to successfully use negotiation strategies to overcome constraints they encounter" (p. 22). The results suggest that higher negotiation-efficacy is correlated with a greater motivation to participate and greater effort given to negotiating constraints. White (2008) similarly found that people with higher perceptions of negotiation-efficacy were more motivated to participate in outdoor recreation.

Alexandris et al. (2013) conducted an ANOVA to compare the mean scores of the five negotiation strategies in terms of different involvement levels, finding that the High Involved group had significantly higher scores from both the Medium and Low Involved groups, and the Medium Involved group had significantly higher scores than the Low Involved group. Similarly, Havitz et al. (2013) found that self-efficacy scores ranged from 5.51 in the Extremely Involved group to 3.45 among the Marginally Involved group. Breaking activity involvement into its sub-dimensions, Jun and Kyle (2011) found that negotiation was positively predicted by leisure identity and identity conflict/facilitation. There have been no similar investigations into the relationship between place attachment and negotiation efficacy, representing a gap in the literature to be filled. 
Table 5: Summary of studies examining the relationship between place attachment and/or activity involvement and coping appraisal variables

\begin{tabular}{|c|c|c|c|}
\hline & Study & Context & Main findings/conclusions \\
\hline $\begin{array}{l}\text { Place } \\
\text { attachment }\end{array}$ & $\begin{array}{l}\text { Hendricks et } \\
\text { al. (2008) }\end{array}$ & $\begin{array}{l}\text { Examined place } \\
\text { attachment, observations } \\
\text { related to fire and fire } \\
\text { management, and } \\
\text { perceived recreational } \\
\text { constraints owing to } \\
\text { wildland fire and fire } \\
\text { management of day-use } \\
\text { and campsite visitors to } \\
\text { Big Sur in California (n } \\
=498 \text { ) }\end{array}$ & $\begin{array}{l}\text { Respondents with higher levels of } \\
\text { place attachment consistently } \\
\text { exhibited higher levels of perceived } \\
\text { constraints (measured as importance } \\
\text { of barrier) }\end{array}$ \\
\hline \multirow[t]{5}{*}{$\begin{array}{l}\text { Activity } \\
\text { involvement }\end{array}$} & $\begin{array}{l}\text { Alexandris et } \\
\text { al. (2013) }\end{array}$ & $\begin{array}{l}\text { Aimed to segment } \\
\text { recreational swimmers } \\
\text { by involvement level, } \\
\text { and test the role of } \\
\text { negotiation strategies in } \\
\text { the development of } \\
\text { swimming involvement } \\
(n=260)\end{array}$ & $\begin{array}{l}\text { Highly involved swimmers had } \\
\text { higher scores in all the negotiation } \\
\text { strategy dimensions than all the other } \\
\text { groups }\end{array}$ \\
\hline & $\begin{array}{l}\text { Havitz et al. } \\
(2013)\end{array}$ & $\begin{array}{l}\text { Explored links between } \\
\text { leisure involvement and } \\
\text { psychological variables } \\
\text { found to influence } \\
\text { participation, including } \\
\text { self-efficacy and } \\
\text { motivations, by } \\
\text { surveying recreationists } \\
\text { in a mid-sized Canadian } \\
\text { city }(n=384) \text {. }\end{array}$ & $\begin{array}{l}\text { Relationship between leisure } \\
\text { involvement and self-efficacy was } \\
\text { consistently positive and strong (all } \mathrm{p} \\
<.001 \text { ); self-efficacy scores, though } \\
\text { average overall among the full } \\
\text { sample ( } M=4.32 \text { on a } 7 \text {-point scale), } \\
\text { ranged from } 5.51 \text { in the Extremely } \\
\text { Involved group to } 3.45 \text { among the } \\
\text { Marginally Involved group }\end{array}$ \\
\hline & \multirow[t]{2}{*}{$\begin{array}{l}\text { Jun \& Kyle } \\
\text { (2011) }\end{array}$} & $\begin{array}{l}\text { Explored the influence } \\
\text { of identity on } \\
\text { respondents' perceived } \\
\text { leisure constraints and } \\
\text { constraint negotiation }\end{array}$ & $\begin{array}{l}\text { Level of perceived constraints } \\
\text { declined along with the salience of } \\
\text { respondents' golfer identity }\end{array}$ \\
\hline & & $\begin{array}{l}\text { using in-depth } \\
\text { interviews }(n=21) \text { in } \\
\text { combination with an } \\
\text { online survey of } \\
\text { recreational golfers in } \\
\text { the United States ( } \mathrm{n}= \\
485)\end{array}$ & $\begin{array}{l}\text { Effort to negotiate constraints } \\
\text { increased in congruence with the } \\
\text { salience of respondents' golfer } \\
\text { identity }\end{array}$ \\
\hline & $\begin{array}{l}\text { Sutton } \\
(2007)\end{array}$ & $\begin{array}{l}\text { Identified constraints } \\
\text { experienced by fishers in } \\
\text { Queensland and } \\
\text { examined how } \\
\text { demographic variables, }\end{array}$ & $\begin{array}{l}\text { Demonstrated a direct positive effect } \\
\text { of commitment on perceived } \\
\text { constraints, suggesting that, as } \\
\text { commitment increases, so do the } \\
\text { factors that prevent the desired level }\end{array}$ \\
\hline
\end{tabular}


fishing participation variables, and fishing motivations influence the amount and type of constraints experienced $(\mathrm{n}=1197)$

Sutton \& Oh (2015)

Tested whether willingness to substitute other activities for fishing is indirectly related to level of fishing commitment through experience preferences, consumptive orientation, and perceived constraints on fishing activity using recreational fishers from Queensland $(\mathrm{n}=1197)$ of participation from being achieved

Commitment had positive direct and indirect effects on fishers' perceived constraints; results demonstrate that perceived fishing constraints also mediates the relationship between commitment and substitutability

\subsubsection{Risk appraisal as a mediator of activity involvement and place attachment}

Several studies have examined the influence of place attachment on perceptions of setting conditions (Eder \& Arnberger, 2012; Kyle, Graefe, Manning, \& Bacon, 2004; Warzecha \& Lime, 2001; Williams et al., 1992; Young, Williams, \& Roggenbuck, 1990). In general, high place attachment scores are associated with a greater sensitivity to or lower tolerance for adverse conditions and behaviours (Table 6). Young et al. (1990), for example, observed that respondents who were more attached to a place tended to be more restrictive toward social conditions they were willing to accept, including the number of people seen on hiking trails and the percentage of time people are in sight, compared to those with less attachment. Williams et al. (1992) similarly found place attachment associated with sensitivity to site impacts. High place attachment scores were associated with a lower tolerance for watercraft encounters among visitors (Warzecha \& Lime 2001) and depreciative visitor behaviour (Eder \& Arnberger, 2012).

There have been a handful of studies that find no relationship between place 
attachment and visitor perceptions (Budruk, Stanis, Schneider, \& Heisey, 2008; White, Virden, \& Van Riper, 2008). In both cases, the authors raise the possibility that visitors whose expectations or preferences for setting conditions were exceeded had adopted coping strategies (e.g. displaced to other areas), something that cannot be captured via insitu surveys, suggesting other experimental techniques that capture visitors ex-situ may be needed to explore displacement. Evidence to support this is provided in the case of White et al., who found that, despite the fact that the area is objectively very heavily impacted, visitors generally did not perceive most types of impacts to be a problem.

There is limited investigation into the effect of activity involvement on visitor perceptions. Kyle et al. (2004) found no support for a relationship between activity involvement and perceptions of setting density, but the authors felt this was related more to the limitations of the method and suggest the construct has much to offer for understanding a variety of leisure behaviour. One of the primary limitations cited is that the measure of activity involvement emphasized hiking as the primary attitude object, though the setting supports a variety of leisure experiences, thus other sources of personal relevance may have been operant. Settings like coral reefs, which support a more limited type of leisure experience, may provide a clearer look into this relationship. The handful of studies to examine the influence of recreation specialization on normative evaluations of resources conditions suggests a similar relationship between involvement and perception of setting condition as that of place attachment. Both Anderson and Loomis (2012) and Young and Loomis (2010) found that bleached and algal covered reefs were significantly less acceptable to more specialized scuba divers. 
The relationship between place attachment/activity involvement and visitor perceptions has been explained using the principles of social judgment theory (Sherif \& Hovland, 1961), on the basis that if an activity or place occupies an important part of one's self that person may be more "ego-involved" than others for whom the activity or place is considered less important (Young et al., 1990; Kyle et al., 2004; Dawson et al., 2011). As with PMT, social judgment theory is concerned with the impact of persuasive messaging, seeking to specify the conditions under which attitude change takes place. According to the theory, a person's preferred position serves as an attitudinal anchor. However, a person's full attitude can only be understood in terms of what other positions he or she finds acceptable or unacceptable, in addition to this preferred position. To accommodate this, attitude is construed as an amalgam of three zones or latitudes: the latitude of acceptance, which is the range of positions that a person sees as acceptable, including the attitudinal anchor; the latitude of rejection, which is the range of positions that a person sees as unacceptable; and the latitude of non-commitment, which is the range of positions that a person sees as neither acceptable nor unacceptable.

These latitudes affect the likelihood of assimilation (i.e. acceptance) and contrast (i.e. rejection). When a stimulus is further from one's attitudinal anchor, a contrast effect (i.e. viewed as being more different from his or her own viewpoint, than it actually is) is likely. When it is closer to the anchor, an assimilation effect (i.e. viewed as being closer to his or her own viewpoint, than it actually is) is more likely. That is to say, setting conditions that are consistent or proximately close to respondents' attitudinal anchor are likely to be accepted, while setting conditions perceived as distal to the attitudinal anchor will be rejected. Latitude width is said to vary as a function of ego-involvement. Sherif et 
al. (1965) speculated that individuals who are ego-involved are more likely to have wider latitude of rejection and more restricted latitude of acceptance because of stronger preexisting opinions.

Table 6: Summary of studies examining the relationship between place attachment and/or activity involvement and risk appraisal variables 


\begin{tabular}{|c|c|c|c|}
\hline & Study & Context & Main findings/conclusions \\
\hline \multirow[t]{3}{*}{$\begin{array}{l}\text { Place } \\
\text { attachment }\end{array}$} & $\begin{array}{l}\text { Budruk et al. } \\
(2008)\end{array}$ & $\begin{array}{l}\text { Explored the moderating } \\
\text { effect of place } \\
\text { attachment dimensions } \\
\text { on the relationships } \\
\text { between experience use } \\
\text { history and water-based } \\
\text { recreationists' crowding } \\
\text { evaluations at a U.S. } \\
\text { Army Corps of } \\
\text { Engineers site }(n=173)\end{array}$ & $\begin{array}{l}\text { No relationship between anglers' } \\
\text { and campers' place dependence } \\
\text { and crowding preferences and } \\
\text { expectations; weak relationship } \\
\text { between crowding expectation } \\
\text { and the reinforcing interaction } \\
\text { between place identity and } \\
\text { frequency of visits for anglers }\end{array}$ \\
\hline & $\begin{array}{l}\text { Eder \& } \\
\text { Arnberger } \\
(2012)\end{array}$ & $\begin{array}{l}\text { Investigated the } \\
\text { influence of place } \\
\text { attachment and } \\
\text { experience use history } \\
\text { on the perception of } \\
\text { depreciative visitor } \\
\text { behavior, recreation } \\
\text { impacts and crowding in } \\
\text { Danube Floodplains } \\
\text { National Park in Vienna } \\
(\mathrm{n}=605)\end{array}$ & $\begin{array}{l}\text { Place attachment dimensions are } \\
\text { related to the perceptions of very } \\
\text { specific visitor behaviours and } \\
\text { recreation impacts: no } \\
\text { relationship between place } \\
\text { attachment and perceived } \\
\text { crowding or perceptions of non- } \\
\text { activity-specific depreciative } \\
\text { visitor behaviour (e.g. littering), } \\
\text { though place attachment did } \\
\text { influence the perceptions of } \\
\text { depreciative visitor behaviour and } \\
\text { recreational impact on the } \\
\text { environment - place dependence } \\
\text { was particularly related to } \\
\text { adverse perceptions of dog } \\
\text { walkers' behaviour, while place } \\
\text { identity was associated with } \\
\text { adverse perceptions of bicyclist } \\
\text { behaviour }\end{array}$ \\
\hline & $\begin{array}{l}\text { Kyle et al. } \\
(2004)\end{array}$ & $\begin{array}{l}\text { Examined place } \\
\text { attachment's effect on } \\
\text { respondents' perceptions } \\
\text { of social and } \\
\text { environmental } \\
\text { conditions along the } \\
\text { Appalachian Trail }(\mathrm{n}= \\
\text { 1879) }\end{array}$ & $\begin{array}{l}\text { Respondents with high place } \\
\text { identity were more likely to } \\
\text { report crowding as a problem; } \\
\text { however, as place dependence } \\
\text { increased, respondents were less } \\
\text { likely to evaluate crowding as a } \\
\text { problem, i.e., setting, regardless } \\
\text { of its condition, provided a } \\
\text { unique opportunity to enjoy } \\
\text { certain leisure experiences }\end{array}$ \\
\hline
\end{tabular}


Wang \&

Chang (2010)

Explore how place

attachment influences

recreation conflict and

coping behaviors based

on the Transactional

Stress/Coping Model,

examining the

interference between

bikers and walkers in

Bali Zon-An Park in

Taipei County

Warzecha \&

Lime (2001)

White et al.

(2008)

al. (1992) in two river
Examined attitudes and preferences of river users

environments in

Canyonlands National

Park

Examined the effect of prior experience with the setting and two dimensions of place attachment on visitors' perceptions of three types of recreation impacts (depreciative behavior, environmental impacts, and recreation conflict) in the Cascade mountains $(\mathrm{n}=$ 351)

The utility of an emotional/symbolic attachment to place is examined through an analysis of the relationships between use history, perceived substitutability, sociodemographic and trip characteristics, and sensitivity to wilderness impacts and level of attachment in four wilderness areas in the south-eastern United States $(\mathrm{n}=892)$

Normative standa
Weekend low-place attached walkers and bikers were the most likely to experience both types of recreation conflicts; weekday walkers and bikers with relatively high place attachment perceived lower levels of recreation conflicts

High place attachment scores, specifically high emotional/ symbolic attachment scores, were associated with a lower tolerance for watercraft encounters among visitors

Place identity and place dependence were not predictors of perceptions of depreciative visitor behaviour, ecological impacts or recreation conflicts

Note: authors controlled for the effect of previous visitation, which may have moderated the effect of place attachment on perceptions of impacts; low levels of place dependence found among the sample

Place-attached wilderness visitors were more sensitive to ecological impacts and encounters with horse riders; no relationship between place attachment and encounters with hikers, perceptions of human noise, or visibility of light originating from outside the recreation area 


\begin{tabular}{|c|c|c|c|}
\hline \multirow[t]{3}{*}{ involvement } & $\begin{array}{l}\text { Loomis } \\
\text { (2012) }\end{array}$ & $\begin{array}{l}\text { for resource conditions } \\
\text { at coral reefs in the } \\
\text { Florida Keys were } \\
\text { compared among three } \\
\text { specialization groups } \\
\text { of SCUBA divers }(\mathrm{n}= \\
959)\end{array}$ & $\begin{array}{l}\text { strongly about the unacceptability } \\
\text { of white coral, algae, and fish } \\
\text { conditions, with greatest } \\
\text { differences exhibited for white } \\
\text { coral and algae conditions, both } \\
\text { of which require some degree of } \\
\text { ecological knowledge in } \\
\text { differentiating }\end{array}$ \\
\hline & $\begin{array}{l}\text { Kyle et al. } \\
(2004)\end{array}$ & $\begin{array}{l}\text { Examined effect of } \\
\text { activity involvement and } \\
\text { place attachment on } \\
\text { Appalachian Trail } \\
\text { hikers' perceptions of } \\
\text { setting density using } \\
\text { social judgment and } \\
\text { cognitive development } \\
\text { theories ( } \mathrm{n}=1561 \text { ) }\end{array}$ & $\begin{array}{l}\text { No support was found for } \\
\text { relationship between activity } \\
\text { involvement and perceptions of } \\
\text { setting density }\end{array}$ \\
\hline & $\begin{array}{l}\text { Young \& } \\
\text { Loomis } \\
(2010)\end{array}$ & $\begin{array}{l}\text { Used specialization } \\
\text { theory to segment divers } \\
\text { in the Florida Keys into } \\
\text { different specialization } \\
\text { categories to evaluate } \\
\text { differences in diver } \\
\text { perceptions of reef } \\
\text { condition }(n=938)\end{array}$ & $\begin{array}{l}\text { Bleached ( } 30 \%, 60 \% \text { and mostly } \\
\text { white) and algal covered reefs ( } 60 \\
\text { or } 100 \% \text { cover) were } \\
\text { significantly less acceptable to } \\
\text { highly specialized divers }\end{array}$ \\
\hline
\end{tabular}

\subsection{Limitations of Protection Motivation Theory}

Despite its demonstrated utility, application of Protection Motivation Theory is not without its limitations. Most criticisms of PMT concern its overemphasis on cognitive processes, with propositions for introducing the mediating role of 'emotion' on PMT (Okazaki \& Chung, 2004). Other criticism of PMT concern its assumption that individuals are rational information processors, which does not account for habitual behaviours (Schuster et al., 2006), examination of individual behaviour in isolation neglecting wider influences, such as past behaviour, social factors, and culture (Schoenbachler \& Whittler, 1996; Tanner, Hunt, \& Eppright, 1991) or how attitudes might change over time (Schwarzer, 1992). 


\subsection{Summary}

This review offered insights into the appropriateness of applying PMT to the study of scuba divers', as tourists or recreationists, adaptation behaviour. PMT suggests that divers' intention to adapt can be predicted from two cognitive mediating processes risk appraisal and coping appraisal. The significance of these constructs was reinforced through consideration of the Theory of Planned Behaviour, which does not consider risk appraisal, and the Transactional Theory of Stress and Coping, which often neglects coping appraisal. It is further postulated that PMT may serve as a suitable framework that links place attachment and activity involvement to behavioural intentions, on the basis that risk and coping appraisal variables may act as mediators to explain the indirect nature of these relationships.

To date, few studies have utilized PMT to understand the behavioural intentions of tourists or recreationists. As well, existing models of recreationists' behaviour (e.g. Graefe and Dawson, 2013; Hyun and Ditton, 2006; Oh et al., 2013; Sutton and Oh, 2015; Wang and Chang, 2010; Wynveen et al., 2008) offer limited explanation of how adaptation decisions can be explained by constructs like activity involvement or place attachment. As such, the current study uses a quantitative questionnaire-based research design to demonstrate the efficacy of PMT in predicting scuba divers' behavioural intentions in response to coral bleaching.

It is expected that perceived severity, perceived vulnerability, response efficacy, self-efficacy, and response costs will combine to explain significant proportions of variance in each of the behavioural intentions under study. Specifically, perceived severity, perceived vulnerability, response efficacy, and self-efficacy will be direct 
positive predictors of behavioural intentions, while response costs will be a direct negative predictor. Moreover, it is hypothesized that the addition of activity involvement and place attachment will explain significant proportions of variance in respondents' intentions over and above PMT-based constructs by accounting for both the direct and indirect of these variables through the risk and coping appraisal processes. The measurement of each of these constructs and the methods used to collect the data for this study are described in the following chapter. 


\section{METHODS}

The following chapter is divided into three main sections. The first section outlines the research design, describing the study population, sampling frame, and data collection procedures. The second section describes the measures of questionnaire variables, which include all PMT and non-PMT constructs (i.e., place attachment, activity involvement, demographic variables). The final section outlines the planned data analyses.

\subsection{Research design}

The study adopts a cross-sectional survey research design, aiming to collect data from multiple scuba divers from multiple dive clubs ex situ. A cross-sectional approach was selected over a retrospective longitudinal design to maximize the number of respondents who could be included in the study by framing responses to a hypothetical scenario. This was deemed important because of the predictive nature of the study, where a larger sample size will lend strength to the results. Data was collected to approximate measures of PMT to evaluate the predictability of behavioural intentions via threat and coping appraisal factors, as well as measures of place attachment and activity involvement to evaluate threat and coping appraisal factors as potential mediators. In keeping with previous PMT, place attachment, and activity involvement prediction studies, the study was quantitative in nature, so as to model the relationships between independent and dependent variables. While this approach risks the loss of contextual information that qualitative data affords, as one of the first applications of PMT to tourists' climate change adaptation, focusing on the hypothesized modelled relationships 
was deemed to be an appropriate first step.

\subsubsection{Data collection}

An online questionnaire was used to collect data between May and August 2016. Before distribution, the questionnaire was reviewed and received ethics clearance from the University of Waterloo's Research Ethics Board in March 2016. The primary advantage of online data collection is that it reaches respondents ex-situ, which allows for the possibility of capturing tourists or recreationists who have already been displaced. Both White et al. (2008) and Budruk et al. (2008) suggested that visitor displacement likely had a significant impact on insignificant or inconclusive findings in their research. Manning and Vallierre (2001) offer a similar explanation for why empirical research often finds that visitor satisfaction may remain relatively high despite crowded conditions, where visitors who are more sensitive to increased use levels or replaced (i.e., displaced) by those who are less sensitive.

There are several other ways in which online questionnaires benefit both respondents and the researcher. Respondents can answer at a convenient time for themselves, taking as much time to answer individual questions as needed, and return later to finish from where they left off earlier. This can translate to a higher item completion rate than mail surveys, and longer answers to open-ended questions (Evans \& Mathur, 2005). For the researcher, online surveys can be administered in a cost-efficient and time-efficient manner. After submission of the last questionnaire, the data are immediately available and accessible in a digital database. Should additional responses be required, it is relatively simple to send reminder emails to increase response rate. Unlike mail surveys, online surveys allow greater control of question order, requiring 
respondents to answer questions in the order intended, as well as prohibiting respondents from looking ahead to later questions, which may help to reduce survey bias. Similarly, questions can designed such that an answer is required before advancing to the next question, which helps to eliminate item non-response.

A limitation of relying on online questionnaires is the possibility of unclear answering instructions. The self-administered nature of the data collection method means that questions and answering instructions must be extremely clear. Unclear framing and phrasing may result in frustration and a failure to complete the survey (Ray \& Tabor, 2003). To ensure question clarity, the questionnaire was reviewed by survey design/behavioural research experts and pilot tested. With online surveys there is also the question of representativeness because of a skew towards a younger (less than 50), well educated, higher income demographic (Pew Research Center, 2018). However, with the exception of age, this skew is also exhibited in the demographics of the dive population, which also tends towards well-educated, high-income individuals (PADI, 2013).

\subsubsection{Study participants}

Participants in this study consisted of scuba divers that belong to a scuba diving club in Canada (overseas travel required for warm water reef diving) or Australia (local and regional warm water reef diving available), where the Great Barrier Reef experienced "the worst mass bleaching event in its history" (Mooney, 2017) in 2016. These participants were selected for recruitment out of a desire to have similar cultural context when making comparisons between the two locations. Similarly, keeping within dive clubs also provides a similar context for comparison, and was deemed the most 
appropriate option for inviting a large number of divers to participate because of difficultly in connecting with individual divers away from dive sites.

An inventory of dive clubs was compiled for Canada and Australia. The initial list of Canadian dive clubs was developed by identifying dive clubs that belonged to the provincial Underwater Councils for Ontario, Alberta, and British Columbia, each province's unofficial governing body for scuba diving. This led to additional dive clubs being identified by executive members of the clubs that were contacted. There were no similar underwater governing bodies in Australia, so scuba clubs affiliated with Australian universities were first identified. These clubs were then similarly relied upon to identify other relevant dive organizations. The executive members of each identified dive club were contacted via email with the request that they distribute a link to the questionnaire to their membership. In order to qualify for inclusion in the study, respondents had to affirm that they (i) have experience diving on coral reefs; and (ii) intend to dive again at some point in the future.

In total, 13 Canadian dive organizations and 14 Australian dive organizations participated (i.e., at least one club member submitted a completed survey), while another 10 and 12 respectively were no longer in operation or did not respond to email requests (Table 7), representing organizational response rates of 56.5\% and 53.8\% respectively. Because the number of dive club members varies across dive club organizations, it is not possible to calculate a participant response rate for this study. Though participating dive clubs are spread across both countries, presenting potential regional differences, for the purposes of this investigation, comparison will be restricted to the national scale. 
A total of 387 questionnaires were submitted. Of this, 9 respondents did not meet the screening criteria. Respondents who stopped the survey part way through were excluded from the sample, removing an additional 75 potential respondents, while those who completed the full survey or answered all questions in part were retained. Missing value analysis was used to fill in any missing data points, an approach suitable when data points are missing at random (Schafer \& Olsen, 1998). Thus, 303 questionnaires were retained for subsequent analysis, of which 194 completed questionnaires were from Canadian respondents and 109 from Australian respondents.

Table 7: Participating and non-participating Canadian and Australian dive clubs

\begin{tabular}{lll}
\hline Participating dive clubs & Non-participating dive clubs \\
\hline Canada & Alberta Underwater Council & Aqua Knights Scuba Club \\
& Canadian Sub Aqua Scuba Club & Ajax Scuba Club \\
Etobicoke Underwater Club & Barrascuba Underwater Club \\
Great Lakes Scuba Club & Canadian Sport Divers \\
Hart House Underwater Club & Deep River Underwater Club \\
Leatherbacks Scuba Club & South-western Ontario Divers' Association \\
London Skin and Scuba Club & Toronto Super Turtles Dive Club \\
Ontario Underwater Council & UBC Aqua Society \\
Ontario Underwater Explorers & UVic Scuba Club \\
Scarborough Underwater Club & Vancouver Pescaderos \\
Steel City Sport Divers & \\
Top Islands Econauts Dive Club & \\
Underwater Council of BC & \\
Black Rock Underwater Diving Group & Australian National University Scuba Diving Club \\
Brisbane Sub-aqua Club & Bass Strait Aquatic Club \\
Dive Organization of University of Technology & Darwin Sub-aqua Club \\
Getunder Dive Club & Hervey Bay Dive Club \\
Murdoch University Divers Club & James Cook University Dive Club \\
Nautilus Scuba Club & Melbourne University Underwater Club \\
St. George Scuba Club & Mildura Desert Divers \\
Underwater Explorers Club of Western Australia & Ryde Underwater Club \\
Underwater Research Group, New South Wales & Sydney Sub-aqua Club \\
Underwater Research Group of Queensland & Tas Uni Dive Club \\
Unidive & Terrigal Underwater Group Limited \\
UWA Underwater Club & UNSW Underwater Club \\
Victorian Sub-aqua Group & \\
Wallaroo Scuba Association & \\
\hline & & \\
\hline
\end{tabular}

The demographics of the total sample were typical of the scuba diving population

(Table 8): predominantly male $(65 \%)$, older $(\mathrm{M}=46.13, \mathrm{SD}=13.88)$, well-educated 
(63\% with an undergraduate or advanced degree), and middle-to-upper middle class (60.1\% with a household income greater than $\$ 100,000)$. The demographics of the Canadian and Australian samples closely adhered to these norms, with some minor variations. The average age of the Canadian sample was slightly older $(\mathrm{M}=46.13, \mathrm{SD}=$ 13.88 vs. $\mathrm{M}=39.42, \mathrm{SD}=14.11$ ); a greater proportion of respondents in the Canadian sample had received at least one university degree (64.3\% vs. 58.9\%); and a greater proportion of Australian divers had a household income of less than $\$ 100,000$ (36.7\% vs. $18.0 \%)$

In addition to standard demographic questions, respondents were also asked to identify their level of dive certification and whom they dived with most frequently. Overall, the most common level of certification was the Advanced Open Water (43.2\%), which was also true of the Canadian (44.3\%) and Australian samples (41.3\%). Within the total sample, $39.6 \%$ of respondents had either a Dive Master or Dive Instructor certification, with a slightly higher proportion amongst the Canadian sample $(40.0 \%)$ than Australian (35.6\%). However, the Australian sample had a greater proportion of divers with a Technical certification $(12.3 \%)$ than the Canadian sample $(6.1 \%)$. Open Water certification accounted for only $9.6 \%$ across all samples. Collectively, this suggests that the respondents in this study represent a fairly advanced level of diver, and may not be representative of novice or beginner divers.

In terms of dive partner, friends were the most frequent dive companions in both the Australian (41.3\%) and Canadian samples (37.6\%), followed by one's partner/spouse (Australian: 26.6\%, Canadian: 35.1\%), and acquaintances, i.e., individuals met at the dive site (Australian: 22.9\%, Canadian: 19.1\%). Diving most frequently with one's children or 
parents/siblings accounted for less than $5 \%$ of the sample. A small proportion of respondents (5\% of the total sample) identified an "other" category as the most frequent dive partner, however, because no further details are offered by respondents, explaining identifying characteristics, this group of divers is assumed to bear similarities to acquaintance divers.

Table 8: Sample demographic and diver characteristics

\begin{tabular}{lccc}
\hline & Total & Australian & Canadian \\
\hline Gender (male) & $65 \%$ & $66.1 \%$ & $64.4 \%$ \\
Age & $46.13(13.88)$ & $39.42(14.11)$ & $49.89(12.27)$ \\
Education & & & \\
High School & $9.6 \%$ & $12.8 \%$ & $7.7 \%$ \\
Certificate/trade & $7.9 \%$ & $11.9 \%$ & $5.7 \%$ \\
College diploma & $19.5 \%$ & $11.9 \%$ & $23.7 \%$ \\
University degree & $26.4 \%$ & $29.4 \%$ & $24.7 \%$ \\
Graduate degree & $36.6 \%$ & $33.9 \%$ & $38.1 \%$ \\
Household income & & & \\
$<\$ 50,000$ & $10.2 \%$ & $14.7 \%$ & $7.7 \%$ \\
\$50,000-\$99,999 & $14.5 \%$ & $22.0 \%$ & $10.3 \%$ \\
\$100,000-\$149,999 & $27.4 \%$ & $22.9 \%$ & $29.9 \%$ \\
\$150,000-\$199,999 & $18.2 \%$ & $17.4 \%$ & $18.6 \%$ \\
$>$ \$200,000 & $29.7 \%$ & $22.9 \%$ & $33.5 \%$ \\
Diver certification & & & \\
Open Water & $9.6 \%$ & $9.6 \%$ & $9.6 \%$ \\
Advanced Open Water & $43.2 \%$ & $41.3 \%$ & $44.3 \%$ \\
Technical & $7.6 \%$ & $12.3 \%$ & $6.1 \%$ \\
Dive Master & $17.5 \%$ & $19.3 \%$ & $16.0 \%$ \\
Dive Instructor & $22.1 \%$ & $15.6 \%$ & $24.0 \%$ \\
Dive partner & & & \\
Partner/spouse & $32 \%$ & $26.6 \%$ & $35.1 \%$ \\
Children & $1.7 \%$ & $1.8 \%$ & $1.5 \%$ \\
Parent/siblings & $2.0 \%$ & $1.8 \%$ & $2.1 \%$ \\
Friends & $38.9 \%$ & $41.3 \%$ & $37.6 \%$ \\
Acquaintances & $20.5 \%$ & $22.9 \%$ & $19.1 \%$ \\
Other & $5.0 \%$ & $5.5 \%$ & $4.6 \%$ \\
\hline
\end{tabular}

Based on preliminary regression analysis, demographics and diver characteristics were excluded from further data analysis (Appendix E). These socio-demographics accounted for little explained variance (adjusted $\mathrm{R}^{2}$ ranging from -.003 to .057 ), with few 
significant regression coefficients. This may be due to the relatively homogenous nature

of the sample and may warrant further investigation with a more diverse group of divers. When many predictors are available for use, the addition of more variables does not usually significantly increase the explanatory power of a model and can result in coefficient instability. Focusing on PMT predictors aligns with the study's research questions and helps to avoid over-fitting.

\subsection{Measures}

The questionnaire was designed to assess PMT constructs in relation to six behavioural intentions that could be used to minimize one's dissatisfaction with dive conditions. Assessing multiple behaviours not only allows for comparisons in terms of significant influencing factors, but also reduces the risk of model failure resulting from the type of behaviour studied, an explanation offered in previous studies (e.g., Murgraff et al., 1999; Sheeran, Conner \& Norman., 2001).

Steiger et al. (2017) identify different categories of behavioural adaptation, including pre-trip decisions (e.g., change destination because of poor conditions), reactions to conditions during a holiday (e.g., change activity), and long-term adaptation, as a result of repeated exposure to unacceptable conditions (e.g., stop activity altogether). This study considered behavioural adaptation in the short-term (i.e., to a single bleaching event), focusing on pre-trip decisions and on-site reaction to conditions. Adapted from Dawson (2009), five of the responses represent the different displacement behaviours (i.e., spatial, temporal, and activity).

The decision was made to exclude options related to change in timing, (e.g., waiting for better conditions or stopping for part of the season), since waiting for 
recovery is an unlikely option in the short term given the extended duration of coral bleaching (Baker et al., 2008). Instead, temporal displacement is assessed with one item that measures change in intensity (i.e., dive less often). Activity displacement is similarly assessed with one item that looks at doing some other recreational activity instead of diving. Spatial displacement is assessed via three items that consider intra-site, intraregional, and inter-regional displacement. Because van Duinen et al. (2015) found that various components of the threat and coping appraisal processes influenced adoption decisions differently across three scales of drought adaptation measures, these three scales of spatial displacement were analysed separately.

Dawson's “do nothing” option (i.e., dive as often and in the same place as usual) was modified, since it could either result from adaptation being deemed unnecessary or cognitive adaptation. Drawing from Lazarus and Folkman's model of stress and coping appraisal, respondents instead were asked to reflect on the statement, "There is nothing I can do about it, so I'll just enjoy the experience for what it is", which represents a form of psychological distancing. This was deemed adequate as Johnson and Dawson (2004) recommend that cognitive coping strategies be evaluated as one measure.

Because behavioural intentions will be analysed as separate models to enable comparisons across the different types of behavioural intentions, measures that are contingent upon behavioural intentions (i.e., coping appraisal items, behavioural intentions) will be assessed as single item measures to reduce the length and complexity of the survey.

The questionnaire also evaluated respondents' place attachment and activity involvement to evaluate threat and coping appraisal measures as potential mediators. The 
following sections describe the scales that were used to measure each variable in the questionnaire. Please refer Appendix $\mathrm{C}$ for the full questionnaire.

\subsubsection{Threat appraisal}

\subsubsection{Perceived severity}

Previous PMT studies have described perceived severity in terms of influence on different dimensions of life (e.g., Dang et al., Clubb \& Hinkle, 2015). However, in this study, primary consideration is given to influence on diver satisfaction, in keeping with focus on satisfaction risk as outlined in chapter 2 . Rather than collectively assess the different attributes that contribute to poor dive conditions (e.g., algal cover, visibility, absence of marine life), the decision was made to focus on one particular resource condition that could be used to assess the relationships of interest. This is similar to the emphasis on snow condition in previous adaptation studies, and focus on a singular impact in previous PMT studies (e.g., wildfire, flooding). Coral bleaching was selected, as it is the most studied condition in the context of divers' perceptions of change (e.g., Cesar, 2000; Dearden et al., 2006; Ngazy, Jiddawi, \& Cesar, 2004), and, unlike attributes like visibility and presence of fish, it is less variable over time. It also typically precedes algal cover, thus representing a more immediate impact, which fits within the timeframe of this study.

There have been criticisms of previous surveys exploring skiers' perceptions of threats for use of descriptive terms, like 'poor' or 'marginal', to describe conditions (Steiger, Scott, Abegg, Pons, \& Aall, 2017), pointing to the subjectivity in interpreting such terms. Previous investigations have addressed this by quantifying the types of impacts that might be expected (e.g., Scott, Jones, \& Konopek, 2007) or through use of 
analogues (e.g., Dawson et al., 2011). With this in mind, coral bleaching is presented in two ways. Following Anderson and Loomis (2012), the descriptor "coral reefs that are mostly white" is used. This is accompanied by an image depicting a coral landscape that adheres to this condition, which has been verified by dive experts (Figure 6). This image was provided as a means of standardizing what is meant by expected coral condition (e.g., Manning \& Freimund, 2004), which is particularly useful for those who have not encountered coral bleaching in real life. Respondents are advised to note that this image is provided as a representation of coral condition and may not directly correspond with the type of coral environment present at the dive destination participants identified.

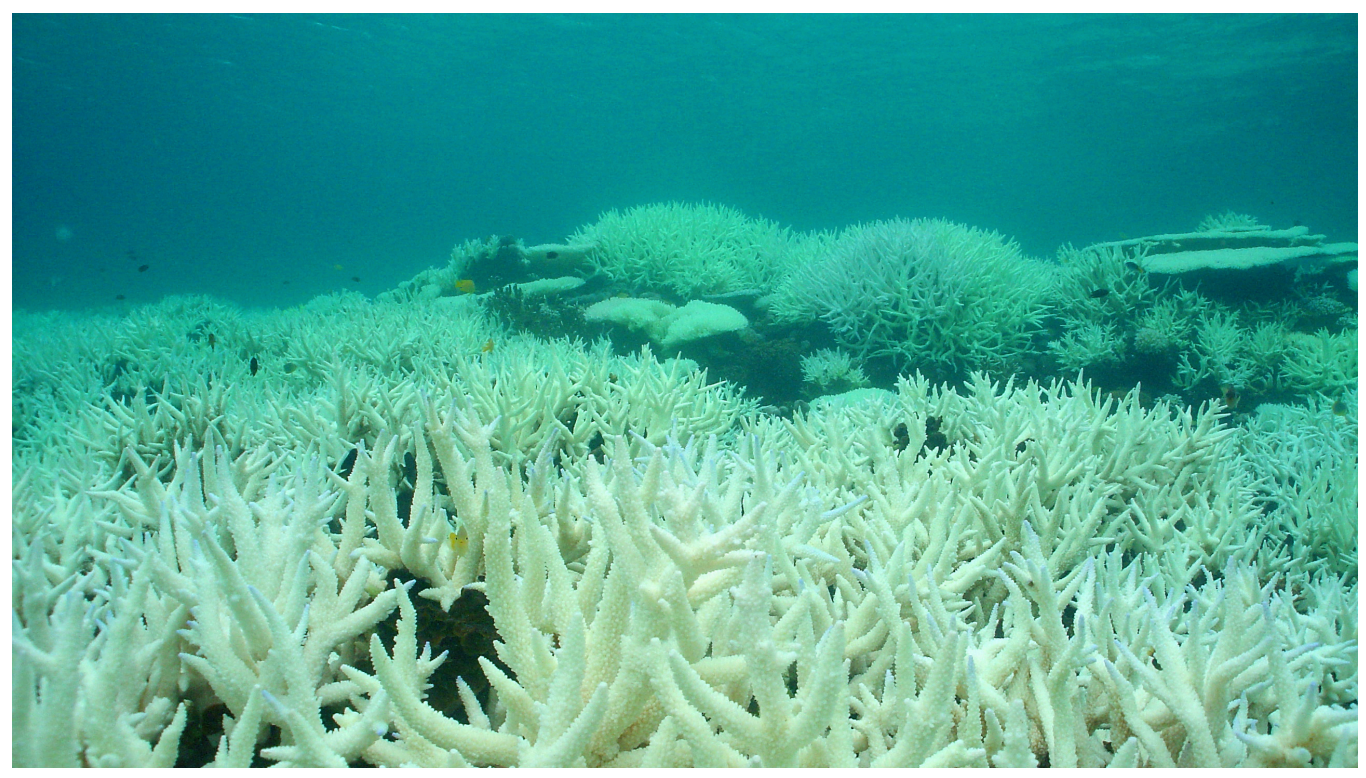

Figure 6: Image depicting coral landscape that is "mostly white" (Climate Commission, 2013)

Perceived severity was measured with two items. Respondents were asked to rate the how much satisfaction with (i) their dive, and (ii) their overall trip, would increase/decrease if coral bleaching were encountered. Assessing the extent to which coral bleaching affects overall trip satisfaction recognizes that participation in scuba diving is only one element of a trip, which is particularly important when considering 
tourists' experience. Because multiple behavioural intentions involve potentially changing where one travels to, it was deemed necessary to situate recreation activity choices within a broader decision-making framework. The inter-item consistency was acceptable, and the responses were averaged across the two items $(\alpha=.904)$.

\subsubsection{Perceived vulnerability}

Martin, Bender, and Raish (2007) define risk vulnerability as the likelihood of harm if there is no change in behaviour. Applying this definition to the current study would see assessment of likelihood of dissatisfaction if there were no change in behaviour. This was believed to be indistinguishable from measures of perceived severity, in which participants are asked to rate the extent to which resource condition affects their satisfaction. As well, taking this approach assumes that respondents believe that coral bleaching will occur. Instead, respondents are asked to rate (on a five-point scale) their likelihood of encountering the specified resource condition. This provides an indication of the perceived immediacy of the threat and avoids any implicit assumptions.

When providing respondents with a hypothetical future scenario, inclusion of a timeframe helps to provide context as to when these impacts are likely to be encountered. Projections of reef health are available for the 2030s. By this point it is estimated that more than $90 \%$ of all reefs will be classified as threatened (Burke et al., 2011). Projections over the short term are less certain, but, given the prevalence of reef degradation expected in less than two decades, it is reasonable to assume that conditions will change for the worse before then. As a result, the decision was made to focus on 'the next 5 years'. Having been used previously to estimate the effect of reef degradation on demand for recreational dive and snorkel trips to the Great Barrier Reef (Kragt, 
Roebeling, \& Ruijs, 2009), this timeframe was considered more meaningful from a tourist operator perspective, and more realistic in terms of accounting for recreation participation attrition; i.e., there is a greater likelihood the study participants will be diving in the next 5 years as opposed to 20 years in the future.

Perceived vulnerability was measured with two items that looked at perceived likelihood of encountering reefs that are mostly white while (i) diving at a self-specified dive location or (ii) while diving elsewhere. This was to assess if one's preferred dive place is seen as more or less vulnerable than other locations. The inter-item consistency was acceptable, and the responses were averaged across the two items $(\alpha=.767)$.

\subsubsection{Coping appraisal}

\subsubsection{Response efficacy}

Defined as the degree to which a proposed adaptation is perceived to be effective at reducing a particular threat, response efficacy was assessed with six items.

Respondents were asked to rate (on a five-point scale) the effectiveness of each of the six behavioural intentions, phrased as "How effective are the following responses at producing a satisfactory experience, should coral reefs that are mostly white be encountered." Because of the unfamiliar nature of this question and some concerns raised during the pilot testing, further clarification was provided. Specifically, it was noted that what is being measured is different from the likelihood of engaging in the listed actions, but rather whether said behaviour would lead to a satisfactory experience.

\subsubsection{Self-efficacy}

Self-efficacy is defined as the belief that one is capable or not capable of performing an adaptation behaviour, often framed in terms of one's confidence in their 
ability to protect themselves from a risk or threat. Respondents were asked to rate (on a five-point scale) their perceived confidence in carrying out each of the six adaptation behaviours "if the need arose" (e.g., How confident are you in your ability to travel elsewhere in the region to find different dive conditions if the need arose). This phrasing allows self-efficacy to be evaluated in isolation of resource conditions, and thus examine the independent influence of this factor on behavioural intentions.

\subsubsection{Response cost}

Response cost refers to barriers that inhibit an adaptive response. Some authors choose not to assess response cost (e.g., Horng et al., 2014). However, its inclusion here was deemed important because of an interest in determining the relative influence of each PMT variable. Response cost has been measured via separate items outlining different types of cost to the individual. For example, Bockarjova et al. (2014) equate cost in terms of functional and uncertainty aspects of adopting electric vehicles. However, the authors were only assessing one behavioural outcome rather than several. The decision was made to adopt the approach taken by Dang et al. (2014), who asked individuals to rate the collective cost, thus removing the need to assess multiple costs for each type of behavioural adaptation, which was deemed to be too cumbersome. Respondents were asked to rate (on a five-point scale) the cost of the six behavioural intentions described above (e.g., How much would travelling elsewhere in the region to find different dive conditions cost you?). Suggestions are provided by way of example to indicate that respondents should consider more than just financial costs (e.g., personal and social costs). 


\subsubsection{Behavioural intentions}

PMT ultimately serves as a framework for the prediction of protective behaviour, the focus of which in this study is on behavioural intentions. Thus, it is necessary to provide some measure of behavioural adaptation against which to assess the predictive power of threat and coping appraisal variables. However, because of the ex situ nature of the survey, capturing actual behaviour is complicated by the variability in dive frequency. While some scuba divers take regular annual dive trips, others can go years without diving. Similarly the number of dives completed throughout the course of a trip can range from one or two to a few dozen (personal observation). This in turn affects the likelihood of one having encountered coral bleaching. Rather than restrict an already limited pool of respondents to those who have previously dived on bleached reefs, an alternate measure was used in its place. Doing so also avoids the risk of potentially biasing the sample towards scuba divers who may seek out bleached reefs.

The adoption of adaptive responses is preceded by a decision or intention to take these actions - what Rogers $(1975,1983)$ termed "protection motivation" and Grothmann and Patt (2005) refer to as "behavioural intention". Distinguishing between intention and actual behavioural adaptation recognizes that people can have intentions, but may not carry them out in actual behaviour. This is because the basis of behavioural intentions is in the behaviour's desirability, rather than its feasibility, representing an idealized aim towards a goal that may involve little commitment. In contrast, self-predictions are probability judgments about what one will do, considering both appraisals of feasibility and desirability of acting (Sheppard et al., 1988). Evidence from meta-analyses suggests that subsequent behaviour is more strongly correlated to self-prediction than 
intention (Armitage \& Conner, 2001; Sheppard et al., 1988). Thus, in order to be of most practical utility to dive tourism operators, measures of self-prediction were adopted as the dependent variable in this study (Note: the term behavioural intention or behavioural intentions is used throughout the study to remain consistent with the terminology used in other PMT studies).

Respondents were asked to rate (on a five-point scale) the likelihood of performing the six coping mechanisms were coral conditions to persist in the specified location. Given the variable rate of recovery from coral bleaching, the phrase "for several years" was adopted, rather than a specific timeframe. This adheres to previous investigations into coral bleaching recovery, which suggests that recovery most often occurs over the course of 3 to 10 years (Baker et al., 2008).

\subsubsection{Place attachment}

Following Williams and Roggenbuck's (1989) two-dimensional conceptualization of place attachment, this questionnaire assessed respondents place dependence and place identity. Place dependence is a function of how well a space facilitates an individual's preferred activity relative to alternative places and the availability of social and physical resources. For example, a person may exhibit high place dependence if they require use of specific resources because of the place's unique ability to facilitate desired experiences. Place identity, on the other hand, relates to the symbolic and emotional attachments a person forms with a place. For example, a person may form a strong attachment with a setting because it offers them the opportunity to express and affirm their identity. The psychometric properties of this two-dimensional conceptualization for place attachment has been extensively tested (e.g., Moore and Graefe, 1994; Bricker and 
Kerstetter, 2000; Kyle et al., 2003) and refined to ensure the reliability of measures, and Williams and Vaske (2003) confirmed the validity and generalizability across several settings.

Place attachments surveys typically state the place in question (e.g., Kyle et al., 2004; White et al., 2008). In this study, following Moskwa (2012), respondents were asked to identify a diving destination that they were familiar with. The advantage of this approach is that there need not be a common place with which all the respondents are familiar, allowing for a broader sampling frame. The scale items used in the questionnaire were adapted from Moskwa (2012), the only known study that evaluates scuba divers' attachment to dive locations. Participants were asked to rate (on a five-point scale) their level of agreement with four statements relating either to place identity or place dependence (Table 9).

Table 9: Place attachment measures (adapted from Moskwa, 2012)

\begin{tabular}{ll}
\hline Place & [This place] means a lot to me \\
identity & I identify strongly with [this place] \\
& I really miss [this place] when I am away from it for too long \\
& I like to bring my family and/or friends to [this place] \\
Place & No other place can compare to [this one] \\
dependence & I get more satisfaction diving at [this place] than any other \\
& I wouldn't substitute other activities for diving here \\
& Diving here is more important than diving anywhere else \\
\hline
\end{tabular}

Given the sample size, number of scale items, and exploratory nature of the study, the decision was made to construct a mean index of place attachment by averaging all eight items. While this results in a loss of specific information about the components of the index, it preserves degrees of freedom in the model. The resulting Cronbach's alpha of 0.86 suggests there is high inter-item consistency. 


\subsubsection{Activity involvement}

This questionnaire employed the Modified Involvement Scale (Kyle et al., 2007) to measure activity involvement. Five dimensions collectively measure one's involvement with an activity, these being attraction, centrality, social bonding, identity affirmation, and identity expression. Attraction measures an activity's importance, including the pleasure derived from participation. Centrality measures the extent to which lifestyle choices and personal investments are made to support continued participation. Social bonding measures the extent to which involvement is driven by social ties. Identity affirmation measures the ability to express oneself, while identify expression measures the opportunity to express oneself to others. Kyle et al. extensively tested the consistency and reliability of this scale, confirming it is a valid and reliable measure of enduring activity involvement. Use of the scale has been supported in a number of subsequent applications (e.g., Dawson et al., 2011; Chang \& Gibson, 2011; Jun \& Kyle, 2011).

Participants were asked to rate (on a five-point scale) their level of agreement with statements relating to each of the five dimensions (Table 10). Following Dawson (2009), two statements are used for each dimension in an effort to reduce the length of the survey and maintain respondent attention, particularly given that activity involvement appears very early on in the survey.

Given the sample size, number of scale items, and exploratory nature of the study, the decision was made to construct a mean index of activity involvement by averaging all ten items. While this results in a loss of specific information about the components of the index, it preserves degrees of freedom in the model. The resulting Cronbach's alpha of 0.84 suggests there is high inter-item consistency. 
Table 10: Activity involvement measures (adapted from Kyle et al., 2007)

\begin{tabular}{ll}
\hline Attraction & $\begin{array}{l}\text { Scuba diving is one of the most enjoyable things I do } \\
\text { Scuba diving is very important to me }\end{array}$ \\
Centrality & $\begin{array}{l}\text { I find a lot of my life is organized around scuba } \\
\text { Scuba diving occupies a central role in my life }\end{array}$ \\
Social bonding & $\begin{array}{l}\text { I enjoy discussing scuba diving with my friends } \\
\text { Most of my friends are scuba divers }\end{array}$ \\
Identity & $\begin{array}{l}\text { When participating in scuba diving, I can really be myself } \\
\text { affirmation }\end{array}$ \\
$\begin{array}{l}\text { Identity } \\
\text { expression }\end{array}$ & $\begin{array}{l}\text { Participating in scuba diving says a lot about who I am } \\
\text { When I scuba dive, others see me the way I want them to see me }\end{array}$ \\
\hline
\end{tabular}

\subsection{Instrument testing}

Several measures were taken to ensure the clarity and reliability of the research instrument. PMT measures were developed with reference to previous PMT studies to ensure appropriate face validity. Consultation with the research advisory committee and the University of Waterloo's Statistical Consulting and Collaborative Research Unit also provided input as to the translation of each construct. Input was also requested as to the clarity of the questions and instructions provided. The concerns raised and response to this feedback is provided in Table 11.

The questionnaire also underwent pilot testing before data collection began. In an effort to attract participants as similar as possible to the study participants, respondents were recruited from Ontario underwater rugby participants, many of which are also scuba divers $(n=7)$, and Australian scuba diving researchers $(n=8)$, with a response rate of $78 \%$ and $40 \%$ respectively. The questionnaire was administered to the pilot subjects in exactly the same way it was administered in the main study. To improve the questionnaire, the following points were reviewed: the time taken to complete the survey, completion of questions, and the range of responses (Peat, 2001). On average the 
questionnaire took approximately 10 minutes to complete, which was deemed adequate.

All of the questions were completed by respondents, and demonstrated a suitable range in responses (ranging from 1 to 5). In addition to completing the questionnaire, respondents were asked to provide feedback on points of clarification or difficult questions. Concerns raised have been aggregated with those of the advisory committee and statistical consultant in Table 11.

Table 11: Survey changes in response to received feedback

\begin{tabular}{|c|c|c|}
\hline $\begin{array}{l}\text { Survey } \\
\text { section }\end{array}$ & Concern & Response to feedback \\
\hline $\begin{array}{l}\text { Qualifying } \\
\text { questions }\end{array}$ & $\begin{array}{l}\text { Unsuitable respondent } \\
\text { included in pilot } \\
\text { testing }\end{array}$ & $\begin{array}{l}\text { Included two qualifying question ensuring that } \\
\text { respondents have scuba experience on coral } \\
\text { reefs and intend to dive at some point in the } \\
\text { future. Negative responses to either of these two } \\
\text { questions bring the respondent to the Thank You } \\
\text { page. }\end{array}$ \\
\hline \multirow[t]{2}{*}{$\begin{array}{l}\text { Identification } \\
\text { of place }\end{array}$} & $\begin{array}{l}\text { Divers may not } \\
\text { frequent the same dive } \\
\text { destination often }\end{array}$ & $\begin{array}{l}\text { Modified instructions to reflect this: "If you do } \\
\text { not often frequent the same reef } \\
\text { diving destination, please choose the one you } \\
\text { have visited most recently" }\end{array}$ \\
\hline & $\begin{array}{l}\text { Ensuring relevance of } \\
\text { bleaching }\end{array}$ & $\begin{array}{l}\text { Made it a condition that the identified dive } \\
\text { destination have coral: "Identify a coral reef } \\
\text { diving destination" }\end{array}$ \\
\hline \multirow[t]{2}{*}{$\begin{array}{l}\text { Depiction of } \\
\text { reef condition }\end{array}$} & $\begin{array}{l}\text { Ensuring clarity of } \\
\text { condition }\end{array}$ & Inclusion of an image \\
\hline & $\begin{array}{l}\text { Length of time } \\
\text { required to load image }\end{array}$ & Reduced size of image \\
\hline $\begin{array}{l}\text { Perceived } \\
\text { vulnerability }\end{array}$ & $\begin{array}{l}\text { Overlap with } \\
\text { perceived severity }\end{array}$ & $\begin{array}{l}\text { Changed to likelihood of encountering } \\
\text { conditions depicted, rather than likelihood of } \\
\text { influencing satisfaction }\end{array}$ \\
\hline $\begin{array}{l}\text { Perceived } \\
\text { severity }\end{array}$ & $\begin{array}{l}\text { Ensuring clarity of } \\
\text { what is at risk }\end{array}$ & $\begin{array}{l}\text { Framed in terms of satisfaction, rather than } \\
\text { extent of threat; inclusion of effect on overall } \\
\text { trip satisfaction }\end{array}$ \\
\hline $\begin{array}{l}\text { Adaptation } \\
\text { options }\end{array}$ & $\begin{array}{l}\text { Lack of recognition of } \\
\text { cognitive adaptation }\end{array}$ & Inclusion of one cognitive adaptation measure \\
\hline
\end{tabular}




\begin{tabular}{|c|c|c|}
\hline \multirow[t]{3}{*}{$\begin{array}{l}\text { Response } \\
\text { efficacy }\end{array}$} & $\begin{array}{l}\text { Ensuring clarity of } \\
\text { construct }\end{array}$ & $\begin{array}{l}\text { Indication of effectiveness with respect to what: } \\
\text { "How effect are the following adaptation } \\
\text { options at producing a satisfactory experience" }\end{array}$ \\
\hline & & $\begin{array}{l}\text { Inclusion of additional instructions that clarify } \\
\text { what is being asked: "this is different from your } \\
\text { likelihood of engaging in this behaviour, but } \\
\text { rather asks whether you think the listed actions } \\
\text { lead to a satisfactory experience" }\end{array}$ \\
\hline & $\begin{array}{l}\text { Oddity of minimizing } \\
\text { dissatisfaction by } \\
\text { diving less frequently }\end{array}$ & $\begin{array}{l}\text { Phrasing changed to discuss in terms of } \\
\text { producing a satisfactory experience should a } \\
\text { threat be encountered, rather than minimizing } \\
\text { the threat }\end{array}$ \\
\hline Self-efficacy & $\begin{array}{l}\text { Ensuring clarity of } \\
\text { construct }\end{array}$ & $\begin{array}{l}\text { Framed question irrespective of changes (i.e., "if } \\
\text { the need arose") to avoid assumption that a } \\
\text { threat will be perceived, as well as clarify the } \\
\text { distinction between ability and likelihood }\end{array}$ \\
\hline $\begin{array}{l}\text { Behavioural } \\
\text { intentions }\end{array}$ & $\begin{array}{l}\text { Appropriate framing } \\
\text { of hypothetical } \\
\text { scenario }\end{array}$ & $\begin{array}{l}\text { Framed scenario with reference to previously } \\
\text { used image }\end{array}$ \\
\hline \multirow[t]{5}{*}{$\begin{array}{l}\text { Socio- } \\
\text { demographics }\end{array}$} & $\begin{array}{l}\text { Relevance of } \\
\text { questions }\end{array}$ & Removal of ethnicity and inclusion of income \\
\hline & Question format & Reformatted as lists \\
\hline & $\begin{array}{l}\text { Selection of dive } \\
\text { buddy }\end{array}$ & $\begin{array}{l}\text { Limited selection of dive partner to most } \\
\text { applicable }\end{array}$ \\
\hline & & $\begin{array}{l}\text { Clarified that acquaintances are people met } \\
\text { during the dive }\end{array}$ \\
\hline & $\begin{array}{l}\text { Dive certification } \\
\text { options }\end{array}$ & $\begin{array}{l}\text { Include 'Other' option to account for other } \\
\text { levels, e.g., Assistant DI }\end{array}$ \\
\hline $\begin{array}{l}\text { Additional } \\
\text { comments }\end{array}$ & $\begin{array}{l}\text { No place to elaborate } \\
\text { on responses }\end{array}$ & $\begin{array}{l}\text { Include open-ended comments section at end of } \\
\text { survey }\end{array}$ \\
\hline
\end{tabular}

\subsection{Data analysis}

The first aim of this research is to predict behavioural intentions by comparing and analyzing the effects of threat and coping appraisal variables (Figure 7). Multiple linear regression analysis is a common statistical procedure used to model the 
relationship between a response variable (i.e., behavioural intentions) and multiple predictor variables (i.e., threat and coping appraisal variables).

A sub-component of this research aim is to examine variations in two diving populations that differ in terms of geographic proximity. Independent t-tests will be used evaluate how the two samples differ in terms of behavioural intentions and threat and coping appraisal factors (i.e., compositional differences). Incorporating a dummy variable and interaction terms for group membership will be used to identify differences in the strength and/or nature of the relationships influencing one's intention to adapt (i.e., structural differences).

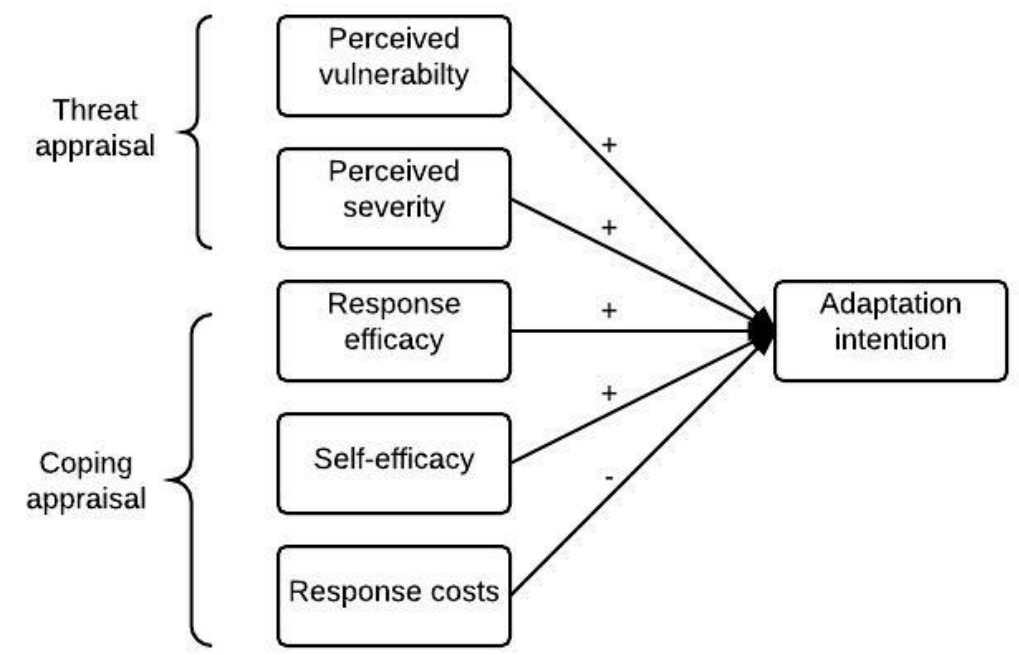

\section{Figure 7: Conceptual diagram of prediction of behavioural intentions}

The second aim of this research is to examine how activity involvement and place attachment influence behavioural intentions. Specifically, by considering the mediating influences of threat and coping appraisal variables. Mediation analysis will be used to model the relationships between each of the behavioural intentions and place attachment and activity involvement (Figure 5). All analyses were performed with SPSS 24. 


\subsubsection{Multiple linear regression}

Linear regression is the study of linear, additive relationships between variables. A linear function is estimated that describes how the response variable is related to the predictors by deriving an intercept and weights for the predictors, referred to as regression coefficients, which quantify the predictors' impact. In unstandardized form, they reveal how many units the response variable changes when a predictor changes one unit, while the other predictors are held constant. Standardized regression coefficients give this information in standard deviations, allowing for comparisons among predictor variables. The goodness of overall model fit is indicated by the multiple coefficient of determination, $\mathrm{R}^{2}$. $\mathrm{R}^{2}$ represents the proportion of variability in the dependent variable explained by the predictor variables over and above the mean model or intercept-only model (i.e., model without any independent variables, where the best prediction of the dependent variable is its mean value). Of note, $\mathrm{R}^{2}$ increases as predictors are added to the regression model regardless of whether predictors are actually improving the model's fit, in which case an adjusted $\mathrm{R}^{2}$ that incorporates the model's degrees of freedom can be reported.

To test the overall significance, the F-test compares the intercept-only model with the regression model, where the null hypothesis is that the fit of these models is equal. A statistically significant result means that the regression model is statistically significantly better at predicting the dependent variable and is a better fit to the data than the mean model.

\subsubsection{Model assumptions}


In order to run a linear regression analysis, there are several assumptions that need to be considered. The first of these assumptions relates to choice of study design, whilst the other assumptions relate to how the data fit the linear regression model.

\section{$\underline{\text { Continuous variables }}$}

Linear regression assumes the dependent variable is measured at the continuous level (i.e., interval or ratio), and the independent variable(s) is/are measured at the continuous or nominal level. The data in this research are a combination of Likert scales (e.g., place dependence) and Likert-type items (e.g., activity response efficacy). Though a number of articles argue that Likert items do not form an interval scale (e.g., Jakobsson, 2004; Jamieson, 2004; Kuzon, Urbanchek, \& McCabe, 1996), treating Likert and Likerttype items and scales as interval scales is an acceptable common practise within the social sciences (e.g., Bockarjova \& Steg, 2014; Dang et al., 2014; Koerth et al., 2013). Indeed, several papers have shown that Likert scales can be analysed effectively as interval scales (e.g., Baggaley \& Hull, 1983; Maurer \& Pierce, 1998; Vickers, 1999).

Further evidence for treating Likert and Likert-type items as interval is offered by comparing responses via a slider scale, known as continuous rating scales, in which respondents use a slider to position themselves on a certain question. Lozano et al. (2008) show that the increase in reliability and validity tends to level off at about 7 response alternatives. Thus, the interval data collected via a slider scale can be said to be adequately represented by a Likert item with a sufficient number of response categories, where 5 response categories appears to be the minimum agreed upon number (Carifio \& Perla, 2007; Lozano, García-Cueto, \& Muñiz, 2008).

$\underline{\text { Normality of the residuals }}$ 
Residuals are the differences between observed and predicted responses, and thus can be thought of as elements of variation the fitted model does not explain. Errors in prediction should occur in a random fashion (e.g., the model should predict values higher or lower than actual with equal probability). Thus, the overall residuals pattern should be similar to a bell-shaped curve, i.e., normally distributed. Violation of this assumption can result in inaccurate parameter estimates and underestimated standard errors, which can negatively affect significance tests (Lei \& Lomax, 2005).

Any graph that displays the distribution of a dataset is suitable for judging the distribution of a group of residuals, examples of which include histograms and normal probability plots. In histograms, deviations from the mean to the left or right indicate that low or high values of the response variable are not well explained. The same is true of points above or below the normal distribution line in the normal probability plot (Miles \& Shevlin, 2001). Figure 8 illustrates these results graphically for the residuals of the regression on BIS1 (intention to change location within a destination) and BIA (intention to change activity). The residuals in the histogram approximate a normal distribution, though the points of the normal probability plot deviate from the normal distribution line somewhat. These results are typical of the six different response variables measured. In large samples, slight to moderate non-normality has no to little effect on standard errors, and thus should not lead to serious problems when interpreting significance tests or confidence intervals (Everitt \& Dunn, 2001; Lei \& Lomax, 2005). Thus, deviations from normality should not prove problematic. 

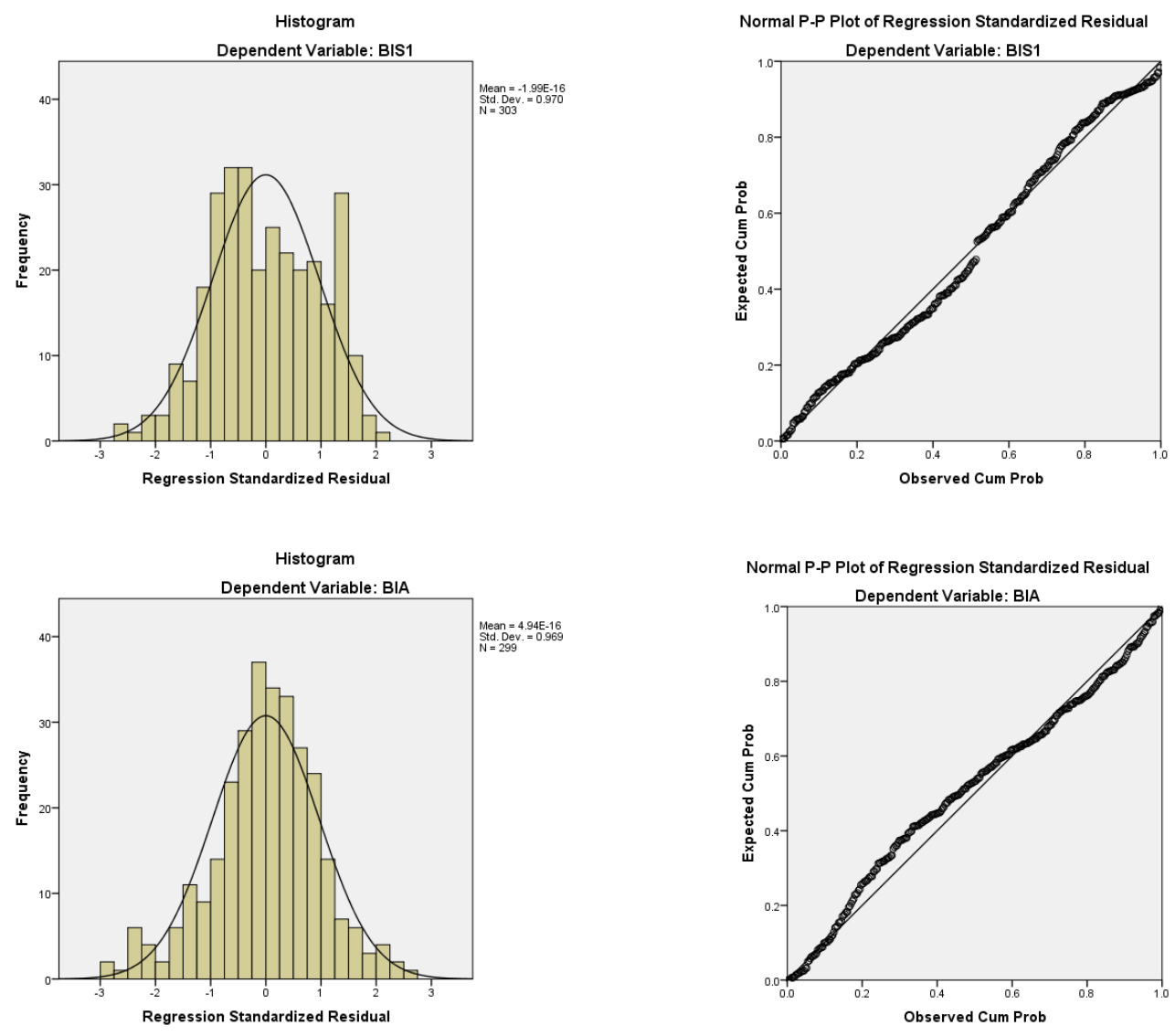

Figure 8: Histograms and normal probability plots for regressions on BIS1 and BIA

\section{Homoscedasticity}

Homoscedasticity describes a situation in which the error term is the same across all values of the independent variables. If it is not, heteroscedasticity is said to be present. When there is heteroscedasticity, the estimates of the standard errors, and hence significance tests and confidence intervals, may be incorrect, and the possibility of a Type I error increases. Homoscedasticity can be evaluated by examining a scatterplot of the standardized residuals by the regression standardized predicted value. If there is homoscedasticity, the points of the plot will be approximately constantly spread above and below the zero line (Everitt \& Dunn, 2001). Figure 9 shows the corresponding plots for two exemplary regressions, intra-regional (BIS2) and cognitive (BIC) behavioural 
intentions. Both cases show slight heteroscedasticity. However, unless the degree of nonconstant variance is large, heteroscedasticity has been shown to have little effect on significance tests, and the confidence intervals will be very close to the correct values (Cohen, Cohen, West, \& Aiken, 2013; Tabachnick \& Fidell, 1996).
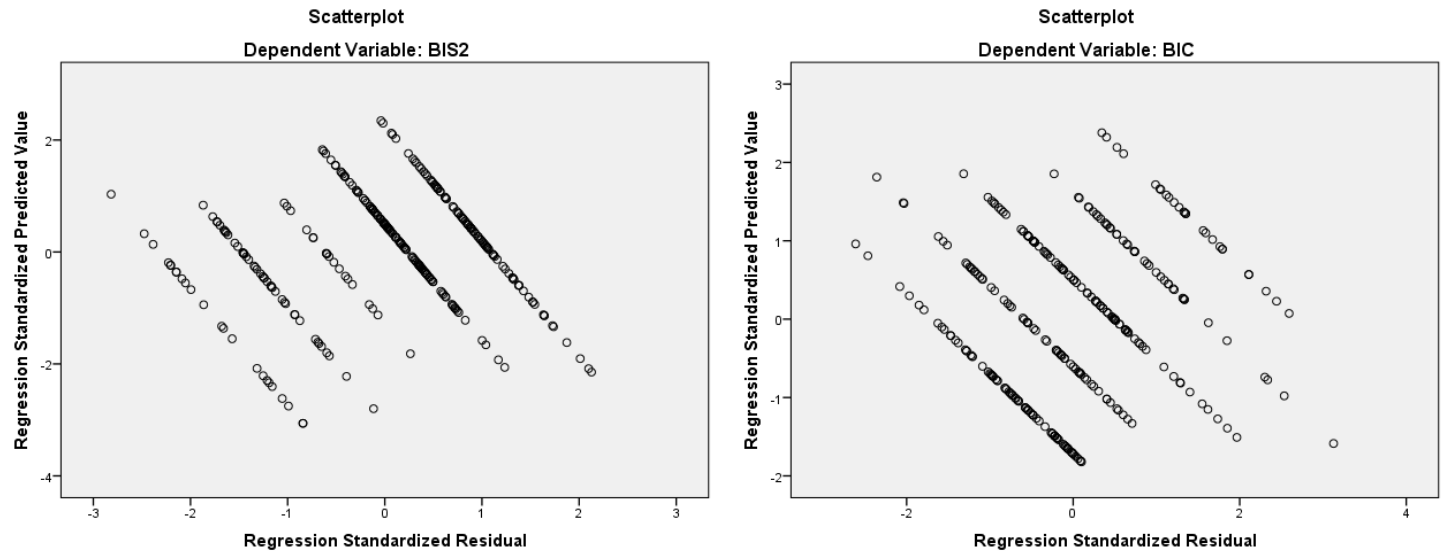

Figure 9: Scatterplots for regressions on BIS2 and BIC

\section{$\underline{\text { No autocorrelation }}$}

The expected correlation between the residuals for any two cases should be equal to zero, i.e., the residuals should be independent of one another. Lack of independence, referred to as autocorrelation, typically occurs in time series or when the cases of a sample can be clustered in some way. By virtue of the study design, it is highly unlikely the observations will be related, and thus this assumption does not require statistical testing (e.g., via the Durbin-Watson test for time-series data).

\section{Linearity}

The expected value of the residuals should equal zero at every possible value of the response variable, i.e., the bivariate relationship between the predictors and the response variable should be linear. If it is non-linear, the estimates of regression 
coefficients and standard errors may be biased, resulting in incorrect significance tests and incorrect confidence intervals. This assumption is evaluated by examining graphical displays to determine if a linear relationship adequately characterizes the data. The above-mentioned scatterplot of the standardized residuals can be used to assess the collective linearity of linear relationships between dependent and independent variables, where its interpretation is the same as for homoscedasticity (Cohen et al., 2013; Everitt \& Dunn, 2001). Partial regression plots can be used to check that each independent variable is linearly related to the dependent variable. Violations of this assumption present as a non-random variation from the expected patterns, the most common of which are Ushaped or J-shaped distributions. For the data of this thesis, scatterplots for predictors indicate moderate to weak linear relationships, as exemplified in Figure 10, while the scatterplot of the residuals, as shown in Figure 9, suggest a possible misspecification of the models. Thus, estimations of regression coefficients and the standard error will be interpreted prudently.
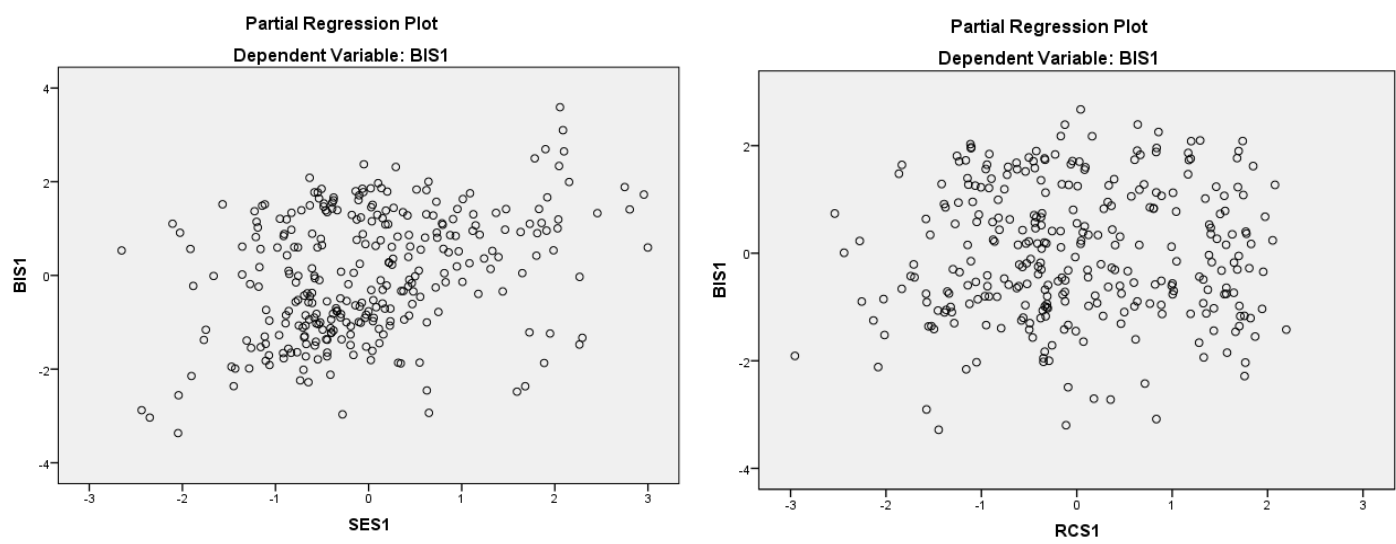

Figure 10: Partial regression plots for regressions on SES1/RCS1 and BIS1 No multicollinearity

Multicollinearity, i.e., the linear dependence between two or more predictors, 
should not be present. If predictors are highly correlated, they will have less unique information to contribute to the prediction of the response variable. The regression coefficients of such redundant predictors may be significantly underestimated and can change in sign (Miles \& Shevlin, 2001). One of the most common ways to check for multicollinearity is the Variance Inflation Factor (VIF), which shows the proportion of variance in each predictor that is shared by all of the other predictors. Conservative estimates of VIF recommend a cut-off value of $>3$ (Everitt \& Dunn, 2001). For the data of this thesis, VIF values were less than 2 for all predicators, indicating multicollinearity is unlikely to be an issue.

Unusual points

Certain data points can be classified as unusual from the perspective of fitting a multiple regression model, which can be detrimental to the fit or generalization of the regression equation. There are three primary types of unusual points: outliers, high leverage points, and highly influential points. An outlier is an observation that does not follow the usual pattern of points (i.e., they are far away from their predicted value). Standardized residuals are a common method to detect outliers, where a value of greater than \pm 3 is a common cut-off criterion. No outliers were detected for models intradestination (BIS1), intra-regional (BIS2), or cognitive (BIC) behavioural intentions. However, models of inter-regional (BIS3), temporal (BIT), and activity (BIA) behavioural intentions each contained one or more outliers. In the case of BIS3, 4 initial outliers were identified, in which respondents indicated they were very unlikely to adapt (i.e., BIS3 = 1). This amounted to two thirds of this type of response (i.e., 4 of 6 responses in which BIS3 =1), and removal led to the subsequent identification of outliers 
where respondents were somewhat unlikely to adapt (i.e., BIS3 = 2). Similarly for BIT, 2 of 11 responses where BIT $=1$ were identified as outliers. Meanwhile, 3 of 22 responses where

$\mathrm{BIA}=5$ were identified as outliers. The decision was made to leave data points in, recognizing that model may be less effective at predicting extremes if these values are underrepresented.

A data point has high leverage if it has "extreme" predictor x values. A general rule of thumb to determine whether any cases exhibit high leverage is to consider leverage values $<0.2$ as safe, $0.2-0.5$ as risky, and values $>0.5$ as dangerous. Several potentially high leverage points were identified for each model, however, because the maximum value never exceeded 0.285 , and none of the points exerted a high influence, this was deemed acceptable. A data point is influential if it unduly influences a part of the regression analysis (e.g., predicted responses, estimated slope coefficients). Cook's distance is the most common measure of influence. As a rule of thumb, a Cook's distance $>1$ is cause for concern. For the data of this thesis, Cook's distance does not indicate any influential points.

\subsubsection{Comparing regression coefficients between two samples}

A sub-component of this research is to examine differences in the strength/nature of PMT relationships by comparing two groups that differ in terms of geographic proximity. Graphing the regression lines of the two samples allows for a visual comparison of the slope coefficients and constants. However, it is also important to statistically test the differences via hypothesis testing to distinguish differences (Gelman \& Stern, 2006; Williams, 2015). When comparing groups by estimating separate models, 
it is possible for a variable to have a significant effect in one group and an insignificant effect in the other. However, the difference in effects between groups may not be statistically significant. This may occur if one group sample is larger than the other, as is the case for this study, where the sample size of Canadians $(\mathrm{n}=194)$ is almost double that of the Australian sample $(\mathrm{n}=109)$.

By incorporating a dummy variable for group membership and interaction terms for group membership with other independent variables it is possible to identify what effects, if any, differ across groups. The inclusion of interaction terms represents an alternative way of expressing the unconstrained model, where the coefficients for the dummy variable and the interaction terms indicate whether groups differ or not. If the intercept and regression coefficients are the same for both groups, the interaction terms should all be zero. Similarly, if the effect of a variable is larger (i.e., more positive or less negative) in group 1 than in group 0 , then the interaction term will have a positive value, while a smaller variable effect will result in a negative interaction term. The $t$ value for an interaction term indicates whether the slope significantly differs from the slope of the reference group.

\subsubsection{Mediation analysis}

The causal steps procedure, popularized by Baron and Kenny (1986), is one of the most common approaches to analyzing mediation. For $M$ to be a mediator of the relationship between $X$ and $Y$, the following conditions must be met:

- The independent variable $(X)$ should relate to the dependent variable $(Y)$, such that $c$ is significant (Figure $3.7-\mathrm{A}$ ). This establishes that there is a relationship between $\mathrm{X}$ and $\mathrm{Y}$ to be mediated.

- $X$ should relate to the mediator variable $(M)$, such that $a$ is significant (Figure 3.7 - B). This establishes the first stage of the mediated effect.

- $M$ should relate to $Y$, such that $b$ is significant. This establishes the second 
stage of the mediated effect.

- $X$ should no longer relate to the dependent variable $Y$ after $M$ is controlled, such that $c^{\prime}$ is not significant. This establishes that the relationship between $X$ and $Y$ disappears when taking the mediated effect into account.

However, the causal steps procedure has undergone considerable scrutiny, with a number of criticisms emerging (e.g., Hayes, 2009, 2017; MacKinnon, Lockwood, Hoffman, West, \& Sheets, 2002; MacKinnon, Lockwood, \& Williams, 2004; Preacher \& Selig, 2012; Shrout \& Bolger, 2002). One of the fundamental problems of this approach is that the indirect effect is not formally quantified, but rather inferred from the outcome of a set of null hypotheses quantifying other effects. Because the indirect effect is not quantified, it encourages researchers to think about mediation in qualitative terms complete, partial, or no mediation. This is problematic because it elevates complete mediation as the ideal, which is easier to establish in smaller samples and says nothing about the presence or absence of other possible mediators. Requiring multiple inferential procedures to accept or reject $M$ as a mediator also increases the possibility of type I or type II errors. For example, the first condition is predicated on the belief that an effect that does not exist cannot be mediated, but situations where multiple indirect effects, some positive, some negative, sum to zero, would result in the incorrect acceptance of the null hypothesis (type II error). To address these criticisms, alternatives to the causal steps procedure focus on the product term $a b$, rather than the individual paths of the mediation model, reasoning that this product is equal to the difference between the total and direct effect.

Discussions of mediation often focus on the simple three-variable model portrayed in

Figure 11. However, many mediation models have more than three variables. For 
example, one might wish to specify and test a single multiple mediation model in lieu of separate simple mediation models. This allows the researcher to determine the relative magnitudes of the specific indirect effects of all potential mediators, while reducing the likelihood of parameter bias due to omitted variables. However, it is important to note that a specific indirect effect through a mediator in the multiple mediation context is not the same as the indirect effect through this mediator alone, i.e., it is conditional on the presence of other mediators in the model.

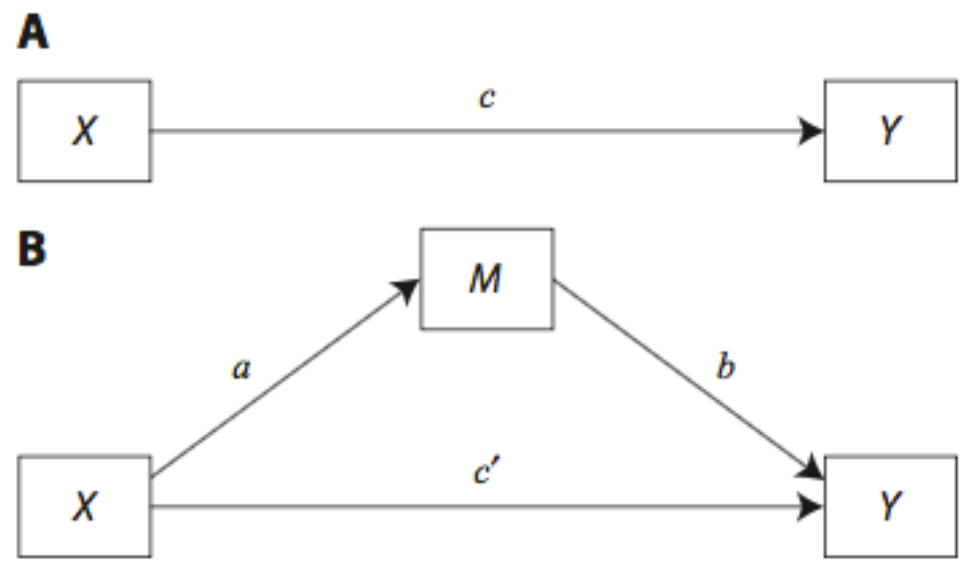

\section{Figure 11: (A) Illustration of a direct effect of X on Y. (B) Illustration of an indirect effect of $\mathrm{X}$ on $\mathrm{Y}$ through $\mathrm{M}$}

To accommodate multiple mediator models, it is useful to apply the principles of path analysis, an extension of multiple regression that aims to provide estimates of the magnitude and significance of hypothesised causal connections between sets of variables. For most researchers, structural equation modeling (SEM) comes to mind as the proper analytical strategy. Yet much of the guidance offered by methodologists is framed in terms of ordinary regression-based path analysis principles (Hayes et al., 2017). The PROCESS macro introduced by Hayes (2013) for SPSS and SAS simplifies the implementation of mediation analysis with manifest variables, doing all of the necessary 
computations so as to apply these same principles. PROCESS uses ordinary least squares regression to estimate the parameters of each of the regression equations separately, rather than solving the entire system of equations simultaneously through iteration using maximum likelihood estimation, as does SEM. While any SEM program can run path analysis with observed variables as PROCESS does, most require additional code to generate many of the statistics produced by PROCESS automatically. Moreover, not all SEM programs can generate all of the statistics PROCESS calculates or execute bootstrapping in a way that facilitates statistical inference (Hayes, Montoya, \& Rockwood, 2017).

Given that SEM and PROCESS are based on different estimation methods and theory, some differences in results can be expected. However, studies investigating these differences suggest variances in results tend to be trivial, and in fact PROCESS may prove more suitable in smaller samples (Hayes, 2013; Hayes et al., 2017). In most SEM programs, default estimation methods rely on large sample asymptotic theory. Generally speaking, in small samples, maximum likelihood standard errors tend to be biased downward (Hoogland \& Boomsma, 1998). So, any apparent advantage evidenced by smaller standard errors can be misleading.

PROCESS estimates the magnitude of the direct, indirect, and total effects of $X$ on $Y$. In mediation models, the indirect effect is of primary interest. Such an effect is complex because it is the product of two regression coefficients and does not conveniently fit into the framework of existing effect sizes. Quantification of effect size in mediation analysis is an evolving area of research; there has been limited development beyond the description and study of various measures in simple mediation analysis, 
without statistical controls (Hayes \& Preacher, 2011). If the variables $X$ and $Y$ are already on meaningful metrics, simply reporting $a b$ and interpreting it may be sufficient in communicating effect size and practical importance.

Effect size describes the association between variables in the data collected, but say nothing about generalizability. To speak to generalization requires statistical inference. Inference about the direct and total effects of $X$ on $Y$ can typically be undertaken using the standard method of inference for any regression coefficient in a regression model, i.e., framed in terms of a null hypothesis test or whether a confidence interval estimate contains zero. However, extending the same logic to inference about the indirect effect of $X$ on $Y$ can be problematic. This "normal theory approach" (also referred to as product of coefficients, delta method, or Sobel test) assumes that the sampling distribution of $a b$ is normal, but analytical and simulation studies have shown that the distribution is often quite irregular unless using very large sample sizes (Bollen \& Stine, 1990; Stone \& Sobel, 1990). When compared to other inferential methods, it is one of the lowest in power, generating confidence intervals that tend to be less accurate than other methods (MacKinnon et al., 2004).

More common today is the use of bootstrap confidence intervals. A bootstrap confidence interval for a specific indirect effect is constructed by taking a random sample with replacement of size $n$ from the sample. By repeating this process over and over, often thousands of time, a representation of the sampling distribution of the statistic is constructed empirically. Endpoints of the confidence intervals are calculated using either the percentiles or bias-corrected method. The bias-corrected method is more widely recommended for inference about the indirect effect in mediation analysis, balancing 
validity and power considerations (Biesanz, Falk, \& Savalei, 2010; Fritz, Taylor, \& MacKinnon, 2012; Hayes \& Scharkow, 2013; Preacher \& Selig, 2012). Endpoints are adjusted upwards or downwards depending on the proportion of values that are less than the point estimate of the indirect effect calculated in the original data. If zero is outside of a confidence interval, than $a b$ is declared different from zero with $95 \%$ confidence (assuming 95\% confidence interval).

Rather than run several models with a single independent variable $(\mathrm{X})$ for each behavioural intention $(\mathrm{Y})$, the decision was made to include both attachment variables in a single model to provide an estimate of part of one X's effect on $\mathrm{Y}$ unique to that $\mathrm{X}$ relative to other Xs. To achieve this, PROCESS was run twice, each time listing one variable as the independent variable and treating the other independent variable as a covariate; each run of PROCESS generates the effects (total, direct, indirect) for the variable currently listed as the independent variable. All analyses included a biascorrected bootstrap 95\% confidence interval based on 10, 000 bootstrap samples. 


\section{REGRESSION OF PROTECTION MOTIVATION THEORY VARIABLES}

The following chapter is organized as follows. First, descriptive statistics of PMT variables are presented for both the total sample and sub-samples. From here, findings from a series of regression analyses that were conducted to test the hypothesized relationships between perceived severity, perceived vulnerability, response efficacy, selfefficacy, and response cost and behavioural intentions are presented. The final section presents findings from separate regression models including interaction effects to test for differences between Canadian and Australian sub-samples.

\subsection{Descriptive statistics}

\subsubsection{Behavioural intentions}

Respondents were asked to rate (on a 5-point scale) the likelihood of performing the six adaptation mechanisms were coral conditions to persist in a self-specified location Figure 12 visually depicts the likelihood of divers engaging in the different types of adaptation.

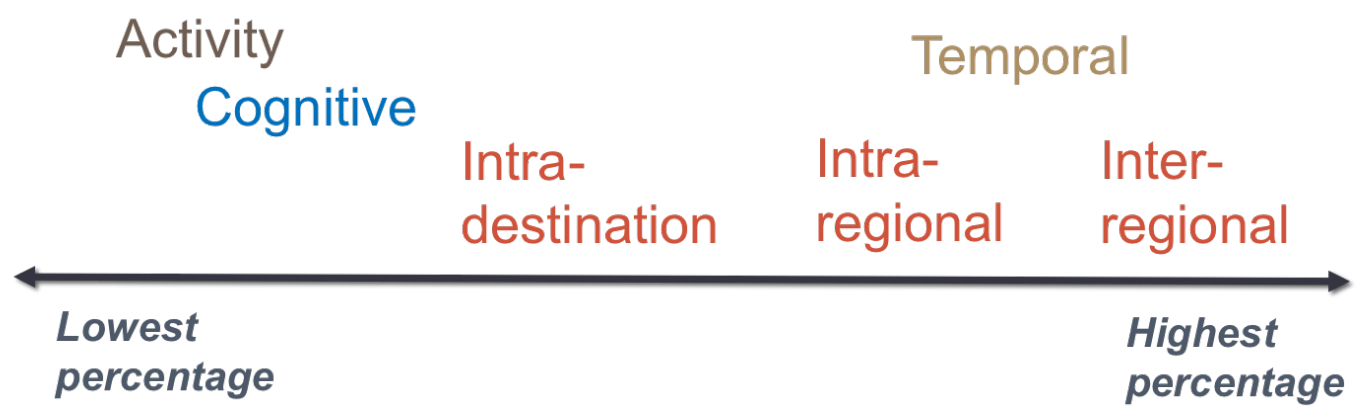

Figure 12: Visualization of the likelihood of divers' different behavioural intentions

Divers were most likely to indicate an intention to dive outside the region (85.8\%, $\mathrm{M}=4.29, \mathrm{SD}=.96)$, reduce dive frequency $(76.9 \%, \mathrm{M}=4.08, \mathrm{SD}=1.12)$, and dive 
elsewhere within the region $(71 \%, \mathrm{M}=3.72, \mathrm{SD}=1.27)$, followed by an intention to dive elsewhere within the destination $(43.9 \%, \mathrm{M}=2.90, \mathrm{SD}=1.47)$. A smaller proportion of respondents indicated a positive intention to change activity $(21.8 \%, \mathrm{M}=2.32, \mathrm{SD}=$ 1.30) or accept the situation $(22.5 \%, \mathrm{M}=2.54, \mathrm{SD}=1.27)$. Independent t-tests revealed that Australian and Canadian divers significantly differed in their intention to engage in spatial adaptation, with Australians being more likely to change the location of diving within a destination $(\mathrm{t}=-3.00, \mathrm{p}=.003)$ or within a region $(\mathrm{t}=-2.07, \mathrm{p}=.040)$. Full descriptive statistics and the results of the independent t-tests comparing Australian and Canadian diver behaviour intentions can be found in Table 12 .

Table 12: Descriptive statistics of behavioural intentions

\begin{tabular}{llcccc}
\hline & & Frequency $^{\wedge}$ & Mean & Std. dev. & $\mathrm{t}$ \\
\hline BIS1 & Total & $\mathbf{4 3 . 9 \%}$ & $\mathbf{2 . 9 0}$ & $\mathbf{1 . 4 7}$ & $-3.00 * *$ \\
& Australian & $52.2 \%$ & 3.22 & 1.33 & \\
& Canadian & $38.6 \%$ & 2.72 & 1.52 & \\
BIS2 & Total & $\mathbf{7 1 . 0 \%}$ & $\mathbf{3 . 7 2}$ & $\mathbf{1 . 2 7}$ & $-2.07 *$ \\
& Australian & $78.0 \%$ & 3.91 & 1.09 & \\
& Canadian & $67.0 \%$ & 3.61 & 1.35 & \\
BIS3 & Total & $\mathbf{8 5 . 8 \%}$ & $\mathbf{4 . 2 9}$ & $\mathbf{0 . 9 6}$ & -1.55 \\
& Australian & $91.8 \%$ & 4.39 & 0.76 & \\
& Canadian & $82.5 \%$ & 4.23 & 1.05 & \multirow{1}{*}{ BIT } \\
& Total & $\mathbf{7 6 . 9 \%}$ & $\mathbf{4 . 0 8}$ & $\mathbf{1 . 1 2}$ & 1.63 \\
& Australian & $72.5 \%$ & 3.94 & 1.19 & \\
& Canadian & $79.4 \%$ & 4.16 & 1.08 & \\
& Total & $\mathbf{2 1 . 8 \%}$ & $\mathbf{2 . 3 2}$ & $\mathbf{1 . 3 0}$ & -0.68 \\
& Australian & $22.1 \%$ & 2.39 & 1.31 & \\
& Canadian & $21.6 \%$ & 2.28 & 1.30 & \multirow{2}{*}{ BIC } \\
& Total & $\mathbf{2 2 . 5 \%}$ & $\mathbf{2 . 5 4}$ & $\mathbf{1 . 2 7}$ & -0.91 \\
& Australian & $23.9 \%$ & 2.63 & 1.26 & \\
& Canadian & $21.6 \%$ & 2.49 & 1.27 & \\
\hline$* p<.05, * * p<.01, * * * p<.001$ & & &
\end{tabular}

A: proportion of respondents whose intentions were likely/very likely

\subsubsection{Coping appraisal variables}


Respondents were asked to rate (on a 5-point scale) the effectiveness of each of the six behavioural intentions, phrased as "How effective are the following responses at producing a satisfactory experience, should coral reefs that are mostly white be encountered." Overall, diving outside the region (BIS3) was considered to be the most effective behavioural intention, with $73.6 \%$ of respondents identifying it as effective (M $=3.83, \mathrm{SD}=1.17)$. Diving elsewhere within the region (BIS2) and diving elsewhere within the destination (BIS1) represent the perceived second and third most effective options, with $65.3 \%$ and $56.1 \%$ of respondents rating the behavioural intention as effective respectively $(\mathrm{M}=3.47, \mathrm{SD}=1.19$ and $\mathrm{M}=3.19, \mathrm{SD}=1.27)$. Reducing dive frequency (BIT) was the most effective non-spatial behavioural intention, with $45.2 \%$ of respondents identifying is as effective $(\mathrm{M}=3.11, \mathrm{SD}=1.28)$, while changing one's activity (BIA) received the lowest effectiveness rating, with $61 \%$ of respondents perceiving it to be ineffective $(\mathrm{M}=2.21, \mathrm{SD}=1.22)$. The two groups of divers significantly differed in their perception of the effectiveness of reducing dive frequency, with Canadians perceiving it to be more effective than Australians $(\mathrm{t}=2.07, \mathrm{p}=.040)$.

Respondents were asked to rate (on a 5-point scale) their perceived confidence in carrying out each of the six adaptation behaviours "if the need arose" (e.g., How confident are you in your ability to travel elsewhere in the region to find different dive conditions if the need arose). As with response efficacy, overall, respondents were most confident (in order of decreasing confidence) in their ability to dive elsewhere outside the region $(\mathrm{M}=4.30, \mathrm{SD}=.88)$, dive elsewhere within the region $(\mathrm{M}=3.99, \mathrm{SD}=1.01)$, and dive elsewhere within the destination $(\mathrm{M}=3.76, \mathrm{SD}=1.23)$, with $87.5 \%, 80.9 \%$, and $70.6 \%$ confidence respectively. Aside from spatial behavioural intentions, respondents 
were most confident in their ability to reduce their dive frequency $(\mathrm{M}=3.79, \mathrm{SD}=1.14)$, with $62.7 \%$ of respondents identifying as confident. Similar to response efficacy, change in activity evoked the least amount of confidence (48.5\% not confident, $\mathrm{M}=2.69, \mathrm{SD}=$ 1.38). As with response efficacy, the two groups of divers significantly differed in their ability to reduce dive frequency, with Canadians having a greater perceived ability to alter their dive rate $(\mathrm{t}=4.19, \mathrm{p}<.001)$.

Respondents were asked to rate (on a 5-point scale) the cost of the six behavioural intentions described above (e.g., How much would travelling elsewhere in the region to find different dive conditions cost you?). Diving outside the region $(\mathrm{M}=2.18, \mathrm{SD}=.99)$ and diving elsewhere within the region $(\mathrm{M}=2.67, \mathrm{SD}=1.03)$ represented the highest perceived costs (69\% and $50.5 \%$ of respondents perceived the cost as high respectively), while perceived costs of the other behavioural intentions were similar, with $20 \%$ to $30 \%$ of respondents perceiving the costs as high. As with response efficacy and self-efficacy, the two groups of divers significantly differed in their perception of the cost of reducing dive frequency, with Canadians perceiving temporal adaptation to have a higher cost than Australians $(\mathrm{t}=-2.44, \mathrm{p}=.016)$. For a full summary of the descriptive statistics of coping appraisal variables refer to Table 13 .

Table 13: Descriptive statistics of coping appraisal variables

\begin{tabular}{llcccc}
\hline & & Frequency $^{\wedge}$ & Mean & Std. dev. & $\mathrm{t}$ \\
\hline RES1 & Total & $\mathbf{5 6 . 1 \%}$ & $\mathbf{3 . 1 9}$ & $\mathbf{1 . 2 7}$ & -1.41 \\
& Australian & $57.8 \%$ & 3.33 & 1.24 & \\
& Canadian & $55.1 \%$ & 3.12 & 1.28 & \\
RES2 & Total & $\mathbf{6 5 . 3 \%}$ & $\mathbf{3 . 4 7}$ & $\mathbf{1 . 1 9}$ & -0.92 \\
& Australian & $67.9 \%$ & 3.55 & 1.13 & \\
& Canadian & $63.9 \%$ & 3.42 & 1.22 & \\
RES3 & Total & $\mathbf{7 3 . 6 \%}$ & $\mathbf{3 . 8 3}$ & $\mathbf{1 . 1 7}$ & 0.61 \\
& Australian & $72.4 \%$ & 3.77 & 1.17 & \\
& Canadian & $74.2 \%$ & 3.86 & 1.16 &
\end{tabular}




\begin{tabular}{|c|c|c|c|c|c|}
\hline \multirow[t]{3}{*}{ RET } & Total & $45.2 \%$ & 3.11 & 1.28 & $2.07 *$ \\
\hline & Australian & $37.6 \%$ & 2.91 & 1.21 & \\
\hline & Canadian & $49.4 \%$ & 3.22 & 1.31 & \\
\hline \multirow[t]{3}{*}{ REA } & Total & $18.5 \%$ & 2.21 & 1.22 & 0.04 \\
\hline & Australian & $16.5 \%$ & 2.21 & 1.20 & \\
\hline & Canadian & $19.6 \%$ & 2.22 & 1.24 & \\
\hline \multirow[t]{3}{*}{ REC } & Total & $31.7 \%$ & 2.58 & 1.36 & -1.26 \\
\hline & Australian & $33.9 \%$ & 2.71 & 1.31 & \\
\hline & Canadian & $30.4 \%$ & 2.51 & 1.38 & \\
\hline \multirow[t]{3}{*}{ SES1 } & Total & $70.6 \%$ & 3.76 & 1.23 & -1.59 \\
\hline & Australian & $73.4 \%$ & 3.90 & 1.10 & \\
\hline & Canadian & $69.0 \%$ & 3.68 & 1.29 & \\
\hline \multirow[t]{3}{*}{ SES2 } & Total & $80.9 \%$ & 3.99 & 1.01 & -0.81 \\
\hline & Australian & $84.4 \%$ & 4.05 & 0.86 & \\
\hline & Canadian & $78.8 \%$ & 3.95 & 1.08 & \\
\hline \multirow[t]{3}{*}{ SES3 } & Total & $87.5 \%$ & 4.30 & 0.88 & 0.379 \\
\hline & Australian & $88.1 \%$ & 4.28 & 0.85 & \\
\hline & Canadian & $87.1 \%$ & 4.31 & 0.89 & \\
\hline \multirow[t]{3}{*}{ SET } & Total & $62.7 \%$ & 3.79 & 1.14 & $4.19 * * *$ \\
\hline & Australian & $47.7 \%$ & 3.43 & 1.09 & \\
\hline & Canadian & $71.2 \%$ & 3.98 & 1.12 & \\
\hline \multirow[t]{3}{*}{ SEA } & Total & $31.0 \%$ & 2.69 & 1.38 & -1.04 \\
\hline & Australian & $34.9 \%$ & 2.80 & 1.32 & \\
\hline & Canadian & $28.8 \%$ & 2.63 & 1.41 & \\
\hline \multirow[t]{3}{*}{ SEC } & Total & $41.9 \%$ & 3.11 & 1.30 & -1.80 \\
\hline & Australian & $46.7 \%$ & 3.28 & 1.13 & \\
\hline & Canadian & $39.2 \%$ & 3.01 & 1.39 & \\
\hline \multirow[t]{3}{*}{ RCS1 } & Total & $27.1 \%$ & 3.29 & 1.14 & 0.98 \\
\hline & Australian & $31.2 \%$ & 3.20 & 1.12 & \\
\hline & Canadian & $24.7 \%$ & 3.34 & 1.16 & \\
\hline \multirow[t]{3}{*}{ RCS2 } & Total & $50.5 \%$ & 2.67 & 1.03 & 1.02 \\
\hline & Australian & $55.1 \%$ & 2.59 & 1.01 & \\
\hline & Canadian & $47.9 \%$ & 2.71 & 1.04 & \\
\hline \multirow[t]{3}{*}{ RCS3 } & Total & $69.0 \%$ & 2.18 & 0.99 & 1.75 \\
\hline & Australian & $74.3 \%$ & 2.05 & 0.98 & \\
\hline & Canadian & $66.0 \%$ & 2.25 & 0.99 & \\
\hline \multirow[t]{3}{*}{$\mathrm{RCT}$} & Total & $25.4 \%$ & 3.30 & 1.20 & $-2.44 *$ \\
\hline & Australian & $20.2 \%$ & 3.52 & 1.19 & \\
\hline & Canadian & $28.4 \%$ & 3.18 & 1.20 & \\
\hline \multirow[t]{3}{*}{ RCA } & Total & $24.4 \%$ & 3.23 & 1.18 & 0.54 \\
\hline & Australian & $23.0 \%$ & 3.18 & 1.11 & \\
\hline & Canadian & $25.3 \%$ & 3.26 & 1.23 & \\
\hline \multirow[t]{3}{*}{$\mathrm{RCC}$} & Total & $21.4 \%$ & 3.13 & 1.10 & -1.60 \\
\hline & Australian & $13.7 \%$ & 3.26 & 1.03 & \\
\hline & Canadian & $25.7 \%$ & 3.05 & 1.14 & \\
\hline
\end{tabular}


A: proportion of respondents who perceived adaptation to be effectivelable to perform/costly or very effectivelable to perform/costly

\subsubsection{Threat appraisal variables}

Respondents were asked to rate the perceived likelihood of encountering reefs that are mostly white in the next 5 years while (i) diving at a self-specified dive location or (ii) while diving elsewhere. Approximately half of respondents (51.5\%) think it is likely they will encounter coral bleaching within the next 5 years at the dive place they specified. In contrast, $74.5 \%$ of respondents think it is likely they will encounter coral bleaching in the next 5 years while diving elsewhere. These two items were averaged for a mean score of $2.45(\mathrm{SD}=1.02)$. Australians divers had a significantly greater perceived vulnerability to coral bleaching at a self-specified dive location than Canadian divers $(\mathrm{t}=$ $2.41, \mathrm{p}=.017)$

Respondents were asked to rate the how much satisfaction with (i) their dive, and (ii) their overall trip, would increase/decrease if coral bleaching were encountered. Most respondents $(89.4 \%)$ would experience a decrease in dive satisfaction were coral bleaching to be encountered at the dive place they specified, while a slightly lower proportion $(83.1 \%)$ would experience a decrease in trip satisfaction. These two items were averaged for a mean score of $4.26(\mathrm{SD}=0.84)$. For a full summary of the descriptive statistics of threat appraisal variables refer to Table 14.

Table 14: Descriptive statistics of threat appraisal variables

\begin{tabular}{llccccc}
\hline & & Frequency $^{\wedge}$ & Mean & Std. dev. & $\alpha$ & $\mathrm{t}$ \\
\hline PV1 & Total & $\mathbf{5 1 . 5 \%}$ & $\mathbf{2 . 7 8}$ & $\mathbf{1 . 3 0}$ & & $2.77 * *$ \\
& Australian & $62.4 \%$ & 2.50 & 1.30 & & \\
& Canadian & $45.4 \%$ & 2.93 & 1.28 & & 1.23 \\
PV2 & Total & $\mathbf{7 4 . 5 \%}$ & $\mathbf{2 . 1 1}$ & $\mathbf{1 . 0 3}$ & & \\
& Australian & $\mathbf{7 8 . 9 \%}$ & 2.02 & 0.97 & & \\
& Canadian & $72.0 \%$ & 2.17 & 1.06 & &
\end{tabular}




\begin{tabular}{lllllll} 
PV & Total & $\mathbf{6 4 . 0 \%}$ & $\mathbf{2 . 4 5}$ & $\mathbf{1 . 0 2}$ & 0.76 & $2.41^{*}$ \\
& Australian & $71.6 \%$ & 2.74 & 0.96 & & \\
& Canadian & $59.8 \%$ & 2.45 & 1.02 & & -0.25 \\
PS1 & Total & $\mathbf{8 9 . 4 \%}$ & $\mathbf{4 . 3 7}$ & $\mathbf{0 . 8 6}$ & & \\
& Australian & $90.8 \%$ & 4.39 & 0.78 & & \\
& Canadian & $88.7 \%$ & 4.36 & 0.91 & & -0.62 \\
PS2 & Total & $\mathbf{8 3 . 1 \%}$ & $\mathbf{4 . 1 5}$ & 0.89 & & \\
& Australian & $85.3 \%$ & 4.19 & 0.80 & & -0.46 \\
& Canadian & $82.0 \%$ & 4.13 & 0.94 & \multirow{2}{*}{0.90} & \\
& Total & $\mathbf{8 3 . 0 \%}$ & $\mathbf{4 . 2 6}$ & $\mathbf{0 . 8 4}$ & & \\
& Australian & $84.4 \%$ & 4.29 & 0.75 & & \\
& Canadian & $82.5 \%$ & 4.25 & 0.89 & &
\end{tabular}

A: proportion of respondents who perceived bleaching to be likely/very likely or would experience a decrease/strong decrease in satisfaction

\subsection{Bivariate correlations of independent and dependent variables}

Before testing the PMT models, bivariate correlations between the independent variables were examined to determine whether or not the PMT variables could be distinguished empirically to reduce estimation biases. Appendix F shows bivariate correlations among the independent variables, and between the independent and dependent variables of the six PMT models. Most bivariate correlations between independent variables are below 0.5 , suggesting they do not strongly overlap. Somewhat stronger bivariate correlations were observed between the response efficacy and selfefficacy constructs in the activity adaptation $(r=0.53)$ and cognitive adaptation $(r=0.62)$ models. However, neither bivariate correlation exceeds the critical 0.75 threshold, which indicates that multicollinearity problems are unlikely. The moderate linear relationship between response and self-efficacies will be referred to when interpreting regression results.

\subsection{Predicting behavioural intentions using Protection Motivation Theory}

A series of regression analyses were conducted to test the hypothesized 
relationships between perceived severity, perceived vulnerability, response efficacy, selfefficacy, and response cost and behavioural intentions:

H1: As perceived vulnerability increases, intention to adapt increases $\mathrm{H} 2$ : As perceived severity increases, intention to adapt increases H3: As perceived effectiveness of an adaptation increases, intention to adapt increases

H4: As perceived ability to carry out adaptation increases, intention to adapt increases

H5: As perceived cost increases, intention to adapt decreases

Separate regression analyses were run for each type of adaptation, such that the coping appraisal predictors were restricted to the corresponding behavioural intention. For example, for activity behavioural intentions, the model included activity behavioural intention efficacy, activity adaptation self-efficacy, and activity behavioural intention cost.

\subsubsection{Model fit}

Results from the regression analyses run on the total sample revealed that threat and coping appraisal variables were able to explain between $12.8 \%$ and $47.7 \%$ of the variance in behavioural intentions, a statistically significant amount of the total variance in all of the models $(\mathrm{p}<.001)$. Figure 13 visually depicts the range in explained variance for the different adaptation models. Separate regression analyses run on the Canadian and Australian sub-samples suggest that the models work well for both dive groups, similarly explaining between $10.4 \%$ and $48.6 \%$ of explained variance. 
Cognitive

Temporal

Activity Intra- Intra- Inter-

destination regional regional

\section{Highest \\ explained \\ variance}

Lowest

explained

variance

Figure 13: Visualization of the range in explained variance of the different adaptation models

PMT was able to explain the greatest amount of variance for cognitive $\left(\mathrm{R}^{2}=.477\right.$,

$\left.\mathrm{F}_{5,29}=59.36, \mathrm{p}<.001\right)$ and activity $\left(\mathrm{R}^{2}=.365, \mathrm{~F}_{5,29}=35.70, \mathrm{p}<.001\right)$ behavioural intentions, while explaining markedly less variance for intra-regional $\left(\mathrm{R}^{2}=.128, \mathrm{~F}_{5,29}=\right.$ $9.90, \mathrm{p}<.001)$ and inter-regional $\left(\mathrm{R}^{2}=.143, \mathrm{~F}_{5,29}=11.04, \mathrm{p}<.001\right)$ adaptation. For all but cognitive behavioural intentions, PMT explained a greater amount of variance for Australian divers. However, comparison of model fit revealed no significant differences. Refer to Table 15 for full regression results relating to model fit.

Table 15: Regression models for PMT variables predicting behavioural intentions

\begin{tabular}{|c|c|c|c|c|}
\hline & & adj. $\mathbf{R}^{2}$ & $\mathbf{F}_{(s, \text { dr })}$ & $\mathbf{Z}$ \\
\hline Intra-destination & Total & $.247 * * *$ & 20.86 & \multirow{3}{*}{-.54} \\
\hline behavioural intentions & Australian & $.262 * * *$ & 8.66 & \\
\hline$(\mathrm{BIS} 1)$ & Canadian & $.225 * * *$ & 12.24 & \\
\hline Intra-regional & Total & $.128 * * *$ & 9.90 & \multirow[t]{3}{*}{-1.03} \\
\hline behavioural intentions & Australian & $.173 * * *$ & 5.52 & \\
\hline$(\mathrm{BIS} 2)$ & Canadian & $.104 * * *$ & 5.46 & \\
\hline Inter-regional & Total & $.143 * * *$ & 11.04 & \multirow[t]{3}{*}{-.55} \\
\hline behavioural intentions & Australian & $.160 * * *$ & 5.12 & \\
\hline$(\mathrm{BIS} 3)$ & Canadian & $.130 * * *$ & 6.79 & \\
\hline Temporal behavioural & Total & $.185 * * *$ & 14.74 & \multirow[t]{3}{*}{-.23} \\
\hline \multirow[t]{2}{*}{ intentions (BIT) } & Australian & $.170 * * *$ & 5.44 & \\
\hline & Canadian & $.168 * * *$ & 8.79 & \\
\hline Activity behavioural & Total & $.365 * * *$ & 35.70 & \multirow[t]{3}{*}{-1.14} \\
\hline \multirow[t]{2}{*}{ intentions (BIA) } & Australian & $.426 * * *$ & 17.01 & \\
\hline & Canadian & $.329 * * *$ & 19.97 & \\
\hline Cognitive behavioural & Total & $.477 * * *$ & 59.36 & .40 \\
\hline
\end{tabular}


intentions (BIC) Australian $\quad .463 * * * \quad 19.59$

Canadian $.486 * * * \quad 40.80$

Note: df2 is 297 for total sample, 103 for Australian sample, and 188 for Canadian sample

\subsubsection{Regression coefficients}

Figure 14 visually depicts the direction of each threat and coping appraisal variables' relationship with behavioural intentions, as well as the relative size of the regression coefficients (generally observed across the different adaptation models).

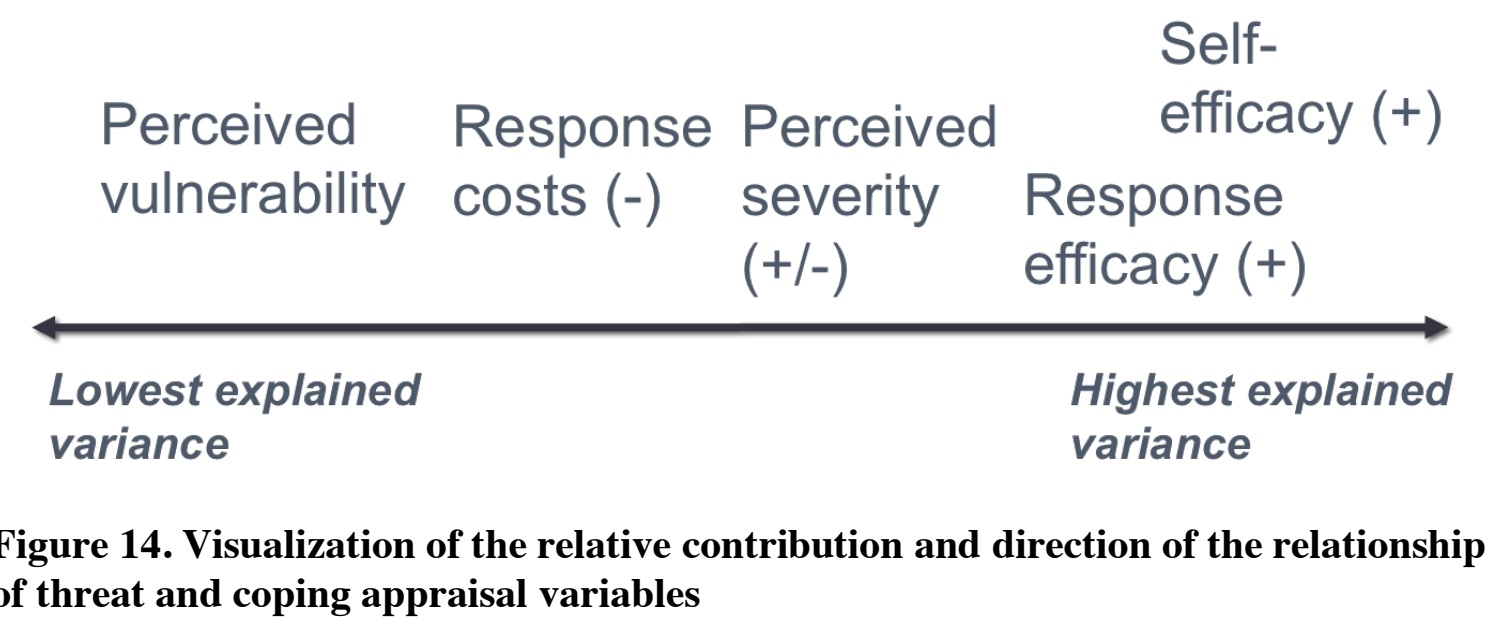

The first hypothesis predicted that greater perceived vulnerability would be associated with stronger behavioural intentions. However, perceived vulnerability was not a significant predictor of any behavioural intentions, and in fact emerged as a negative, though non-significant predictor of intra-destination $(\beta=-.026, \mathrm{p}=.608)$ behavioural intentions (Error! Reference source not found.).

The second hypothesis predicted that a greater perceived threat would be associated with stronger behavioural intentions. This relationship held true for interregional $(\beta=.192, \mathrm{p}=.003)$ and temporal behavioural intentions $(\beta=.242, \mathrm{p}<.001)$, for which perceived severity was a significant positive predictor, but did not hold true for 
intra-destination $(\beta=-.119, \mathrm{p}=.021)$ or cognitive $(\beta=-.132, \mathrm{p}=.004)$ behavioural intentions, for which perceived severity was a significant negative predictor, suggesting this hypothesis was partially met. Perceived severity was not a significant predictor for intra-regional $(\beta=-.002, \mathrm{p}=.969)$ or activity $(\beta=.014, \mathrm{p}=.765)$ behavioural intentions (Table 16).

The third hypothesis predicted that greater perceived effectiveness of an adaptation at addressing the threat (i.e., avoiding dissatisfaction as a result of encountering coral bleaching) would be associated with stronger behavioural intentions. This hypothesis held true across the different behavioural intentions, with response efficacy emerging as a significant positive predictor for all but intra-regional behavioural intentions, in which case the predictor was not significant $(\beta=.103, \mathrm{p}=.077)$ (Table 16).

The fourth hypothesis predicted that greater perceived ability to carry out an adaptation would be associated with stronger behavioural intentions. This hypothesis held true across the different behavioural intentions, with self-efficacy emerging as a significant positive predictor for all behavioural intentions (Table 16). Furthermore, selfefficacy consistently contributed the most to explained variance, emerging as the largest significant predictor for all but temporal behavioural intentions, where perceived severity was a marginally larger predictor $(\beta=.242, \mathrm{p}<.001$ vs. $\beta=.220, \mathrm{p}<.001)$ (Table 16$)$.

The fifth hypothesis predicted that lower perceived response cost would be associated with stronger behavioural intentions. While this relationship held true across the different behavioural intentions, response cost was only a significant negative predictor of intra-regional $(\beta=-.151, \mathrm{p}=.007)$ and inter-regional behavioural intentions $(\beta=-.120, \mathrm{p}=.030)$, providing mixed support for hypothesis 5 (Table 16). 
Table 16: Regression coefficients for threat and coping appraisal variables predicting behavioural intentions

\begin{tabular}{|c|c|c|c|c|}
\hline & & B & SE & $\beta$ \\
\hline \multirow{6}{*}{$\begin{array}{l}\text { Perceived } \\
\text { vulnerability } \\
(\mathrm{PV})\end{array}$} & BIS1 & -.038 & .074 & -.026 \\
\hline & BIS2 & .064 & .068 & .051 \\
\hline & BIS3 & .080 & .051 & .084 \\
\hline & BIT & .061 & .058 & .055 \\
\hline & BIA & .055 & .059 & .043 \\
\hline & $\mathrm{BIC}$ & .041 & .052 & .033 \\
\hline \multirow{6}{*}{$\begin{array}{l}\text { Perceived } \\
\text { severity (PS) }\end{array}$} & BIS1 & -.196 & .091 & $-.119 *$ \\
\hline & BIS2 & -.003 & .083 & -.002 \\
\hline & BIS3 & .227 & .062 & $.192 * *$ \\
\hline & BIT & .324 & .070 & $.242 * * *$ \\
\hline & BIA & .022 & .073 & .014 \\
\hline & $\mathrm{BIC}$ & -.200 & .067 & $-.132 * *$ \\
\hline \multirow{6}{*}{$\begin{array}{l}\text { Response } \\
\text { efficacy (RE) }\end{array}$} & BIS1 & .159 & .068 & $.137 *$ \\
\hline & BIS2 & .110 & .062 & .103 \\
\hline & BIS3 & .113 & .046 & $.138 *$ \\
\hline & BIT & .192 & .049 & $.242 * * *$ \\
\hline & BIA & .301 & .059 & $.283 * * *$ \\
\hline & $\mathrm{BIC}$ & .216 & .051 & $.231 * * *$ \\
\hline \multirow{6}{*}{$\begin{array}{l}\text { Self-efficacy } \\
\text { (SE) }\end{array}$} & BIS1 & .466 & 0.69 & $.389 * * *$ \\
\hline & BIS2 & .380 & .073 & $.302 * * *$ \\
\hline & BIS3 & .304 & .061 & $.278 * * *$ \\
\hline & BIT & .217 & .055 & $.220 * * *$ \\
\hline & BIA & .395 & .051 & $.418 * * *$ \\
\hline & BIC & .471 & .052 & $.484 * * *$ \\
\hline \multirow{6}{*}{$\begin{array}{l}\text { Response } \\
\text { cost (RC) }\end{array}$} & BIS1 & -.070 & .066 & -.055 \\
\hline & BIS2 & -.187 & .068 & $-.151 * *$ \\
\hline & BIS3 & -.116 & .053 & $-.120 *$ \\
\hline & BIT & -.011 & .049 & -.012 \\
\hline & BIA & -.007 & .051 & -.006 \\
\hline & $\mathrm{BIC}$ & -.037 & .048 & -.032 \\
\hline
\end{tabular}

$* p<.05, * * p<.01, * * * p<.001$

\subsection{Differences in prediction of behavioural intentions by geographic proximity}

A series of regression analyses with a dummy variable for nationality (Nat) and

interaction terms for group membership with PMT variables were conducted to identify

what effects, if any, differ across Canadians and Australians. As with the regressions run on the entire sample outlined in the previous section, separate regression analyses were 
run for each type of adaptation, such that the coping appraisal predictors were restricted to the corresponding behavioural intention.

Table 17 contains the unstandardized coefficients (B) for all six behavioural intentions. There is only one significant difference in effect of independent variables between the two samples. Specifically, the effect of perceived severity has a significantly greater effect on cognitive behavioural intentions for Australian divers than Canadian divers $(\mathrm{B}=-.290, \mathrm{p}=.049)$. That is to say, the severity of a threat has more meaning to Australian divers when it comes to accepting a situation of coral bleaching.

Table 17: Differences in behavioural intentions by geographic proximity

\begin{tabular}{|c|c|c|c|c|}
\hline & & Interactions & Canadians only & Australians only \\
\hline \multirow[t]{6}{*}{ PV } & BIS1 & .117 & -.060 & .057 \\
\hline & BIS2 & .097 & .044 & .141 \\
\hline & BIS3 & .033 & .087 & .100 \\
\hline & BIT & .041 & .040 & .081 \\
\hline & BIA & .177 & -.008 & .169 \\
\hline & BIC & .024 & .023 & .046 \\
\hline \multirow[t]{6}{*}{ PS } & BIS1 & -.017 & -.202 & -.219 \\
\hline & BIS2 & -.030 & .016 & -.014 \\
\hline & BIS3 & -.143 & $.227 * *$ & .083 \\
\hline & BIT & -.030 & $.342 * * *$ & $.312 *$ \\
\hline & BIA & -.081 & .041 & -.040 \\
\hline & $\mathrm{BIC}$ & $-.290 *$ & -.112 & $-.402 * *$ \\
\hline \multirow[t]{6}{*}{$\mathrm{RE}$} & BIS1 & .171 & .095 & $.267 *$ \\
\hline & BIS2 & .110 & .075 & .184 \\
\hline & BIS3 & -.030 & $.127 *$ & .150 \\
\hline & BIT & .122 & $.151 * *$ & $.273 * *$ \\
\hline & BIA & .162 & $.245 * * *$ & $.407 * * *$ \\
\hline & $\mathrm{BIC}$ & .063 & $.191 * *$ & $.254 * *$ \\
\hline \multirow[t]{6}{*}{ SE } & BIS1 & -.115 & $.487 * * *$ & $.371 * * *$ \\
\hline & BIS2 & -.150 & $.406 * * *$ & $.256^{*}$ \\
\hline & BIS3 & -.026 & $.317 * * *$ & $.325 * * *$ \\
\hline & BIT & .007 & $.206 * *$ & $.213^{*}$ \\
\hline & BIA & -.015 & $.400 * * *$ & $.385 * * *$ \\
\hline & BIC & -.072 & $.485 * * *$ & $.413 * * *$ \\
\hline \multirow[t]{5}{*}{$\mathrm{RC}$} & BIS1 & .128 & -.112 & .016 \\
\hline & BIS2 & -.156 & -.129 & $-.286^{* *}$ \\
\hline & BIS3 & .023 & -.120 & -.125 \\
\hline & BIT & -.052 & .013 & -.039 \\
\hline & BIA & .073 & -.037 & .036 \\
\hline
\end{tabular}




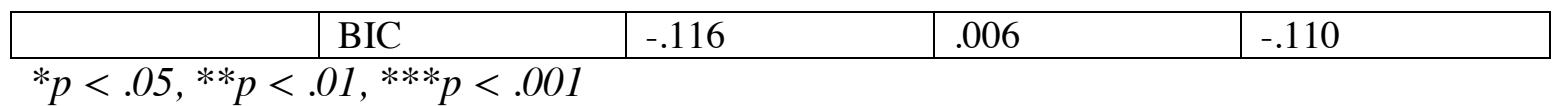




\section{MEDIATION OF ACTIVITY INVOLVEMENT AND PLACE ATTACHMENT}

This chapter reports the results of a set of mediation analyses that were conducted to test the direct and indirect nature of the relationships between attachment variables and behavioural intentions. Comparisons across behavioural intentions are made with respect to attachment variables that contributed significant direct and/or indirect effects, evaluating the size and nature of the relationship, as well as which threat and coping appraisal variables functioned as mediators.

\subsection{Descriptive statistics}

\subsubsection{Place attachment}

Place attachment was measured using Williams and Roggenbuck's (1989) twodimensional conceptualization of place dependence and place identity. Respondents scored higher on questions related to their symbolic/emotional attachment to place, with a mean place identity score of 3.95 on a scale of $5(\mathrm{SD}=0.85)$. Questions of how well a space facilitates diving relative to alternative places (i.e., place dependence) produced a score of 2.74 on a scale of $5(\mathrm{SD}=1.03)$. The place attachment index was calculated by averaging all place attachment items for a mean score of $3.35(\mathrm{SD}=0.82)$. Canadian and Australian divers only significantly differed in their place identity scores, with Australian divers showing a greater emotional attachment to place $(\mathrm{t}=-2.28, \mathrm{p}=.024)$. Table 18 summarizes the descriptive statistics for place attachment variables.

Table 18: Descriptive statistics of place attachment variables

\begin{tabular}{llllll}
\hline & & Mean & $\begin{array}{l}\text { Std. } \\
\text { dev. }\end{array}$ & $\alpha$ & $\mathrm{t}$ \\
\hline Place & Total & $\mathbf{2 . 7 4}$ & $\mathbf{1 . 0 3}$ & 0.89 & -.268 \\
dependence & Australian & 2.76 & 0.98 & &
\end{tabular}




\begin{tabular}{llllll} 
& Canadian & 2.73 & 1.05 & & \\
Place identity & Total & $\mathbf{3 . 9 5}$ & $\mathbf{0 . 8 5}$ & 0.84 & $-2.28^{*}$ \\
& Australian & 4.10 & 0.77 & & \\
& Canadian & 3.89 & 0.88 & & \\
\hline Place & Total & $\mathbf{3 . 3 5}$ & $\mathbf{0 . 8 2}$ & 0.88 & 1.34 \\
attachment & Australian & 2.57 & 0.76 & & \\
index & Canadian & 2.67 & 0.85 & & \\
\hline$* p<.05, * * p<.01, * * * p<.001$ & & & &
\end{tabular}

\subsubsection{Activity involvement}

Activity involvement was assessed using the five items of the Modified Involvement Scale (Kyle et al., 2007). Attraction, or the importance of an activity to an individual's life, was the highest rated of these dimensions, with a mean score of 4.66 on a scale of $5(\mathrm{SD}=0.59)$. The ability to express oneself through diving (i.e., identity affirmation) was the next highest dimension. The remaining dimensions of centrality (M $=3.73, \mathrm{SD}=1.12)$, social bonding $(\mathrm{M}=3.83, \mathrm{SD}=0.84)$, and identity expression $(\mathrm{M}=$ $3.80, \mathrm{SD}=0.87)$ had similar mean scores. The activity involvement index was calculated by averaging all activity involvement items for a mean score of $4.03(\mathrm{SD}=0.66)$.

Australian and Canadian divers did not significantly differ in their activity involvement.

Table 19 summarizes the descriptive statistics for activity involvement variables.

Table 19: Descriptive statistics of activity involvement variables

\begin{tabular}{llcccc}
\hline & & Mean & Std. dev. & $\alpha$ & $\mathrm{t}$ \\
\hline Attraction & Total & $\mathbf{4 . 6 6}$ & $\mathbf{0 . 5 9}$ & 0.86 & .018 \\
& Australian & 4.66 & 0.54 & & \\
Canadian & 4.66 & 0.61 & & \\
Tentrality & Total & $\mathbf{3 . 7 3}$ & $\mathbf{1 . 1 2}$ & 0.91 & .341 \\
& Australian & 3.70 & 1.11 & & \\
Social bonding & Canadian & 3.75 & 1.13 & & \\
& Total & $\mathbf{3 . 8 3}$ & $\mathbf{0 . 8 4}$ & 0.74 & .362 \\
Identity expression & Australian & 3.85 & 0.83 & & \\
& Canadian & 3.82 & 0.84 & & \\
& Total & $\mathbf{3 . 8 0}$ & $\mathbf{0 . 8 7}$ & 0.77 & .152 \\
& Australian & 3.79 & 0.79 & & \\
& Canadian & 3.80 & 0.91 & &
\end{tabular}




\begin{tabular}{llllll} 
Identity affirmation & Total & $\mathbf{4 . 1 0}$ & $\mathbf{0 . 7 7}$ & 0.76 & .228 \\
& Australian & 4.10 & 0.64 & & \\
& Canadian & 4.12 & 0.84 & & \\
\hline Activity involvement & Total & $\mathbf{4 . 0 3}$ & $\mathbf{0 . 6 6}$ & 0.88 & .121 \\
index & Australian & 4.02 & 0.58 & & \\
& Canadian & 4.03 & 0.70 & & \\
\hline$* p<.05, * * p<.01, * * * p$ & $<.001$ & & & & \\
&
\end{tabular}

\subsection{Bivariate correlations}

Appendix F shows the bivariate correlations among the independent, mediator, and dependent variables. Activity involvement correlated significantly with place attachment, cognitive response efficacy, activity self-efficacy and response costs, temporal response costs, and activity behavioural intentions; place attachment correlated significantly with response costs for all behavioural intentions, as well as intradestination, inter-regional, and temporal behavioural intentions, and inter-regional and temporal response and self-efficacies. Bivariate correlations for attachment variables were all below 0.5 , suggesting they do not strongly overlap.

\subsection{Direct and indirect effects of activity involvement and place attachment}

Mediation analysis was run to determine whether the relationship between activity involvement and place attachment and behavioural intentions is linked via threat and coping appraisal variables (refer to Figure 5 for conceptual diagram) using Hayes’ PROCESS Model 4, a multiple mediator model (Hayes, 2013). In order for a mediator to carry X's effect on $\mathrm{Y}$, it is assumed that $\mathrm{X}$ causes $\mathrm{M}$, which in turn causes $\mathrm{Y}$ (Hayes, 2017), thus the relationship between attachment and PMT variables is also considered.

\subsubsection{Model fit}

Direct effect (i.e., effects of independent variables and mediators on dependent variable) and total effect (i.e., sum of direct and indirect effects of independent variables 
on dependent variable) models were produced for each of the six adaptation behaviours (Table 20). Similar to the previously run regression analyses, the variance explained by the direct effect models ranged from $14.4 \%$ to $49.7 \%$, with cognitive $\left(\mathrm{R}^{2}=.50, \mathrm{~F}_{7,25}=\right.$ 41.67, $\mathrm{p}<.001)$ and activity $\left(\mathrm{R}^{2}=.40, \mathrm{~F}_{7,295}=27.63, \mathrm{p}<.001\right)$ behavioural intentions having the greatest explained variance, and intra-regional $\left(\mathrm{R}^{2}=.14, \mathrm{~F}_{7.295}=7.11, \mathrm{p}<.001\right)$ and inter-regional $\left(\mathrm{R}^{2}=.16, \mathrm{~F}_{7,295}=8.18, \mathrm{p}<.001\right)$ behavioural intentions the least explained variance.

However, comparing model fits derived from PMT variables (Table 15) suggests the contribution of attachment variables ranged from $0 \%$ to $3.1 \%$ in additional explained variance when included as direct predictors with threat and coping appraisal variables.

Results from the total effects model, which considers both the direct and indirect effects of the attachment variables, parallel this finding. Attachment variables explained between $0 \%$ and $5.4 \%$ of the variance in behavioural intentions, which was statistically significant for intra-destination $\left(\mathrm{R}^{2}=.03, \mathrm{~F}_{2,300}=4.41, \mathrm{p}=.013\right)$, temporal $\left(\mathrm{R}^{2}=.02, \mathrm{~F}_{2,300}=3.10, \mathrm{p}=\right.$ $.046)$, and activity behavioural intentions $\left(\mathrm{R}^{2}=.05, \mathrm{~F}_{2,300}=8.63, \mathrm{p}<.001\right)$.

Table 20: Direct and total effect models for attachment variables predicting behavioural intentions

\begin{tabular}{lcccc}
\hline & \multicolumn{2}{c}{$\begin{array}{c}\text { Direct effect } \\
\text { model }\end{array}$} & \multicolumn{2}{c}{$\begin{array}{c}\text { Total effect } \\
\text { model }\end{array}$} \\
& $\mathbf{R}^{2}$ & $\mathbf{F}_{7,25}$ & $\mathbf{R}^{2}$ & $\mathbf{F}_{2,300}$ \\
\hline Intra-destination behavioural intentions & $.29 * * *$ & 17.27 & $.03 *$ & 4.41 \\
(BIS1) & & & & \\
Intra-regional behavioural intentions (BIS2) & $.14 * * *$ & 7.11 & .00 & 0.25 \\
Inter-regional behavioural intentions (BIS3) & $.16 * * *$ & 8.18 & .01 & 2.15 \\
Temporal behavioural intentions (BIT) & $.20 * * *$ & 10.85 & $.02 *$ & 3.10 \\
Activity behavioural intentions (BIA) & $.40 * * *$ & 27.63 & $.05 * * *$ & 8.63 \\
Cognitive behavioural intentions (BIC) & $.50 * * *$ & 41.67 & .02 & 2.78 \\
\hline$* p<.05, * * p<.01, * * * p<.001$ & & & &
\end{tabular}




\subsubsection{Intra-destination behavioural intentions}

Activity involvement had no significant direct or indirect effects on intradestination behavioural intentions or any threat or coping appraisal variables. Place attachment had a significant positive direct $(\mathrm{B}=.33, \mathrm{p}<.001)$ and total $(\mathrm{B}=.32, \mathrm{p}<$ .001) effect on intra-destination behavioural intentions, suggesting a greater attachment to place is associated with stronger intentions to change dive location within a destination. As well, place attachment had a significant positive effect on response costs $(\mathrm{B}=.21, \mathrm{p}=$ .01 ), indicating stronger place attachment is associated with a higher response cost.

Figure 15 and Figure 16 summarize the relationships between intra-destination behavioural intentions (BIS1) and leisure involvement and place attachment respectively via threat and coping appraisal variables.

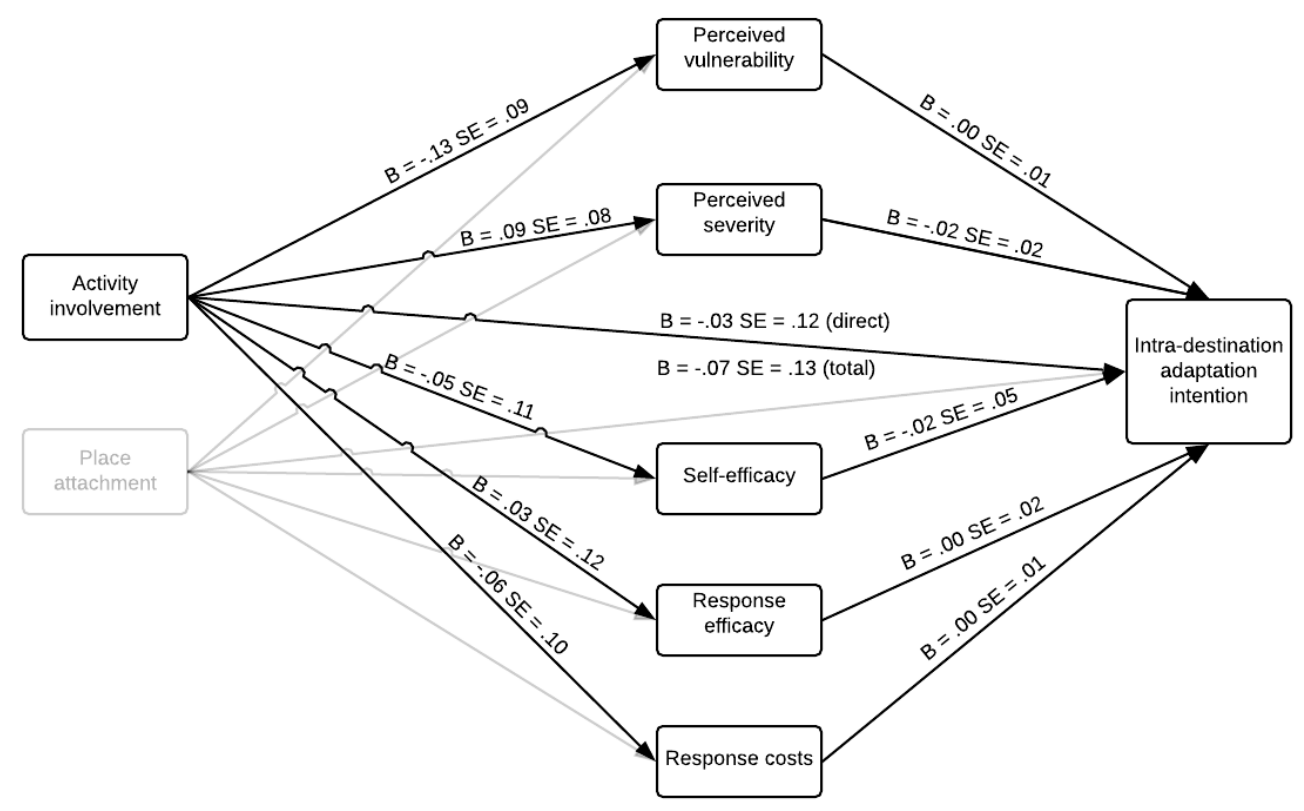

Figure 15: Relationship between activity involvement and intra-destination behavioural intentions (BIS1) via threat and coping appraisal variables 


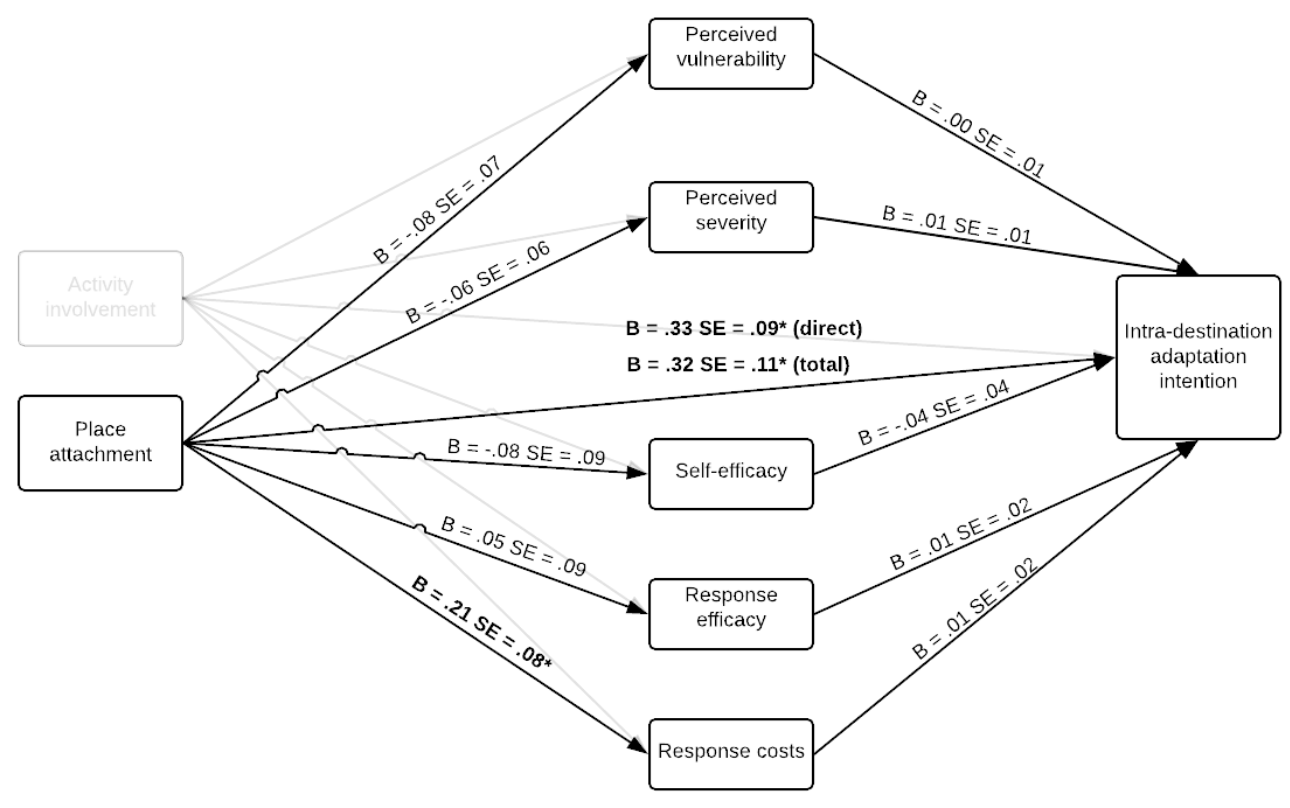

Figure 16: Relationship between place attachment and intra-destination behavioural intentions (BIS1) via threat and coping appraisal variables

\subsubsection{Intra-regional behavioural intentions}

As at the scale of intra-destination, activity involvement did not have any significant direct or indirect effect on intra-regional behavioural intentions. Place attachment similarly had no significant direct or indirect effect, but continued to have a significant positive effect on response costs $(B=.14, \mathrm{p}=.05)$. Figure 17 and Figure 18 summarize the relationships between intra-regional behavioural intentions (BIS2) and leisure involvement and place attachment respectively via threat and coping appraisal variables. 


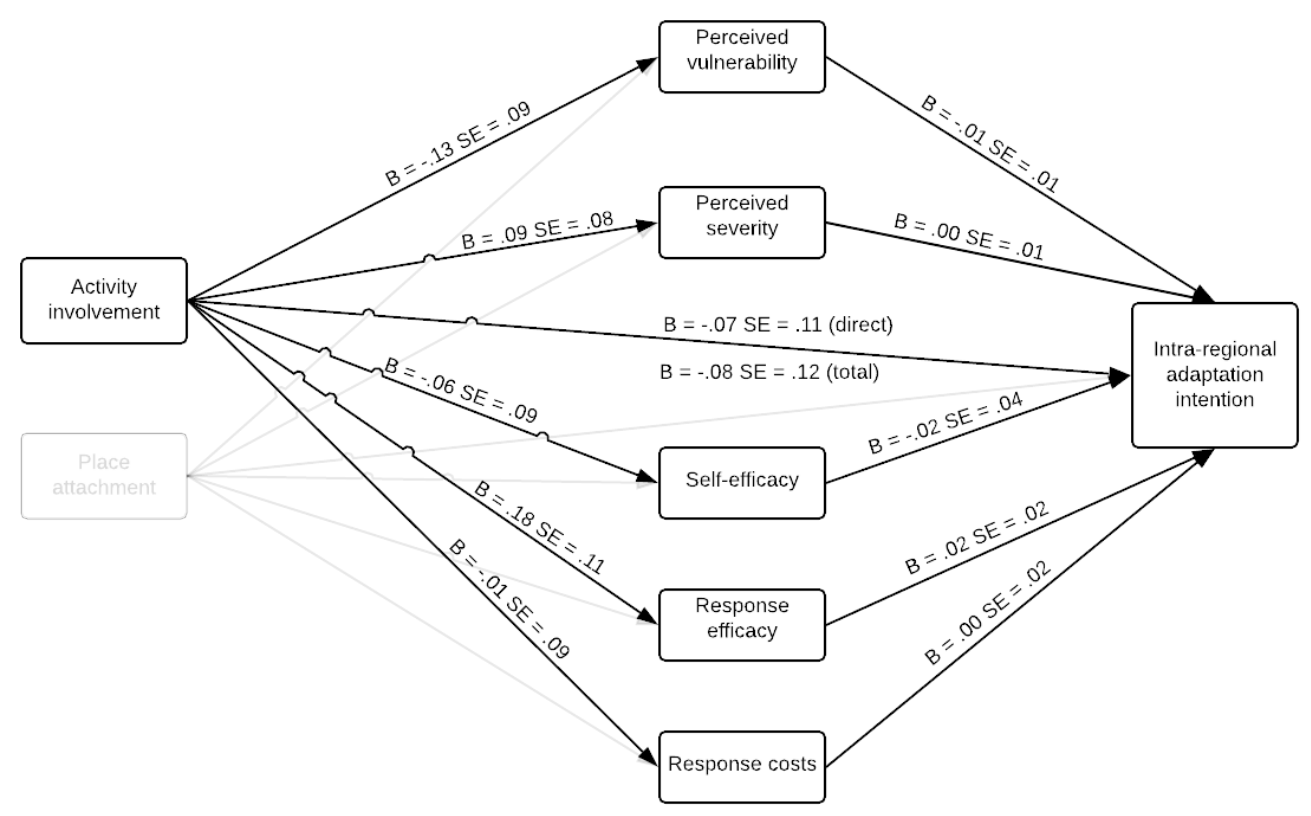

Figure 17: Relationship between activity involvement and intra-regional behavioural intentions (BIS2) via threat and coping appraisal variables

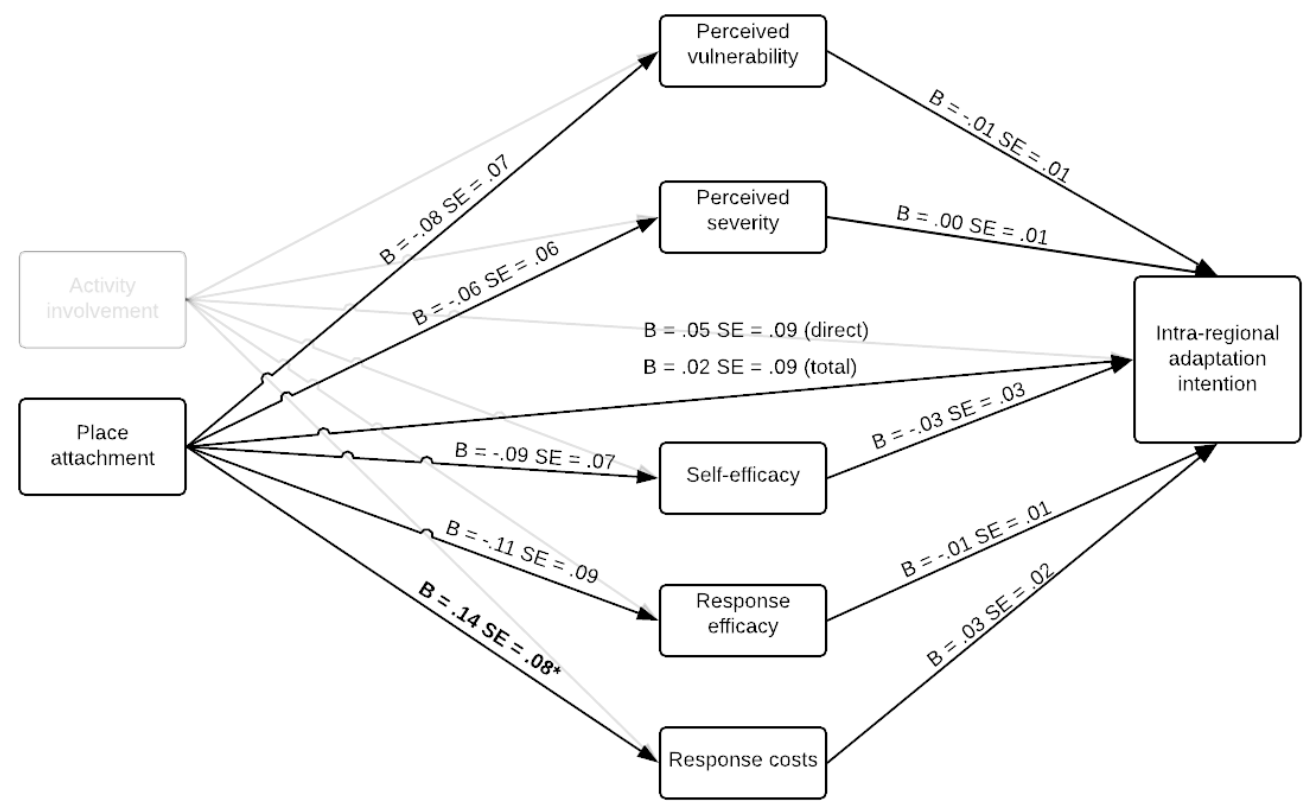

Figure 18: Relationship between place attachment and intra-regional behavioural intentions (BIS2) via threat and coping appraisal variables

\subsubsection{Inter-regional behavioural intentions}


As within a destination and within a region, activity involvement had no significant direct or indirect effect on inter-regional behavioural intentions. Place attachment similarly did not have a significant direct or indirect effect, but continued to have a significant positive effect on response costs $(\mathrm{B}=.18, \mathrm{p}=.01)$, as well as having a significant negative effect on self-efficacy $(B=-.14, p=.04)$ and response efficacy $(B=-$ $.20, \mathrm{p}=.02)$. This suggests that, when considering travelling outside a region, stronger place attachment is associated with greater cost, less perceived ability to carry out said adaptation, and less perceived effectiveness in the behavioural intention. Figure 19 and Figure 20 summarize the relationships between inter-regional behavioural intentions (BIS3) and leisure involvement and place attachment respectively via threat and coping appraisal variables.

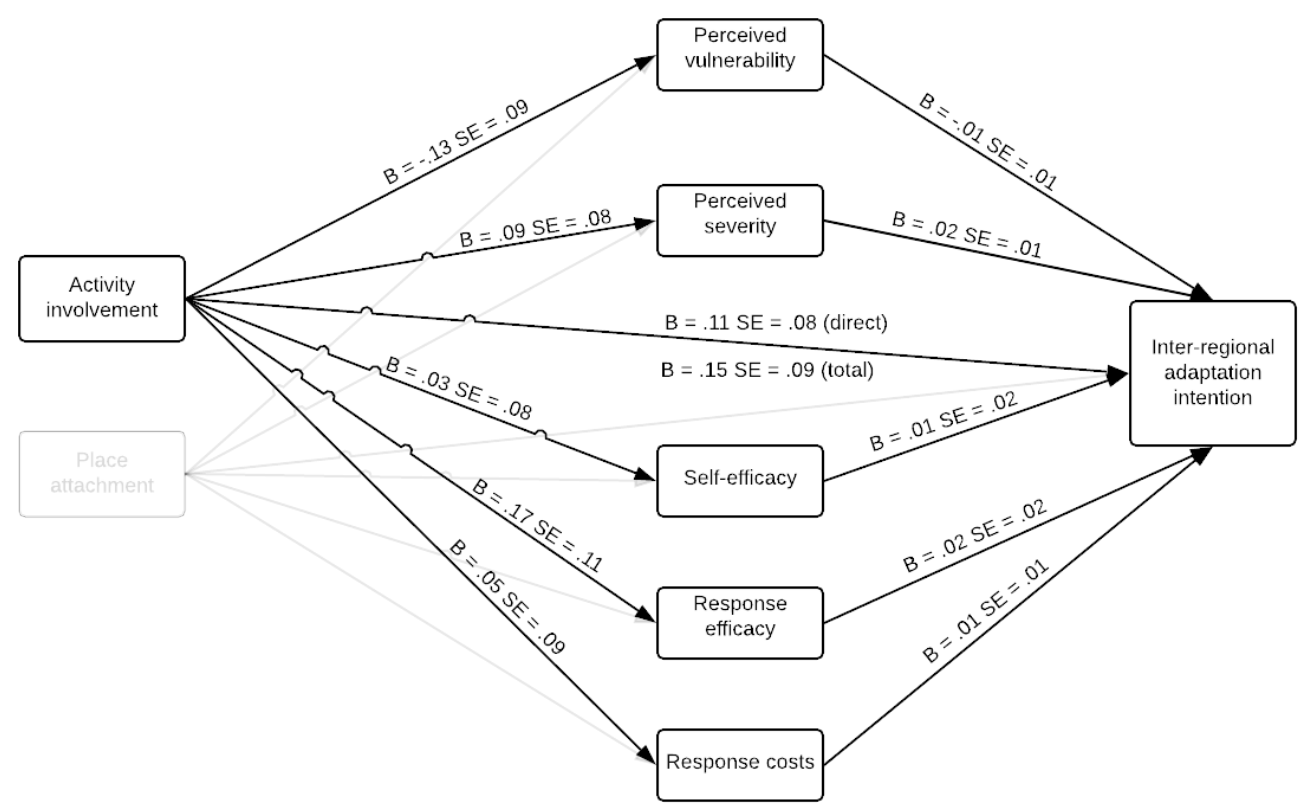

Figure 19: Relationship between activity involvement and inter-regional behavioural intentions (BIS3) via threat and coping appraisal variables 


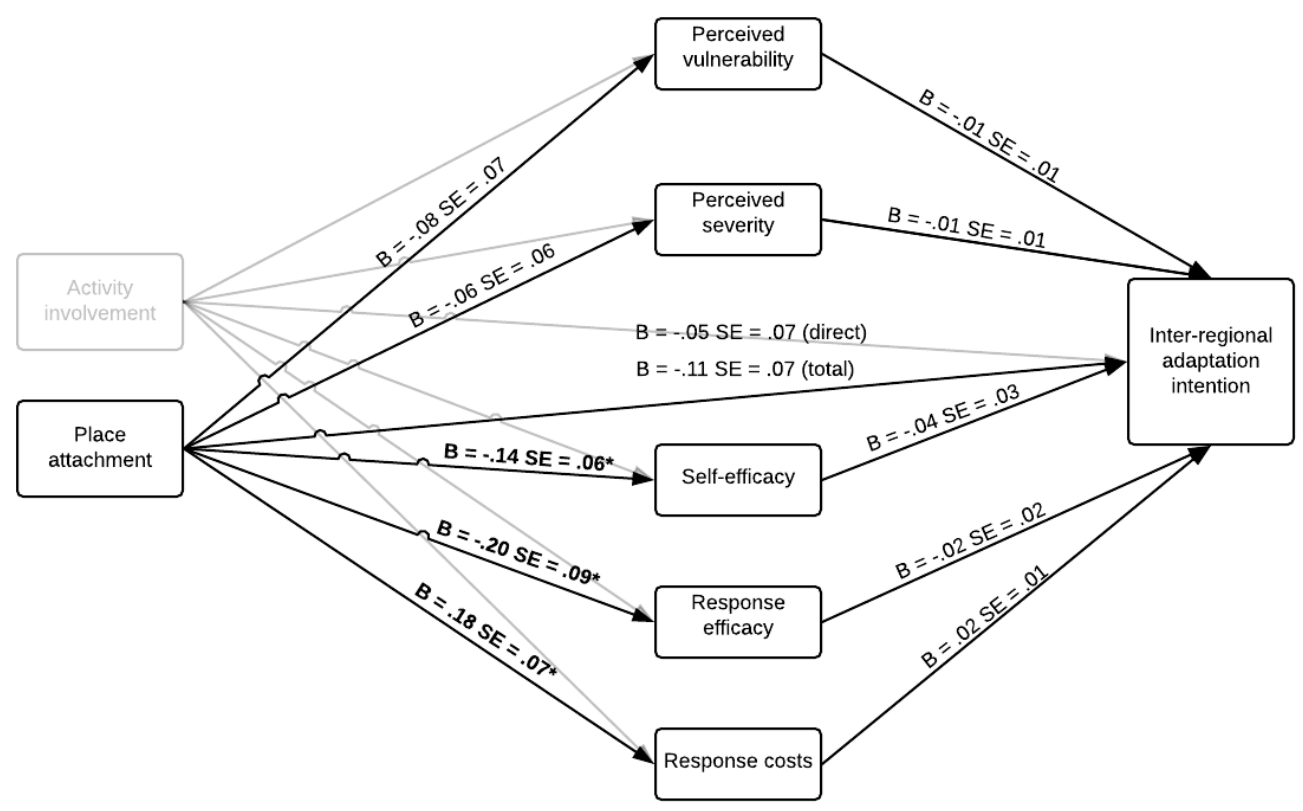

Figure 20: Relationship between place attachment and inter-regional behavioural intentions (BIS3) via threat and coping appraisal variables

\subsubsection{Temporal behavioural intentions}

Activity involvement had a significant positive indirect effect on temporal behavioural intentions via response efficacy $(B=.06,95 \% \mathrm{CI}: .02$ to 13$)$, suggesting the perceived effectiveness of reducing dive frequency helps explain why activity involvement predicts an increased likelihood of temporal adaptation. Activity involvement had a significant positive effect on response efficacy $(B=.30, p=.01)$.

Place attachment had a significant negative total effect on temporal behavioural intentions $(\mathrm{B}=-.18, \mathrm{p}=.03)$, suggesting a stronger attachment to place is associated with lesser intentions to reduce dive frequency. Specifically, place attachment also had significant negative indirect effects via self-efficacy ( $\mathrm{B}=-.08,95 \% \mathrm{CI}$ : -.14 to -.03 ) and response efficacy $(\mathrm{B}=-.06,95 \% \mathrm{CI}:-.12$ to -.02$)$. This suggests that ability to reduce dive frequency and perceived effectiveness of doing so help to explain why place attachment 
predicts a decreased likelihood of temporal adaptation. Place attachment had a significant negative effect on self-efficacy $(B=-.38, p<.001)$, response efficacy $(B=-.29, p<$ $.001)$, and significant positive effect on response costs $(\mathrm{B}=.20, \mathrm{p}=.02)$.

Figure 21 and Figure 22 summarize the relationships between temporal behavioural intentions (BIT) and leisure involvement and place attachment respectively via threat and coping appraisal variables.

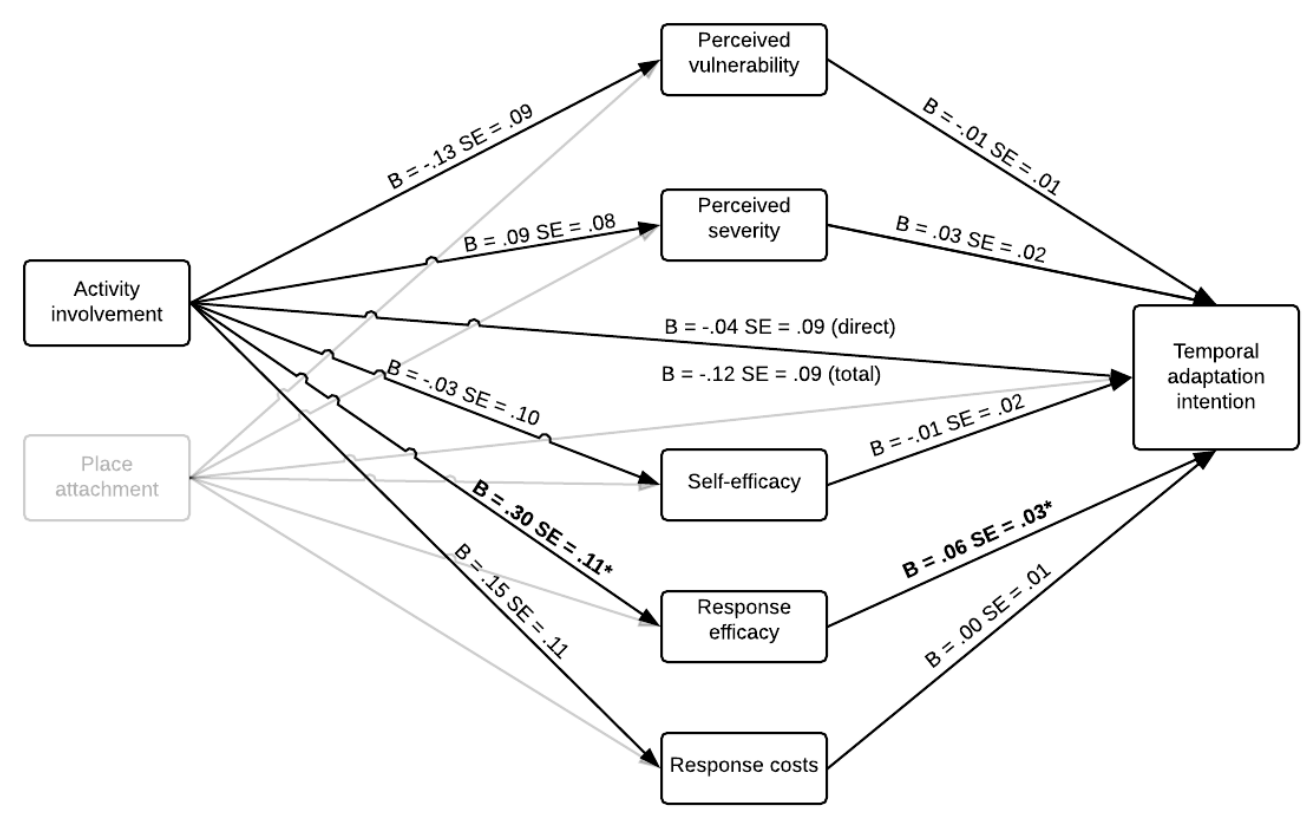

Figure 21: Relationship between activity involvement and temporal behavioural intentions (BIT) via threat and coping appraisal variables 


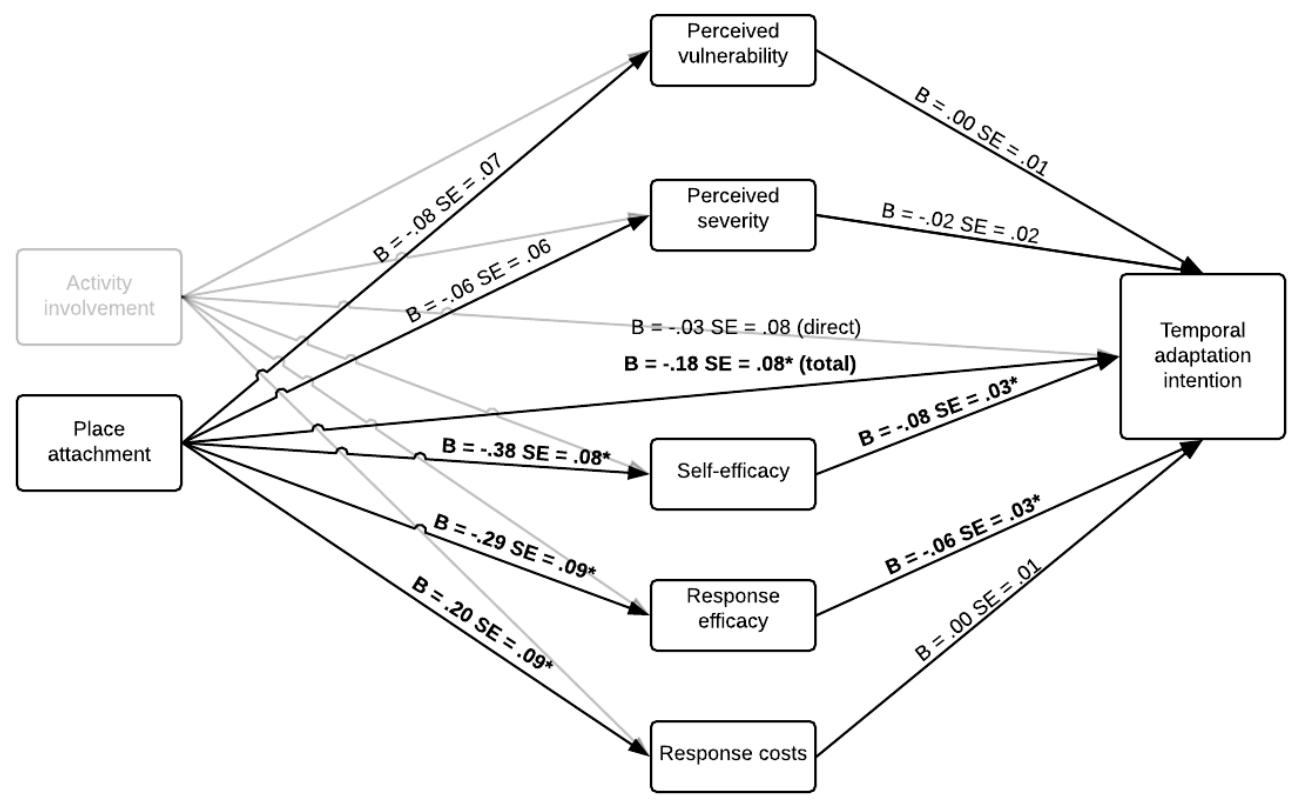

Figure 22: Relationship between place attachment and temporal behavioural intentions (BIT) via threat and coping appraisal variables

\subsubsection{Activity behavioural intentions}

Activity involvement had a significant negative direct $(\mathrm{B}=-.24, \mathrm{p}=.01)$ and total effect $(B=-.45, p<.001)$ on activity behavioural intentions, suggesting greater involvement with diving is associated with a lesser intention to change activity. Activity involvement also had a significant negative indirect effect via self-efficacy $(\mathrm{B}=-.15$, 95\%CI: -.28 to -.06$)$, suggesting that the ability to change activity helps to explain why activity involvement predicts a decreased likelihood of activity adaptation. Activity involvement had a significant negative effect on self-efficacy $(\mathrm{B}=-.40, \mathrm{p}<.001)$ and a significant positive effect on response costs $(\mathrm{B}=.27, \mathrm{p}=.01)$.

Place attachment had a significant positive direct $(B=.20, p=.01)$ and total effect $(\mathrm{B}=.25, \mathrm{p}=.01)$ on activity behavioural intentions, suggesting a stronger attachment to place is associated with a greater intention to change activity. Figure 23 
and Figure 24 summarize the relationships between activity behavioural intentions (BIA) and leisure involvement and place attachment respectively via threat and coping appraisal variables.

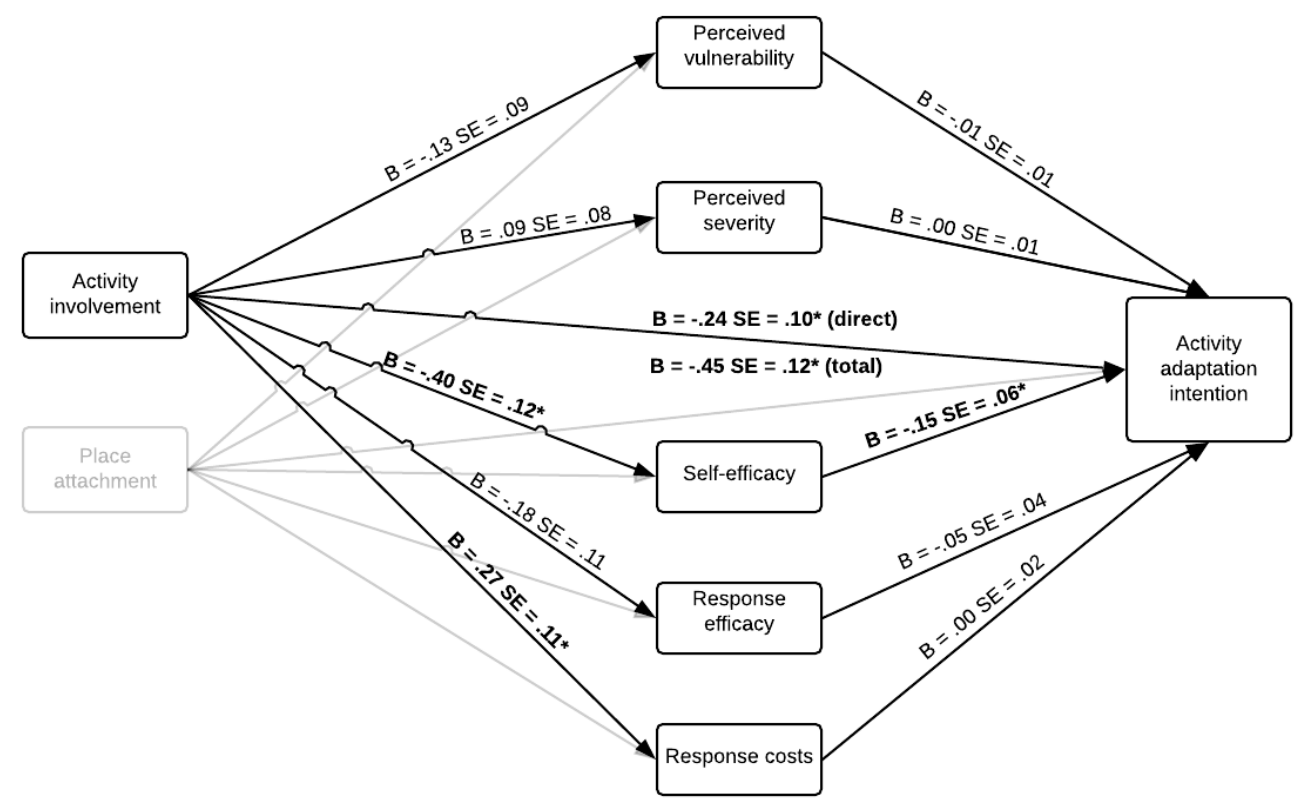

Figure 23: Relationship between activity involvement and activity behavioural intentions (BIA) via threat and coping appraisal variables

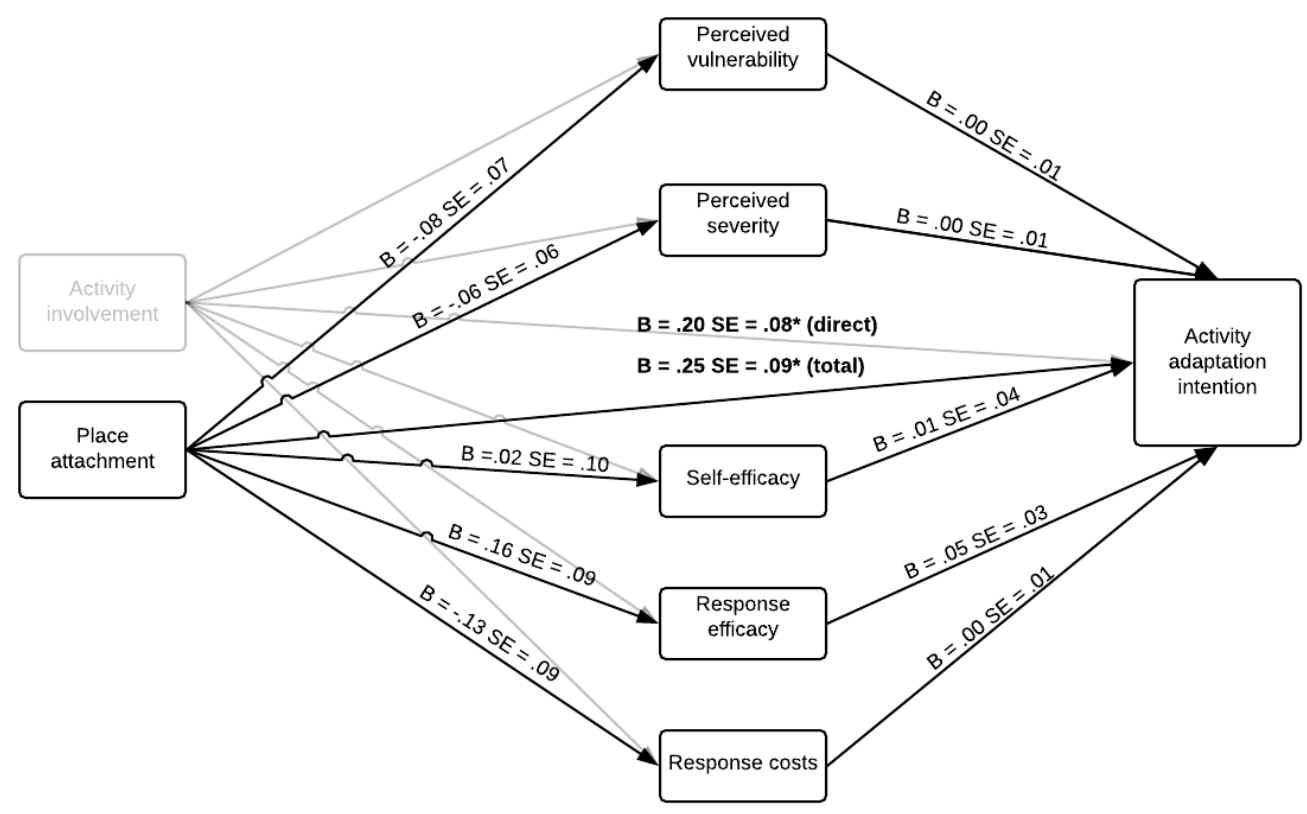


Figure 24: Relationship between place attachment and activity behavioural intentions (BIA) via threat and coping appraisal variables

\subsubsection{Cognitive behavioural intentions}

Activity involvement had a significant negative total effect on cognitive behavioural intentions $(\mathrm{B}=-.20, \mathrm{p}=.05)$, suggesting greater involvement with diving is associated with a lesser intention to accept a situation of coral bleaching. Specifically, activity involvement had significant negative indirect effects via self-efficacy $(B=-.10$, 95\%CI: -.22 to -.01$)$ and response efficacy $(\mathrm{B}=-.06,95 \% \mathrm{CI}:-.15$ to -.01$)$, suggesting ability to accept the situation and perceived effectiveness of doing so help to explain why activity involvement predicts a reduced likelihood of accepting coral bleaching. Activity involvement had a significant negative effect on self-efficacy $(B=-.22, p=.05)$ and response efficacy $(\mathrm{B}=-.27, \mathrm{p}=.03)$.

Place attachment had a significant positive direct $(\mathrm{B}=.17, \mathrm{p} .=.05)$ and total effect $(\mathrm{B}=.19, \mathrm{p}=.01)$ on cognitive behavioural intentions, suggesting stronger attachment to place is associated with greater intentions to accept a situation of coral bleaching. Place attachment also had a significant positive effect on response costs $(\mathrm{B}=$ $.16, \mathrm{p}=.03)$, suggesting stronger attachment to place is associated with a higher response cost in the case of cognitive adaptation. Figure 25 and Figure 26 summarize the relationships between cognitive behavioural intentions (BIC) and leisure involvement and place attachment respectively via threat and coping appraisal variables. 


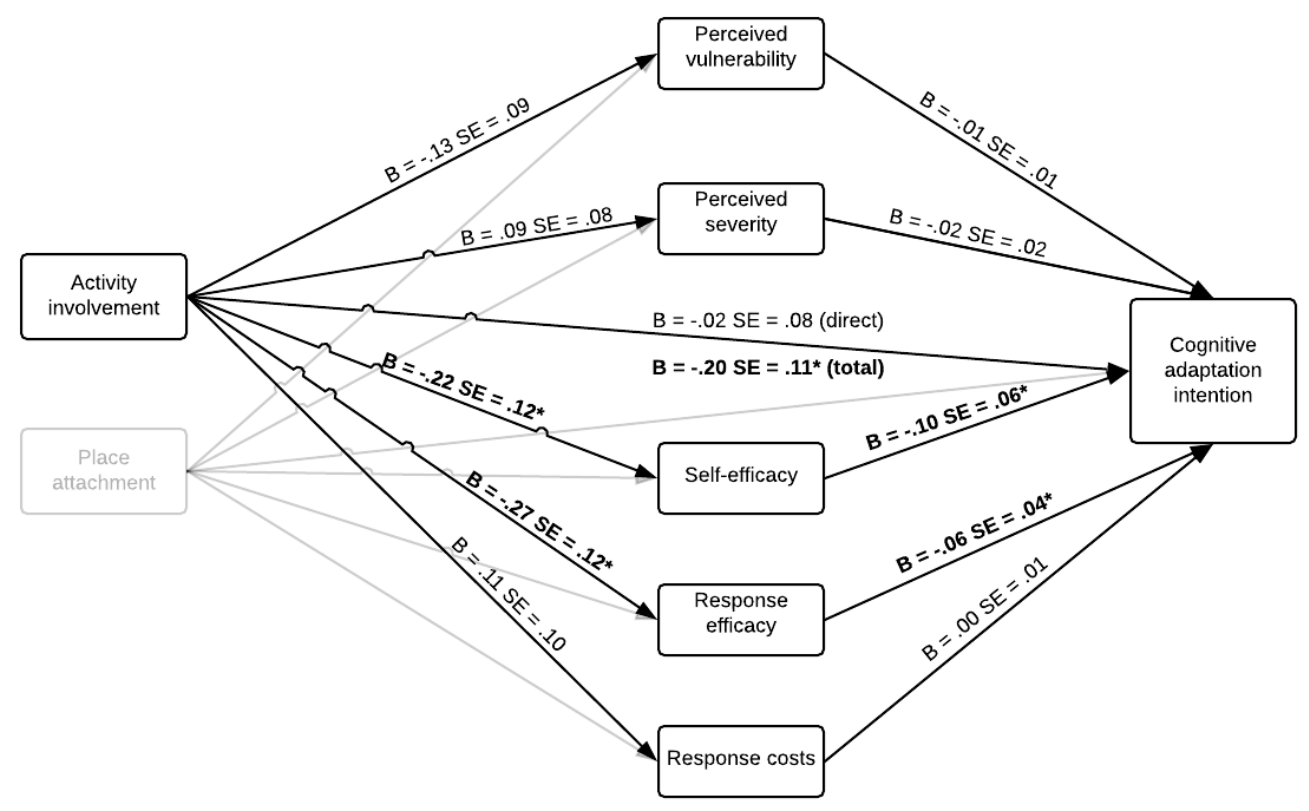

Figure 25: Relationship between activity involvement and cognitive behavioural intentions (BIC) via threat and coping appraisal variables

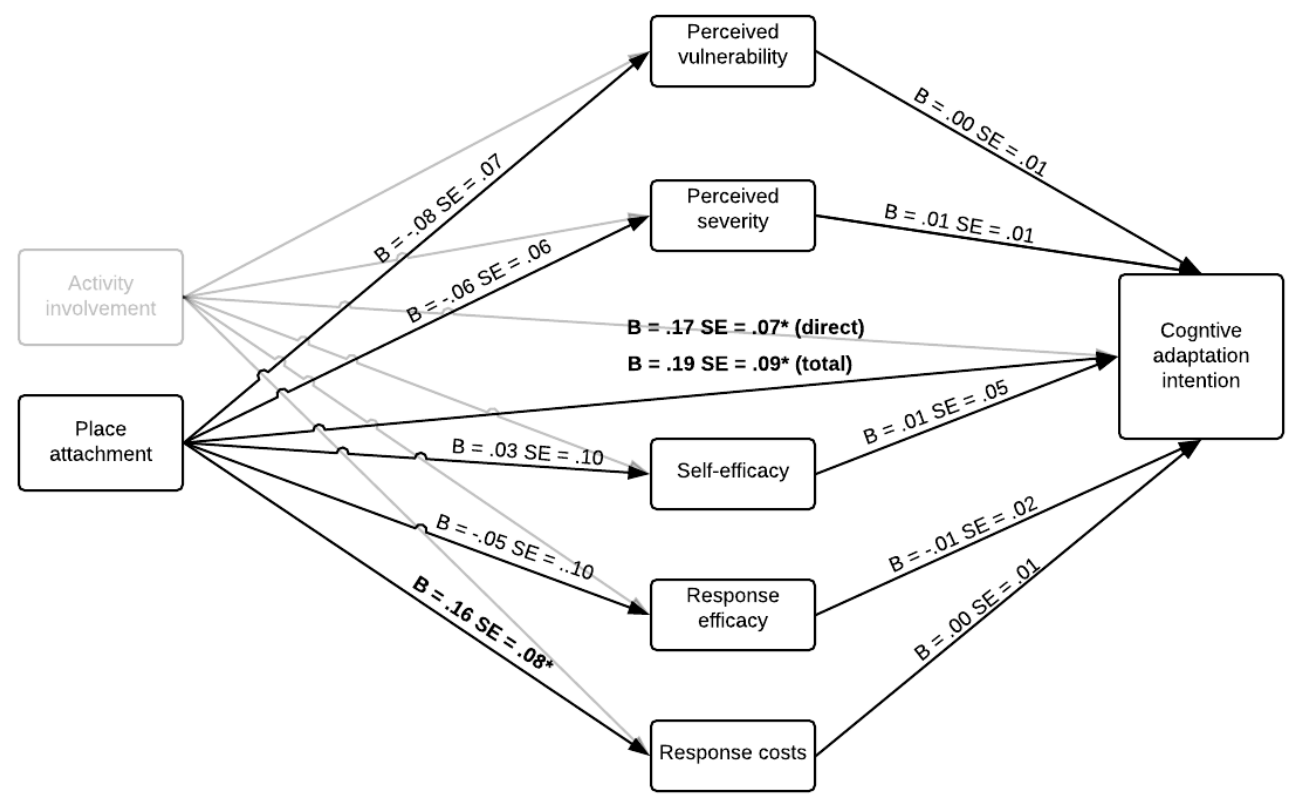

Figure 26: Relationship between place attachment and cognitive behavioural intentions (BIC) via threat and coping appraisal variables 


\section{DISCUSSION}

This chapter is divided into four sections. The first section considers how scuba divers are likely to adapt based on divers' responses to behavioural intention questions, and compares these responses to previous investigations into skiers' adaptation behaviour. The second section explores why scuba divers will or will not adapt by evaluating the contribution of Protection Motivation Theory variables. The third section considers differences in how and why scuba divers respond based on differences in geographic proximity. Finally, the last section discusses the insights gained from integrating activity involvement and place attachment into a PMT framework.

\subsection{How scuba divers will adapt}

As in this study, the results from studies examining how skiers may adapt their future behaviour in response to marginal snow conditions suggest that the majority of respondents would significantly alter their behaviour in some way. Compared to the literature, there are a number of similarities and differences. Though not directly comparable to previous studies by König (1998), Pickering et al. (2010), Behringer et al., (2000), and Rutty et al. (2015) who did not allow for multiple responses, the results of

this study can be generally compared and direct comparison can be made to Dawson et al. (2013) who did allow respondents to select multiple behavioural intentions.

Change in location is often the most commonly selected response (Behringer et al., 2000; Dawson et al., 2013; König, 1998). However, few studies have considered different geographic scales of spatial substitution, instead specifying "outside the region" (e.g., König, 1998) or a different "more snow-reliable" alternative (e.g., Behringer et al., 2000). Considering both outside the region and within the region, Dawson et al. (2013) 
found that more skiers were likely to travel further afield (67\% vs. $60 \%)$. This is consistent with findings from this study in which more divers indicated an intention to dive outside the region (86\%) than elsewhere within the region (71\%). Notably, there are fewer divers engaging in intra-regional adaptation relative to inter-regional adaptation (i.e., greater reduction in percentage) than skiers. Even fewer divers stated they would dive elsewhere within a destination (44\%), lending credence to the notion that the likelihood of engaging in spatial substitution is influenced by geographic scale of the behavioural intention.

In the case of coral bleaching, this may be due to the possible widespread nature of a bleaching event. Examining the spatial variability in the decline of coral cover in the Indo-Pacific, Bruno and Selig (2007) found that coral cover did not significantly vary among ten sub-regions despite a number of differences within these regions thought to influence coral reef resilience, (e.g., enforcement, coral diversity). While knowledge of the geographic extent of coral bleaching is incomplete (Donner, Rickbeil, \& Heron, 2017), it is known that the frequency and geographic extent of coral bleaching events have increased since the early 1980s (Goreau \& Hayes, 1994; Goreau et al., 2000). This has implications for the availability of alternatives within a dive destination or region.

Another consideration with coral bleaching is the extended nature of recovery. In some cases recovery rate can be detected within as little as 2 years, while in other locations recovery is absent even after 20 years (Baker, Glynn, \& Riegl, 2008). Rutty et al. (2015) found that skiers' engagement in spatial substitution varied depending on the duration of the impact, with respondents indicating a greater likelihood of change in location in the event of permanent closure (61\%) over partial season closure (48\%) or 
single day closure (30\%). The relatively high proportion of divers intending to engage in spatial adaptation might suggest that they have considered the prolonged impact to a reef ecosystem.

After inter-regional spatial adaptation, the next most frequent response in this study was temporal adaptation, with $77 \%$ of respondents indicating they would reduce dive frequency if they were to encounter bleached reefs. This again aligns with findings from Dawson et al. (2013) (34\%), König (1998) (31\%), Behringer et al. (2000) (32\%). However, in a follow up to König's (1998) study, Pickering et al. (2010) found that the proportion of skiers' anticipating behavioural adaptation was $90 \%$ (up from $75 \%$ in 1996), of which a reduction in skiing was now the most common response (69\% vs. $31 \%)$. The authors suggest this increase in sensitivity may reflect their experience of low snow conditions, noting the duration and depth of natural snow are declining in Australia, and the limited skiing opportunities available compared to other ski regions in which studies have taken place (e.g., Europe, North America). Similarly, considering the potential scarcity of destination or regional dive alternatives described above may help to explain the much greater likelihood of activity reduction in this study compared to Dawson et al. (2013) (77\% vs. 34\%).

With respect to activity adaptation, $22 \%$ of respondents stated they would change activity if they were to encounter bleached reefs, indicating changing one's activity consistently proves to be the least attractive option provided as in previous studies (Behringer et al., 2000; Dawson et al., 2013; König, 1998; Pickering et al., 2010; Rutty et al., 2015). However, Dawson et al. (2013) found that almost half (46\%) of skiers would engage in an alternative leisure activity in the event of consistently poor snow season in 
the future. This could suggest a potential difference for skiing compared to diving. Though studies investigating diver motivations consistently cite the opportunity to look at corals and other underwater marine life as the main reason for diving (e.g., Ditton et al., 2002; Garrod, 2008), these elements are not essential for scuba diving to occur - the only requirement is dive equipment (i.e., regulator, buoyancy control device, air tank) and water of a sufficient depth, neither of which necessarily involve a dive tourism operator. In contrast, skiers depend on the presence of snow, be it sub-optimal or degraded and operational lifts, the latter of which generally requires an active ski resort. Thus, from a demand-perspective, scuba diving may appear to be less vulnerable to alternative activity engagement, but this continued engagement in the activity may not occur within the tourism sector. Note this does not take into consideration the implementation of supplyside adaptations (e.g., artificial snow, artificial reefs), which may not be equivalent in terms of contribution to activity experience.

Unlike previous studies into skiers' behavioural adaptation, this study included a measure of cognitive adaptation. Only $23 \%$ of respondents stated they would accept the situation if coral bleaching were encountered. This differs from previous studies into stress-coping response, which find that cognitive coping strategies often have a higher mean score than behavioural coping (e.g., Manning \& Valliere, 2001; Schuster et al., 2006; Yoon, 2012), indicating a stronger preference for cognitive adaptation. Notably, in these studies, respondents were asked to indicate the extent to which a list of behavioural intentions described their response to the negative situations or conditions they experienced. In comparison, this study asked respondents to make their decision based on a hypothetical scenario. It is possible that this methodological difference contributes to 
this difference in findings.

\subsection{Why scuba divers will/will not adapt}

PMT explained a statistically significant amount of the total variance in all six of the adaptation models for both dive groups and for the sample as a whole, indicating the regression models are statistically significantly better at predicting behavioural intentions than the intercept-only model. However, the total amount of variance explained and the extent to which predictors contributed significantly to the explanation of behavioural intentions varied considerably.

PMT explained between $12.8 \%$ and $47.7 \%$ of the variance in behavioural intentions. This is comparable to previous studies applying PMT to climate change behavioural intentions where between $23 \%$ and $49 \%$ of variance in behavioural intentions was explained (Dang et al., 2014; Koerth et al., 2013; Kuruppu \& Liverman, 2011; Tapsuwan \& Rongrongmuang, 2015; Truelove et al., 2015; van Duinen et al., 2015). The model explained the greatest amount of variance for activity (BIA) and cognitive (BIC) behavioural intentions. Interestingly, these were the two adaptation options divers were least like to employ. These adaptations were also perceived as being the least effective (i.e., response efficacy) and least confident in one's ability to carry out (i.e., selfefficacy). Thus, it appears that PMT is a stronger model when there is a perceived restriction of choice. That is to say, the decision about intention to adapt when the response is perceived to be ineffective and one is perceived to be unable to perform said adaptation may be simpler by virtue of these perceptions than when the response is perceived to be effective and one is perceived to be capable. This is consistent with 
findings that models with the least explained variance (BIS2 and BIS3) are associated with the highest perceived effectiveness and greatest perceived ability to perform. Response efficacy and self-efficacy consistently emerged as the strongest significant predictors of behavioural intentions in the expected direction. This is consistent with previous studies applying PMT to climate change adaptation (e.g., Dang et al., 2014; Kuruppu \& Liverman, 2011; Truelove et al., 2015) and meta-analyses of health studies (Floyd et al., Milne et al., 2000). As discussed in section 1.2, research on climate change adaptation and adaptive capacity has often emphasized the role of objective assets or determinants. The results from this study align with a growing body of research that suggests taking people's estimation of their perceived adaptive capacity offers a much clearer picture of the decision to respond to a threat (Grothmann \& Patt, 2005; Marshall \& Marshall, 2007; Marshall et al., 2013; Viscusi \& Chesson, 1999; Weber, 1997). These findings demonstrate the value of considering coping appraisal variables when evaluating what motivates people to engage in adaptation to ensure a satisfactory dive experience.

Response efficacy was a significant positive predictor for all but intra-regional behavioural intentions (BIS2). However, it became significant when self-efficacy was removed as a predictor. That is to say, when it comes to changing location within a region, perceived ability predicts much of the same variance as perceived effectiveness. In fact, controlling for self-efficacy consistently reduced the effect size of response efficacy, i.e., perceived effectiveness of adaptation is less influential for divers with the perceived ability to adapt. Because self-efficacy is significantly positively related to response efficacy (moderate to strong relationship), this suggests that the perceived 
effectiveness of an adaptation may be biased by the perception of one's ability to actually carry out that response. For example, if one is not able to perform a response, it may be seen as less effective. This relationship is least pronounced for temporal and interregional spatial behavioural intentions, for which perceived severity is of greatest influence, suggesting that perceived effectiveness may be less influenced by confidence when perceived threat is of greater importance.

Response costs, though consistent in its relationship to behavioural intentions in the expected direction, was only a significant predictor of intra-regional and inter-regional behavioural intentions (BIS2 and BIS3). It is notable that these are the adaptation options that have the highest monetary cost. While efforts were made to distinguish different types of costs that could be collectively considered (e.g., personal, social), it is not clear whether this advice was heeded.

Overall, threat appraisal variables performed more poorly, which is consistent with previous studies (e.g., Horng et al., 2014; Tapsuwan et al., 2015; van Duinen et al., 2015). Perceived vulnerability was not a significant predictor of any behavioural intentions, and in fact emerged as a negative, though non-significant predictor of intradestination behavioural intentions. It is possible this is because of the phrasing of behavioural intention questions. Framed as "if coral reefs that are mostly white were to persist in [dive location] for several years", a phrasing adopted based on previous investigations into behavioural adaptation (e.g., "if poor ski/snowboard conditions occurred in 3 out of the next 5 winters", Dawson, 2009), this precludes the perceived likelihood of actually encountering bleaching. Examination of the different scales of perceived vulnerability and behavioural intentions provides some support for this 
explanation. Respondents indicated a much greater perceived vulnerability to bleached coral reefs elsewhere than within a self-specified dive location ( $74.5 \%$ vs. $51.5 \%)$. Meanwhile, the effect size of perceived vulnerability is greatest for inter-regional adaptation and lowest for intra-destination intention. That is to say, perceived vulnerability is a stronger predictor when there is greater consistency with what one is expecting to encounter.

Perceived severity was a significant positive predictor for inter-regional and temporal behavioural intentions, but a significant negative predictor of intra-destination and cognitive behavioural intentions and non-significant predictor of intra-regional and activity behavioural intentions. This suggests that the nature of the relationship may vary depending on the type of coping strategy under consideration. In the case of cognitive adaptation, it may be harder to accept a situation if a threat is deemed to be more severe. This is consistent with findings from stress-coping studies. For example, Miller and McCool (2003) found that higher levels of stress were negatively associated with coping strategies characterized as cognitive adjustment. That is, as stress levels increased respondents were less likely to employ cognitive adjustment strategies. These cognitive adjustments were more likely to be associated with lower levels of stress, for the variables measured in this analysis.

Just as van Duinen et al. (2015) found that the scale of implementation matters with respect to the predictor's explanatory power, perceived severity may have emerged as a negative predictor for intra-destination adaptation because of the scale of the threat. As discussed previously, coral bleaching may extend to other areas within a destination, in which case a greater perceived threat could result in a decreased likelihood to adapt. 
Note, respondents indicated a decrease in perceived effectiveness from macro (i.e., RES3) to micro-scale (i.e., RES1) adaptation. Similarly, it is possible that the predictor was non-significant for intra-regional adaptation (BIS2) because of the lack of clarity around the phrasing "in a region" and ambiguity around the extent to which coral bleaching might affect the surrounding region.

\subsection{Influence of geographic proximity}

One of the goals of this study was to contrast two diver populations (Australians and Canadians) that may experience the threat of coral bleaching differently to see what influence this has on the relationships between PMT predictors and behavioural intention. There were several significant compositional differences between the two groups. Unsurprisingly, given the 2016 mass bleaching event on the Great Barrier Reef, Australian divers, many of whom identified the GBR when asked to select a dive destination, had a significantly greater perceived vulnerability to coral bleaching at this self-specified dive location.

In the case of temporal adaptation, Canadian divers perceived dive reduction to be more effective and had a greater perceived ability to alter their dive rate than Australian divers, but this adaptation comes at a higher cost. In contrast, Australian divers were significantly more likely to change the location of diving within a destination or within a region. One possible explanation for this is perceived availability of local or regional alternatives. Hall and Shelby (2000) suggest that, if few alternative sites are available, one might adopt temporal strategies, while having many acceptable alternatives might encourage spatial strategies. Results from McFarlane, Boxall, and Watson (1998) suggest that those with experience in a particular recreation setting are better able to match their 
preferences with what is available because they have more knowledge and awareness of available sites. Similarly, studies comparing differences in local and visitor strategies have suggested that locals may find it easier to adopt intra-area displacement because of their knowledge of the area (Arnberger and Brandenburg, 2007; Manning and Vallierre, 2001).

That this relationship did not hold true for inter-regional adaptation also makes sense in the context of distance travelled. Given that Canadian divers must travel greater distances to any coral reef dive site relative to Australian divers, it follows that a greater perceived threat lends itself to traveling elsewhere outside a region to dive. In this vein, Rutty et al. (2015) found that Blue Mountain Resort respondents, who had travelled the farthest to go skiing, were the most willing to leave Ontario to continue skiing, indicating an acceptance to travel longer distances to participate in the sport.

There was only one statistically significant difference in effect between the groups as measured via interaction terms, underscoring the importance of evaluating beyond differences in the two separate models apparent at face value. Specifically, perceived severity is a significant negative predictor of cognitive behavioural intentions for Australian divers, but not Canadian divers, i.e., the greater the perceived threat, the less likely Australian divers are to accept the situation. One possible explanation for this is attachment to place. Having examined respondents' attachment to diving and dive place, Australian and Canadian divers only significantly differed with respect to place identity scores, with Australian divers showing a significantly greater emotional attachment to place. This is consistent with results from Budruk, Stanis, Schneider, and Anderson (2011), who found that place identity was stronger and significantly different 
for proximate versus distant water-based recreationists, while differences in place dependence were not significant at the scale level. Similarly, Moskwa (2012) found that local divers recorded a stronger place identify than visiting scuba divers that was "marginally significant" $(\mathrm{p}=.08)$. Further examination of attachment variables will take place in the next section of this chapter.

\subsection{Place attachment/activity involvement}

\subsubsection{Relative explanatory power}

Attachment variables added little to the explanatory power of the models, significant only for three of the six models (BIS1, BIT, BIA) to a maximum of 5\% explained variance (BIA). These findings are consistent with what has previously been reported regarding activity involvement and place attachment's predictive power (Kyle et al., 2007, 2004; McFarlane, 2004; Oh et al., 2013; Pritchard \& Howard, 1997; Sutton \& Oh, 2015; Wynveen et al., 2007). This study also incorporated additional constructs that provide insight into why or why not individuals participate (e.g., response efficacy, selfefficacy) in hopes of obtaining a more complete accounting of behaviour by accounting for indirect effects, but this did not prove to be the case. Rather, the intervening PMT variables provided a much greater accounting of variability.

Eder and Arnberger (2012) question why individuals continue to explore these variables despite their limited explanatory power across a variety of dependent and independent variables and settings. That is not to say attachment variables are of no utility. One of the primary challenges of studying any human system is that it is not understandable using the same laws observed in applied sciences (Yiannakoulias, 2016). That is to say, the quirks of human behaviour reduce the utility of models involving 
people, particularly at the individual-level, relative to natural science models. In this sense, even a significant small $\mathrm{R}^{2}$ value can be important; it is the subjective decision of the researcher to determine what is "too small" to be of importance.

\subsubsection{Direct and indirect effects of attachment variables}

Place attachment and activity involvement significantly affected self-efficacies (AI-SEA, AI-SEC, PA-SES3, PA-SET) and response efficacies (AI-RET, AI-REC, PARES3, PA-RET) of both spatial and non-spatial adaptation strategies. With the exception of AI-RET, this relationship was negative suggesting greater attachment typically predicts less ability to perform an adaptation and less perceived effectiveness of an adaptation. This builds on research into the perception of leisure constraints (Hendricks et al., 2008; Jun \& Kyle, 2011; Sutton, 2007; Sutton \& Oh, 2015), which proposes that greater attachment comes with more factors that prevent the desired level or type of participation from being achieved. That is to say, not only is desired participation more likely to be impeded, but adaptation is perceived to be of less utility.

Place attachment and activity involvement were also positively associated with response costs (AI-RCA, PA-RCS1, PA-RCS2, PA-RCS3, PA-RCT, PA-RCC), suggesting greater attachment results in a greater cost to adaptation. This cost may be attributed to the cost of not being able to participate at the aforementioned desired level or type. Notably, this is true of all response cost, suggesting that at least some consideration beyond monetary cost.

\subsubsection{Spatial adaptation strategies}

Activity involvement did not have any significant direct or indirect effects on spatial adaptation strategies, offering some initial support for restricting activity 
involvement for consideration of activity adaptation and place attachment for spatial adaptation. In contrast, place attachment only had a direct positive relationship with intradestination behavioural intentions. This contradicts results from previous studies where place attachment is negatively related to willingness to alter the location of recreation (Oh et al., 2013; Wang \& Chang, 2010; Williams et al., 1992). What is more, place attachment negatively influenced response efficacy and self-efficacy of inter-regional adaptation, i.e., stronger attachment to place predicts the change of dive location outside a region to be less effective and respondents to be less able to perform said adaptation, though neither acts as mediators. This too contradicts the previously observed pattern of place attachment decreasing with increasing distance (Bonaiuto, Carrus, Martorella, \& Bonnes, 2002; Nyaupane, Graefe, \& Burns, 2003).

One possible explanation for this is the method by which divers identified the object of place attachment. Based on the study by Moskwa (2012), the only known investigation into scuba diving and place attachment, divers were asked to nominate a diving place that they were familiar. In Moskwa's study, all but six respondents identified dive sites in South Australia. By way of comparison, responses for this study varied from specific dive sites (e.g., Flynn reef), and reef systems (e.g., Great Barrier Reef) to countries (e.g., Mexico) and dive regions (e.g., all of the South Pacific). It is likely that this fluctuating scale of places identified contributed to the atypical results seen with respect to spatial adaptation.

\subsubsection{Non-spatial adaptation strategies}

Both response efficacy and self-efficacy acted as mediators for non-spatial adaptation strategies, underscoring the additional contribution of the perception of a 
response's effectiveness and one's ability to adapt in explaining the adaptive influence of attachment variables. In particular, multiple indirect effects were identified for both temporal and cognitive adaptation, for which the relationship between attachment variables and behavioural intentions is less apparent. However, activity involvement also had a significant indirect effect on activity adaptation by way of self-efficacy, which contributed a third of the construct's total effect, demonstrating the importance of considering both direct and indirect effects.

The only adaptation strategy for which activity involvement was a direct predictor was activity adaptation. As expected, this relationship was negative, which is consistent with much of the previous research into willingness to alter type of activity (Ditton \& Sutton, 2004; Hyun \& Ditton, 2006; Needham \& Vaske, 2013; Sutton \& Oh, 2015; Tseng, 2009). PA was also a direct predictor of activity adaptation, differentiating its predictive power beyond spatial adaptation. This relationship was positive, and thus is a competing effect to that of activity involvement.

Including both activity involvement and place attachment as covariates in the analyses provides an estimate of part of one $\mathrm{X}$ 's effect on $\mathrm{Y}$ unique to that $\mathrm{X}$ relative to other Xs. However, previous investigations have found a relationship between place attachment and activity involvement (e.g., Kyle, Graefe, Manning, \& Bacon, 2005), introducing the possibility of confounding effects. Indeed, in a test run of univariate mediation models, the relationship between activity involvement and response costs, which had previously been significant for place attachment, became significant. Thus, interpretation of the results of this study should take into consideration the possibility of interactions between covariates. 
In the case of activity involvement, there is a clear drive to continue to engage in diving, as might be expected, but that this activity is negatively affected. This balance is seen in the perceived effectiveness of reducing dive frequency, thus lowering one's exposure to coral bleaching, and perceived ineffectiveness of accepting and enjoying the situation. In contrast, place attachment is driven more by a desire to remain in the area, as might be expected, but varies in terms of the effect on one's exposure to coral bleaching - exposure is completely avoided in activity adaptation, but does not otherwise appear to be behaviourally or cognitively affected with regards to reducing dive frequency or not accepting the situation. That dive reduction is perceived as less effective as a means of producing a satisfactory experience and one being less able to perform dive reduction, speaks to the dominant desire to continue to dive in place despite adverse environmental conditions, a direct contrast to place attachment's direct positive relationship with activity adaptation.

This begs the question: does coral bleaching have a greater negative impact on activity experience than place experience for more attached individuals? Evidence from this study would suggest that individuals more strongly attached to the activity of diving might be more negatively affected by instances of coral bleaching. This close relationship between scuba diving and coral condition aligns with a large body of research investigating diver motivations and satisfaction in which corals and other underwater marine life are cited as the main reason for diving and diver satisfaction (Davis \& Tisdell, 1996; Dearden, Bennett, \& Rollins, 2006; Ditton, Osburn, Baker, \& Thailing, 2002; Fitzsimmons, 2007; Garrod, 2008; Graham, Idechong, \& Sherwood, 2000; Loomis, Anderson, Hawkins, \& Paterson, 2008; MacCarthy, O’Neill, \& Williams, 2006; Meyer, 
Thapa, \& Pennington-Gray, 2002; Musa, 2002; Musa, Kadir, \& Lee, 2006; Paterson, Young, Loomis, \& Obenour, 2012; Shani, Polak, \& Shashar, 2012; Tabata, 1992;

Thailing \& Ditton, 2003; Todd, Graefe, \& Mann, 2002; Uyarra et al., 2005). Similarly, investigations into normative standards for coral reef conditions suggest that with more specialized divers indicate a lower acceptability for bleached and algal covered reefs (Anderson \& Loomis, 2012; Young \& Loomis, 2010).

There remain issues as to why this relationship is less clear-cut for place attachment. The limited investigation into place and reef environments does suggest that abundance and diversity of coral and other wildlife is an important theme of place meaning (Wynveen, Kyle, \& Sutton, 2010). Notably, this differs from the literature into place meaning of terrestrial environments, for which presence of wildlife has been part of other place meaning themes, but has generally not been a theme on its own (Davenport \& Anderson, 2005; Gunderson \& Watson, 2007). Thus, whether this apparent divide between place attachment and resource condition in this study is a by-product of the previously identified methodological issues of scale and/or confounding effects or by virtue of the nature of the relationship with an underwater environment is worthy of further investigation. While previous research has explored the influence of place attachment on the perception of resource condition (Eder \& Arnberger, 2012; Kyle et al., 2004; Warzecha \& Lime, 2001; Williams et al., 1992), there does not appear to be similar investigations into the construct's relationship with preference for resource condition. 


\section{SUMMARY AND CONCLUSION}

The overarching purpose of this dissertation was to provide insight into how and why scuba divers intend to adapt. In response to disagreement among researchers and dive stakeholders, this study sought to provide empirical evidence of scuba divers' behavioural and cognitive adaptation to coral bleaching. Consistent with research into skier adaptation behaviour, the majority of respondents indicated an intention to adapt in some way. Spatial adaptation was the most common response with a tendency towards movement farther afield (i.e., outside a dive region), possibly a result of the scale and duration of bleaching events. These characteristics of coral bleaching may also have contributed to the relatively high percentage of respondents in favour of reduction in activity frequency, by limiting perceived availability of dive opportunities. Notably, divers in this study were less likely than skiers to change activity, which could point to potential differences in the necessity of resource condition for skiing compared to diving.

This is the one of the first studies to apply Protection Motivation Theory to consider the cognitive appraisal process of tourists' adaptation behaviour, building on and addressing the limitations of the study by Wang et al. (2018). It was expected that the constructs that comprise PMT would combine to explain significant proportions of the variance in each of the behavioural intentions under investigation in the current study. PMT explained a statistically significant amount of the total variance in all six of the adaptation models. However, the total amount of variance explained and the extent to which predictors contributed significantly to the explanation of behavioural intentions varied considerably. In particular, PMT appeared to be a stronger model when there is a perceived restriction of choice. 
As per the PMT, it was expected that:

H1: As perceived vulnerability increases, intention to adapt increases (not supported)

H2: As perceived severity increases, intention to adapt increases (partially supported)

H3: As perceived effectiveness of an adaptation increases, intention to adapt increases (supported)

H4: As perceived ability to carry out adaptation increases, intention to adapt increases (supported)

H5: As perceived cost increases, intention to adapt decreases (partially supported)

The study offers mixed support for these hypotheses. Contrary to the first hypothesis, perceived vulnerability was not a significant predictor of behavioural intentions, possibly a result of how the construct was measured in the survey. Hypothesis two held true for inter-regional and temporal behavioural intentions, but perceived severity emerged as a significant negative predictor of intra-destination and cognitive behavioural intentions, indicating the importance of considering type of coping strategy and scale of threat. As per hypotheses three and four, response efficacy and self-efficacy consistently emerged as the strongest significant predictors of behavioural intentions in the expected direction, demonstrating the value of considering coping appraisal variables when evaluating what motivates people to engage in adaptation to ensure a satisfactory dive experience. Finally, in accordance with the last hypothesis, response cost was consistent in its relationship to behavioural intentions in the expected direction, but only a significant predictor of intra-regional and inter-regional behavioural intentions (BIS2 and BIS3), i.e., adaptation options with the highest monetary cost.

Previous research suggests that resource proximity is strongly correlated to aspects of visitation behaviour, including the length/frequency of visits and type of activity undertaken, as well as perception of climate change risk. This study sought to 
explore whether or not these differences translated to differences in adaptation behaviour by comparing Australian diver, who live in close proximity to the Great Barrier Reef, among other recreational diving opportunities, and Canadian divers. While there were several significant compositional differences between Australian and Canadian divers, possibly a result of differences in perceived availability of local or regional alternatives, there is only one significant structural difference between the two samples. Specifically, the effect of perceived severity has a significantly greater effect on cognitive behavioural intentions for Australian divers than Canadian divers, which may be attributed to differences in emotional attachment to place.

Lastly, this investigation hypothesized that PMT will be a useful framework to assess how place activity and activity involvement transmit their effect on behavioural intentions by accounting for both the direct and indirect effect of these variables through the risk and coping appraisal processes. Results from the study suggest that the direct and indirect effects of attachment variables added little to the explanatory power of the models. Rather, the intervening PMT variables provided a much greater accounting of variability. However, the mediation models did offer some insights into the pathway of attachment effects. Notably response efficacy and self-efficacy acted as mediators for non-spatial adaptation strategies, typically predicting less ability to perform an adaptation and less perceived effectiveness of an adaptation with greater attachment. The next sections of this chapter will consider the implications of these findings for research and practise, and conclude with suggestions for future research.

\subsection{Practical implications and recommendations}


This study provides the first empirical evidence of scuba diver adaptation in response to marginal reef conditions, indicating that the majority of respondents would significantly alter their behaviour in some way, favouring change of dive location and reduction in dive frequency. As coral bleaching and mortality are expected to continue to increase in frequency and magnitude, the economic ramifications are likely to be significant. For example, the Australian Institute speculates that continued coral bleaching on the Great Barrier Reef could reduce international and domestic visitors to the region by more than a million people a year, resulting in the loss of $\$ 1$ billion in tourism income (Willacy, 2016). support

Tourists' tendency towards spatial adaptation is also an important consideration as a contributor to greenhouse gas emissions (Steiger et al., 2017). Dive tourists' in this study favoured inter-regional and intra-regional adaptation over intra-destination, potentially increasing the travel distance to a dive site. Of course, the magnitude of this change in distance will depend on a diver's resource proximity. For example, an Australian diver would have to travel further than they would otherwise have had to in order to find a suitable dive location outside the region.

Ultimately, dive operators are unlikely to see a stop in diving altogether, which bodes well for the future of the dive tourism industry. Indeed, the intended shifts in dive location observed in this study may be less relevant in the mid-to-long term with increasingly widespread bleaching events. This change in scale of affected dive regions may result in generational differences as evidenced by shifting expectations of new divers, what Pauly (1995) refers to as "shifting baseline syndrome". Dive operators can proactively prepare for this transition in the short-term by developing and promoting 
elements of diving that are not dependent on coral reefs, such as dive skill development, service quality, and other underwater formations. It is notable that there is likely to be a greater variability of tolerances than included in this study, which can be used to target marketing strategies to attract or retain particular market segments. For example, differences in the response of Canadian vs. Australian divers supports the use of targeted regional marketing to retain domestic divers and differentiate less-affected regions for international divers.

In general, this study provides a useful framework for policy makers, destination marketers, and investment developers to consider the elasticity of dive tourism demand, which can inform decisions about capital investments and supply-side adaptations. Beyond information about behavioural intentions, PMT can also assess different types of adaptation in terms of effectiveness, capability, and cost, which may provide insight into how to counter potential changes in behaviour. For example, inter-regional spatial adaptation was perceived to be the most effective behavioural intention, which may prompt destination marketers to increase awareness of local alternatives and/or greater investment in developing alternative dive sites in the area.

\subsection{Theoretical implications and recommendations}

This study is at the nexus of research into climate/environmental change, tourist behaviour, and PMT (Figure 2), with theoretical implications for each of these research areas. The study contributes to the climate change and tourism literature, which has largely neglected to consider the value of theoretical constructs within behavioural psychology. This is the first known study to evaluate the cognitive appraisal process of tourists' adaptation to climate change effects via PMT, and tie this together with previous 
research applying theoretical constructs from the recreation-leisure literature. This application has advanced the limited understanding of the impact that climate change is likely to exact on diver demand.

This study partially supported the Protection Motivation Theory proposed by Rogers (1983). Consideration of multiple behavioural intentions demonstrates the variability of model performance and highlights the need to consider the context of adaptation behaviour when interpreting results. For example, the hypothesis that perceived severity is a positive predictor of behavioural intentions may not be true for cognitive adaptation. It is recommended that future studies investigating tourists' response to climate change apply PMT to different recreation and threat contexts and consider different adaptation strategies to gauge the general applicability of the framework.

Addressing some of the methodological limitations identified in the previous chapter may also increase the utility of the framework. In particular, investigating respondents' actual encounters with coral bleaching may help to address the low performance of threat appraisal variables. Korstanje (2009) argued that the study of risk perception prior to one's actual holiday is more accurately an assessment of anxiety given that fear and risk perception require a direct stimulus. While a person can either confront the hazard at hand or escape the situation at the point risk perception, anxiety is a secondary emotion experienced before concreteness develops, often emerging from news or rumors. He suggests that this emphasis on pre-trip assessment is a main limitation of tourism applications of risk perception theory.

In interpreting the relatively weak performance of threat appraisal as predictors of tourists' carbon reduction behaviours, Horng et al. (2014) consider the underlying 
motivation that prompts protective behaviours, suggesting that, while health protection is motivated by fear, environmental protection behaviours appear to be motivated by responsibility. In this study, tourist adaptation is framed as being motivated by gratification, specifically a desire to have a satisfactory dive experience. However, some studies have criticized the underlying premise that satisfaction will lead to positive behavioural intentions, suggesting that simply satisfying consumers may not be sufficient to drive repurchase behaviour (Agustin \& Singh, 2005; Seiders, Voss, Grewal, \& Godfrey, 2005; Voss, Godfrey, \& Seiders, 2010). Applying this principle to behavioural intentions, is it enough to consider satisfaction as the primary driver of cognitive or behavioural change? Future studies could investigate different motivations for adaptation, as these may differ from past investigations into motivations for participation.

The high performance of coping appraisal variables, in particular that of response efficacy and self-efficacy, highlights the importance of including some measure of subjective adaptive capacity when considering tourists' adaptation behaviour and supports Schuster et al.'s (2006) suggestion that future stress-coping research should consider the efficacy of coping mechanisms. To gain further insight into the contribution of response costs, it is recommended that future studies break down response costs into multiple items that assess its different aspects, being cognizant of balancing this greater specificity with survey length.

Finally, this study did not support the notion of PMT as a useful extension of place activity and activity involvement effects in terms of additional explained variance, but did offer some insights into competing and indirect effects when considering attachmentbehaviour models beyond that of place attachment-spatial adaptation/activity 
involvement-activity adaptation. Two methodological issues likely impeded this investigation, specifically, a bias towards respondents with strong levels of attachment and inconsistencies in scale of place attachment, which would benefit from a broader socio-demographic of respondent and specific place of encounter respectively, as previously discussed.

\subsection{Methodological implications and recommendations}

An online survey was used to collect data from divers ex situ in response to previous suggestions of displacement accounting for insignificant or inconclusive findings into the relationship between place attachment or activity involvement and visitors' perception of resource conditions (Budruk et al., 2008; Kyle et al., 2004; White

et al., 2008). However, this study similarly found no relationship between attachment and visitor perceptions of threat severity/vulnerability, despite addressing this methodological consideration. Notably, most respondents would experience a decrease in dive satisfaction were coral bleaching to be encountered $(M=4.26)$, in contrast to the higher acceptability scores of 3.04 to 3.83 (on a scale of 1 to 9 , with 9 being very unacceptable) in Kyle et al. (2004) or 1.43 to 3.02 (on a scale of 1 to 5 , with 5 being very unacceptable) in White et al. (2008). This adheres to Manning and Vallierre's (2001) explanation that displacement can result in elevated visitor satisfaction despite crowded conditions, having accounted for a broader range of respondents ex situ, suggesting there be more at play than just the influence of displacement. It is recommended that future research analyse the dimensions of place attachment and activity involvement individually, accounting for differences in the nature and strength of the relationship, and consider other moderating variables, such as past experience with a site. 


\subsection{Study limitations}

The respondents included in this study represented a relatively advanced level of diver, limiting the general applicability of the results beyond the sample populations under investigation. Future research might considering applying the PMT among different samples of a population (e.g., novice divers, resort divers). It may be that some segments of the dive market are less vulnerable to coral bleaching then others. For example, Dearden et al. (2006) found that less specialized divers tended to value servicerelated elements of the experience (e.g. skill development). Knowledge of different behavioural responses to coral bleaching will better prepare dive operators' ability to cope with possible shifts in demand and market segments. Further, future research should also include an option to increase dive frequency to account for the possibility that coral bleaching may be an attraction to some divers, as posed by (Lemelin et al., 2010, 2013).

A limitation of the current investigation is that measures of intention were assessed at a single point in time, and thus does not account for the fact that one's intention to perform an action can vary from one point in time to the next. Further to this point, the study did not assess the extent to which intention translated into action. In this regard, additional follow-up research with respondents who have since encountered coral bleaching may offer insights into the models' ability to predict actual behaviours.

Since the study relied on quantitative data to evaluate the predictability of behavioural intentions, further qualitative research is recommended with a subset of the study's respondents to provide contextual information for the different response variables. As this is one of the first applications of PMT to the study of tourists' 
adaptation behaviour, this contextual information will be of use in interpreting the validity of the survey measures.

Another limitation of this study is that it did not take into consideration adaptations in supply-side factors. Yet, such modifications will likely become more common in response to enduring effects. For example, Dawson et al. (2009) found that ski area operators adapted better to warmer conditions in consecutively marginal seasons (1997-1999), posting a profit regionally despite increased operating costs and a shorter ski season, having likely learned from the experiences of the previous winters. Technological adaptations such as snowmaking can significantly influence the vulnerability of the tourism sector, where ski areas with insufficient snowmaking facilities experience a higher sensitivity to climate change impacts (Steiger et al., 2017). Such adaptations will help to determine the geographic distribution of future supply. In the context of scuba diving, Kirkbride-Smith, Wheeler, \& Johnson (2013) found that novice divers elected artificial reefs in preference to natural reefs, suggesting there are supply-side adaptations that can be utilized to retain a portion of the dive market. It is recommended that further research investigate the acceptability of alternative dive sites, including the use of artificial reefs.

Overall, results from the study demonstrate that evaluation of possible adaptation options provides insight into how and why scuba divers intend to adapt, thus addressing the two-fold need for evidence of dive-related adaptation and understanding the cognitive processes that determine whether or not divers adapt their behaviour in response to an environmental threat. The study supports the application of Protection Motivation Theory over the use of the more commonly applied activity involvement and place attachment 
constructs in the tourism and recreation literatures, and recommends further investigation into using this framework to strengthen and build on the practical, theoretical, and methodological contributions of this research. 


\section{REFERENCES}

Abraham, C. S., Sheeran, P., Abrams, D., \& Spears, R. (1994). Exploring teenagers' adaptive and maladaptive thinking in relation to the threat of hiv infection. Psychology \& Health, 9(4), 253-272.

Agustin, C., \& Singh, J. (2005). Curvilinear effects of consumer loyalty determinants in relational exchanges. Journal of Marketing Research, 42(1), 96-108.

Ajzen, I. (1985). From Intentions to Actions: A Theory of Planned Behaviour. In Action Control (pp. 11-39). Springer Berlin Heidelberg. 69746-3_2

Ajzen, I. (1991). The theory of planned behaviour. Organizational Behaviour and Human Decision Processes, 50(2), 179-211.

Ajzen, I. (2005). Attitudes, Personality, and Behaviour. United Kingdom: McGraw-Hill Education.

Ajzen, I., \& Fishbein, M. (1969). The prediction of behavioural intentions in a choice situation. Journal of Experimental Social Psychology, 5(4), 400-416.

Alexandris, K., Kouthouris, C., Funk, D., \& Tziouma, O. (2013). The use of negotiation strategies among recreational participants with different involvement levels: The case of recreational swimmers. Leisure Studies, 32(3), 299-317.

Amelung, B., Nicholls, S., \& Viner, D. (2007). Implications of Global Climate Change for Tourism Flows and Seasonality. Journal of Travel Research, 45(3), 285-296.

Anderson, L. E., \& Loomis, D. K. (2012). Normative Standards for Coral Reef Conditions: A Comparison of SCUBA Divers by Specialization Level. Journal of Leisure Research, 44(2), 257-274.

Andersson, J. E. C. (2007). The recreational cost of coral bleaching - A stated and revealed preference study of international tourists. Ecological Economics, 62(3-4), 704-715.

Anthony, K. R. N., Kline, D. I., Diaz-Pulido, G., Dove, S., \& Hoegh-Guldberg, O. (2008). Ocean acidification causes bleaching and productivity loss in coral reef builders. Proceedings of the National Academy of Sciences , 105(45), 17442-17446.

Armitage, C. J., \& Conner, M. (2001). Efficacy of the Theory of Planned Behaviour: A meta-analytic review. British Journal of Social Psychology, 40(4), 471-499.

Baggaley, A. R., \& Hull, A. L. (1983). The effect of nonlinear transformations on a Likert scale. Evaluation \& the Health Professions, 6(4), 483-491.

Baker, A. C., Glynn, P. W., \& Riegl, B. (2008). Climate change and coral reef bleaching: An ecological assessment of long-term impacts, recovery trends and future outlook. Estuarine, Coastal and Shelf Science, 80(4), 435-471.

Bandura, A. (1977). Self-efficacy: Toward a unifying theory of behavioural change. Psychological Review, 84(2), 191-215.

Bandura, A. (1982). Self-efficacy mechanism in human agency. American Psychologist, $37(2), 122-147$.

Batra, A. (2008). Foreign Tourists' Perception Towards Personal Safety And Potential Crime While Visiting Bangkok. Anatolia, 19(1), 89-101.

Baumgartner, R., \& Heberlein, T. A. (1979). Process, Goal, and Social Interaction Differences in Recreation: What Makes and Activity Substitutable. In Annual 
Meeting of the Rural Sociological Society. Burlington, VT.

Becker, R. H. (1981). Displacement of recreational users between the lower St. Croix and upper Mississippi rivers. Journal of Environmental Management, UK, 13(3), 259267.

Bedoya, D. (2013). Exploring Detracting Elements and Coping Mechanisms Reported in Four Trails along the Going-To-The-Sun Road Corridor in Glacier National Park. University of Montana.

Behringer, J., Buerki, R., \& Fuhrer, J. (2000). Participatory integrated assessment of adaptation to climate change in alpine tourism and mountain agriculture. Integrated Assessment, 1(4), 331-338.

Belk, R. W., Wallendorf, M., \& Holbrook, M. B. (n.d.). Collecting in a consumer culture. In R. W. Belk (Ed.), Highways and Buyways: Naturalistic Research from the Consumer Behaviour Odyssey. Provo, UT: Association for Consumer Research.

Biesanz, J. C., Falk, C. F., \& Savalei, V. (2010). Assessing mediational models: Testing and interval estimation for indirect effects. Multivariate Behavioural Research, 45(4), 661-701.

Bollen, K. A., \& Stine, R. (1990). Direct and indirect effects: Classical and bootstrap estimates of variability. Sociological Methodology, 115-140.

Bonaiuto, M., Carrus, G., Martorella, H., \& Bonnes, M. (2002). Local identity processes and environmental attitudes in land use changes: The case of natural protected areas. Journal of Economic Psychology, 23(5), 631-653.

Bricker, K. S., \& Kerstetter, D. L. (2000). Level of Specialization and Place Attachment: An Exploratory Study of Whitewater Recreationists. Leisure Sciences, 22(4), 233 257.

Brody, S. D., Zahran, S., Vedlitz, A., \& Grover, H. (2008). Examining the Relationship Between Physical Vulnerability and Public Perceptions of Global Climate Change in the United States. Environment and Behaviour, 40(1), 72-95.

Brown, B. E. (1997). Coral bleaching: causes and consequences. Coral Reefs, 16(1), S129--S138.

Bruno, J. F., \& Selig, E. R. (2007). Regional decline of coral cover in the Indo-Pacific: Timing, extent, and subregional comparisons. PLOS ONE, 2(8), e711.

Brunson, M. W., \& Shelby, B. (1993). Recreation Substitutability - a Research Agenda. Leisure Sciences, 15(1), 67-74.

Bryan, H. (1977). Leisure value systems and recreational specialization: The case of trout fishermen. Journal of Leisure Research, 9(3), 174-187.

Bryant, C. R., Smit, B., Brklacich, M., Johnston, T. R., Smithers, J., Chiotti, Q., \& Singh, B. (2000). Adaptation in Canadian agriculture to climatic variability and change. In Societal adaptation to climate variability and change (pp. 181-201). Springer.

Budruk, M., Stanis, S. A. W., Schneider, I. E., \& Anderson, D. H. (2011). Differentiating place attachment dimensions among proximate and distant visitors to two waterbased recreation areas. Society and Natural Resources, 24(9), 917-932.

Budruk, M., Wilhem Stanis, S. A., Schneider, I. E., \& Heisey, J. J. (2008). Crowding and experience-use history: A study of the moderating effect of place attachment among water-based recreationists. Environmental Management, 41(4), 528-537.

Burke, L., Reytar, K., Spalding, M., \& Perry, A. (2011). Reefs at risk: Revisited. Washington, D.C. 
Cao, L., \& Caldeira, K. (2008). Atmospheric CO2 stabilization and ocean acidification. Geophysical Research Letters, 35(19).

Carifio, J., \& Perla, R. J. (2007). Ten common misunderstandings, misconceptions, persistent myths and urban legends about Likert scales and Likert response formats and their antidotes. Journal of Social Sciences, 3(3), 106-116.

Cesar, H. (2000). Impacts of the 1998 Coral Bleaching Event on Tourism in El Nido, Philippines.

Chang, S., \& Gibson, H. J. (2011). Physically active leisure and tourism connection: Leisure involvement and choice of tourism activities among paddlers. Leisure Sciences, 33(2), 162-181.

Chen, R. J. C., \& Noriega, P. (2004). The Impacts of Terrorism. Journal of Travel \& Tourism Marketing, 15(2-3), 81-97.

Climate Commission. (2013). Bleaching on the Great Barrier Reef. Retrieved August 1, 2014, from https://climatecommission.angrygoats.net/others/avoiding-unadaptablea-4-degree-celsius-world/attachment/image-collection-officer/

Cohen, J., Cohen, P., West, S. G., \& Aiken, L. S. (2013). Applied multiple regression/correlation analysis for the behavioural sciences. Routledge.

Conner, M., \& Armitage, C. J. (1998). Extending the Theory of Planned Behaviour: A Review and Avenues for Further Research. Journal of Applied Social Psychology, 28(15), 1429-1464.

Dang, H. Le, Li, E., Nuberg, I., \& Bruwer, J. (2014). Understanding farmers' behavioural intention to climate change: A structural equation modelling study in the Mekong Delta, Vietnam. Environmental Science and Policy, 41(August 2016), 11-22.

Davenport, M. A., \& Anderson, D. H. (2005). Getting from sense of place to place-based management: An interpretive investigation of place meanings and perceptions of landscape change. Society and Natural Resources, 18(7), 625-641.

Davis, D., \& Tisdell, C. (1996). Economic Management of Recreational Scuba Diving and the Environment. Journal of Environmental Management, 48(February 1994), 229-248.

Dawson, J., Havitz, M., \& Scott, D. (2011). Behavioural adaptation of alpine skiers to climate change: Examining activity involvement and place loyalty. Journal of Travel \& Tourism Marketing, 28(May), 388-404.

Dawson, J., Scott, D., \& Havitz, M. (2013). Skier demand and behavioural adaptation to climate change in the US Northeast. Leisure/Loisir, 37(2), 127-143.

Dawson, J., Scott, D., \& Mcboyle, G. (2009). Climate change analogue analysis of ski tourism in the northeastern USA. Climate Research, 39(1), 1-9.

Dearden, P., Bennett, M., \& Rollins, R. (2006). Implications for coral reef conservation of diver specialization. Environmental Conservation, 33(04), 353-363.

Deloitte Access Economics. (2013). Economic Contribution of the Great Barrier Reef. Great Barrier Reef Marine Park Authority, Townsville, pp. 195.

Dickson, T., \& Dolnicar, S. (2004). No risk, no fun the role of perceived risk in adventure tourism. In C. Cooper (Ed.), CAUTHE 2004: Creating Tourism Knowledge (pp. 184-189). Brisbane, Qld.: Common Ground Publishing.

Ditton, R. B., Osburn, H. R., Baker, T. L., \& Thailing, C. E. (2002). Demographics, attitudes, and reef management preferences of sport divers in offshore Texas waters. ICES Journal of Marine Science, 59, S186-S191. 
Donner, S. D., Rickbeil, G. J. M., \& Heron, S. F. (2017). A new, high-resolution global mass coral bleaching database. PloS One, 12(4), e0175490.

Eakin, C. M., Lough, J. M., \& Heron, S. F. (2009). Climate Variability and Change: Monitoring Data and Evidence for Increased Coral Bleaching Stress. In M. J. H. van Oppen \& J. M. Lough (Eds.), Coral Bleaching: Patterns, Processes, Causes and Consequences (pp. 41-67). Berlin, Heidelberg: Springer Berlin Heidelberg.

Eakin, C. M., Lough, J. M., Heron, S. F., \& Liu, G. (2018). Climate Variability and Change: Monitoring Data and Evidence for Increased Coral Bleaching Stress. In Coral Bleaching (pp. 51-84). Springer.

Eder, R., \& Arnberger, A. (2012). The Influence of Place Attachment and Experience Use History on Perceived Depreciative Visitor Behaviour and Crowding in an Urban National Park. Environmental Management, 50(4), 566-580.

Evans, J. R., \& Mathur, A. (2005). The value of online surveys. Internet Research, 15(2), 195-219.

Everitt, B. S., \& Dunn, G. (2001). Applied multivariate data analysis (Vol. 2). Wiley Online Library.

Fitt, W. K., McFarland, F. K., Warner, M. E., \& Chilcoat, G. C. (2000). Seasonal patterns of tissue biomass and densities of symbiotic dinoflagellates in reef corals and relation to coral bleaching. Limnology and Oceanography, 45(3), 677-685.

Fitzsimmons, C. (2007). Why Dive? And Why Here? A study of recreational diver enjoyment at a Fijian eco-tourist resort. In Proceedings of the 5th International Coastal and Marine Tourism Congress. Auckland, NZ.

Floyd, D. L., Prentice-Dunn, S., \& Rogers, R. W. (2000). A Meta-Analysis of Research on Protection Motivation Theory. Journal of Applied Social Psychology, 30(2), 407429.

Floyd, M. F., Gibson, H., Pennington-Gray, L., \& Thapa, B. (2004). The Effect of Risk Perceptions on Intentions to Travel in the Aftermath of September 11, 2001. Journal of Travel \& Tourism Marketing, 15(2-3), 19-38.

Fornell, C., Johnson, M. D., Anderson, E. W., Cha, J., \& Bryant, B. E. (1996). The American Customer Satisfaction Index: Nature, Purpose, and Findings. Journal of Marketing, 60(4), 7.

Fritz, M. S., Taylor, A. B., \& MacKinnon, D. P. (2012). Explanation of two anomalous results in statistical mediation analysis. Multivariate Behavioural Research, 47(1), 61-87.

Fuchs, G. (2013). Low Versus High Sensation-seeking Tourists: a Study of Backpackers' Experience Risk Perception. International Journal of Tourism Research, 15(1), 8192.

Gahwiler, P., \& Havitz, M. E. (1998). Towards a Relational Understanding of Leisure Social Worlds, Involvement Psychological Commitment and Behavioural Loyalty.pdf. Leisure Sciences, 20(1), 1-23.

Garrod, B. (2008). Market segments and tourist typologies for diving tourism. In New Frontiers in Marine Tourism (pp. 31-49).

Gelman, A., \& Stern, H. (2006). The difference between "significant" and "not significant" is not itself statistically significant. The American Statistician, 60(4), $328-331$.

Giles-Corti, B., Broomhall, M. H., Knuiman, M., Collins, C., Douglas, K., Ng, K., ... \& 
Donovan, R. J. (2005). Increasing walking: how important is distance to, attractiveness, and size of public open space?. American journal of preventive medicine, 28(2), 169-176.

Goreau, T. J., \& Hayes, R. L. (1994). Coral bleaching and ocean" hot spots". AmbioJournal of Human Environment Research and Management, 23(3), 176-180.

Goreau, T., Mcclanahan, T. R., Hayes, R., \& Strong, A. (2000). Conservation of Coral Reefs after the 1998 Bleaching Event. Conservation Biology, 14(1), 5-15.

Gossling, S., Lindén, O., Helmersson, J., Liljenberg, J., \& Quarm, S. (2008). Diving and Global Environmental Change: A Mauritius Case Study. In B. Garrod \& S. Gössling (Eds.), New Frontiers in Marine Tourism: Diving Experiences, Sustainability, Management.

Gössling, S., Scott, D., Hall, C. M., Ceron, J. P., \& Dubois, G. (2012). Consumer behaviour and demand response of tourists to climate change. Annals of Tourism Research, 39(1), 36-58.

Graefe, D. A., \& Dawson, C. P. (2013). Rooted in Place: Understanding Camper Substitution Preferences. Leisure Sciences, 35(4), 365-381.

Graham, T., Idechong, N., \& Sherwood, K. (2000). The Value of Dive-tourism and the Impacts of Coral Bleaching on Diving in Palau. In 9th International Coral Reef Symposium.

Gregory, D., Johnston, R., Pratt, G., Watts, M., \& Whatmore, S. (Eds.). (2011). The dictionary of human geography. John Wiley \& Sons.

Grothmann, T., \& Patt, A. (2005). Adaptive capacity and human cognition: The process of individual adaptation to climate change. Global Environmental Change, 15(3), 199-213.

Gunderson, K., \& Watson, A. (2007). Understanding place meanings on the bitterroot national forest, Montana. Society and Natural Resources, 20(8), 705-721.

Hagger, M. S., Chatzisarantis, N. L. D., \& Biddle, S. J. H. (2002). A Meta-Analytic Review of the Theories of Reasoned Action and Planned Behaviour in Physical Activity: Predictive Validity and the Contribution of Additional Variables. Journal of Sport and Exercise Psychology, 24(1), 3-32.

Hall, T. E., \& Cole, D. N. (2007). Changes in the motivations, perceptions, and behaviours of recreation users: Displacement and coping in wilderness. Research Paper RMRS-RP-63, (April), 37.

Hall, T. E., \& Shelby, B. (2000). Temporal and Spatial Displacement: Evidence from A High-Use Reservoir and Alternate Sites. Journal of Leisure Research, 32(4), 435456.

Hammitt, W. E., Backlund, E. A., \& Bixler, R. D. (2004). Experience use history, place bonding and resource substitution of trout anglers during recreation engagements. Journal of Leisure Research, 36(3).

Han, J. H., Noh, E. J., \& Oh, C.-O. (2015). Applying the concept of site substitution to coastal tourism. Tourism Geographies, 17(3), 370-384.

Havitz, M. E., \& Dimanche, F. (1997). Leisure involvement revisited: Conceptual conundrums and measurement advances. Journal of Leisure Research, 29(3), 245278.

Havitz, M. E., \& Dimanche, F. (1999). Leisure Involvement Revisited: Drive Properties and Paradoxes. Journal of Leisure Research, 31(2), 122-149. 
Havitz, M. E., Kaczynski, A. T., \& Mannell, R. C. (2013). Exploring relationships between physical activity, leisure involvement, self-efficacy, and motivation via participant segmentation. Leisure Sciences, 35(1), 45-62.

Hayes, A. F. (2009). Beyond Baron and Kenny: Statistical mediation analysis in the new millennium. Communication Monographs, 76(4), 408-420.

Hayes, A. F. (2013). Introduction to mediation, moderation, and conditional process analysis: A regression-based approach.

Hayes, A. F. (2017). Introduction to mediation, moderation, and conditional process analysis: A regression-based approach. Guilford Publications.

Hayes, A. F., Montoya, A. K., \& Rockwood, N. J. (2017). The analysis of mechanisms and their contingencies: PROCESS versus structural equation modeling. Australasian Marketing Journal (AMJ), 25(1), 76-81.

Hayes, A. F., \& Preacher, K. J. (2011). Indirect and direct effects of a multicategorical causal agent in statistical mediation analysis. Manuscript Submitted for Publication, 6.

Hayes, A. F., \& Scharkow, M. (2013). The relative trustworthiness of inferential tests of the indirect effect in statistical mediation analysis: Does method really matter? Psychological Science, 24(10), 1918-1927.

Hellier, P. K., Geursen, G. M., Carr, R. A., \& Rickard, J. A. (2003). Customer repurchase intention. European Journal of Marketing, 37(11/12), 1762-1800.

Hendee, J. C., \& Burdge, R. J. (1974). The substitutability concept: Implications for recreation research and management. Journal of Leisure Research, 6(2), 157-162.

Hendricks, W. W., Chavez, D. J., \& Bricker, K. S. (2008). Place attachment and recreational constraints relating to fire management. Fire Social Science Research From the Pacific Southwest Research Station: Studies Supported by National Fire Plan Funds. Riverside, CA.

Hillmer-Pegram, K. C. (2011). The Social-Ecological Resilience of Dive Operators in the US Virgin Islands. Pennsylvania State University.

Hoegh-Guldberg, O. (1999). Climate change, coral bleaching and the future of the world's coral reefs. Marine and Freshwater Research, 50, 839-866.

Hoegh-Guldberg, O., Mumby, P. J., Hooten, A. J., Steneck, R. S., Greenfield, P., Gomez, E., ... Hatziolos, M. E. (2007). Coral Reefs under Rapid Climate Change and Ocean Acidification. Science, 318, 1737-1742.

Hoegh-Guldberg, O., Poloczanska, E. S., Skirving, W., \& Dove, S. (2017). Coral reef ecosystems under climate change and ocean acidification. Frontiers in Marine Science, 4, 158.

Hoey, A. S., Howells, E., Johansen, J. L., Hobbs, J.-P. A., Messmer, V., McCowan, D. M., ... Pratchett, M. S. (2016). Recent advances in understanding the effects of climate change on coral reefs. Diversity, 8(2), 12.

Hoogland, J. J., \& Boomsma, A. (1998). Robustness studies in covariance structure modeling: An overview and a meta-analysis. Sociological Methods \& Research, 26(3), 329-367.

Horng, J.-S., Hu, M.-L. M., Teng, C.-C. C., \& Lin, L. (2014). Energy Saving and Carbon Reduction Behaviours in Tourism \&\#8211; A Perception Study of Asian Visitors from a Protection Motivation Theory Perspective. Asia Pacific Journal of Tourism Research, 19(6), 721-735. 
Hubbard, J., \& Mannell, R. C. (2001). Testing competing models of the leisure constraint negotiation process in a corporate employee recreation setting. Leisure Sciences, 23(3), 145-163.

Hughes, T. P., Baird, A. H., Bellwood, D. R., Card, M., Connolly, S. R., Folke, C., ... \&

Lough, J. M. (2003). Climate change, human impacts, and the resilience of coral reefs. science, 301(5635), 929-933.

Hunter, E., \& Röös, E. (2016). Fear of climate change consequences and predictors of intentions to alter meat consumption. Food Policy, 62, 151-160.

Hyun, W.-Y., \& Ditton, R. B. (2006). Using Multinomial Logistic Regression Analysis to Understand Anglers Willingness to Substitute Other Fishing Locations. In Proceedings of the 2009 Northeastern Recreation Research Symposium (pp. 248257). Bolton Landing, NY.

Iso-Ahola, S. E. (1986). A theory of substitutability of leisure behaviour. Leisure Sciences, 8(4), 367-389.

Iwasaki, Y., \& Havitz, M. E. (2004). Examining relationships between leisure involvement, psychological commitment and loyalty to a recreation agency. Journal of Leisure Research, 36(1), 45-72.

Jackson, E. L., Crawford, D. W., \& Godbey, G. (1993). Negotiation of leisure constraints. Leisure Sciences, 15(1), 1-11.

Jacob, G. R., \& Schreyer, R. (1980). Conflict in Outdoor Recreation: A Theoretical Perspective. Journal of Leisure Research, 12(4).

Jacoby, J., \& Kaplan, L. B. (1972). The Components of Perceived Risk. ACR Special Volumes, $\mathrm{SV}$-02.

Jakobsson, U. (2004). Statistical presentation and analysis of ordinal data in nursing research. Scandinavian Journal of Caring Sciences, 18(4), 437-440.

Jamieson, S. (2004). Likert scales: how to (ab) use them. Medical Education, 38(12), 1217-1218.

Johnson, A. K., \& Dawson, C. P. (2004). An exploratory study of the complexities of coping behavior in Adirondack wilderness. Leisure Sciences, 26(3), 281-293.

Jun, J., \& Kyle, G. T. (2011). Understanding the Role of Identity in the Constraint Negotiation Process. Leisure Sciences, 33(4), 309-331.

Khoo-Lattimore, C., \& Mura, P. (2011). Away from Home: A New Revelation of Young Tourist Behaviour. Tourism Analysis, 16, 1-0.

Kingsbury, P. T., \& Brunn, S. D. (2004). Freud, Tourism, and Terror. Journal of Travel \& Tourism Marketing, 15(2-3), 39-61.

Kirkbride-Smith, A. E., Wheeler, P. M., \& Johnson, M. L. (2013). The Relationship between Diver Experience Levels and Perceptions of Attractiveness of Artificial Reefs - Examination of a Potential Management Tool. PLoS ONE, 8(7).

Koerth, J., Vafeidis, A. T., Hinkel, J., \& Sterr, H. (2013). What motivates coastal households to adapt pro-actively to sea-level rise and increasing flood risk? Regional Environmental Change, 13(4), 897-909.

König, U. (1998). Tourism in a warmer world: implications of climate change due to enhanced greenhouse effect for the ski industry in the Australian Alps. Zurich: University of Zurich.

Korstanje, M. (2009). Re-visiting risk perception therory in the context of travel. EReview of Tourism Research, 7(4), 68-82. 
Kragt, M. E., Roebeling, P. C., \& Ruijs, A. (2009). Effects of Great Barrier Reef degradation on recreational reef-trip demand: A contingent behaviour approach. Australian Journal of Agricultural and Resource Economics, 53(2), 213-229.

Kuentzel, W. F., \& Heberlein, T. a. (1992). Cognitive and behavioural adaptations to perceived crowding: A panel study of coping and displacement. Journal of Leisure Research, 24(4), 377-393.

Kuruppu, N., \& Liverman, D. (2011). Mental preparation for climate adaptation: The role of cognition and culture in enhancing adaptive capacity of water management in Kiribati. Global Environmental Change, 21(2), 657-669.

Kuzon Jr, W. M., Urbanchek, M. G., \& McCabe, S. (1996). The seven deadly sins of statistical analysis. Annals of Plastic Surgery, 37(3), 265-272.

Kyle, G., Graefe, A., Manning, R., \& Bacon, J. (2004). Effects of place attachment on users' perceptions of social and environmental conditions in a natural setting. Journal of Environmental Psychology, 24(2), 213-225.

Kyle, G., Absher, J., Norman, W., Hammitt, W., \& Jodice, L. (2007). A Modified Involvement Scale. Leisure Studies, 26(4), 399-427.

Kyle, G., \& Chick, G. (2002). The social nature of leisure involvement. Journal of Leisure Research, 34(4), 426-448.

Kyle, G., Graefe, A., Manning, R., \& Bacon, J. (2004). Effect of activity involvement and place attachment on recreationists' perceptions of setting density.pdf. Journal of Leisure Research, 36(2), 209-231.

Kyle, G. T., Graefe, A. R., Manning, R. E., \& Bacon, J. (2005). An examination of the relationship between leisure activity involvement and place attachment among hikers along the Appalachian Trail. Journal of Leisure Research, 35(3), 219-273.

Laurent, G., \& Kapferer, J.-N. (1985). Measuring Consumer Involvement Profiles. Journal of Marketing Research, 22(1), 41.

Law, R. (2006). The perceived impact of risks on travel decisions. International Journal of Tourism Research, 8(4), 289-300.

Lazarus, R. S. (1966). Psychological stress and the coping process. New York: McGrawHill.

Lazarus, R. S., \& Folkman, S. (1984). Coping and adaptation. The Handbook of Behavioural Medicine, 282-325.

Lei, M., \& Lomax, R. G. (2005). The effect of varying degrees of nonnormality in structural equation modeling. Structural Equation Modeling, 12(1), 1-27.

Lemelin, H., Dawson, J., \& Stewart, E. J. (Eds.). (2013). Last chance tourism: Adapting tourism opportunities in a changing world. Routledge.

Lemelin, H., Dawson, J., Stewart, E. J., Maher, P., \& Lueck, M. (2010). Last-chance tourism: the boom, doom, and gloom of visiting vanishing destinations. Current Issues in Tourism, 13(5), 477-493.

Leventhal, H. (1970). Findings and Theory in the Study of Fear Communications. Advances in Experimental Social Psychology, 5, 119-186.

Lew, A. (2013). A world geography of recreational scuba diving. In Scuba diving tourism: contemporary geographies of leisure, tourism and mobility (pp. 29-51). United Kingdom: Routledge.

Loomis, D. K., Anderson, L. E., Hawkins, C., \& Paterson, S. K. (2008). Understanding Coral Reef Use: SCUBA Diving in the Florida Keys by Residents and Non-Residents 
during 2006-2007. Human Dimensions of Marine and Coastal Ecosystems Program.

Loucks-Atkinson, A., \& Mannell, R. C. (2007). Role of self-efficacy in the constraints negotiation process: The case of individuals with fibromyalgia syndrome. Leisure Sciences, 29(1), 19-36.

Lozano, L. M., García-Cueto, E., \& Muñiz, J. (2008). Effect of the number of response categories on the reliability and validity of rating scales. Methodology: European Journal of Research Methods for the Behavioural and Social Sciences, 4(2), 73.

Luers, A. L., Lobell, D. B., Sklar, L. S., Addams, C. L., \& Matson, P. A. (2003). A method for quantifying vulnerability, applied to the agricultural system of the Yaqui Valley, Mexico. Global Environmental Change, 13(4), 255-267.

Maccarthy, M., O'neill, M., \& Williams, P. (2006). Customer satisfaction and Scubadiving: Some insights from the deep. The Service Industries Journal, 26(5), 537555.

MacKinnon, D. P., Lockwood, C. M., Hoffman, J. M., West, S. G., \& Sheets, V. (2002). A comparison of methods to test mediation and other intervening variable effects. Psychological Methods, 7(1), 83.

MacKinnon, D. P., Lockwood, C. M., \& Williams, J. (2004). Confidence limits for the indirect effect: Distribution of the product and resampling methods. Multivariate Behavioural Research, 39(1), 99-128.

Manfredo, M. J., \& Anderson, D. (1987). The influence of activity importance and similarity on perception of recreation substitutes. Leisure Sciences, 9(2), 77-86.

Manning, R. E. (1986). Studies in outdoor recreation - a review and synthesis of the social science literature in outdoor recreation. Studies in outdoor recreation - a review and synthesis of the social science literature in outdoor recreation. Corvallis, OR: Oregon State University Press.

Manning, R. E., \& Freimund, W. A. (2004). Use of Visual Research Methods to Measure Standards of Quality for Parks and Outdoor Recreation. Journal of Leisure Research, 36(4), 557-579.

Manning, R. E., \& Valliere, W. A. (2001). Coping in Outdoor Recreation : Causes and Consequences of Crowding and Conflict Among Community Residents. Journal of Leisure Research, 33(4), 410-426.

Marshall, N. A., \& Marshall, P. A. (2007). Conceptualizing and Operationalizing Social Resilience within Commercial Fisheries in Northern Australia. Ecology and Society, 12(1).

Marshall, N. A., Marshall, P. A., Abdulla, A., Rouphael, T., \& Ali, A. (2011). Preparing for climate change: recognising its early impacts through the perceptions of dive tourists and dive operators in the Egyptian Red Sea. Current Issues in Tourism, 14(6), 507-518.

Marshall, N. A., Tobin, R. C., Marshall, P. A., Gooch, M., \& Hobday, A. J. (2013). Social Vulnerability of Marine Resource Users to Extreme Weather Events. Ecosystems, 16(5), 797-809.

Martin, I. M., Bender, H., \& Raish, C. (2007). What motivates individuals to protect themselves from risks: The case of wildland fires. Risk Analysis, 27(4), 887-900.

Maurer, T. J., \& Pierce, H. R. (1998). A comparison of Likert scale and traditional measures of self-efficacy. Journal of Applied Psychology, 83(2), 324.

McFarlane, B. L. (2004). Recreation specialization and site choice among vehicle-based 
campers. Leisure Sciences, 26(3), 309-322.

McFarlane, B. L., Boxall, P. C., \& Watson, D. O. (1998). Past Experience and Behavioural Choice among Wilderness Users. Journal of Leisure Research, 30(2), 195-213.

McIntyre, N. (1989). The Personal Meaning of Participation: Enduring Involvement. Journal of Leisure Research, 21(2), 167-179.

McIntyre, N., \& Pigram, J. J. (1992). Recreation specialization reexamined: The case of vehicle-based campers. Leisure Sciences, 14(1), 3-15.

Meyer, L. a, Thapa, B., \& Pennington-Gray, L. (2002). An Exploration of Motivation among Scuba Divers in North Central Florida. In Proceedings of the 2002 Northeastern Recreation Research Symposium.

Miles, J., \& Shevlin, M. (2001). Applying regression and correlation: A guide for students and researchers. Sage.

Miller, J., Muller, E., Rogers, C., Waara, R., Atkinson, A., Whelan, K. R. T., .. Witcher, B. (2009). Coral disease following massive bleaching in 2005 causes $60 \%$ decline in coral cover on reefs in the US Virgin Islands. Coral Reefs, 28(4), 925-937.

Miller, T. a, \& Mccool, S. F. (2003). Leisure Sciences : An Interdisciplinary Journal Coping with Stress in Outdoor Recreational Settings : An Application of Transactional Stress Theory Coping with Stress in Outdoor Recreational Settings : An Application of Transactional Stress Theory. Leisure Sciences, 25(1), 257-275.

Milne, S., Sheeran, P., \& Orbell, S. (2000). Prediction and Intervention in Health Related Behaviour: A Meta Analytic Review of Protection Motivation Theory. Journal of Applied Social Psychology, 30(1), 106-143.

Mooney, C. (2017, April 10). Scientists weep as Australia's Great Barrier Reef struck again by large-scale bleaching. Toronto Star. Toronto. Retrieved from https://www.thestar.com/news/world/2017/04/10/scientists-weep-as-australias-greatbarrier-reef-struck-again-by-large-scale-bleaching.html

Moore, R. L., \& Graefe, A. R. (1994). Attachments to recreation settings: The case of rail-trail users. Leisure Sciences, 16(1), 17-31.

Mortreux, C., \& Barnett, J. (2017). Adaptive capacity : exploring the research frontier. Wiley Interdisciplinary Reviews: Climate Change, 8, e467.

Murgraff, V., White, D., \& Phillips, K. (1999). An application of protection motivation theory to riskier single-occasion drinking. Psychology and Health, 14(2), 339-350.

Musa, G. (2002). Sipadan: A SCUBA-diving paradise: An analysis of tourism impact, diver satisfaction and tourism management. Tourism Geographies, 4(2), 195-209.

Musa, G., Kadir, S. L. S. a., \& Lee, L. (2006). Layang Layang: An Empirical Study on Scuba Divers' Satisfaction. Tourism in Marine Environments, 2(2), 89-102.

National Oceanic and Atmospheric Administration. (2014). No Title. Retrieved April 11, 2017, from http://oceanservice.noaa.gov/education/kits/corals/media/supp_coral05a.html

Needham, M. D., \& Vaske, J. J. (2013). Activity Substitutability and Degree of Specialization among Deer and Elk Hunters in Multiple States. Leisure Sciences, 35(3), 235-255.

Newell, N. D. (1971). An outline history of tropical organic reefs. American Museum novitates; no. 2465.

Ngazy, Z., Jiddawi, N., \& Cesar, H. (2004). Coral bleaching and the demand for coral 
reefs: A marine recreation case in Zanzibar. In Economic valuation and policy priorities for sustainable management of coral reefs (pp. 118-125). WorldFish Center.

Nyaupane, G. P., Graefe, A., \& Burns, R. C. (2003). Does distance matter? Differences in characteristics, behaviours, and attitudes of visitors based on travel distance. In Proceedings of the 2003 Northeastern recreation research symposium (pp. 74-81). United States Department of Agriculture.

O'Brien, K., Eriksen, S. E. H., Schjolden, A., \& Nygaard, L. P. (2004). What's in a word? Conflicting interpretations of vulnerability in climate change research (No. 2004:04). CICERO Working Paper. CICERO Center for International Climate and Environmental Research - Oslo.

Oh, C. O., Sutton, S. G., \& Sorice, M. G. (2013). Assessing the Role of Recreation Specialization in Fishing Site Substitution. Leisure Sciences, 35(3), 256-272.

Okazaki, S., \& Chung, H. (2004). Fear appeal and Protection Motivation Theory in anticigarette campaign: Literature review and research propositions.

Oliver, R. L. (1980). A Cognitive Model of the Antecedents and Consequences of Satisfaction Decisions. Journal of Marketing Research, 17(4), 460.

PADI. (2013). Global Certification and Membership Statistics Worldwide Corporate Statistics. Retrieved from https://www.padi.com/

Pandolfi, J. M. (2011). The paleoecology of coral reefs. In Coral reefs: an ecosystem in transition (pp. 13-24). Springer.

Pandolfi, J. M., \& Greenstein, B. J. (2007). Using the past to understand the future: palaeoecology of coral reefs. The Great Barrier Reef Marine Park Authority.

Pandolfi, J. M., \& Jackson, J. B. (2006). Ecological persistence interrupted in Caribbean coral reefs. Ecology Letters, 9(7), 818-826.

Paterson, S., Young, S., Loomis, D. K., \& Obenour, W. (2012). Resource Attributes That Contribute to Nonresident Diver Satisfaction in the Florida Keys. Tourism in Marine Environments, 8, 47-60.

Pauly, D. (1995). Anecdotes and the shifting baseline syndrome of fisheries. Trends in ecology \& evolution, 10(10), 430.

Peat, J. (2001). Health science research: a handbook of quantitative methods. Sage.

Perch-Nielsen, S. L., Bättig, M. B., \& Imboden, D. (2008). Exploring the link between climate change and migration. Climatic change, 91(3-4), 375.

Peter, J. P., \& Olson, J. C. (1987). Consumer Behaviour: Marketing Strategy Perspectives. Homewood, IL: Irwin.

Pew Research Center. (2018). Internet/ Broadband Fact Sheet. Retrieved June 1, 2018, from http://www.pewinternet.org/fact-sheet/internet-broadband/

Pickering, C. M., Castley, J. G., \& Burtt, M. (2010). Skiing less often in a warmer world: Attitudes of tourists to climate change in an Australian ski resort. Geographical Research, 48(2), 137-147.

Preacher, K. J., \& Selig, J. P. (2012). Advantages of Monte Carlo confidence intervals for indirect effects. Communication Methods and Measures, 6(2), 77-98.

Pritchard, M. P., \& Howard, D. R. (1997). The loyal traveler: Examining a typology of service patronage. Journal of Travel Research, 35(4), 2-10.

Proshansky, H. M. (1978). The City and Self-Identity. Environment and Behaviour, 10(2), 147-169. 
Randall, D. M., \& Wolff, J. A. (1994). The time interval in the intention-behaviour relationship: Meta-analysis. British Journal of Social Psychology, 33(4), 405-418.

Ray, N. M., \& Tabor, S. . (2003). Cyber surveys come of age. Marketing Research, 3237.

Roehl, W. S., \& Fesenmaier, D. R. (1992). Risk Perceptions and Pleasure Travel: An Exploratory Analysis. Journal of Travel Research, 30(4), 17-26.

Rogers, R. W. (1975). A Protection Motivation Theory of Fear Appeals and Attitude Change. The Journal of Psychology, 91(1), 93-114.

Rogers, R. W. (1983). Cognitive and psychological processes in fear appeals and attitude change: A revised theory of protection motivation. Social Psychophysiology: A Sourcebook, 153-176.

Rogers, R. W., \& Maddux, J. E. (1983). Protection motivation and self-efficacy: A revised theory of fear appeals and attitude change. Journal of Experimental Social Psychology, 19(5), 469-479.

Rossi, S. D., Byrne, J. A., \& Pickering, C. M. (2015). The role of distance in peri-urban national park use: Who visits them and how far do they travel?. Applied Geography, 63, 77-88.

Rutty, M., \& Scott, D. (2016). Comparison of climate preferences for domestic and international beach holidays: A case study of Canadian travelers. Atmosphere, 7(2), 30-42.

Rutty, M., Scott, D., Johnson, P., Jover, E., Pons, M., \& Steiger, R. (2015). Behavioural adaptation of skiers to climatic variability and change in Ontario, Canada. Journal of Outdoor Recreation and Tourism, 11, 13-21.

Schafer, J. L., \& Olsen, M. K. (1998). Multiple imputation for multivariate missing-data problems: A data analyst's perspective. Multivariate Behavioural Research, 33(4), 545-571.

Schneider, I. E., \& Hammitt, W. E. (1995). Visitor response to outdoor recreation conflict: A conceptual approach. Leisure Sciences, 17(3), 223-234.

Schneider, I. E., \& Wilhelm Stanis, S. A. (2007). Coping: An alternative conceptualization for constraint negotiation and accommodation. Leisure Sciences, 29(4), 391-401.

Schoenbachler, D. D., \& Whittler, T. E. (1996). Adolescent processing of social and physical threat communications. Journal of Advertising, 25(4), 37-54.

Schreyer, R., \& Knopf, R. C. (1984). The dynamics of change in outdoor recreation environments - some equity issues. Journal of Park and Recreation Administration, 2(1), 9-19.

Schuster, R., Hammitt, W. E., \& Moore, D. (2006). Stress apraisal and coping response to hassles experienced in outdoor recreation settings. Leisure Sciences, 28(2), 97-113.

Schuster, R. M., Hammitt, W. E., Moore, D., \& Hammitt, W. E. (2003). A Theoretical Model to Measure the Appraisal and Coping Response to Hassles in Outdoor Recreation Settings A Theoretical Model to Measure the Appraisal and Coping Response to Hassles in Outdoor Recreation Settings, (912280237), 277-299.

Schwarzer, R. (1992). Self-efficacy in the adoption and maintenance of health behaviours: Theoretical approaches and a new model. In Self-Efficacy: Thought Control of Action (pp. 217-243). Washington, DC.

Scott, D., Gossling, S., \& Hall, C. M. (2012). International tourism and climate change. 
Wiley Interdisciplinary Reviews: Climate Change, 3(3), 213-232.

Scott, D., Jones, B., \& Konopek, J. (2007). Implications of climate and environmental change for nature-based tourism in the Canadian Rocky Mountains: A case study of Waterton Lakes National Park. Tourism Management, 28(2), 570-579.

Scott, D., \& Shafer, C. S. (2001). Recreational specialization: a critical look at the construct. Journal of Leisure Research, 33(3), 319-343.

Sealey-Baker, M. (2011). Coral Bleaching and Dive Operators in the Caribbean: Perceptions of Environmental Change. University of Waterloo.

Seiders, K., Voss, G. B., Grewal, D., \& Godfrey, A. L. (2005). Do satisfied customers buy more? Examining moderating influences in a retailing context. Journal of Marketing, 69(4), 26-43.

Selig, E. R., Casey, K. S., \& Bruno, J. F. (2010). New insights into global patterns of ocean temperature anomalies: Implications for coral reef health and management. Global Ecology and Biogeography, 19(3), 397-411.

Shafer, C. S., \& Inglis, G. J. (2000). Influence of Social, Biophysical, and Managerial Conditions on Tourism Experiences Within the Great Barrier Reef World Heritage Area. Environmental Management, 26(1), 73-87.

Shani, A., Polak, O., \& Shashar, N. (2012). Artificial Reefs and Mass Marine Ecotourism. Tourism Geographies, 14(March 2015), 361-382.

Sheeran, P. (2002). Intention-Behaviour Relations: A Conceptual and Empirical Review. European Review of Social Psychology, 12(1), 1-36.

Sheeran, P., Conner, M., \& Norman, P. (2001). Can the theory of planned behavior explain patterns of health behavior change?. Health psychology, 20(1), 12.

Shelby, B., Vaske, J. J., \& Heberlein, T. A. (1989). Comparative Analysis of Crowding in Multiple Locations: Results from Fifteen Years of Research. Leisure Sciences, 11, 269-291.

Sheppard, B. H., Hartwick, J., \& Warshaw, P. R. (1988). The Theory of Reasoned Action: A Meta-Analysis of Past Research with Recommendations for Modifications and Future Research. Journal of Consumer Research, 15(3), 325.

Sherif, C. W., Sherif, M., \& Nebergall, R. E. (1965). ttitude and attitude change: The social judgment-involvement approach. Westport, CT: Greenwood Press.

Sherif, M., \& Hovland, C. I. (1961). Social judgment: Assimilation and contrast effects in communication and attitude change. Oxford, England: Yale University Press.

Shrout, P. E., \& Bolger, N. (2002). Mediation in experimental and nonexperimental studies: new procedures and recommendations. Psychological Methods, 7(4), 422.

Silverman, J., Lazar, B., Cao, L., Caldeira, K., \& Erez, J. (2009). Coral reefs may start dissolving when atmospheric CO2 doubles. Geophysical Research Letters, 36(5).

Solomon, M. R. (1999). Consumer Behaviour (4th ed.). Upper Saddle River, NJ: Prentice-Hall.

Sönmez, S., \& Graefe, A. R. (1998a). Determining Future Travel Behaviour from Past Travel Experience and Perceptions of Risk and Safety. Journal of Travel Research, 37(2), 172-177.

Sönmez, S., \& Graefe, A. R. (1998b). Influence of terrorism risk on foreign tourism decisions. Annals of Tourism Research, 25(1), 112-144.

Steiger, R. (2011). The impact of snow scarcity on ski tourism: an analysis of the record warm season 2006/2007 in Tyrol (Austria). Tourism Review, 66(3), 4-13. 
Steiger, R., Scott, D., Abegg, B., Pons, M., \& Aall, C. (2017). A critical review of climate change risk for ski tourism. Current Issues in Tourism, 1-37.

Stokols, D., \& Shumaker, S. A. (1981). People in places: A transactional view of settings. Cognition, Social Behaviour, and the Environment, 441-488.

Stone, C. A., \& Sobel, M. E. (1990). The robustness of estimates of total indirect effects in covariance structure models estimated by maximum. Psychometrika, 55(2), 337352.

Sutton, S. (1998). Predicting and Explaining Intentions and Behaviour: How Well Are We Doing? Journal of Applied Social Psychology, 28(15), 1317-1338.

Sutton, S. G., \& Ditton, R. B. (2005). The Substitutability of One Type of Fishing for Another. North American Journal of Fisheries Management, 25(2), 536-546.

Sutton, S. G., \& Oh, C.-O. (2015). How Do Recreationists Make Activity Substitution Decisions? A Case of Recreational Fishing. Leisure Sciences, 37(4), 332-353.

Tabachnick, B. G., \& Fidell, L. S. (1996). Using Multivariate Statistics (3rd ed.). New York: Harper Collins.

Tabata, R. S. (1992). Scuba diving holidays. In Special Interest Tourism (pp. 171-184).

Tanner, J. F., Hunt, J. B., \& Eppright, D. R. (1991). The protection motivation model: A normative model of fear appeals. Journal of Marketing, 55(3), 36-45.

Tapsuwan, S., \& Rongrongmuang, W. (2015). Climate change perception of the dive tourism industry in Koh Tao island, Thailand. Journal of Outdoor Recreation and Tourism, 11, 58-63.

Thailing, C. E., \& Ditton, R. B. (2003). Demographics, motivations, and participation patterns of sport divers in the Flower Garden Banks National Marine Sanctuary. In Proceedings of the Fifty-Fourth Annual Gulf and Caribbean Fisheries Institute (pp. 338-348).

Todd, S. L., Graefe, A. R., \& Mann, W. (2002). Differences in scuba diver motivations based on level of development. In 2001 Northeastern Recreation Research Symposium (pp. 107-114).

Truelove, H. B., Carrico, A. R., \& Thabrew, L. (2015). A socio-psychological model for analyzing climate change adaptation: A case study of Sri Lankan paddy farmers. Global Environmental Change, 31, 85-97.

Tseng, Y.-P. (2009). From Substitution to Coping: Developing and Testing a Leisure Constraints-based Coping Model. Texas A\&M University.

Tuan, Y.-F. (1980). The Significance of the Artifact. Geographical Review, 70(4), 462.

Tuan, Y. F. (1974). Topophilia. Englewood Cliffs, N.J: Prentice-Hall.

Um, S., Chon, K., \& Ro, Y. (2006). Antecedents of revisit intention. Annals of Tourism Research, 33(4), 1141-1158.

Uyarra, M. C., Côté, I. M., Gill, J. a., Tinch, R. R. T., Viner, D., \& Watkinson, A. R. (2005). Island-specific preferences of tourists for environmental features: implications of climate change for tourism-dependent states. Environmental Conservation, 32(1), 11-19.

Van den Putte, B. (1991). 20 years of the theory of reasoned action of Fishbein and Ajzen: A meta-analysis. University of Amsterdam.

van Dijk, T., \& van der Wulp, N. (2010). Not in my open space: Anatomy of neighbourhood activism in defence of land use conversion. Landscape and Urban Planning, 96(1), 19-28. 
van Duinen, R., Filatova, T., Geurts, P., \& van der Veen, A. (2015). Coping with drought risk: empirical analysis of farmers' drought adaptation in the south-west Netherlands. Regional Environmental Change, 15(6), 1081-1093.

Van Hooidonk, R., Maynard, J., Tamelander, J., Gove, J., Ahmadia, G., Raymundo, L., ... Planes, S. (2016). Local-scale projections of coral reef futures and implications of the Paris Agreement. Scientific Reports, 6, 39666.

Vickers, A. J. (1999). Comparison of an ordinal and a continuous outcome measure of muscle soreness. International Journal of Technology Assessment in Health Care, 15(4), 709-716.

Viscusi, W. K., \& Chesson, H. (1999). Hopes and Fears: the Conflicting Effects of Risk Ambiguity. Theory and Decision, 47(2), 157-184.

Vivian, K. A. (2011). Behavioural adaptation of skiers and snowboarders in the US Northeast to climate variability and change. University of Waterloo.

Voss, G. B., Godfrey, A., \& Seiders, K. (2010). How complementarity and substitution alter the customer satisfaction-repurchase link. Journal of Marketing, 74(6), 111127.

Wang, C., \& Chang, Y.-H. (2010). How Place Attachments Influence Recreation Conflict and Coping Behaviour. In Proceedings of the 2010 Northeastern Recreation Research Symposium (pp. 141-146).

Wang, W., Lin, C., Lu, W., Lee, S., Lin, C., Lu, W., \& When, S. L. (2018). Current Issues in Tourism When destination attractiveness shifts in response to climate change : tourists' behavioural intention in Taiwan' s Kenting National Park. Current Issues in Tourism, O(0), 1-26.

Warzecha, C. A., \& Lime, D. W. (2001). Place Attachment in Canyonlands National Park: Visitors' Assessment of Setting Attributes on the Colorado and Green Rivers. Journal of Park \& Recreation Administration, 19(1), 59-78.

Weber, E. U. (1997). Perception and expectation of climate change: Precondition for economic and technological adaptation. In B. M., M. D., T. A., \& W.-B. K. (Eds.), Psychological perspectives to environmental and ethical issues in management (pp. 314-341).

Wellman, J. D., Roggenbuck, J. W., \& Smith, A. C. (1982). Recreation Specialization and Norms of Depreciative Behaviour among Canoeists.pdf. Journal of Leisure Research, 14(4), 323-340.

Westmacott, S., Cesar, H., \& Pet-Soede, L. (2000). Socio-economic assessment of the impacts of the 1998 coral bleaching in the Indian Ocean. In Coral reef degradation in the Indian Ocean: Status report 2000 (pp. 143-159). Stockholm.

White, D. D. (2008). A structural model of leisure constraints negotiation in outdoor recreation. Leisure Sciences, 30(4), 342-359.

White, D. D., Virden, R. J., \& Van Riper, C. J. (2008). Effects of place identity, place dependence, and experience-use history on perceptions of recreation impacts in a natural setting. Environmental Management, 42(4), 647-657.

Wilkinson, C. (2008). Status of Coral Reefs of the World: 2008. Townsville, Australia.

Willacy, M. (2016). Great Barrier Reef coral bleaching could cost $\$ 1 \mathrm{~b}$ in lost tourism, research suggests. $A B C$ News. Retrieved from http://www.abc.net.au/news/2016-0621/reef-bleaching-could-cost-billion-in-lost-tourism/7526166

Williams, D. R., Patterson, M. E., Roggenbuck, J. W., \& Watson, A. E. (1992). Beyond 
the commodity metaphor: Examining emotional and symbolic attachment to place. Leisure Sciences, 14(1), 29-46.

Williams, D. R., \& Roggenbuck, J. W. (1989). Measuring Place Attachment: Some Preliminary Results. In NRPA Symposium on Leisure Research. San Antonio, TX.

Williams, D. R., \& Vaske, J. J. (2003). The Measurement of Place Attachment: Validity and Generalizability of a Psychometric Approach. Forest Science, 49(6), 830-840.

Williams, R. (2015). Interaction effects and group comparisons. University of Notre Dame.

Wong, P. P., Losada, I. J., Gattuso, J.-P., Hinkel, J., Khattabi, A., McInnes, K. L., ... Sallenger, A. (2014). Coastal Systems and Low-lying Areas. In C. B. Field, V. R. Barros, D. J. Dokken, K. J. Mach, M. D. Mastrandrea, T. E. Bilir, ... L. L. White (Eds.), Climate Change 2014: Impacts, Adaptation, and Vulnerability. Part A: Global and Sectoral Aspects. Contribution of Working Group II to the Fifth Assessment Report of the Intergovernmental Panel on Climate Change (pp. 361409). Cambridge, United Kingdom and New York, NY: Cambridge University Press.

World Tourism Organization. (2001). Tourism 2020 vision. Vol. 7. Global forecasts and profiles of market segments. Madrid: WTO.

Wu, B., \& Cai, L. A. (2006). Spatial modeling: Suburban leisure in Shanghai. Annals of Tourism Research, 33(1), 179-198.

Wynveen, C. J., Kyle, G. T., Hammitt, W. E., \& Absher, J. D. (2007). Exploring the Effect of Experience Use History and Place Bonding on Resource Substitution. In Proceedings of the 2007 Northeastern Recreation Research Symposium (pp. 114122).

Wynveen, C. J., Kyle, G. T., \& Sutton, S. G. (2010). Place meanings ascribed to marine settings: The case of the great barrier reef marine park. Leisure Sciences, 32(3), 270-287.

Yang, C. L., \& Nair, V. (2014). Risk Perception Study in Tourism: Are we Really Measuring Perceived Risk? Procedia - Social and Behavioural Sciences, 144, 322327.

Yiannakoulias, N. (2016). The use and abuse of the $\mathrm{R}^{2}$ (R-squared) in the social sciences.

Yoon, J. I. (2012). An Eamination of Coping Processes within the Context of Waterbased Recreation. Texas A\&M University.

Young, M. J., Williams, D. R., \& Roggenbuck, J. W. (1990). The Role of Involvement in Identifying Users' Preferences for Social Standards in the Cohutta Wilderness. In Southeastern Recreation Research Conference (Vol. 12, pp. 173-183).

Young, S., \& Loomis, D. K. (2009). Diver Perceptions of Florida Keys Reef Conditions by Specialization Level. In Proceedings of the 2002 Northeastern Recreation Research Symposium (pp. 24-30). Bolton Landing, NY.

Yuzhanin, S., \& Fisher, D. (2016). The efficacy of the theory of planned behaviour for predicting intentions to choose a travel destination: a review. Tourism Review, 71(2), $135-147$.

Zaichkowsky, J. L. (1985). Measuring the Involvement Construct. Journal of Consumer Research, 12(3), 341. 


\section{APPENDIX A: Recruitment Email}

Hello,

My name is Stephanie Verkoeyen and I am a PhD student working under the supervision of Dr. Sanjay Nepal in the Geography Department at the University of Waterloo. We are conducting a study that looks into how scuba divers respond to changes to the marine environment, and are currently seeking divers to participate in this study. As the head of (insert dive club name), I am contacting you regarding the possibility of approaching your membership to complete a simple questionnaire.

In the questionnaire, participants will be asked to respond to a hypothetical scenario, as well as provide information regarding their dive habits. Completion of the questionnaire should take no more than 10-15 minutes. In appreciation of the time given to this study, participants can enter their name into a draw for 1 of 2 cash prizes of $\$ 100$. The odds of winning a prize are based on the number of individuals who participate in the study. Information collected to draw for the prizes will not be linked to the study data in any way, and this identifying information will be stored separately then destroyed after the prizes have been provided. The amount received is taxable. It is winners' responsibility to report this amount for income tax purposes.

The study has been reviewed and received ethics clearance through the Office of Research Ethics at the University of Waterloo.

If you are willing to complete the questionnaire and/or distribute to other (insert dive club name) divers, please contact Stephanie at sverkoeyen@uwaterloo.ca or Dr. Sanjay Nepal at snepal@uwaterloo.ca to express your interest, or for further information. Ultimately the final decision about participation will be up to individual divers.

Sincerely,

Stephanie Verkoeyen 


\title{
APPENDIX B: Information Letter and Consent Form
}

\author{
[Note: the information letter and consent form was the first page of the online \\ questionnaire]
}

You are invited to participate in a research study conducted by Stephanie Verkoeyen, under the supervision of Dr. Sanjay Nepal in the Geography Department at the University of Waterloo. The objectives of the research study are to explore how scuba divers perceive and respond to environmental changes. The study is part of a Doctoral research project.

If you decide to volunteer, you will be asked to complete a 10-15 minute online survey. You will be asked to respond to a hypothetical scenario, as well as provide information regarding your experience with diving. There are no known or anticipated risks to participation in this study. Participation in this project is voluntary and anonymous neither the researcher nor the president of your dive club will know who does/does not participate in this survey - and you may omit any question you prefer not to answer. When information is transmitted over the Internet confidentiality cannot be guaranteed. University of Waterloo practises are to turn off functions that collect machine identifiers such as IP addresses. Survey Monkey may collect this information without our knowledge and make this accessible to us. However, we will not use or save this information without your consent. Please note that Survey Monkey is a web survey company located in the USA, and thus all responses to the survey will be stored and accessed in the USA. This company is subject to U.S. laws, in particular, to the U.S. Patriot Act that allows authorities access to the records of Internet service providers. If you choose to participate in the survey you understand that your responses to the questions will be stored and accessed in the USA. The security and privacy policy for Survey Monkey can be viewed at http://www.surveymonkey.com/

If you prefer not to submit your survey responses through this host, please contact one of the researchers so you can participate using an alternative method. The alternate method may decrease anonymity but confidentiality will be maintained. The data, with no personal identifiers, collected from this study will be maintained on a password-protected computer database in a restricted access area of the university. As well, the data will be electronically archived after completion of the study and maintained for 7 years and then erased.

In appreciation of the time given to this study, you can enter your name into a draw for 1 of 2 cash prizes of $\$ 100$. The odds of winning a prize are based on the number of individuals who participate in the study. Information collected to draw for the prizes will not be linked to the study data in any way, and this identifying information will be stored separately, and then destroyed after the prizes have been provided. The amount received is taxable. It is your responsibility to report this amount for income tax purposes. Those individuals who choose to withdraw from the study can still enter the draw. 
Should you have any questions about the study, please contact either Stephanie Verkoeyen (sverkoeyen@uwaterloo.ca) or Dr. Sanjay Nepal (snepal@uwaterloo.ca). Further, if you would like to receive a copy of the results of this study (expected by August 2017), please contact either investigator.

This project has been reviewed and received ethics clearance through a University of Waterloo Research Ethics Committee. However, the final decision about participation is yours. Participants who have concerns or questions about their involvement in the project may contact Dr. Maureen Nummelin, Chief Ethics Officer, at 519-888-4567 x36005 or maureen.nummelin@uwaterloo.ca.

Thank you in advance for your interest in this project.

By submitting the following online survey you are not waving your legal rights or releasing the investigators or involved institution from their legal and professional responsibilities

With full knowledge of all foregoing, I agree, of my own free will, to participate in this study: Y/N 


\section{APPENDIX C: Online Questionnaire}

1. Have you ever dived somewhere with coral reefs?

2. Do you intend to dive at some point in the future?

3. Identify a coral reef diving destination with which you are familiar

This diving destination will be referred to in subsequent questions. You should select a destination where you have dived previously. If you do not often frequent the same reef diving destination, please choose the one you have visited most recently.

Note: There are some responses that may seem similar in the next set of questions. This is purposeful and designed solely for statistical purposes - thank you for your patience with this

4. Please indicate your level of agreement or disagreement with the following statements about how you feel about $\{\{\mathrm{Q} 3\}\}$. Select the one answer that best represents your level of agreement.

\begin{tabular}{|l|c|c|c|c|c|}
\hline & $\begin{array}{c}\text { Strongly } \\
\text { disagree }\end{array}$ & $\begin{array}{c}\text { Somewhat } \\
\text { disagree }\end{array}$ & Neutral & $\begin{array}{c}\text { Somewhat } \\
\text { agree }\end{array}$ & $\begin{array}{c}\text { Strongly } \\
\text { agree }\end{array}$ \\
\hline$\{\{$ Q3 \}\} means a lot to me & $\bigcirc$ & $\bigcirc$ & $\bigcirc$ & $\bigcirc$ & $\bigcirc$ \\
\hline $\begin{array}{l}\text { I identify strongly with \{\{Q3 } \\
\text { \} }\end{array}$ & $\bigcirc$ & $\bigcirc$ & $\bigcirc$ & $\bigcirc$ & $\bigcirc$ \\
\hline $\begin{array}{l}\text { I really miss \{\{ Q3 \}\} when I } \\
\text { am away from it for too long }\end{array}$ & $\bigcirc$ & $\bigcirc$ & $\bigcirc$ & $\bigcirc$ & $\bigcirc$ \\
\hline $\begin{array}{l}\text { I like to bring my family } \\
\text { and/or friends to \{\{ Q3 \}\} }\end{array}$ & $\bigcirc$ & $\bigcirc$ & $\bigcirc$ & $\bigcirc$ & $\bigcirc$ \\
\hline $\begin{array}{l}\text { No other place can compare to } \\
\{\{\text { Q3 \}\} }\end{array}$ & $\bigcirc$ & $\bigcirc$ & $\bigcirc$ & $\bigcirc$ & $\bigcirc$ \\
\hline $\begin{array}{l}\text { I get more satisfaction diving } \\
\text { at \{\{ Q3 \}\} than anywhere } \\
\text { else }\end{array}$ & $\bigcirc$ & $\bigcirc$ & $\bigcirc$ & $\bigcirc$ & $\bigcirc$ \\
\hline $\begin{array}{l}\text { I wouldn't substitute other } \\
\text { places for the type of diving I } \\
\text { do here }\end{array}$ & $\bigcirc$ & $\bigcirc$ & $\bigcirc$ & $\bigcirc$ & $\bigcirc$ \\
\hline $\begin{array}{l}\text { Diving here is more important } \\
\text { than diving in any other place }\end{array}$ & $\bigcirc$ & $\bigcirc$ & $\bigcirc$ & $\bigcirc$ & $\bigcirc$ \\
\hline
\end{tabular}

5. Please indicate your level of agreement or disagreement with each of the following statements about how you feel about diving. Select the one response that best represents your level of agreement. 


\begin{tabular}{|l|c|c|c|c|c|}
\hline & $\begin{array}{c}\text { Strongly } \\
\text { disagree }\end{array}$ & $\begin{array}{c}\text { Somewhat } \\
\text { disagree }\end{array}$ & Neutral & $\begin{array}{c}\text { Somewhat } \\
\text { agree }\end{array}$ & $\begin{array}{c}\text { Strongly } \\
\text { agree }\end{array}$ \\
\hline $\begin{array}{l}\text { Scuba diving is one of the } \\
\text { most enjoyable things I do }\end{array}$ & $\bigcirc$ & $\bigcirc$ & $\bigcirc$ & $\bigcirc$ & $\bigcirc$ \\
\hline $\begin{array}{l}\text { Scuba diving is very } \\
\text { important to me }\end{array}$ & $\bigcirc$ & $\bigcirc$ & $\bigcirc$ & $\bigcirc$ & $\bigcirc$ \\
\hline $\begin{array}{l}\text { I find a lot of my life is } \\
\text { organized around scuba } \\
\text { diving }\end{array}$ & $\bigcirc$ & $\bigcirc$ & $\bigcirc$ & $\bigcirc$ & $\bigcirc$ \\
\hline $\begin{array}{l}\text { Scuba diving occupies a } \\
\text { central role in my life }\end{array}$ & $\bigcirc$ & $\bigcirc$ & $\bigcirc$ & $\bigcirc$ & $\bigcirc$ \\
\hline $\begin{array}{l}\text { I enjoy discussing scuba } \\
\text { diving with my friends }\end{array}$ & $\bigcirc$ & $\bigcirc$ & $\bigcirc$ & $\bigcirc$ & $\bigcirc$ \\
\hline $\begin{array}{l}\text { Most of my friends are scuba } \\
\text { divers }\end{array}$ & $\bigcirc$ & $\bigcirc$ & $\bigcirc$ & $\bigcirc$ & $\bigcirc$ \\
\hline $\begin{array}{l}\text { When I participate in scuba } \\
\text { diving, I can really be myself }\end{array}$ & $\bigcirc$ & $\bigcirc$ & $\bigcirc$ & $\bigcirc$ & $\bigcirc$ \\
\hline $\begin{array}{l}\text { I identify with the people } \\
\text { and image associated with } \\
\text { scuba diving }\end{array}$ & $\bigcirc$ & $\bigcirc$ & $\bigcirc$ & $\bigcirc$ & $\bigcirc$ \\
\hline $\begin{array}{l}\text { Participating in scuba diving } \\
\text { says a lot about who I am }\end{array}$ & $\bigcirc$ & $\bigcirc$ & $\bigcirc$ & $\bigcirc$ & $\bigcirc$ \\
\hline $\begin{array}{l}\text { When I scuba dive, others } \\
\text { see me the way I want them } \\
\text { to see me }\end{array}$ & $\bigcirc$ & $\bigcirc$ & $\bigcirc$ & $\bigcirc$ & $\bigcirc$ \\
\hline
\end{tabular}

The following questions reflect on your perception of coral reefs that are mostly white, as in the image shown below (Note: this image is provided as a representation; it may not directly correspond with the type of coral environment present at the destination you've identified).

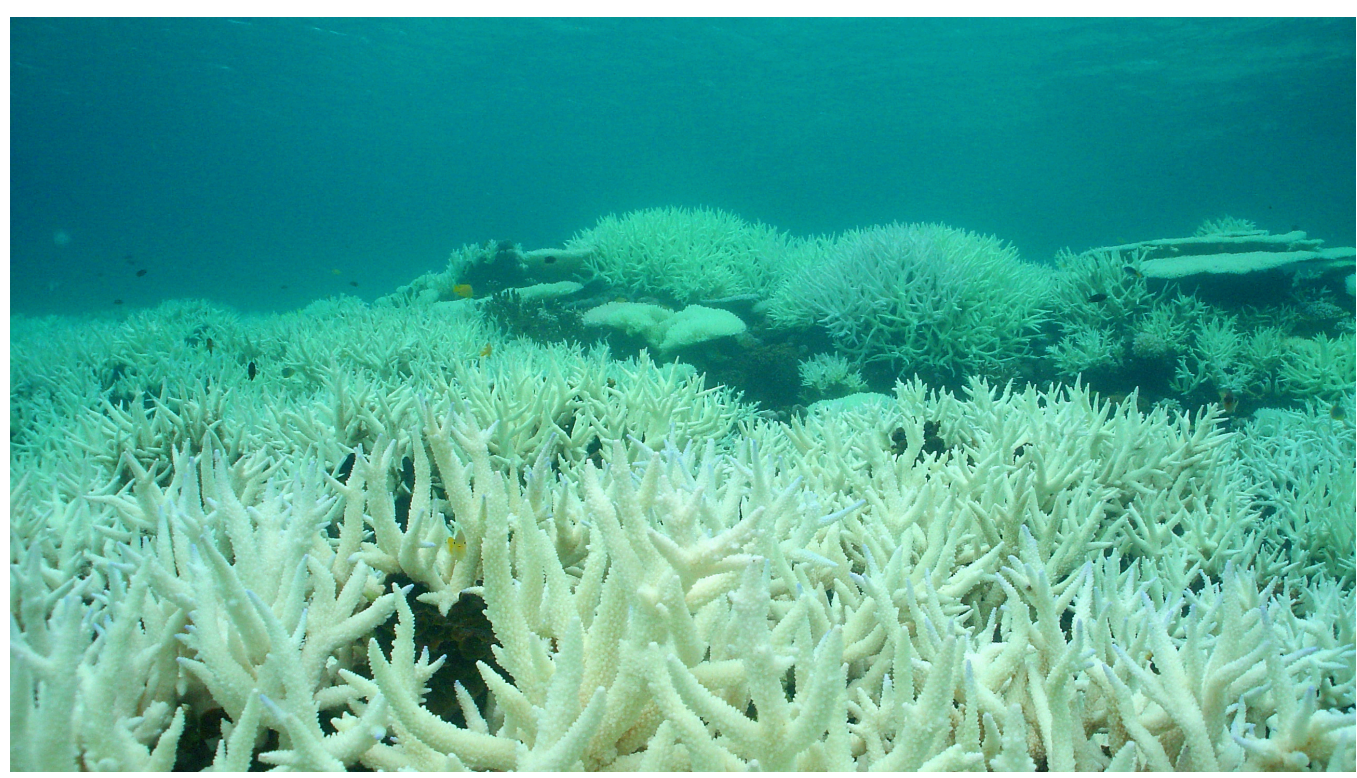


6. How likely is it that you will coral reefs that are mostly white in the next 5 years:

\begin{tabular}{|l|c|c|c|c|c|}
\hline & $\begin{array}{c}\text { Very } \\
\text { unlikely }\end{array}$ & $\begin{array}{c}\text { Somewha } \\
\text { t unlikely }\end{array}$ & Neutral & $\begin{array}{c}\text { Somewha } \\
\text { t likely }\end{array}$ & $\begin{array}{c}\text { Very } \\
\text { likely }\end{array}$ \\
\hline $\begin{array}{l}\text { While diving in } \\
\{\{\text { Q3 }\}\end{array}$ & $\bigcirc$ & $\bigcirc$ & $\bigcirc$ & $\bigcirc$ & $\bigcirc$ \\
\hline $\begin{array}{l}\text { While diving } \\
\text { elsewhere }\end{array}$ & $\bigcirc$ & $\bigcirc$ & $\bigcirc$ & $\bigcirc$ & $\bigcirc$ \\
\hline
\end{tabular}

7. If you were to encounter coral reefs that are mostly white in $\{\{\mathrm{Q} 3\}\}$, how would this influence:

\begin{tabular}{|l|c|c|c|c|c|}
\hline & $\begin{array}{c}\text { Decrease } \\
\text { satisfaction } \\
\text { substantially }\end{array}$ & $\begin{array}{c}\text { Decrease } \\
\text { satisfaction } \\
\text { somewhat }\end{array}$ & Neutral & $\begin{array}{c}\text { Increase } \\
\text { satisfaction } \\
\text { somewhat }\end{array}$ & $\begin{array}{c}\text { Increase } \\
\text { satisfaction } \\
\text { substantially }\end{array}$ \\
\hline $\begin{array}{l}\text { Your level } \\
\text { of } \\
\text { satisfaction } \\
\text { with your } \\
\text { dive } \\
\text { experience }\end{array}$ & $\bigcirc$ & $\bigcirc$ & $\bigcirc$ & $\bigcirc$ & $\bigcirc$ \\
\hline $\begin{array}{l}\text { Your level } \\
\text { of overall } \\
\text { trip } \\
\text { satisfaction }\end{array}$ & $\bigcirc$ & $\bigcirc$ & $\bigcirc$ & $\bigcirc$ & $\bigcirc$ \\
\hline
\end{tabular}

8. Next, we would like to know to what extent you believe in the effectiveness of the following adaptive responses (Note: this is different from your likelihood of engaging in this behaviour, but rather asks whether you think the listed actions lead to a satisfactory experience)

How effective are the following responses at producing a satisfactory experience, should coral reefs that are mostly white be encountered in $\{\{\mathrm{Q} 3\}\}$ ?

\begin{tabular}{|l|c|c|c|c|c|}
\hline & $\begin{array}{c}\text { Very } \\
\text { ineffective }\end{array}$ & $\begin{array}{c}\text { Somewhat } \\
\text { ineffective }\end{array}$ & Neutral & $\begin{array}{c}\text { Somewhat } \\
\text { effective }\end{array}$ & $\begin{array}{c}\text { Very } \\
\text { effective }\end{array}$ \\
\hline $\begin{array}{l}\text { Travel within }\{\{\text { Q3 }\}\} \\
\text { to find different dive } \\
\text { conditions }\end{array}$ & $\bigcirc$ & $\bigcirc$ & $\bigcirc$ & $\bigcirc$ & $\bigcirc$ \\
\hline $\begin{array}{l}\text { Travel elsewhere in the } \\
\text { region to find different } \\
\text { dive conditions }\end{array}$ & $\bigcirc$ & $\bigcirc$ & $\bigcirc$ & $\bigcirc$ & $\bigcirc$ \\
\hline $\begin{array}{l}\text { Travel outside the } \\
\text { region to find different } \\
\text { dive conditions }\end{array}$ & $\bigcirc$ & $\bigcirc$ & $\bigcirc$ & $\bigcirc$ & $\bigcirc$ \\
\hline
\end{tabular}




\begin{tabular}{|l|c|c|c|c|c|}
\hline $\begin{array}{l}\text { Dive less often in } \\
\{\{\mathrm{Q}\}\}\end{array}$ & $\bigcirc$ & $\bigcirc$ & $\bigcirc$ & $\bigcirc$ & $\bigcirc$ \\
\hline $\begin{array}{l}\text { Do some other } \\
\text { recreational activity in } \\
\left\{\begin{array}{l}\{\text { Q3 }\} \text { instead of } \\
\text { diving }\end{array}\right.\end{array}$ & 0 & $\bigcirc$ & $\bigcirc$ & $\bigcirc$ & $\bigcirc$ \\
\hline $\begin{array}{l}\text { Accept that there } \\
\text { is nothing I can do } \\
\text { about the situation, and } \\
\text { enjoy the experience for } \\
\text { what it is }\end{array}$ & $\bigcirc$ & $\bigcirc$ & $\bigcirc$ & $\bigcirc$ & $\bigcirc$ \\
\hline
\end{tabular}

9. How confident are you in your ability to do the following if the need arose?

\begin{tabular}{|c|c|c|c|c|c|}
\hline & $\begin{array}{c}\text { Very } \\
\text { unconfident }\end{array}$ & $\begin{array}{c}\text { Somewhat } \\
\text { unconfident }\end{array}$ & Neutral & $\begin{array}{c}\text { Somewhat } \\
\text { confident }\end{array}$ & $\begin{array}{c}\text { Very } \\
\text { confident }\end{array}$ \\
\hline $\begin{array}{l}\text { Travel within }\{\{\mathrm{Q} 3 \\
\}\} \text { to find different } \\
\text { dive conditions }\end{array}$ & 0 & $\bigcirc$ & 0 & $\bigcirc$ & $\bigcirc$ \\
\hline $\begin{array}{l}\text { Travel elsewhere in } \\
\text { the region to find } \\
\text { different dive } \\
\text { conditions }\end{array}$ & $\bigcirc$ & $\bigcirc$ & $\bigcirc$ & $\bigcirc$ & $\bigcirc$ \\
\hline $\begin{array}{l}\text { Travel outside the } \\
\text { region to find } \\
\text { different dive } \\
\text { conditions }\end{array}$ & $\bigcirc$ & $\bigcirc$ & $\bigcirc$ & $\bigcirc$ & $\bigcirc$ \\
\hline $\begin{array}{l}\text { Dive less often in } \\
\{\{\mathrm{Q} 3\}\}\end{array}$ & 0 & $\bigcirc$ & $\bigcirc$ & $\bigcirc$ & $\bigcirc$ \\
\hline $\begin{array}{l}\text { Do some other } \\
\text { recreational activity } \\
\text { in }\{\{Q 3\}\} \text { instead } \\
\text { of diving }\end{array}$ & $\bigcirc$ & $\bigcirc$ & $\bigcirc$ & $\bigcirc$ & 0 \\
\hline $\begin{array}{l}\text { Accept that there } \\
\text { is nothing I can do } \\
\text { about the situation, } \\
\text { and enjoy the } \\
\text { experience for what } \\
\text { it is }\end{array}$ & 0 & $\bigcirc$ & $\bigcirc$ & $\bigcirc$ & $\bigcirc$ \\
\hline
\end{tabular}

10. How much would each response cost you? For example, it may cost you more to travel elsewhere, or there could be a social or personal cost to doing something other than diving

\begin{tabular}{|l|c|c|c|c|c|}
\hline & Very low & $\begin{array}{c}\text { Somewhat } \\
\text { low }\end{array}$ & Neutral & $\begin{array}{c}\text { Somewhat } \\
\text { high }\end{array}$ & Very high \\
\hline $\begin{array}{l}\text { Travel within }\{\{\mathrm{Q} 3 \\
\text { \}\} to find different }\end{array}$ & $\bigcirc$ & $\bigcirc$ & $\bigcirc$ & $\bigcirc$ & $\bigcirc$ \\
\hline
\end{tabular}




\begin{tabular}{|c|c|c|c|c|c|}
\hline dive conditions & & & & & \\
\hline $\begin{array}{l}\text { Travel elsewhere in } \\
\text { the region to find } \\
\text { different dive } \\
\text { conditions }\end{array}$ & $\bigcirc$ & $\bigcirc$ & $\bigcirc$ & $\bigcirc$ & $\bigcirc$ \\
\hline $\begin{array}{l}\text { Travel outside the } \\
\text { region to find different } \\
\text { dive conditions }\end{array}$ & $\bigcirc$ & $\bigcirc$ & $\bigcirc$ & $\bigcirc$ & $\bigcirc$ \\
\hline $\begin{array}{l}\text { Dive less often in } \\
\{\{\mathrm{Q} 3\}\}\end{array}$ & $\bigcirc$ & $\bigcirc$ & $\bigcirc$ & $\bigcirc$ & $\bigcirc$ \\
\hline $\begin{array}{l}\text { Do some other } \\
\text { recreational activity in } \\
\{\{Q 3\}\} \text { instead of } \\
\text { diving }\end{array}$ & $\bigcirc$ & $\bigcirc$ & $\bigcirc$ & $\bigcirc$ & $\bigcirc$ \\
\hline $\begin{array}{l}\text { Accept that there } \\
\text { is nothing I can do } \\
\text { about the situation, } \\
\text { and enjoy the } \\
\text { experience for what it } \\
\text { is }\end{array}$ & $\bigcirc$ & $\bigcirc$ & $\bigcirc$ & $\bigcirc$ & $\bigcirc$ \\
\hline
\end{tabular}

11. If coral reefs that are mostly white were to persist in $\{\{\mathrm{Q} 3\}\}$ for several years, how likely are you to do the following?

\begin{tabular}{|c|c|c|c|c|c|}
\hline & $\begin{array}{c}\text { Very } \\
\text { unlikely }\end{array}$ & $\begin{array}{c}\text { Somewhat } \\
\text { unlikely }\end{array}$ & Neutral & $\begin{array}{l}\text { Somewhat } \\
\text { likely }\end{array}$ & Very likely \\
\hline $\begin{array}{l}\text { Travel within }\{\{\mathrm{Q} 3 \\
\text { \}\} to find different } \\
\text { dive conditions }\end{array}$ & 0 & 0 & 0 & 0 & $\bigcirc$ \\
\hline $\begin{array}{l}\text { Travel elsewhere in } \\
\text { the region to find } \\
\text { different dive } \\
\text { conditions }\end{array}$ & $\bigcirc$ & 0 & $\bigcirc$ & $\bigcirc$ & 0 \\
\hline $\begin{array}{l}\text { Travel outside the } \\
\text { region to find } \\
\text { different dive } \\
\text { conditions }\end{array}$ & 0 & 0 & 0 & $\bigcirc$ & $\bigcirc$ \\
\hline $\begin{array}{l}\text { Dive less often in } \\
\{\{Q 3\}\}\end{array}$ & $\bigcirc$ & $\bigcirc$ & $\bigcirc$ & $\bigcirc$ & $\bigcirc$ \\
\hline $\begin{array}{l}\text { Do some other } \\
\text { recreational activity } \\
\text { in }\{\{Q 3\}\} \text { instead } \\
\text { of diving }\end{array}$ & $\bigcirc$ & 0 & 0 & $\bigcirc$ & $\bigcirc$ \\
\hline $\begin{array}{l}\text { Accept that there } \\
\text { is nothing I can do } \\
\text { about the situation, } \\
\text { and enjoy the } \\
\text { experience for what it } \\
\text { is }\end{array}$ & $\bigcirc$ & $\bigcirc$ & 0 & $\bigcirc$ & $\bigcirc$ \\
\hline
\end{tabular}


12. Please indicate your gender?

$\bigcirc$ Male $\bigcirc$ Female $\bigcirc$ Transgender

13. How old are you?

14. What is the highest level of education you have completed?

$\bigcirc \quad$ Elementary school

$\bigcirc$ High school

Post-secondary certificate, trade, or apprenticeship

College diploma

$\bigcirc \quad$ University degree (e.g., BA, BSc)

$\bigcirc \quad$ Graduate degree (e.g., MA, MSc, PhD)

15. What is your current total household income?

$\bigcirc \quad$ Less than $\$ 50,000$

○ $\$ 50,000-\$ 99,999$

$\bigcirc \$ 100,000-\$ 149,999$

○ $\$ 150,000-\$ 199,999$

$\bigcirc \$ 200,000$ or more

16. Who do you usually dive with on holiday? (Select the most applicable response)

O Partner

$\bigcirc \quad$ Children

$\bigcirc \quad$ Parents

$\bigcirc \quad$ Siblings

Friends

$\bigcirc$ Acquaintances

$\bigcirc \quad$ Other (please specify)

17. What level of dive certification do you currently hold?

$\bigcirc \quad$ Enrolled in diving course

$\bigcirc \quad$ Open Water

O Advanced Open Water

$\bigcirc \quad$ Dive Master 
$\bigcirc \quad$ Dive Instructor

18. What dive club/organization do you belong to?

19. Do you have any further comments? 


\section{APPENDIX D: Feedback Letter to Participants}

[Note: the feedback letter was the last page of the online questionnaire]

I would like to thank you for your participation in this study entitled "Understanding Dive Tourists' Intentions to Adapt to Environmental Changes". As a reminder, the purpose of this study is to explore how scuba divers perceive and respond to environmental changes. The data collected from surveys will contribute to a better understanding of the future demand for dive-related travel.

Please remember that any data pertaining to you as an individual participant will be kept confidential. Once all the data are collected and analysed for this project, I plan on sharing this information with the research community through seminars, conferences, presentations, and journal articles. If you are interested in receiving more information regarding the results of this study, or would like a summary of the results, please provide your email address, and when the study is completed, anticipated by August 2017, I will send you the information. In the meantime, if you have any questions about the study, please do not hesitate to contact Stephanie at sverkoeyen@uwaterloo.ca or Dr. Sanjay Nepal at snepal@uwaterloo.ca.

As with all University of Waterloo projects involving human participants, this project was reviewed by, and received ethics clearance through a University of Waterloo Research Ethics Committee. Should you have any comments or concerns resulting from your participation in this study, please contact Dr. Maureen Nummelin, Chief Ethics Officer, at 519-888-4567 x36005 or maureen.nummelin@uwaterloo.ca.

In appreciation of the time given to this study, you can enter your name into a draw for 1 of 2 cash prizes of $\$ 100$. The odds of winning this prize will depend on the number of participants.

The prizewinner will be notified by the end of August 2016.

Name:

Email address: 


\section{APPENDIX E: Socio-demographic Regression Results}

\section{Regression models for socio-demographic variables predicting behavioural intentions}

\begin{tabular}{lcc}
\hline & adj. $\mathbf{R}^{2}$ & $\mathbf{F}_{(\mathrm{ds}, 28 \mathrm{~s}}$ \\
\hline Intra-destination behavioural intentions & -.003 & .96 \\
(BIS1) & & \\
Intra-regional behavioural intentions (BIS2) & .009 & 1.15 \\
Inter-regional behavioural intentions (BIS3) & .020 & 1.34 \\
Temporal behavioural intentions (BIT) & -.009 & .86 \\
Activity behavioural intentions (BIA) & .057 & $2.01 * *$ \\
Cognitive behavioural intentions (BIC) & -.005 & .91 \\
\hline$* p<.05, * * p<.01, * * * p<.001$ & &
\end{tabular}

Regression coefficients for socio-demographic variables predicting intra-destination behavioural intentions (BIS1)

\begin{tabular}{lccc}
\hline & B & SE & $\boldsymbol{\beta}$ \\
\hline Female & .193 & .163 & .072 \\
Age & -.004 & .006 & -.038 \\
EDU_HS & -.145 & .271 & -.034 \\
EDU_CERT & .502 & .298 & .107 \\
EDU_COLL & -.311 & .211 & -.097 \\
EDU_GRAD & -.048 & .189 & -.017 \\
INC_50k & -.343 & .285 & -.082 \\
INC_150k & .120 & .204 & .042 \\
INC_200k & .370 & .225 & .112 \\
INC_250k & .012 & .246 & .003 \\
DP_SPOU & -.343 & .179 & -.126 \\
DP_CHILD & .099 & .602 & .010 \\
DP_SIB & -.222 & .560 & -.024 \\
DP_ACQU & -.028 & .199 & -.009 \\
CERT_OW & -.041 & .279 & -.009 \\
CERT_DM & -.056 & .210 & -.017 \\
CERT_DI & .143 & .196 & .047 \\
CERT_TECH & .212 & .297 & .044 \\
\hline$* p<.05, * * p<.01, * * * p<.001$ & &
\end{tabular}

Regression coefficients for socio-demographic variables predicting intra-regional behavioural intentions (BIS2) 


\begin{tabular}{lccc}
\hline & B & SE & $\boldsymbol{\beta}$ \\
\hline Female & .152 & .151 & .061 \\
Age & -.000 & .005 & -.001 \\
EDU_HS & -.502 & .252 & $-.125^{*}$ \\
EDU_CERT & .210 & .277 & .048 \\
EDU_COLL & -.138 & .196 & -.046 \\
EDU_GRAD & -.206 & .176 & -.077 \\
INC_50k & -.279 & .265 & -.071 \\
INC_150k & .023 & .190 & .009 \\
INC_200k & .020 & .209 & .007 \\
INC_250k & -.171 & .228 & -.051 \\
DP_SPOU & -.389 & .167 & $-.153 *$ \\
DP_CHILD & .454 & .559 & .049 \\
DP_SIB & -.841 & .520 & -.099 \\
DP_ACQU & -.116 & .185 & -.039 \\
CERT_OW & .269 & .259 & .067 \\
CERT_DM & .010 & .195 & .003 \\
CERT_DI & .170 & .182 & .060 \\
CERT_TECH & -.123 & .275 & -.028 \\
\hline$* p<.05, * * p<.01, * * * p<.001$ & &
\end{tabular}

Regression coefficients for socio-demographic variables predicting inter-regional behavioural intentions (BIS3)

\begin{tabular}{lccc}
\hline & B & SE & $\boldsymbol{\beta}$ \\
\hline Female & .149 & .148 & .061 \\
Age & .003 & .005 & .034 \\
EDU_HS & -.452 & .246 & -.114 \\
EDU_CERT & .377 & .270 & .088 \\
EDU_COLL & .080 & .192 & .027 \\
EDU_GRAD & .079 & .172 & .030 \\
INC_50k & -.170 & .258 & -.044 \\
INC_150k & -.207 & .185 & -.079 \\
INC_200k & -.195 & .204 & -.065 \\
INC_250k & -.217 & .223 & -.066 \\
DP_SPOU & -.104 & .163 & -.042 \\
DP_CHILD & .731 & .546 & .080 \\
DP_SIB & .176 & .508 & .021 \\
DP_ACQU & -.144 & .180 & -.050
\end{tabular}




\begin{tabular}{lccc} 
CERT_OW & .345 & .253 & .087 \\
CERT_DM & -.059 & .191 & -.019 \\
CERT_DI & .196 & .178 & .070 \\
CERT_TECH & -.567 & .269 & $-.129 *$ \\
\hline$* p<.05, * * p<.01, * * * p<.001$ & &
\end{tabular}

Regression coefficients for socio-demographic variables predicting temporal behavioural intentions (BIT)

\begin{tabular}{lccc}
\hline & B & SE & $\boldsymbol{\beta}$ \\
\hline Female & .032 & .165 & .012 \\
Age & .017 & .006 & $.181^{* *}$ \\
EDU_HS & -.191 & .275 & -.044 \\
EDU_CERT & .133 & .302 & .028 \\
EDU_COLL & .017 & .214 & .005 \\
EDU_GRAD & .129 & .192 & .045 \\
INC_50k & .218 & .288 & .052 \\
INC_150k & .118 & .207 & .041 \\
INC_200k & .024 & .228 & .007 \\
INC_250k & .026 & .249 & .007 \\
DP_SPOU & -.135 & .181 & -.049 \\
DP_CHILD & .139 & .609 & .014 \\
DP_SIB & -.113 & .567 & -.012 \\
DP_ACQU & -.150 & .201 & -.047 \\
CERT_OW & .143 & .282 & .033 \\
CERT_DM & .009 & .213 & .003 \\
CERT_DI & .040 & .198 & .013 \\
CERT_TECH & -.443 & .300 & -.092 \\
\hline$* p<.05, * * p<.01, * * * p .001$ & &
\end{tabular}

Regression coefficients for socio-demographic variables predicting activity behavioural intentions (BIA)

\begin{tabular}{lccc}
\hline & B & SE & $\boldsymbol{\beta}$ \\
\hline Female & .004 & .152 & .001 \\
Age & -.007 & .005 & -.076 \\
EDU_HS & -.040 & .254 & -.010 \\
EDU_CERT & -.005 & .279 & -.001 \\
EDU_COLL & -.062 & .198 & -.020 \\
EDU_GRAD & .082 & .177 & .029 \\
INC_50k & .165 & .266 & .041
\end{tabular}




\begin{tabular}{lccc} 
INC_150k & .036 & .191 & .013 \\
INC_200k & -.437 & .210 & $-.138^{*}$ \\
INC_250k & -.370 & .230 & -.107 \\
DP_SPOU & .063 & .168 & .024 \\
DP_CHILD & .118 & .563 & .012 \\
DP_SIB & -.081 & .524 & -.009 \\
DP_ACQU & .409 & .186 & $.135^{*}$ \\
CERT_OW & .539 & .261 & $.130^{*}$ \\
CERT_DM & -.197 & .197 & -.061 \\
CERT_DI & -.268 & .183 & -.091 \\
CERT_TECH & -.445 & .277 & -.096 \\
\hline$* p<.05, * * p<.01, * * * p<.001$ & &
\end{tabular}

Regression coefficients for socio-demographic variables predicting cognitive behavioural intentions (BIC)

\begin{tabular}{lccc}
\hline & B & SE & $\boldsymbol{\beta}$ \\
\hline Female & -.099 & .174 & -.035 \\
Age & .000 & .006 & -.004 \\
EDU_HS & -.388 & .290 & -.084 \\
EDU_CERT & .293 & .319 & .058 \\
EDU_COLL & -.103 & .226 & -.030 \\
EDU_GRAD & .188 & .203 & .061 \\
INC_50k & -.013 & .305 & -.003 \\
INC_150k & .113 & .218 & .037 \\
INC_200k & .343 & .241 & .098 \\
INC_250k & .120 & .263 & .031 \\
DP_SPOU & -.215 & .192 & -.074 \\
DP_CHILD & -.909 & .644 & -.085 \\
DP_SIB & -.033 & .599 & -.003 \\
DP_ACQU & -.153 & .213 & -.046 \\
CERT_OW & .120 & .298 & .026 \\
CERT_DM & -.394 & .225 & -.111 \\
CERT_DI & -.394 & .210 & -.121 \\
CERT_TECH & .013 & .317 & .003 \\
\hline$* p<.05, * * p<.01, * * * p<.001$ & &
\end{tabular}




\section{APPENDIX F: Correlation Tables}

\section{Correlation between PMT and attachment variables and intra-destination behavioural intentions (BIS1)}

\begin{tabular}{lcccccccc}
\hline & Var. $\#$ & 1 & 2 & 3 & 4 & 5 & 6 & 7 \\
\hline Activity involvement (AI) & 1 & & & & & & & \\
Place attachment (PA) & 2 & $.296^{* * *}$ & & & & & & \\
Perceived vulnerability (PV) & 3 & -.103 & -.092 & & & & & \\
Perceived severity (PS) & 4 & .058 & -.033 & .078 & & & & \\
Response efficacy (RES1) & 5 & .028 & .040 & .051 & $-.223^{* * *}$ & & & \\
Self-efficacy (SES1) & 6 & -.044 & -.064 & .081 & $-.203 * * *$ & $.481^{* *}$ & \\
Response costs (RCS1) & 7 & -.013 & $-.141^{*}$ & $.115^{*}$ & .013 & $-.143^{*}$ & .076 \\
Intra-destination intention (BIS1) & 8 & .022 & $-.167 * *$ & -.003 & $-.224^{* * *}$ & $.356^{* * *}$ & $.472^{* * *}$ & -.049 \\
\hline
\end{tabular}

$* p<.05, * * p<.01, * * * p<.001$

\section{Correlation between PMT and attachment variables and intra-regional behavioural intentions (BIS2)}

\begin{tabular}{lcccccccc}
\hline & Var. \# & 1 & 2 & 3 & 4 & 5 & 6 & 7 \\
\hline Activity involvement (AI) & 1 & & & & & & & \\
Place attachment (PA) & 2 & $.296^{* * *}$ & & & & & & \\
Perceived vulnerability (PV) & 3 & -.103 & -.092 & & & & & \\
Perceived severity (PS) & 4 & .058 & -.033 & .078 & & & & \\
Response efficacy (RES2) & 5 & .077 & -.045 & .067 & $-.126^{*}$ & & & \\
Self-efficacy (SES2) & 6 & -.063 & -.087 & .107 & $-.154^{* *}$ & $.309^{* * *}$ & & \\
Response costs (RCS2) & 7 & -.025 & $-.112^{*}$ & .098 & -.079 & $-.135^{*}$ & .107 & \\
Intra-regional intention (BIS2) & 8 & -.039 & -.001 & .075 & -.041 & $.219^{* * *}$ & $.322^{* * *}$ & $-.128^{*}$ \\
\hline
\end{tabular}

$* p<.05, * * p<.01, * * * p<.001$

Correlation between PMT and attachment variables and inter-regional behavioural intentions (BIS3)

\begin{tabular}{lcccccccc}
\hline & Var. \# & 1 & 2 & 3 & 4 & 5 & 6 & 7 \\
\hline Activity involvement (AI) & 1 & & & & & & & \\
Place attachment (PA) & 2 & $.296^{* * *}$ & & & & & & \\
Perceived vulnerability (PV) & 3 & -.103 & -.092 & & & & & \\
Perceived severity (PS) & 4 & .058 & -.033 & .078 & & & & \\
Response efficacy (RES3) & 5 & .053 & $-.115^{*}$ & .063 & -.046 & & & \\
Self-efficacy (SES3) & 6 & -.015 & $-.120^{*}$ & .048 & $-.118^{*}$ & $.250^{* * *}$ & & \\
Response costs (RCS3) & 7 & -.078 & $-.159^{* *}$ & .079 & $-.134^{*}$ & -.108 & $.117^{*}$ & \\
Inter-regional intention (BIS3) & 8 & .076 & -.064 & .110 & $.149^{* *}$ & $.218^{* * *}$ & $.283^{* * *}$ & $-.118^{*}$ \\
\hline
\end{tabular}

$* p<.05, * * p<.01, * * * p<.001$

\section{Correlation between PMT and attachment variables and temporal behavioural intentions (BIT)}

\begin{tabular}{lcccccccc}
\hline & Var.\# & 1 & 2 & 3 & 4 & 5 & 6 & 7 \\
\hline Activity involvement (AI) & 1 & & & & & & & \\
Place attachment (PA) & 2 & $.296^{* * *}$ & & & & & & \\
Perceived vulnerability (PV) & 3 & -.103 & -.092 & & & & \\
Perceived severity (PS) & 4 & .058 & -.033 & .078 & & & \\
Response efficacy (RET) & 5 & .101 & $-.141^{*}$ & .013 & .010 & &
\end{tabular}




\begin{tabular}{lcccccccc} 
Self-efficacy (SET) & 6 & -.098 & $-.278^{* * *}$ & -.034 & .033 & $.351 * * *$ & & \\
Response costs (RCT) & 7 & $-.126^{*}$ & $-.163^{* *}$ & -.001 & -.043 & -.046 & .025 & \\
Temporal intention (BIT) & 8 & -.062 & $-.141^{*}$ & .069 & $.256^{* * *}$ & $.300^{* * *}$ & $.303^{* * *}$ & -.027 \\
\hline
\end{tabular}

$* p<.05, * * p<.01, * * * p<.001$

\section{Correlation between PMT and attachment variables and activity behavioural intentions (BIA)}

\begin{tabular}{lcccccccc}
\hline & Var. $\#$ & 1 & 2 & 3 & 4 & 5 & 6 & 7 \\
\hline Activity involvement (AI) & 1 & & & & & & & \\
Place attachment (PA) & 2 & $.296^{* * *}$ & & & & & & \\
Perceived vulnerability (PV) & 3 & -.103 & -.092 & & & & \\
Perceived severity (PS) & 4 & .058 & -.033 & .078 & & & \\
Response efficacy (REA) & 5 & -.064 & .079 & -.058 & $-.185^{* *}$ & & & \\
Self-efficacy (SEA) & 6 & $-.189^{* *}$ & -.044 & -.109 & -.090 & $.531^{* * *}$ & & \\
Response costs (RCA) & 7 & $-.179^{* *}$ & $-.132^{*}$ & .030 & .012 & -.098 & -.031 \\
Intra-destination intention (BIA) & 8 & $-.181^{* *}$ & .088 & -.018 & -.073 & $.500^{* * *}$ & $.563^{* * *}$ & -.045 \\
\hline
\end{tabular}

$* p<.05, * * p<.01, * * * p<.001$

\section{Correlation between PMT and attachment variables and cognitive behavioural intentions (BIC)}

\begin{tabular}{lcccccccc}
\hline & Var. $\#$ & 1 & 2 & 3 & 4 & 5 & 6 & 7 \\
\hline Activity involvement (AI) & 1 & & & & & & & \\
Place attachment (PA) & 2 & $.296^{* * *}$ & & & & & & \\
Perceived vulnerability (PV) & 3 & -.103 & -.092 & & & & \\
Perceived severity (PS) & 4 & .058 & -.033 & .078 & & & \\
Response efficacy (REC) & 3 & $-.142^{*}$ & -.067 & -.029 & $-.312^{* * *}$ & & & \\
Self-efficacy (SEC) & 4 & -.107 & -.014 & -.036 & $-.275^{* * *}$ & $.624 * * *$ & & \\
Response costs (RCC) & 5 & -.100 & $-.137 *$ & .036 & .049 & -.084 & -.055 & \\
Intra-destination intention (BIC) & 6 & -.070 & .090 & -.001 & $-.330 * * *$ & $.567 * * *$ & $.654^{* * *}$ & -.077 \\
\hline
\end{tabular}

$* p<.05, * * p<.01, * * * p<.001$ 